\title{
Effects of aggregate grading and admixtures/fillers on fresh and hardened properties of self-consolidating concrete
}

Arka Bhattacharya

West Virginia University

Follow this and additional works at: https://researchrepository.wvu.edu/etd

\section{Recommended Citation}

Bhattacharya, Arka, "Effects of aggregate grading and admixtures/fillers on fresh and hardened properties of self-consolidating concrete" (2008). Graduate Theses, Dissertations, and Problem Reports. 4357. https://researchrepository.wvu.edu/etd/4357

This Thesis is protected by copyright and/or related rights. It has been brought to you by the The Research Repository @ WVU with permission from the rights-holder(s). You are free to use this Thesis in any way that is permitted by the copyright and related rights legislation that applies to your use. For other uses you must obtain permission from the rights-holder(s) directly, unless additional rights are indicated by a Creative Commons license in the record and/ or on the work itself. This Thesis has been accepted for inclusion in WVU Graduate Theses, Dissertations, and Problem Reports collection by an authorized administrator of The Research Repository @ WVU. For more information, please contact researchrepository@mail.wvu.edu. 


\title{
Effects of Aggregate Grading and Admixtures/ Fillers on Fresh and Hardened Properties of Self- Consolidating Concrete
}

\author{
Arka Bhattacharya \\ Thesis submitted to the College of Engineering and Mineral \\ Resources \\ at West Virginia University \\ in partial fulfillment of the requirements \\ for the degree of \\ Master of Science \\ in \\ Civil Engineering \\ Indrajit Ray, Ph.D., Chair \\ J ulio F .Davalos, Ph.D.,Co-Chair \\ Udaya Halabe, Ph.D. \\ Department of Civil and Environmental Engineering \\ Morgantown, West Virginia \\ 2008
}

Keywords: Admixtures, Aggregate gradation, Cracking, Durability, Fresh properties, Self-consolidating concrete, Shrinkage, Strength

Copyright 2008 Arka Bhattacharya 


\title{
Abstract \\ Effects of Aggregate Grading and Admixtures/ Fillers on Fresh and Hardened Properties of Self-Consolidating Concrete
}

\author{
Arka Bhattacharya
}

Self-consolidating concrete (SCC) is becoming a popular material in the concrete industry, due to ease of placement in congested reinforcement, reduced labor and equipment, nonsegregating character, and excellent surface finish. In spite of its several advantages, SCC is exceedingly sensitive to aggregate grading, size, admixtures, and filler contents. Though many studies have been conducted on rheological behavior of SCC, there is limited information on effects of aggregate size, grading, mineral admixture types, and fillers on durability, shrinkage and cracking properties.

In this study 17 SCC mixtures were initially developed using local aggregates, fly ash, slag, limestone fillers, commercial silica fume, viscosity-modifying admixtures (VMA), high-range water-reducing admixtures (HRWRA), shrinkage-reducing admixtures (SRA), and steel fibers. The mixtures were evaluated for slump-flow, visual stability, J-ring blocking test, L-box passing ability, and column static segregation. Comparisons of results with the concept of workability factors (representing fine fraction) and coarseness factor (representing coarse fraction) that were proposed for normal concrete, indicate that most of the rheological properties of SCC are strongly influenced by admixtures and fillers. Based on fresh properties and strength criteria, six best SCC were selected for in-depth study of strength development with time, free shrinkage, autogenous shrinkage, cracking potential, freeze-thaw, air-void parameters, and rapid chloride permeability.

Results show that compressive strength increased as water/powder ratio decreased and paste volume increased. The ACI prediction equation for limestone SCC underestimated the compressive strength with time. The shrinkage and cracking data showed that mixtures containing higher size of coarse aggregates $(25 \mathrm{~mm}$ graded) had lower shrinkage and cracking potential compared to $12.5 \mathrm{~mm}$ graded aggregates. Autogenous shrinkage contributed significant portions of the total drying shrinkage measured. The data was calibrated for six existing models of shrinkage and finally a modified ACI based model was recommended for these SCC mixtures. SCC with coarse fractions of aggregate cracked later that those with finer fractions of aggregate. However, the inclusion of fibers and shrinkage reducing admixtures significantly reduced potential cracking, and SCC containing fibers improved the post-cracking behavior as well. Though the air-content of most SCC were higher than normal, the air-void parameters were within acceptable limits. This was confirmed by excellent resistance of SCC against freeze-thaw cycles and high durability factors obtained according to ASTM C 666 and C 215. Rapid chloride permeability values of SCC were adequate and close to regular HPC. Further studies on fracture parameters of hardened SCC are recommended. This should follow a full-scale implementation plan for specific structures and long-term monitoring. 


\section{Acknowledgement}

I wish to express my sincere gratitude towards my advisor Dr. Julio F. Davalos for providing me with the scope to work in such an interesting project. I am deeply grateful to have him as my teacher as well as advisor. His magnificent ideas, along with his whole-hearted support guided me through the two years of my M.S. program at West Virginia University.

My faithful appreciation and respect goes to Dr. Indrajit Ray, who provided me with the topic of research and invaluable guidance along with it. His extensive knowledge in the field of concrete technology was of utmost help throughout my project. By virtue of his extreme encouragement, suggestions and advice he made my task a lot simpler. I was very fortunate to be working under Dr. Davalos and Dr. Ray.

I would also like to express my sincere thanks to Dr. Udaya Halabe who was present as a member of my committee and provided a lot of technical inputs.

Also I would like to thank Jared Grim, Sathish Konduru, Santiago Velez, and Stephen Wallington for helping me in the laboratory with concreting and associated tasks. My heartfelt regards go to Mr. David Turner for his immense technical assistance in the concrete laboratory.

I gratefully acknowledge West Virginia Department of Transportation - Division of Highways for their financial support, and Arrow Concrete Company, BASF and other material suppliers for generously donating the materials. My sincere thanks go to $\mathrm{Mr}$. Jeff Stoker and Dr. Van Bui of BASF for their valuable suggestions during mix design.

I would like to dedicate this work to my parents, my uncle Mr. Dilip Bhattacharyya, and my friend Aniruddha Chatterjee, without whose constant motivation and support this work could not have been accomplished. 


\section{Table of Content}

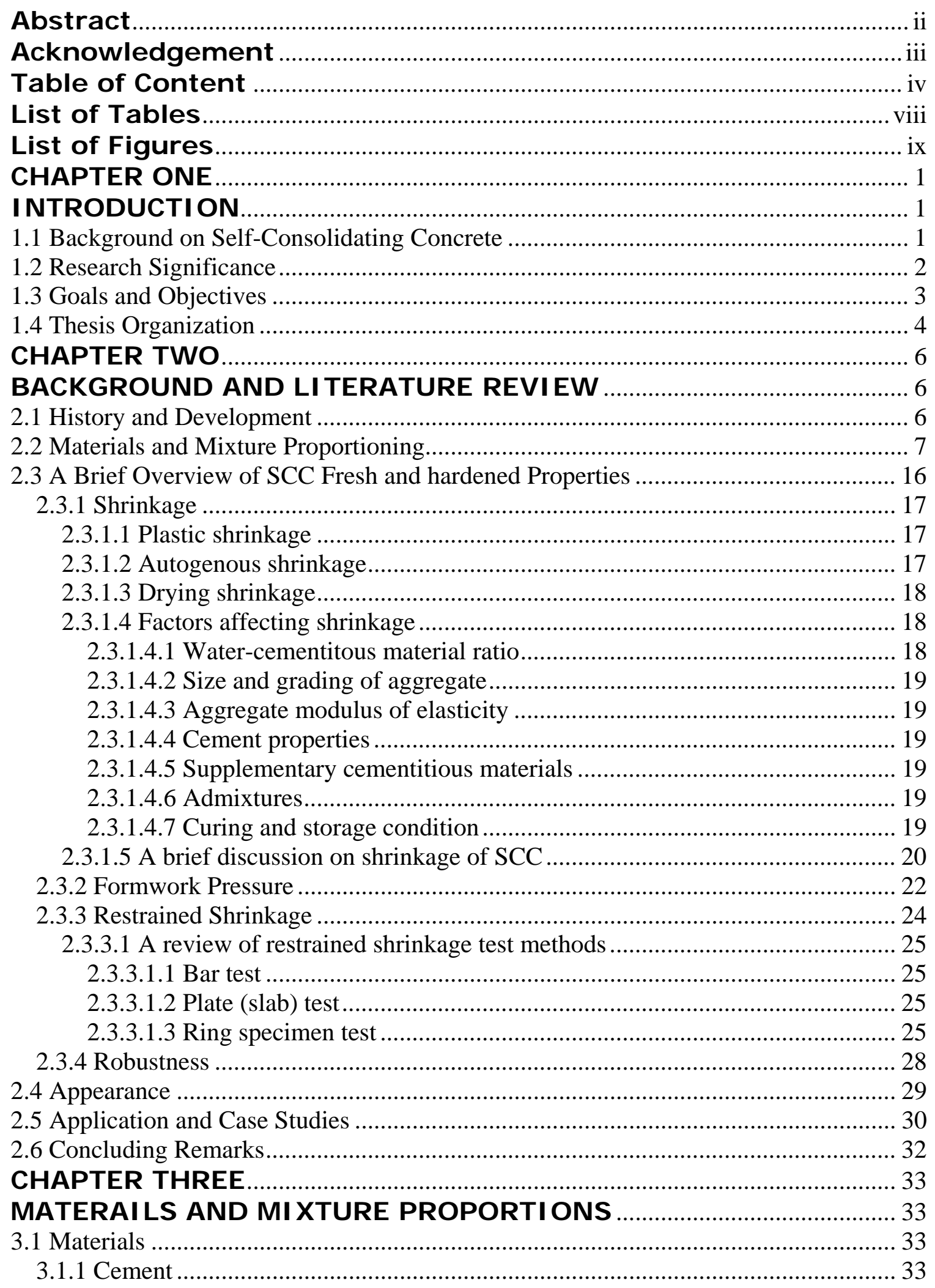




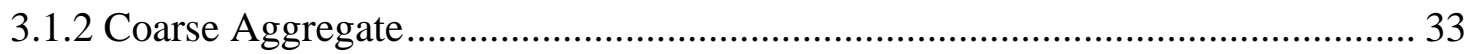

3.1.3 Fine Aggregate (FA) ............................................................................ 35

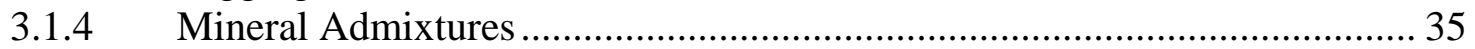

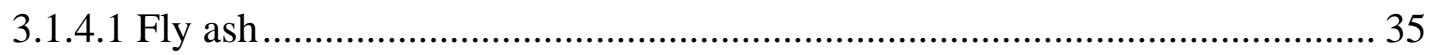

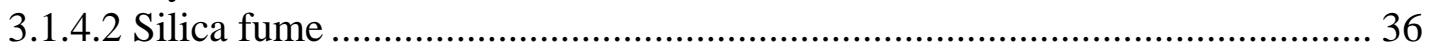

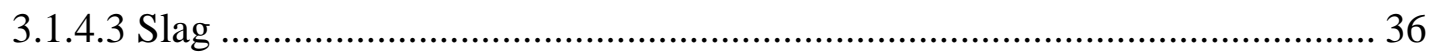

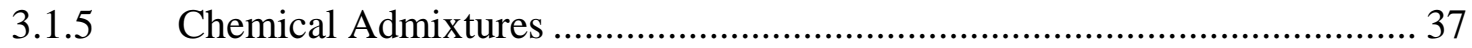

3.1.5.1 Water reducing admixture (WRA)................................................................. 37

3.1.5.2 High-range water reducing admixture (HRWRA)..................................... 37

3.1.5.3 Viscosity-modifying admixture (VMA) …………..................................... 38

3.1.5.4 Shrinkage-reducing admixture (SRA) …………...................................... 38

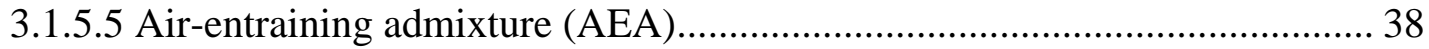

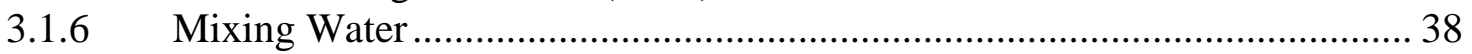

3.1.7 Limestone Powder (LP) .................................................................................. 38

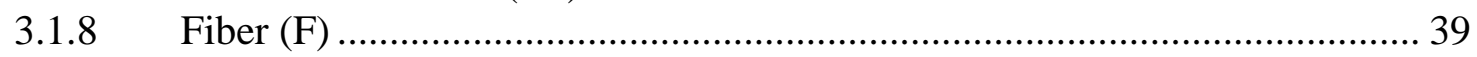

3.2 Mixture Proportioning of SCC............................................................................... 39

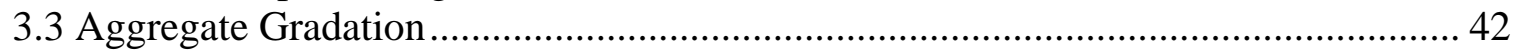

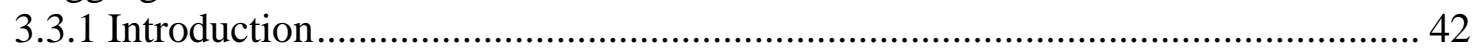

3.3.2 Combined Grading Curves ......................................................................... 42

3.3.3 Coarseness Factor and Workability Factor .............................................................. 43

3.4 Mixing Procedure....................................................................................................... 45

3.4.1 Mixing Sequence for SCC with Limestone Powder ............................................. 45

3.4.2 Mixing Sequence for SCC with Slag and Silica Fume......................................... 46

3.4.3 Mixing Sequence for SCC with Fiber................................................................. 46

3.4.4 Mixing Sequence for SCC with SRA ………................................................... 47

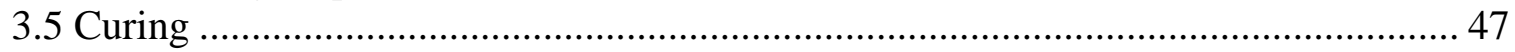

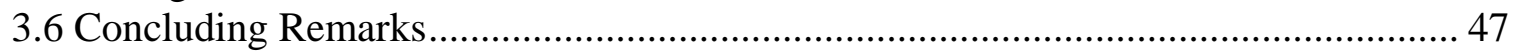

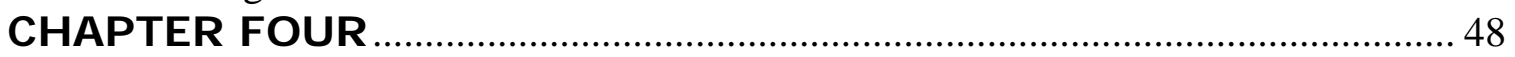

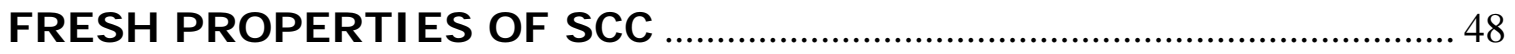

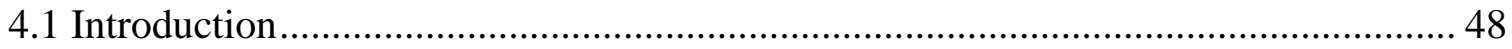

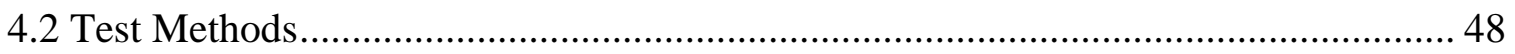

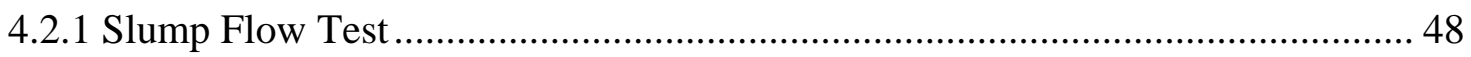

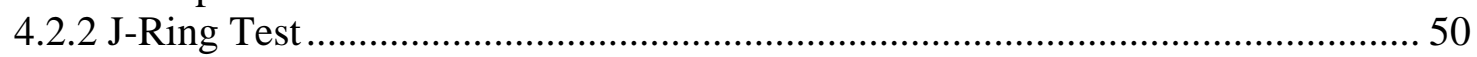

4.2.3 Column Segregation Test............................................................................ 51

4.2.4 L-box Test............................................................................................. 52

4.3 Test Results and Discussion................................................................................. 53

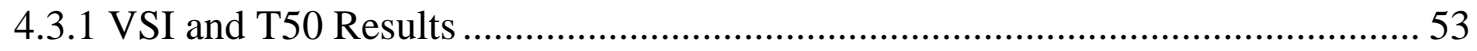

4.3.2 Slump Flow Test Results ............................................................................ 54

4.3.3 J-Ring Flow Test Results ........................................................................ 56

4.3.4 Column Segregation Test Results ................................................................... 57

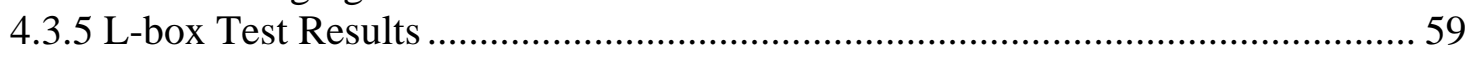

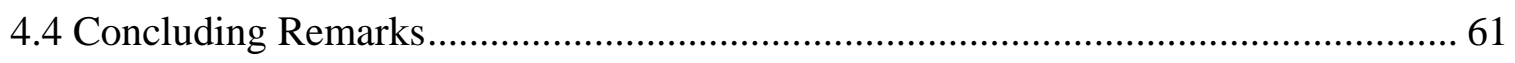

CHAPTER FIVE

HARDENED PROPERTIES OF SCC AND MI XTURE SELECTI ON ...... 62

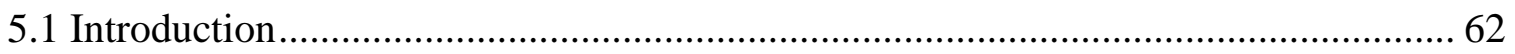

5.2 Compressive Strength Measurement ......................................................................... 62 
5.3 Compressive Strength of 17 Mixtures ....................................................................... 62

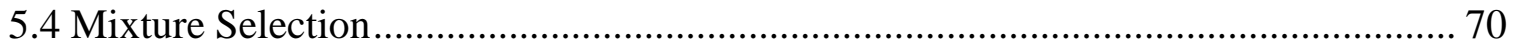

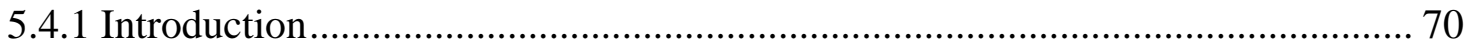

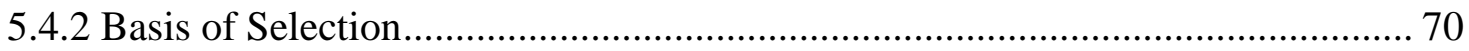

5.4.3 Tests on Selected Mixtures ................................................................................. 71

5.4.3.1 Compressive strength results for selected mixtures...................................... 72

5.4.3.2 Comparison with ACI Prediction Eqn. for Compressive strength.................. 73

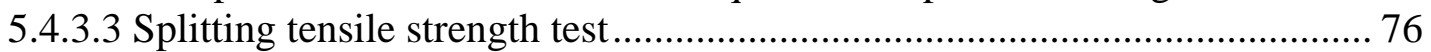

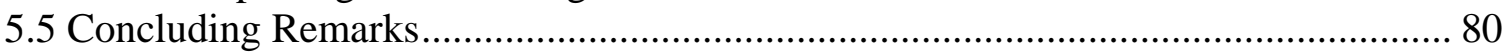

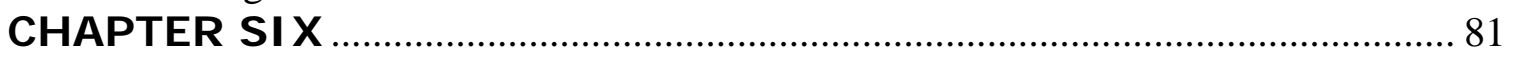

SHRI NKAGE AND CRACKI NG OF SELECTED SCC MI XTURES ......... 81

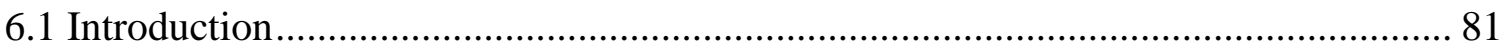

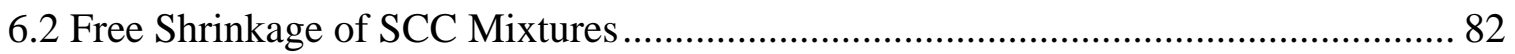

6.2.1 Test Procedure .............................................................................................. 82

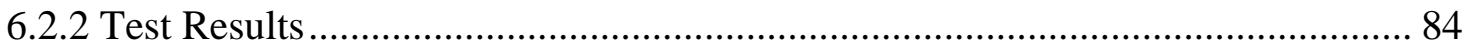

6.2.2.1 Comparison and discussion of experimental values with NC, HPC and SCC mixtures from other studies ................................................................................. 90

6.2.3 Comparison and Prediction of Free Shrinkage .................................................... 91

6.2.3.1 Shrinkage models....................................................................................... 91

6.2.3.1.1 ACI prediction equation.......................................................................... 91

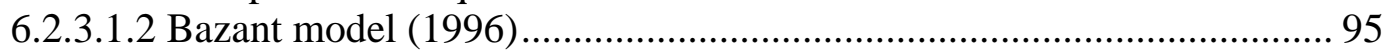

6.2.3.1.3 Gardner and Lockman model (2001) ..................................................... 96

6.2.3.1.4 The AASHTO specification model (2000) ………................................... 97

6.2.3.1.5 CEB MC90-99 model ......................................................................... 97

6.2.3.2 Comparison with models ........................................................................... 99

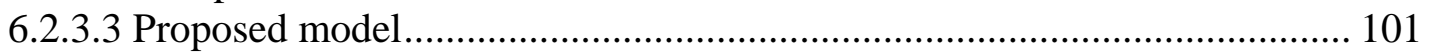

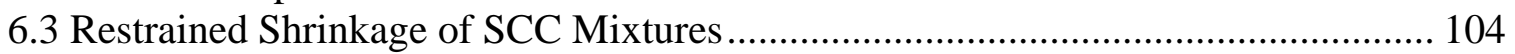

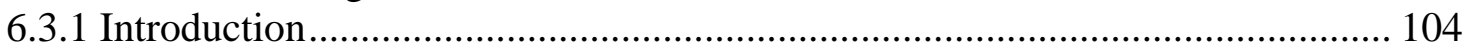

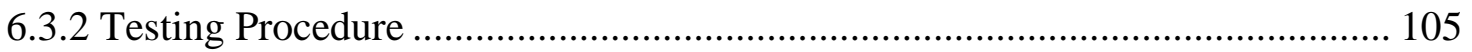

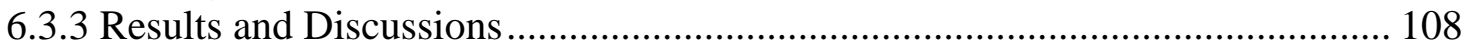

6.3.3.1 Strain versus time for ring specimens ......................................................... 108

6.3.3.2 Relation between free shrinkage and restrained shrinkage ........................... 111

6.3.3.3 Comparison with HPC ............................................................................ 113

6.3.3.4 Post-cracking ductility of FRSCC ............................................................. 114

6.3.3.5 Potential for cracking for different SCC mixtures...................................... 115

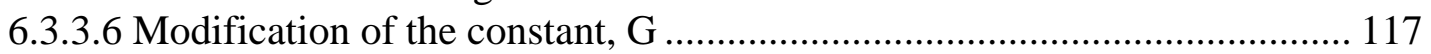

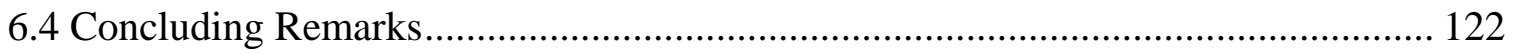

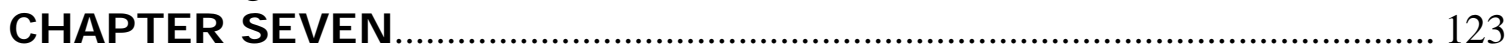

DI SCUSSI ONS ON AIR-VOI D PARAMETERS, FREEZI NG AND

THAWI NG, AND CHLORI DE PERMEABI LI TY ……………….................. 123

7.1 Chloride Permeability Test ............................................................................... 123

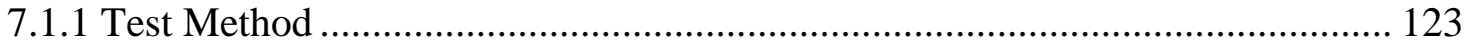

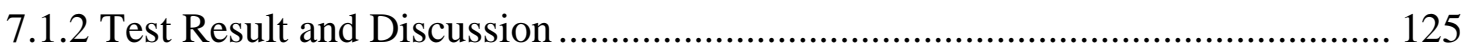

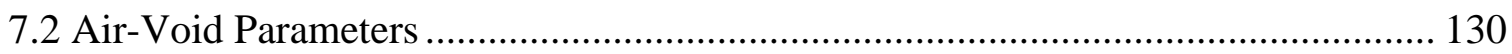

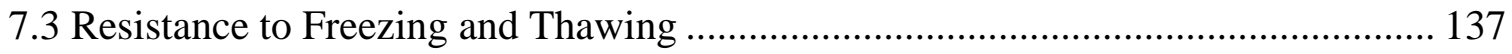

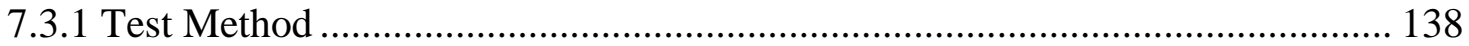




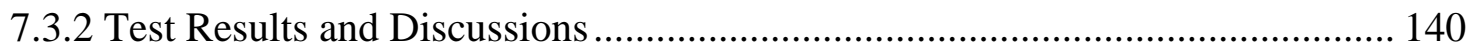

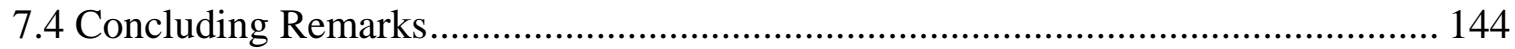

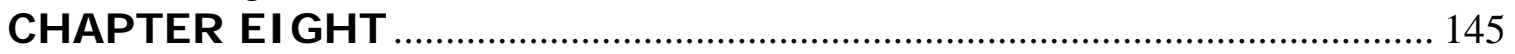

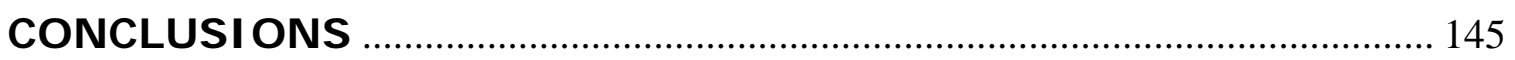

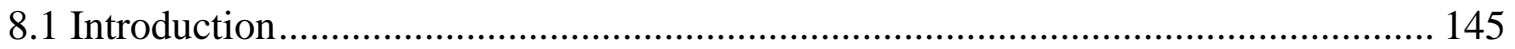

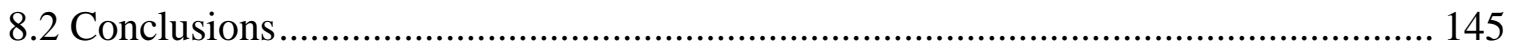

8.2.1 Materials and Mixture Proportions ............................................................. 145

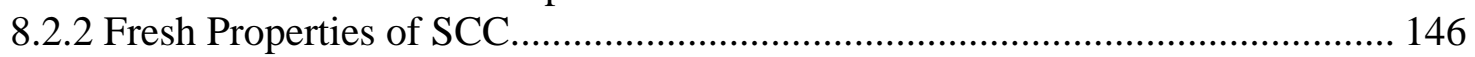

8.2.3 Hardened Properties of SCC and Mixture selection ...................................... 147

8.2.4 Shrinkage and Cracking of Selected SCC Mixtures ........................................ 148

8.2.5 Discussions on Air-void Parameters, Freezing and Thawing, and Chloride

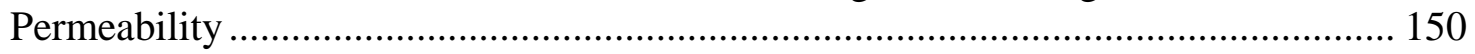

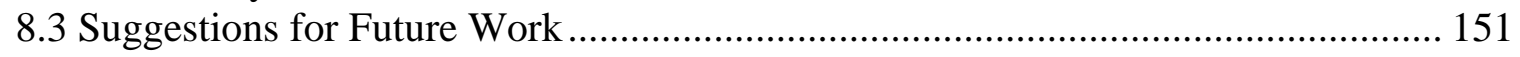

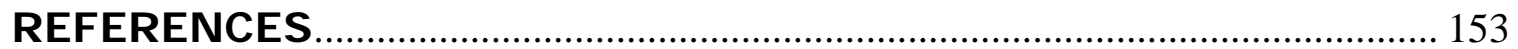

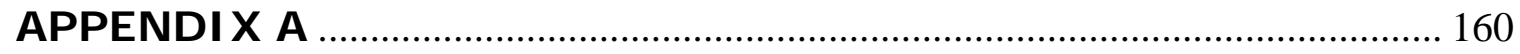

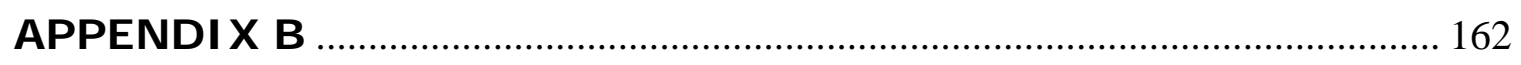




\section{List of Tables}

Table 3.1 Physical properties of Type I Portland cement used.................................. 33

Table 3.2 - Compound compositions of Portland cement............................................ 33

Table 3.3 - Properties of coarse aggregates.................................................................. 34

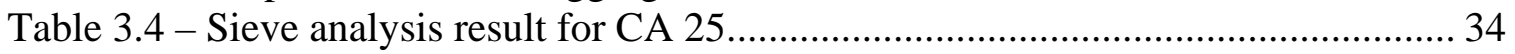

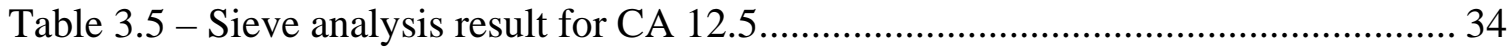

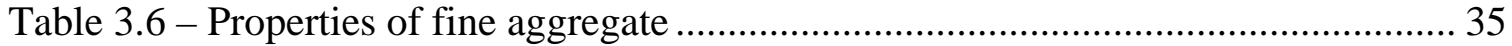

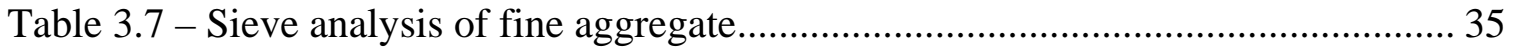

Table 3.8 - Basic properties of silica fume and fly ash ................................................ 36

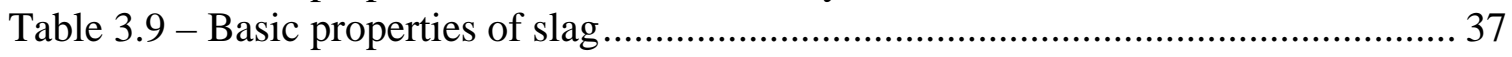

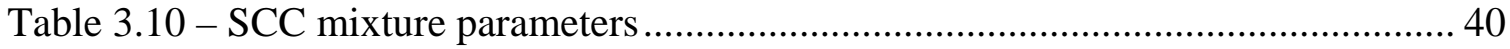

Table 3.11 - Aggregate gradation of different SCC mixtures ........................................ 41

Table 3.12 - Mixture proportioning for $1 \mathrm{~m}^{3}$ of SCC .................................................. 41

Table 3.13 - Combined aggregate grading ................................................................. 42

Table 3.14 - Coarseness factor and workability factor................................................ 44

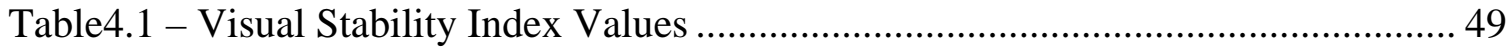

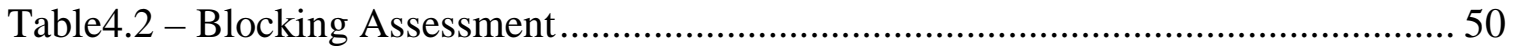

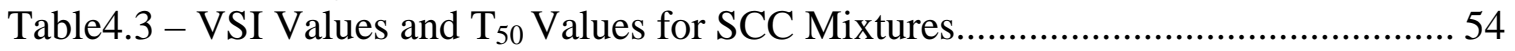

Table5.1 - Selected Six Mixtures .............................................................................. 70

Table5.2 - Ratio of splitting tensile strength to compressive strength .............................. 79

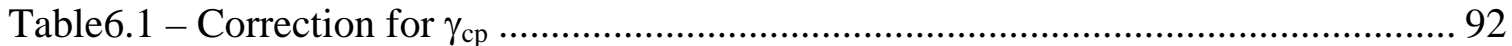

Table6.2 - Correction factors for average thickness method of members less than 150

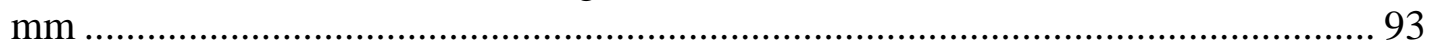

Table6.3 - Coefficients for CEB MC90-99 model ..................................................... 98

Table6.4 - Cracking age for selected SCC mixtures ................................................ 109

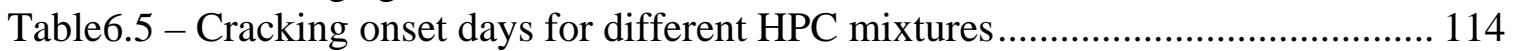

Table6.6 - Strain rate factor for different SCC mixtures........................................... 117

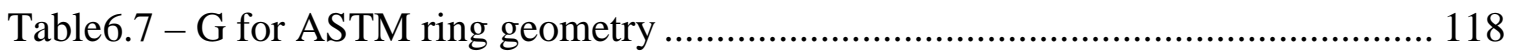

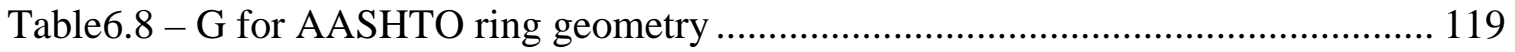

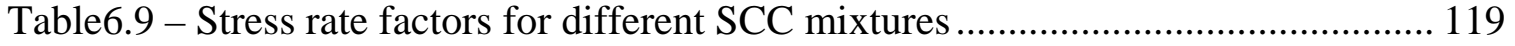

Table6.10 - Potential for cracking classification...................................................... 120

Table6.11 - Potential for cracking for selected SCC mixtures...................................... 121

Table 7.1 - Summary of charge passed results for all the mixtures ............................. 125

Table 7.2 - Chloride ion permeability based on charge passed.................................... 129

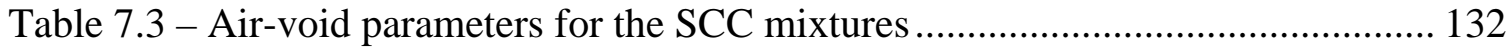

Table 7.4 - DF and mass loss for the SCC mixtures ................................................. 141 


\section{List of Figures}

Figure 2.1 Effect of different mixture ingredients on the rheological properties of SCC .. 8

Figure 2.2 An ideal SCC mixture 9

Figure 2.3 Difference of ingredients in SCC and Regular concrete mixture proportioning9

Figure 2.4 Comparison in proportioning of SCC and mixtures and ordinary concrete mixtures. 10

Figure 2.5 Shrinkage mechanism in concrete .......................................................... 18

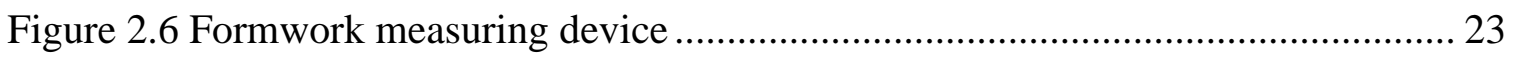

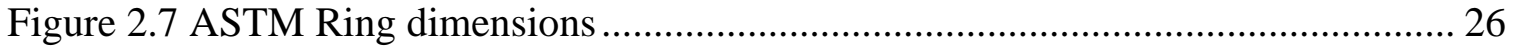

Figure 2.8 Comparison of aesthetics in SCC and OC ............................................... 29

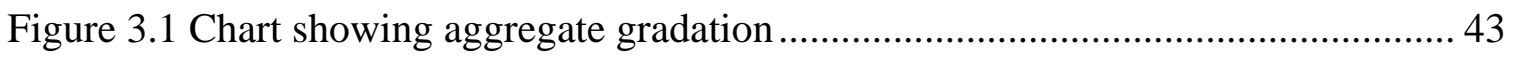

Figure 3.2 Band of aggregate gradation on CF-WF chart ............................................. 44

Figure 3.3 Variable speed laboratory mixture machine.............................................. 45

Figure 4.1 (a) Base plate for slump flow test Figure (b) Slump flow measurement......... 49

Figure 4.2 (a) J-ring dimensions (b) J-ring test in laboratory ...................................... 50

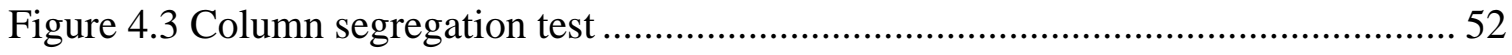

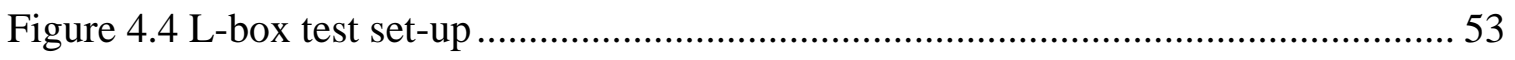

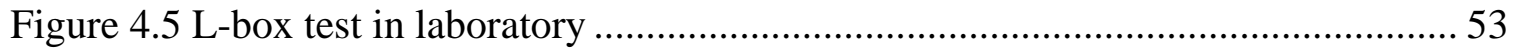

Figure 4.6 Slump flow test result for 17 SCC mixtures................................................ 55

Figure 4.7 Slump flow vs. (a) coarseness factor (b) workability factor .......................... 55

Figure 4.8 Blocking assessments for 17 SCC mixtures.............................................. 56

Figure 4.9 Blocking assessments vs. coarseness factor and workability factor................ 57

Figure 4.10 Static segregation as per column segregation for 17 SCC mixtures ............. 58

Figure 4.11 Aggregate fractions vs. static segregation ............................................... 58

Figure 4.12 Static segregations vs. (a) coarseness factor (b) workability factor .............. 59

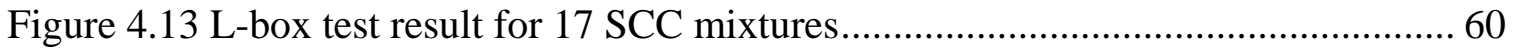

Figure 4.14 L-box PA vs. (a) coarseness factor (b) workability factor ........................... 60

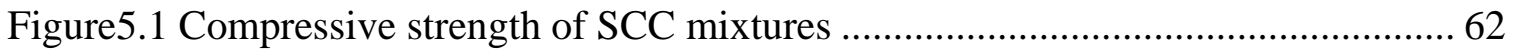

Figure 5.2 Compressive strength comparisons case-I (a) 7-day (b) 28-day .................... 63

Figure 5.3 Compressive strength comparisons case-II (a) 7-day (b) 28-day .................... 63

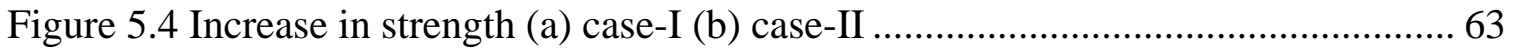


Figure5.5 w/cm versus (a) 7-day (b) 28-day Compressive strength................................... 66

Figure5.6 w/p versus (a) 7-day (b) 28-day Compressive strength...................................... 66

Figure5.7 Paste volume versus (a) 7-day (b) 28-day Compressive strength ...................... 66

Figure5.8 CF versus (a) 7-day (b) 28-day Compressive strength...................................... 67

Figure5.9 WF versus (a) 7-day (b) 28-day Compressive strength...................................... 67

Figure5.10 w/p versus (a) 7-day Compressive strength (b) 28-day Compressive strength

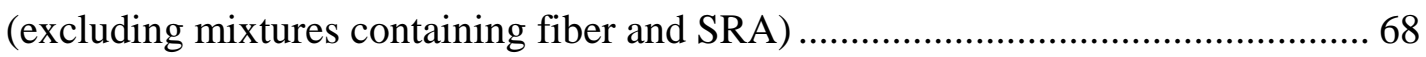

Figure5.11 Compressive strength for selected mixtures................................................... 72

Figure5.12 Relative comparison of compressive strength for selected mixtures .............. 72

Figure5.13 Comparison of compressive strengths at different ages predicted by ACI 209

R and (a) SCC A (70-30); (b) SCC B (50-50); (c) SCC C (30-70); (d) SCC D (0-

100); (e) SCC E (F) and (f) SCC F (SRA).......................................................... 74

Figure5.14 Comparison of compressive strengths at different ages predicted by modified

ACI equation and (a) SCC A (70-30); (b) SCC B (50-50); (c) SCC C (30-70); (d)

SCC D (0-100); (e) SCC E (F) and (f) SCC F (SRA)............................................. 76

Figure5.15 Splitting tensile strength of selected mixtures with time................................ 76

Figure5.16 Comparison of splitting tensile strength, direct tensile strength and modulus

of rupture for (a) SCC A (70-30); (b) SCC B (50-50); (c) SCC C (30-70); (d) SCC D

(0-100); (e) SCC E (F) and (f) SCC F (SRA) ……………................................... 78

Figure6.1 Test set up for (a) drying shrinkage (b) autogenous shrinkage ......................... 83

Figure6.2 Test set up for shrinkage test in the laboratory................................................. 83

Figure6.3 Total and autogenous shrinkage test results for (a) SCC A (70-30) (b) SCC B

(50-50) (C) SCC C (30-70) (d) SCC D (0-100) (e) SCC E (F) (f) SCC F (SRA) .... 85

Figure 6.4 Total shrinkage test results for selected SCC mixtures ..................................... 86

Figure 6.5 Autogenous shrinkage test results for selected SCC mixtures ......................... 86

Figure6.6 Drying shrinkage (due to external drying) test results for selected SCC

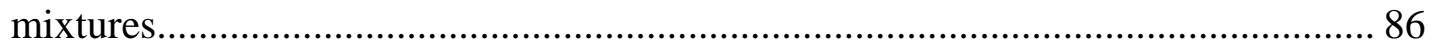

Figure6.7 CF versus Total and autogenous shrinkage ……….......................................... 87

Figure6.8 (a) Early age autogenous shrinkage (b) Temperature change within concrete

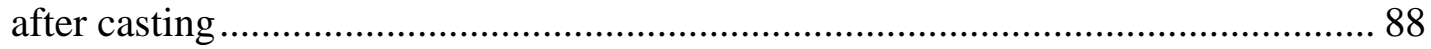

Figure6.9 Rate of heat evolution for typical portland cements......................................... 89 
Figure6.10 Comparison of free shrinkage with different available models for (a) SCC A (70-30) (b) SCC B (50-50) (C) SCC C (30-70) (d) SCC D (0-100) (e) SCC E (F) (f)

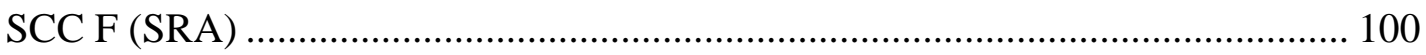

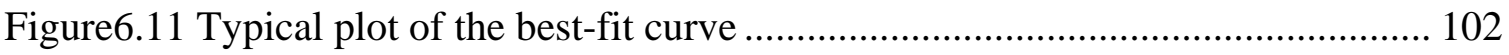

Figure6.12 Comparative plots of proposed model and experimental values.................. 102

Figure6.13 Residual plot of the proposed model ...................................................... 103

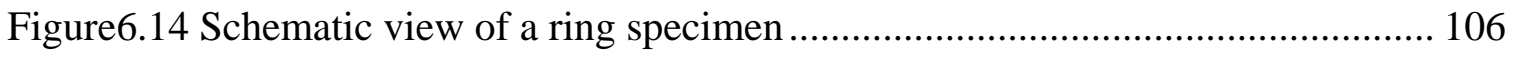

Figure6.15 Close view of a typical ring specimen with strain gauges.......................... 107

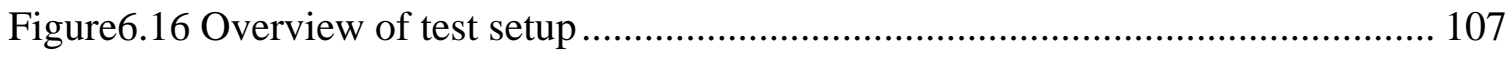

Figure 6.17 Strain developments with time inside steel ring..................................... 108

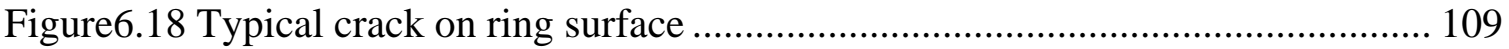

Figure6.19 Average age of cracking versus (a) CF (b) WF........................................ 110

Figure6.20 Shrinkage comparisons for (a) SCC A (70-30) (b) SCC B (50-50) (C) SCC C (30-70) (d) SCC D (0-100) (e) SCC E (F) (f) SCC F (SRA)................................ 113

Figure6.21 Net strain versus square root of time for SCC A $(70-30) \ldots \ldots \ldots \ldots \ldots \ldots \ldots \ldots . . . . . . . . . . . . . .116$

Figure6.22 Interaction between concrete ring and steel ring.................................... 118

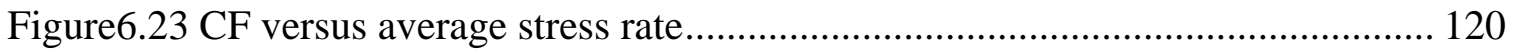

Figure 7.1 RCPT test being conducted in the laboratory......................................... 124

Figure 7.2 Charge passed versus time for (a) RCPT (b) blank test ............................. 126

Figure 7.3 Comparison of charge passed between RCPT and blank test ...................... 126

Figure 7.4 Comparison of normal RCPT and suggested extrapolated charge passed values

Figure 7.5 (a) Typical view of the prepared cross section of the cylinder (b) Typical view at a depth of 2 inches in the cylinder (c) Typical view at a depth of 4 inches in the cylinder (d) Typical view at a depth of 6 inches in the cylinder.

Figure 7.6 (a) View of the prepared cross section of the cylinder SCC E (F) (b) Typical view at a depth of 2 inches in the cylinder SCC E (F) (c) Typical view at a depth of 4 inches in the cylinder SCC E (F) (d) Typical view at a depth of 6 inches in the cylinder SCC E (F). 134

Figure 7.7 (a) View of the prepared cross section of the cylinder SCC F (SRA) (b) Typical view at a depth of 2 inches in the cylinder SCC F (SRA) (c) Typical view at 
a depth of 4 inches in the cylinder SCC F (SRA) (d) Typical view at a depth of 6 inches in the cylinder SCC F (SRA) .................................................................... 135

Figure 7.8 Effect of (a) Spacing factor and (b) Void frequency on 28-day strength...... 136

Figure 7.9 Temperature cycles used for freezing and thawing ..................................... 139

Figure 7.10 Relative dynamic modulus of elasticity versus number of cycles................ 140

Figure 7.11 Durability factor against spacing factor for different SCC mixtures .......... 142

Figure 7.12 Relationship between durability factor and spacing factor .......................... 143 


\section{CHAPTER ONE}

\section{NTRODUCTI ON}

This introductory chapter presents background information on self-consolidating concrete (SCC). Also, the significance, objectives, and organization of the present research work are discussed.

\subsection{Background on Self-Consolidating Concrete}

Self-consolidating concrete (SCC) as defined by ACI 237R-07, is a highly flowable concrete which do not segregate and can spread into place, fill the formwork with heavily congested reinforcement, and encapsulate the reinforcement without any mechanical vibration. It is also known as self-compacting concrete, selfleveling concrete, and SCC. Okamura in Japan first proposed the necessity of SCC in 1986 to cater for the reduction in skilled workers in Japan's construction industry and to achieve a durable structure independent of the quality of construction work. After its first application in Japan in the late 1980s, interest and use of SCC spread into many European countries. Use of SCC in USA started around late 1990s. At first, its use was limited in precast industries and cast-in-place application of SCC was limited. The use of SCC is increased to 1.8 million cubic meters (2.3 million cubic yards) in 2003. In 2002, $40 \%$ of precast manufacturers in the USA had used SCC. On the other hand, the use of SCC in the ready mixed concrete industry has been very limited, with estimated production in 2002 limited to 100,000 cubic meters (130,000 cubic yards). It can be seen that the use of SCC has grown tremendously since its incorporation. The development of high performance polycarboxylate polymers and viscosity modifiers have made it possible to create this "flowing" concrete without compromising the durability, cohesiveness, and other hardened properties.

SCC is defined as a concrete mixture that can be placed purely by its own weight, with little or no vibration. The main characteristics of SCC are (1) Filling ability, (2) Passing ability, and (3) Segregation resistance. Filling ability requires SCC to flow into forms and within reinforcements without any vibration and under its own weight. Passing ability signifies that SCC must pass through blockage due to aggregate being restricted from passing through narrow openings and fill all the open spaces. Stability criteria specify that SCC should remain stable during mixing, transportation, 
placing, and curing without any significant segregation. The advantages of using SCC are:

$\checkmark$ Reduced labor and equipment cost,

$\checkmark$ Easier placement in congested reinforcements,

$\checkmark$ Reduce noise pollution,

$\checkmark$ Faster placement,

$\checkmark$ Excellent surface finish,

$\checkmark$ Easier to fill complex shapes,

$\checkmark$ Easier reinforcement detailing,

SCC can be produced with the same ingredients of traditional vibrated concrete with the addition of high-range water reducers and some times a viscosity modifying admixture. Although a basic difference between SCC and normal concrete mixture ( $\mathrm{NC} / \mathrm{OC} / \mathrm{TC}$ ) is the amount of fines present in the mixtures. SCC mixtures generally contain more fines than $\mathrm{OC}$ and the maximum aggregate size used in SCC are smaller than OC. Different inert fillers and supplementary cementitious materials (SCM) are also used to produce SCC. Hence it is extremely important to know the effect of aggregate gradation, and admixtures/ fillers on fresh and hardened properties of self-consolidating concrete.

\subsection{Research Significance}

SCC is an engineered material and its performance is mainly dependent on the quality of local materials, local climatic conditions to which concrete will be exposed, and also, mixing and construction methods. Thus, it is necessary to develop suitable SCC mixtures using local material sources and construction technologies specific for a location or state.

Although there are several advantages of using SCC researchers listed some concerns about SCC that need to be addressed. Some of the concerns are summarized below:

> Proper selection of materials, mixture proportions, differences in local aggregate gradation and dosage of chemical admixtures.

$>$ Possible increased shrinkage and cracking risk due to high finer content

$>$ Long term durability due to different pore structure and paste volume compared to normal concrete

$>$ Possible loss of stability and segregation 
> Designing and monitoring false works and forms considering the fluid nature of the concrete.

$>$ Fatigue behavior

$>$ proper quality control at the job site

$>$ proper concrete transportation and placement techniques for SCC

In this research project, emphasis is given on mainly first four points above. Over the last few years, many researches and discoveries have been made on different behaviors of SCC which includes the concerns listed above. But due to variations in different aggregate used, different gradation of aggregates, different filler and mineral admixture types, use of a wide range of admixtures made it difficult to generalize any specific trend on the properties and behavior of SCC. Hence an indepth study on at least some of the concerns would help choosing the proper mixture for use in structural applications.

\subsection{Goals and Objectives}

The primary goal of this research is to conduct exploratory study and develop guide lines for a follow-up comprehensive project on implementing SCC in West Virginia (WV) through investigation and comparison of number of SCC mixtures. The main objectives of this study are summarized below:

$>$ Reviewing extensively the published literatures, reports and state-of-the art information about SCC.

$>$ Developing 17 SCC mixtures containing different graded aggregates and various combinations of mineral admixtures, fiber, SRA and admixtures.

$>$ Testing the fresh properties of the developed mixtures and comparing with some acceptable values set earlier based on industry use or from literatures.

> Understanding the effects of aggregate gradation and mineral admixtures on flowability, passing ability, segregation, and as a whole on fresh properties

$>$.Evaluating compressive strength for all the mixtures and compare with normal concrete and HPC.

> Understanding the effect of aggregate gradation, paste volume, water to binder ratio on compressive strength

$>$ Selecting six mixtures between the 17 mixtures.

$>$ Evaluating shrinkage development of selected six SCC mixtures based on different parameters and comparing them with normal concrete and HPC shrinkage values. 
Dvaluating restrained shrinkage cracking potential of the selected six mixtures.

> Evaluating durability properties namely rapid chloride permeability (RCPT), air-void parameters, and freezing and thawing resistance of the selected SCC mixtures.

\subsection{Thesis Organization}

This thesis is organized into eight chapters as follows:

Chapter 1: A brief introduction is given about SCC and its characteristics, followed by the research significance, objectives and organization of the thesis.

Chapter 2: A detailed literature review on various topics on SCC is presented in this chapter. Topics include history and development of SCC, materials and mixture proportioning of SCC mixtures, a brief overview of SCC fresh and hardened properties. Special emphasis was given on robustness, shrinkage, formwork pressure, and restrained shrinkage of SCC mixtures.

Chapter 3: In this chapter, all the materials used in this project are listed. Their sources and detailed properties (chemical and/or physical) are included. The mixture proportions and preparation methods of the specimens are presented. An emphasis is given on the aggregate gradation of SCC and comparison with NC.

Chapter 4: Fresh properties of SCC are evaluated in this chapter. The different test methods are described in detail in this chapter. Finally the test results are evaluated and correlations with different mixture parameters are studied.

Chapter 5: Hardened properties of SCC mixtures are evaluated in this chapter. Compressive strength of the SCC mixtures are evaluated and compared with NC and HPC, and correlations with different mixture parameters are studied. Six mixtures are selected from the 17 mixtures in this chapter. A detailed analysis of compressive strength and splitting tensile strength properties of these mixtures are presented in this chapter. Some useful relationships are established based on those results.

Chapter 6: This chapter is exclusively devoted to the shrinkage and restrained shrinkage cracking potential of the selected SCC mixtures. The drying shrinkage and autogenous shrinkage of these mixtures were evaluated using a vibrating-wire strain gage for better precision. The AASHTO ring specimen test (AASHTO Designation PP34-99) is adopted for the restrained shrinkage test. The cracking onset day, the average stress development in the steel ring is evaluated and a potential for cracking was found for the mixtures based on ASTM C 1581. 
Chapter 7: The durability properties of the SCC mixtures are developed here on the basis of three tests. The tests are rapid chloride permeability test (RCPT), air-void content, and resistance to freezing and thawing. Some useful observations are also established based on the test results.

Chapter 8: Conclusions are given in this chapter, and further research needs in this area are recommended. 


\section{CHAPTER TWO}

\section{BACKGROUND AND LITERATURE REVIEW}

In this chapter, the history and development of the different stages and properties of self-consolidating concrete are reviewed. Those include history of development, mixture proportion, robustness, fresh and hardened concrete properties, formwork pressure, durability characteristics, and use of SCC in USA.

\subsection{History and Development}

Self-consolidating concrete (SCC) as defined by ACI 237R-07, is a highly flowable concrete which do not segregate and can spread into place, fill the formwork with heavily congested reinforcement, and encapsulate the reinforcement without any mechanical vibration. Okamura in Japan first proposed the necessity of SCC in 1986 to cater for the reduction in skilled workers in Japan's construction industry and to achieve a durable structure independent of the quality of construction work. The first satisfactory prototype of self-consolidating concrete was completed in 1988 using materials in the market (Ouchi M, 1998). SCC was developed from the existing technology used for high workability and underwater concretes, where additional cohesiveness was required (Goodier, 2003).

The first paper on self-consolidating concrete was presented by Ozawa at the second East-Asia and Pacific Conference on Structural Engineering and Construction (EASEC-2) in January 1989 (Ozawa et al., 1989). The concept of SCC was spread to the world after the presentation on self-consolidating concrete by Ozawa at CANMET \& ACI International Conference, Istambul, in May 1992. RILEM's committee on selfconsolidating concrete was founded in January 1997. In April 1997, the Japanese Society of Civil Engineers (JSCE) set up a research sub-committee for establishing recommendations for the practical application of SCC. This was subsequently published in English in August 1999 (Uomoto and Ozawa, 1999). In August 1998, the first workshop on self-consolidating concrete was held in Kochi, Japan which was an important event for the development of SCC. In the late 1990s, interest and use of SCC spread from Japan to other countries, including Europe. Sweden was the first country in Europe to begin development of SCC, and in 1993 the CBI organized a seminar in Sweden for contractors and producers leading to a project aimed at studying SCC for housing (Billberg, 1999). A specification and guideline document has been produced in 2002 by EFNARC (European Federation of Producers and 
Contractors of Specialist Products for Structures) aiming to provide a guideline for the design and use of SCC in Europe based on latest research findings combined with field experience. Most of the major European countries have developed or currently in the process of developing guidelines or specifications for the use of SCC. Since the early development of SCC in Japan, this new class of high-performance concrete (HPC) has been adopted in several countries in cast-in-place and precast applications (ACI 237R, 2007).

From that time, application of SCC had been increased in a gigantic scale because of its enormous advantages over normal concrete. High workability, reduced labor and equipment, faster and less noisy construction, energy efficiency, flowability through highly congested reinforcement, better finish are some of them. It has been used in many construction applications such as building, bridge, tunnel construction in many European countries and Japan. However, in the United States the scope of application of SCC was limited and mainly confined in the precast concrete industry until recently. But now advantages of using SCC are being recognized by the concrete industry in the U.S. and many organizations like State Departments of Transportation, FHWA, Precast/Presterssed Concrete Institute (PCI) and American Concrete Institute (ACI) are working towards implementing SCC in different construction applications (Ouchi et al., 2003).

The use of SCC in North America has grown dramatically, especially, in the precast industry, where it has been used in regular production at present plants in the United States since 2000. The majority of such concrete has been used to produce precast elements for parking garage structure and architectural panels. The estimated volume of SCC in the precast market in the United States was 135,000 cubic meters $(177,000$ cubic yards) in 2000; it increased to 1.8 million cubic meters ( 2.3 million cubic yards) in 2003. In $2002,40 \%$ of precast manufacturers in the USA had used SCC, and in some cases, new plants are currently being built around the idea of using SCC technology. On the other hand, the use of SCC in the ready mixed

concrete industry has been very limited, with estimated production in 2002 limited to 100,000 cubic meters (130,000 cubic yards) (Vachon and Dackzo 2002).

\subsection{Materials and Mixture Proportioning}

Traditional concrete with high fluidity usually have a very high water to cement ratio, which lower the compressive strength and may compromise the durability. But a properly designed SCC can flow through the reinforcements and fill 
the forms without sacrificing the performance. Three major properties specific to SCC in its plastic state are its flowability and stability, segregation resistance, and Passing Ability. The high flowability of SCC is generally attained by using highrange water-reducing (HRWRA) admixtures and not by adding extra water. The stability or resistance to segregation of the plastic concrete mixture is attained by increasing the total quantity of fines in the concrete and/or by using admixtures that modify the viscosity of the mixture (viscosity Modifying Admixtures). Increased fines contents can be achieved by increasing the content of cementitious materials or by incorporating inert fines such as limestone powder. Admixtures that affect the viscosity of the mixture are especially helpful when the grading of available aggregate sources cannot be optimized for cohesive mixtures or with large source variations. A well distributed aggregate grading helps achieve SCC with reduced cementitious materials content and reduced admixture dosage. While successful SCC mixtures can be produced with $38 \mathrm{~mm}$ ( $1 \frac{1}{2}$ inch) aggregate, it is easier to design and control with smaller-sized aggregate. Control of aggregate moisture content is also critical to producing a good mixture.

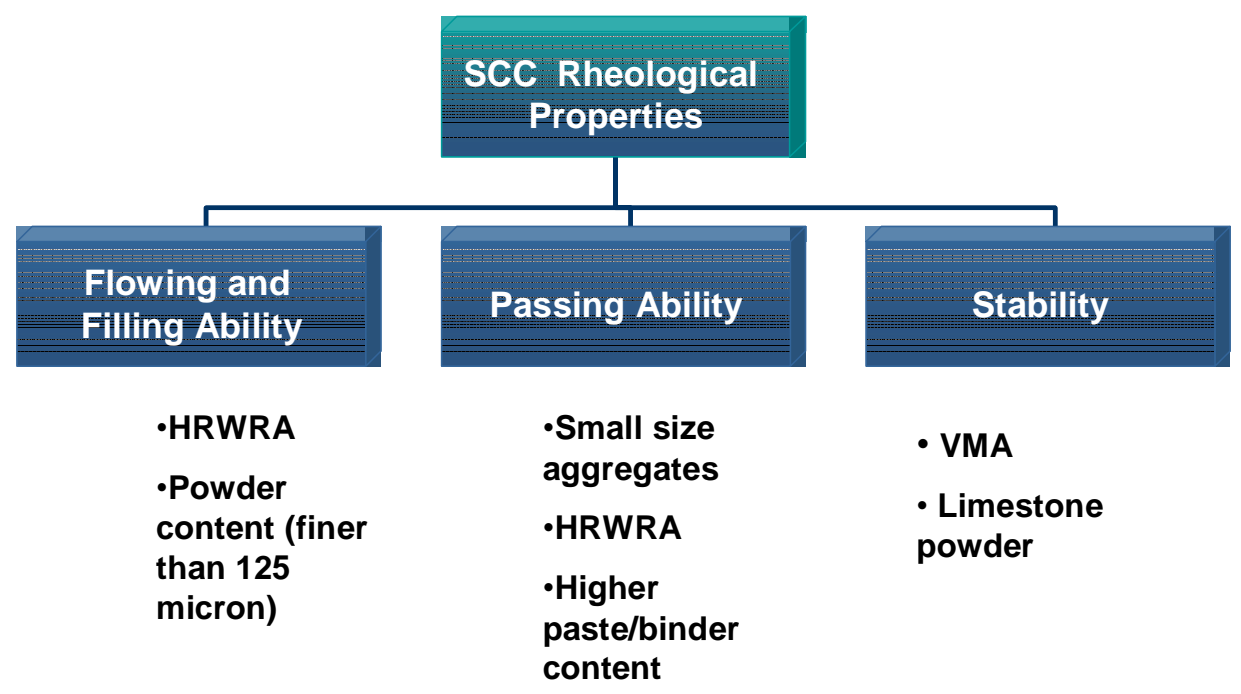

Figure 2.1 Effect of different mixture ingredients on the rheological properties of SCC

Figure 2.1 illustrates the three prongs of SCC mixtures and illustrates the effect of different mixture ingredients on the rheological properties of SCC. The HRWRA and the powder contents affect the flowing and filling ability of the SCC mixtures. Similarly, the passing ability of SCC is influenced by the small size coarse aggregates, HRWRA, and paste/ binder content of the mixture. The stability of the 
SCC mixtures is affected by the quantity of VMA and fine powders such as limestone powder quantity. An ideal SCC should contain a right blend of aggregate size and grading, HRWRA, and VMA to achieve a target flowing ability, passing ability, and stability or segregation resistance. This fact is clearly shown in the Figure 2.2 below.

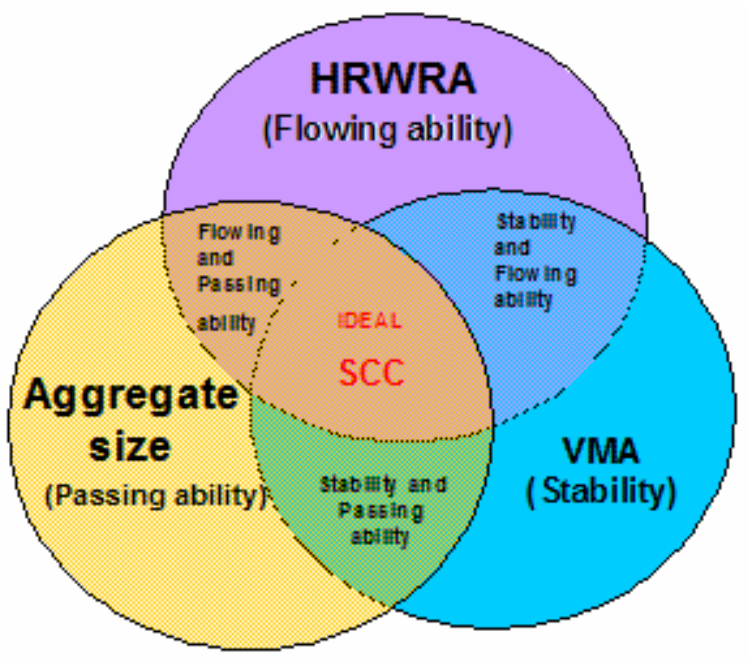

Figure 2.2 An ideal SCC mixture

SCC mixtures typically designed to have a higher paste volume, lesser coarse aggregate, and higher sand-to-coarse aggregate ratio compared to traditional concrete. SCC mixtures can be designed to have a desired mechanical performance and hardened properties for a particular application, similar to regular concrete.

Regular Mix

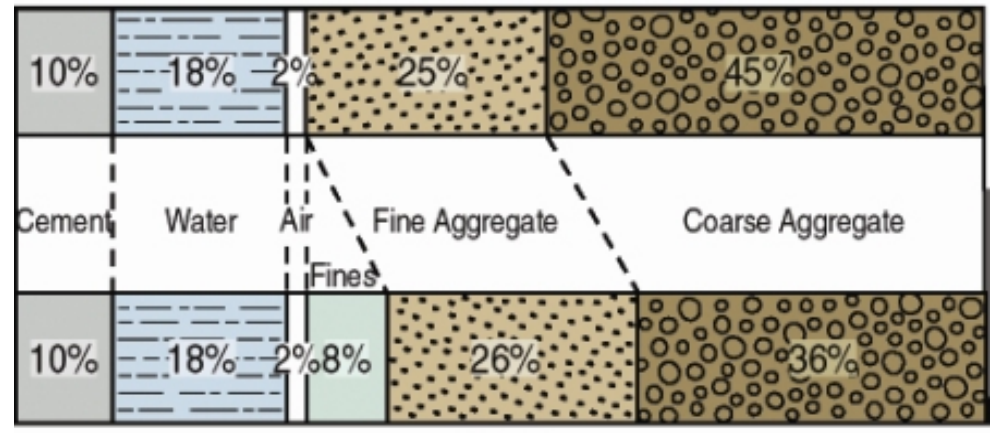

SCC

Figure 2.3 Difference of ingredients in SCC and Regular concrete mixture proportioning

(Adopted from: www.selfconsolidatingconcrete.org) 
Figure 2.3 shows differences between a typical normal concrete mixture and a typical SCC mixture. It can be seen that keeping the water and cement quantity same for both of the mixtures, SCC properties can be achieved by lowering the coarse aggregate (CA) fraction and increasing the fines.

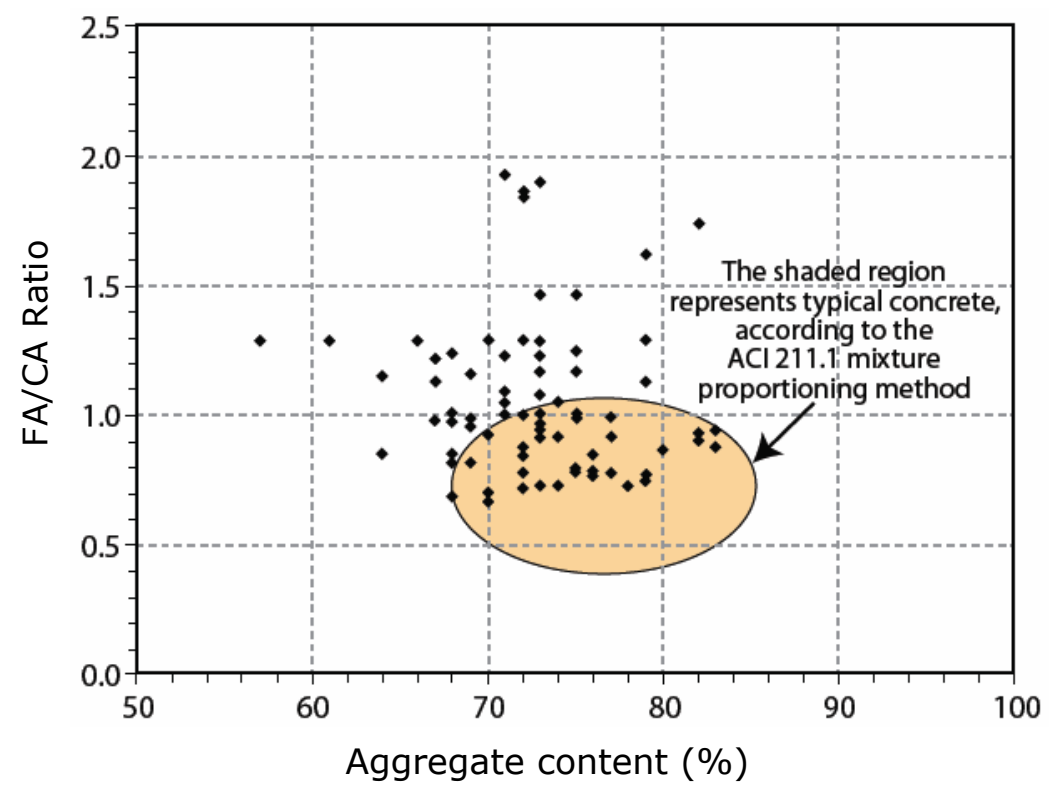

Figure 2.4 Comparison in proportioning of SCC and mixtures and ordinary concrete mixtures

(Adopted from: D'Ambrosia, 2007)

Figure 2.4 illustrates the fine aggregate to coarse aggregate ratio (FA/CA) and aggregate content for SCC mixtures compiled from the literature to illustrate the differences between SCC and normal vibrated concrete (D'Ambrosia, 2007). The shaded oval on the figure represents normal concrete according to ACI 211.1 mixture proportioning method. The average water to cementitious material ratio $(\mathrm{w} / \mathrm{cm})$ in the SCC database was 0.41 . It was observed that the total aggregate content was lower for SCC than for typical concrete. Low aggregate volume and smaller coarse aggregate size are often preferred to improve the passing ability of SCC. Higher proportion of sand is observed in the SCC mixtures to provide the required cohesiveness, uniformity and segregation resistance.

SCC can be produced with the same materials as of normal concrete and using some special type of admixtures such as viscosity modifying admixtures (VMA) and high-range water reducing admixtures (HRWRA) in some cases. But unlike the ordinary concrete, the mix design and fresh and hardened properties of SCC are 
much more sensitive to variability of the quality and consistency of the mixture components. To produce a highly flowable concrete with a good resistance against segregation, the amount of course aggregate has to be less than that of normal concrete and the reduced part to be replaced by the finer particles. As cement is an expensive and energy consuming material, fillers and cementitious materials are widely used for SCC production. Mineral admixtures like slag, silica fume, ground granulated blast furnace slag (GGBS), fly-ash or inert material such as limestone powder are most commonly used (Heirman et al., 2003; Goodier, 2003). This fact is also supported by Ghezal et al. (2002), who pointed out that cement replacement with incorporation of non-cementitious fillers in SCC has not been a popular choice in North America and the cost of SCC can be reduced through proper selection of locally available materials for making concrete and mixture constituents, with partial substitutions of cement and supplementary cementitious materials by readily available inert materials such as fillers and limestone powder is a very good choice. It has been observed that a particular cement content which is needed to achieve a given slump flow, viscosity, and early age compressive strength ; is reduced by replacing high volume of cement (on the order of $100 \mathrm{~kg} / \mathrm{m}^{3}$ ) by limestone filler. As noted by Heirman et al. (2003), the influence of filler characteristics on fresh properties is not clear because of the high influence of the Superplasticizer and the combined effect of filler and admixtures on the rheology of the paste. Also, depending on the filler type, the SCC mixtures had a higher or comparable compressive strength in comparison with the traditionally vibrated concrete with the same water/ cement ratio. The types, uses and effects of powders and fillers are described below.

Generally a powder or a superplasticizer or both are required to produce a stable yet flowing concrete with controlled bleeding and segregation. An increase in cement content significantly increases the cost of the mixture. Hence, the requirement of powder material has been met with higher use of pozzolanic and less reactive filler materials now-a-days (Zhu and Gibbs, 2004). Use of limestone powder not only increases the early age compressive strength but also improve the deformability and stability of the mixture. This may be due to the better particle packing of the limestone powder. In their study regarding use of different limestone and chalk powders in SCC, Zhu et al. concluded that increase in powder content resulted in a decrease of superplasticizer demand and could lead to a more economic SCC. They also observed that the mixtures containing limestone powders and chalk 
powders developed significantly higher compressive strength than the conventional concrete mixtures at the same water to cement ratio.

Ghezal and Khayat (2002) reported that higher material cost of SCC compared to conventional concrete of similar mechanical property is due to the use of different chemical admixtures and higher fines. Use of non-cementitious fillers as cement replacement has not been widely employed in North America. Partial substitution of cement by proper selection of filler material can reduce the cost of SCC. They developed statistical response models to develop cost-effective SCC with highvolume replacements of limestone filler. It was concluded that large volumes of cement replacement by limestone filler $(\sim 100 \mathrm{~kg} / \mathrm{m} 3)$ is shown to reduce the cement content needed to achieve a given slump flow, viscosity and compressive strength at early age Also the increase in limestone filler content can reduce the HRWRA demand of the mixture for a given deformability.

Heirman and Vandewalle (2003) studied the influence of filler properties on SCC fresh and hardened properties to link the measured properties with the characterizing properties of the fillers. Twelve different SCC mixtures and one traditionally vibrated concrete mixture were developed. Between the twelve SCC mixtures, seven contained limestone filler, two contained fly ashes, two contained quartzite fillers, and the remaining mixture contained dolomite filler. Water to cement ratio of all the mixtures were 0.5 and the mixtures had a constant volume filler to cement ratio of 0.9 . It was not possible to find a relationship between the filler characteristics and the results of the workability. This could be explained by the fact that the workability depends much more on the superplasticizer than the filler characteristics. It was also found that compressive strength developed for the SCC mixtures were higher than the traditional concrete. Also, strength of the mixtures developed with limestone and dolomite fillers were greater than mixtures developed with fly ash and quartzite fillers. The shrinkage of the SCC mixtures was found to be greater. The freeze-thaw resistance of the mixtures was good but a greater amount of scaled material was found when de-icing salts were added.

It is well known that the addition of steel fibers in concrete improves crack resistance, ductility and toughness as well as greater tensile strength. Though casting of fiber-reinforced SCC presents greater handling difficulty, Khayat et al. (2000) concluded highly flowable yet cohesive FR-SCC with a very good passing ability can greatly facilitate constructability of FRC and high deformability was obtained when the fiber volume was limited to $0.5 \%$ by volume of concrete. Similar 
findings were achieved by Nehdi et al. (2004). They reported reduction in workability and flowability of SCC developed with fibers and the best post-first-crack residual strength results for FRSCC mixtures were achieved by a combination of steel and synthetic microfibers. Hemant et al. (2007) conducted a study on fresh and hardened properties of fiber reinforced SCC mixtures. To improve the workability, fiber reinforced SCC mixtures were developed for application in prestressed concrete beams. The developed mixtures demonstrated satisfactory performance with regards to the stability and workability up to a fiber factor of 55. In general, the FRSCC mixtures had greater normalized tensile strength than the traditional fiber reinforced concrete mixtures for the same fiber factor. The optimum fiber content was found to be dependent upon the workability requirements. They concluded that highly workable and stable FRSCC mixtures can be made from locally available construction materials. It was also observed that although a higher CA/FA ratio reduced the filling ability and deformability of SCC, concrete with a higher CA/FA ratio can be produced with the addition of VMA to maintain required stability. The steel fiber enhanced the tensile and flexural properties significantly.

The chemical admixtures such as the VMA and HRWRA play very important roles on the fresh properties of SCC. In general VMAs' change the viscosity of the water and facilitate to resist segregation. It is very difficult to make a concrete with high workability having low w/c ratios. But the recently invented Superplasticizer (SP) or HRWRA can impart high slump-flow having low water cement ratios and retain this slump-flow for an extended period of time which is highly required to the manufacture and production of SCC and specially in the precast industry (Sugamata et al., 2005).

The rheology of paste depends on aggregate-paste volume, aggregate gradation of fine and course aggregates, shape of aggregate, fine aggregate-course aggregate ratio, aggregate surface characteristics and difference of density between aggregate and paste (Bui et al., 2002). Bui et al. (2002) developed a new approach of mix design based on paste rheology where the effect of aggregate properties and content is considered. Experimental results showed that the model is related to aggregate spacing and average aggregate diameter, and can be applied for different coarse-total aggregate ratios, different cement contents and different water-tobinder ratios. Stability and workability of fresh SCC are greatly enhanced by improving the fine-particle packing, which also facilitates in improving the paste matrix density and Interfacial transition zone (ITZ) (Bosiljkov, 2003). In the mixture 
proportions of traditional concrete, the water/cement ratio is kept constant for achieving required strength and durability. But in case of SCC, water/powder ratio has to be chosen instead of $w / c$ ratio as self compactibility is more dependent on the $\mathrm{w} / \mathrm{p}$ ratio and it is another important criterion for SCC other than strength and durability. Felekoglu et al. (2007) noted that optimum water/ cement ratio for producing SCC is in the range of $0.84-1.07$ by volume. The ratios above and below this range may cause blocking or segregation of the mixture due to presence of high cementitious material or high water content respectively. Paste volume is another important criterion for SCC as it is designed with a higher paste volume than NC. Flowability of SCC increases with higher volume of paste but it may have detrimental effects on mechanical properties, time-dependent deformations and cracking susceptibility (Roziere et al., 2007). Aggregates are one of the most important parameters in any type of concrete and SCC is no exception. The choice of aggregates, ratio of coarse and fine aggregate, volume of aggregates affects the fresh and hardened properties directly. Xie et al. (2005) found an optimum $V_{g} / V_{m}$ value to obtain good fresh properties, where $V_{g}$ is the volume of coarse aggregate and $V_{m}$ is the volume of mortar. It had been also reported that reduction of flowability, filling capacity and increase in stability of fresh SCC takes place with the decrease of maximum size of coarse aggregate. Aggregate gradation is of utmost importance for successful production and quality control for SCC. As it contains different graded aggregates (course and fine), a combined aggregate gradation curve is more appropriate. Shilstone (1990) defined coarseness factor (CF) and workability factor (WF) for normal concrete and plotted band of aggregate gradations on CF chart that produce optimum concrete mixtures in terms of workability. In this experimental program, the importance of CF and WF on the properties of SCC will be studied.

Compared to normal concrete, SCC generally requires longer mixing time. Chopin et al. (2004) investigated the reason behind the longer mixing time of SCC. They reported that mixing time is one of the problems reported by ready-mixed concrete firms. Mixing time often reaches $2 \mathrm{~min}$ for SCC produced in concrete plants, while, ordinary concrete is mixed for approximately for $35 \mathrm{~s}$. To understand why SCC and HPC require longer mixing time an experimental plan had been set up to study the influence of mix-design parameters through 36 different mixtures. The parameters that have been studied were the fine element content, the use of limestone filler or silica fume and the HRWRA type and dosage. A first linear, 
empirical model had been proposed, directly accounting for the mix-design ratios. Furthermore, it had been established that the mixing time of a given mixture is linked to its actual and its maximum solid content. Those two concepts were related to mixture design of concrete. An experimental model, based on those conclusions, was proposed for a given mixer. They concluded that mixing time can be reduced by the following means (1) increasing the fine particle content, with a constant w/c ratio, (2) increasing the total water content, (3) optimizing the granular skeleton will lead to a higher maximum solid content, for a constant total aggregate content, and (4) replacing part of the cement with silica fume.

The use of more fines and different chemical admixtures to produce SCC with desired properties may increase the material cost of the project. But in the long run, the cost offset by less labor cost and reduced construction time generally compensates the increase in material cost. Many researches had been done in the past and also currently going on to produce cost effective SCC from locally available materials. Lachemi et al. (2003) studied the comparative performance of different SCC mixtures made with FA, slag and different VMAs based on fresh and mechanical properties and also on cost. 21 mixtures had been prepared with $\mathrm{w} / \mathrm{cm}$ ratio varied between 0.35 to 0.45 and cement replacement up to $60 \%$ for FA SCC mixtures and up to $70 \%$ cement replacement for slag SCC mixtures. They concluded that an economical SCC mixture with desired properties can be successfully developed by incorporating FA, slag, and VMA. It was also found that the most economical SCCs with satisfactory properties with a 28-day strength of $35 \mathrm{MPa}$ can be obtained by using 50\% FA, 60\% slag cement as cement replacement. Such SCC can replace a normal SCC with significantly reduced cost.

Another study by Naik et al. (2005) focused on usefulness of limestonequarry by-product material in the development of economical SCC. Class C fly ash was also used in the study. The main objective of the research was to evaluate the possibility for using the stated materials for SCC production and to reduce the cost of expensive chemical admixtures. It was observed that the limestone-quarry fines and Class $C$ fly ash had a noticeable improvement and high potential for utilization in the production of SCC. The test results showed that, the requirements for chemical admixtures such as HRWRA and VMA were reduced when the quarry fines and fly ash were used as partial replacements of sand and cement, respectively. The major observations made from the study are as follows: 
- Partial replacement of sand with limestone-quarry fines improves the cost effectiveness of SCC without affecting the strength, and

- Use of Class C fly ash as a partial replacement of cement proved to be very beneficial to the cost and long-term strength gain for the SCC.

\subsection{A Brief Overview of SCC Fresh and hardened Properties}

Due to the high flowability of the SCC mixtures fresh concrete properties are significantly different than normal concrete mixtures. Hence it follows that tests should also be different for normal concrete and SCC at fresh stage. The main characteristics of SCC at plastic stage are flowability, passing ability, and segregation resistance as stated earlier which make it superior than normal concrete. Different test methods have been developed to quantify and characterize these properties at fresh state. Among these tests the most popular tests are slump flow, J-Ring flow, LBox Test, and Column Segregation Test. Details of these tests are described in Chapter 4. among these tests, Slump flow test measures the flowability, J-Ring and L-box test measure the passing ability, and the column segregation test measures the segregation resistance of the SCC. Many international organizations such as RILEM, ACI, ASTM etc. has set some target limits for these properties depending on the type of application and acceptability of the concrete as SCC. Hwang et al. (2006) proposed that SCC designed for structural applications should have a slump flow of 620 to $720 \mathrm{~mm}$, J-Ring flow 600 to $700 \mathrm{~mm}$ (Slump flow - J-Ring flow $\leq 50 \mathrm{~mm}$ ), LBox blocking ratio $\left(h_{2} / h_{1}\right) 0.7$ and maximum surface settlement $\leq 0.5 \%$. Also, $a$ combination of the slump flow and either the L-box blocking ratio $\left(h_{2} / h_{1}\right), J$-Ring, or V-funnel flow time can be used to assess filling capacity of SCC for placement in highly congested reinforcement typically encountered in structural applications. To qualify these limits and to achieve the required hardened properties, choice of proper mix design and required rheology of paste is of utmost importance.

Although the fresh properties of SCC and normal concrete (NC) are significantly different, the hardened properties with respect to testing and types of tests are almost same. As far as compressive strength is concerned, there is not much significant difference between SCC and normal concrete (NC). Though the modulus of elasticity of SCC is slightly lower than that of NC, the tensile splitting strength of SCC is higher than NC (Suksawang et al., 2006). This may be due to the fact that NC mix contains more coarse aggregate than SCC and lower cementitious 
paste volume. Also, drying shrinkage of SCC is higher than NC because of its higher finer content. An investigation of the early age mechanical behavior of SCC by Ambrosia et al. (2005) has revealed a potentially high risk for cracking at early age. The main factors which contribute to the cracking risk are stress developed by autogenous shrinkage at early age and diminished creep capacity in low $\mathrm{w} / \mathrm{cm}$ ratio materials.

Some of the properties of SCC were expected to be different that NC. A detail literature review of these properties is discussed below:

\subsubsection{Shrinkage}

Shrinkage maybe defines as time dependent volumetric change of concrete due to loss of moisture from the surface or within the concrete, or due to the carbonation of Hcp.

Types of Shrinkage:

1. Plastic Shrinkage

2. Autogenous Shrinkage

3. Drying Shrinkage

4. Carbonation Shrinkage

\subsubsection{Plastic shrinkage}

This type of shrinkage occurs when the concrete is in the plastic stage. The water in concrete mixture is lost by evaporation from the surface of the concrete or suction from dry sub-surface. When the evaporation or suction rate exceeds the rate of bleeding, and the free settlement period is ended, a hydrostatic tension begins to develop due to the formation of menisci at the water surfaces within the capillaries (Neville, 1996). As a result, concrete may be subjected to cracking unless evaporation loss is prevented.

\subsubsection{Autogenous shrinkage}

This type of shrinkage occurs after the setting of the cement paste has taken place and is the result of self-desiccation. When the cement particle and water are in contact, the hydration begins. During this process, if no additional water is provided (through curing), concrete will begin to dry internally and the autogenous deformation occurs. The autogenous shrinkage tends to increase with higher cement content, and possibly with finer cement. For HPC, due to its lower porosity and high volumes of cementitious paste, autogenous shrinkage due to self-desiccation within 
concrete is significant in spite of water sprayed on the outside of the concrete decks, and sometimes, constitutes more than $50 \%$ of total drying shrinkage.

\subsubsection{Drying shrinkage}

Drying shrinkage occurs in hardened concrete stored in unsaturated air when the water (free water or adsorbed water) is removed from inside of the hardened concrete. The lower the relative humidity of the air surrounding the concrete, the higher the rate of drying shrinkage is. Three phenomena are believed to contribute to drying shrinkage of concrete (Mindess et al., 2003): capillary stress, disjoining pressure, and changes in surface free energy, as shown in Figure 2.5 respectively.

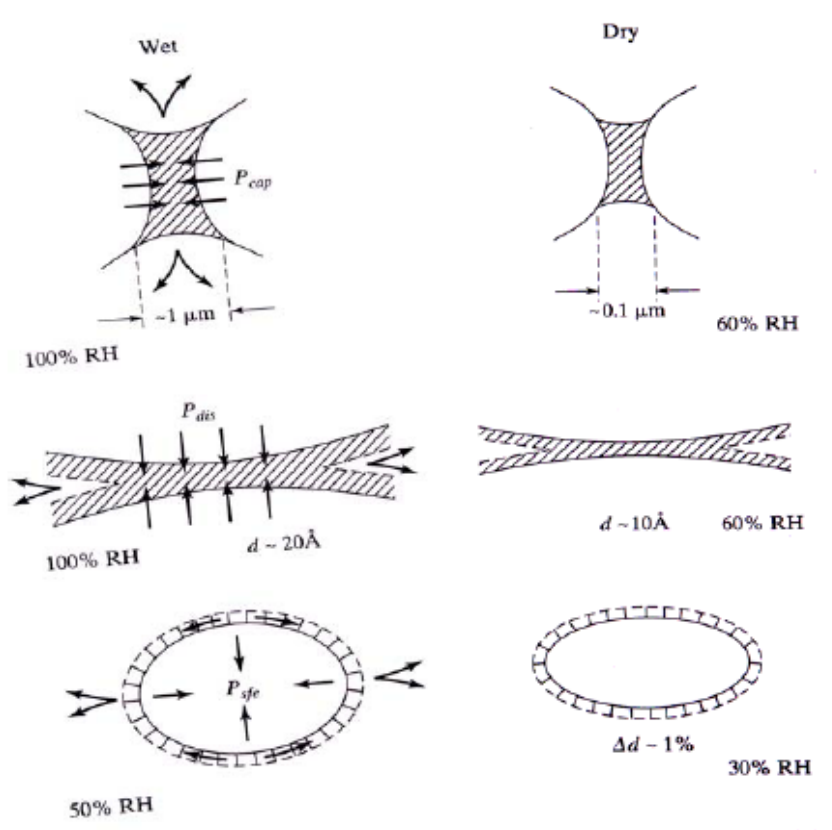

Figure 2.5 Shrinkage mechanism in concrete (Adopted from: Mindess et al., 2003)

\subsubsection{Factors affecting shrinkage}

Factors that affect the drying and autogenous shrinkage of concrete have been outlined below

\subsection{Water-cementitous material ratio}

For normal concrete, shrinkage becomes larger as the water to cementitious materials ratio $(\mathrm{w} / \mathrm{cm})$ becomes higher, as the $\mathrm{w} / \mathrm{cm}$ determines the amount of evaporable water in the cement paste. Brooks (1989) showed that shrinkage of hydrated cement paste is directly proportional to $\mathrm{w} / \mathrm{cm}$ ratio between the values of 0.2 to 0.6 . Above the $0.6 \mathrm{w} / \mathrm{cm}$ ratio water is evaporated without causing shrinkage. 
With constant $\mathrm{w} / \mathrm{cm}$ ratio, increase in cement content increases shrinkage due to greater paste volume. If workability is kept constant that means the water content is kept constant increase in cement content decreases shrinkage since effective $\mathrm{w} / \mathrm{cm}$ is reduced.

High strength concretes having a low w/cm has a greater early age shrinkage this is probably due to the greater amount of paste content. In case of HPC using supplementary cementing materials (particularly silica fume) and low w/cm $(\leq 0.4)$ the shrinkage values are much higher, if the drying of concrete starts at very early stage (within 72 hours). This happens due to loss of moisture internally and subsequent self desiccation and additional shrinkage.

\subsection{Size and grading of aggregate}

The size and grading of aggregate do not influence the amount of shrinkage. Since use of larger size aggregates make the mix leaner, hence in a lower shrinkage.

\subsection{Aggregate modulus of elasticity}

More the aggregate modulus of elasticity, higher its restraining capacity hence the concretes have a lower shrinkage. If aggregates have a tendency to shrink the overall shrinkage of concrete is increases.

\subsection{Cement properties}

Cement properties have little effect on shrinkage. Fineness of cement is a factor in the sense that the cement particles coarser than 75 micron hydrates very slowly hence cause a restraining effect. Cements deficient in gypsum exhibit considerably greater shrinkage.

\subsection{Supplementary cementitious materials}

Inclusion of supplementary cementing materials (SCM) increases shrinkage to a considerable extent. Brooks and Neville (1992) showed that often this increase is from 20 to 60 percent more than a concrete containing same amount of Ordinary Portland Cement and same $\mathrm{w} / \mathrm{cm}$. Whereas addition of slag with silica fume increases drying shrinkage and addition of fly ash to silica fume was found to increase drying shrinkage though the effect of variation of fly ash content from 15 to $25 \%$ was found not to have a significant difference.

\subsection{Admixtures}

Neville (1996) reported that both WRA's and superplasticizers (High range water reducing admixtures) increase shrinkage. Although WRA causes small increase in shrinkage 10 to $20 \%$ more shrinkage is observed due to addition of superplasticizers.

\subsection{Curing and storage condition}


Prolonged moist curing delays the advent of shrinkage and also reduces ultimate shrinkage of concrete. However for neat cement pastes greater the amount of hydrated paste lesser the amount of restraint. Hence a prolonged curing cause a higher amount of shrinkage in neat cement pastes.

The mechanical performance of SCC is an increasing concern among the researchers. This is due to different paste rheology, more fine aggregate content, and higher paste content, low water to cementitious material ratio compared to ordinary concrete.

\subsubsection{A brief discussion on shrinkage of SCC}

Ambrosia et al. (2005) conducted a study on mechanical performance of SCC at early age. He concluded that lower $\mathrm{w} / \mathrm{cm}$ ratio and higher paste volume are the factors which lead to higher compressive strength of SCC mixtures compared to normal concrete. The rate of strength gain is also higher for SCC due to its high paste content. In their experiment on shrinkage, it was found that SCC mixtures had a high autogenous shrinkage at early age. Low w/cm and high paste content were attributed to the fact and may result in stress development and cracking at early age. Overall the investigation revealed a potentially high risk of cracking. Higher use of cement paste content and a relatively low $\mathrm{w} / \mathrm{cm}$ ratio resulted in high autogenous shrinkage that may cause significant stress at early age and the creep capacity may be diminished due to the low $\mathrm{w} / \mathrm{cm}$ ratio.

Turcry and Loukili (2003) conducted a study of plastic shrinkage cracking of SCC. They developed six SCC mixtures with water to binder $(w / b)$ ratio varied from 0.23 to 0.41 for the study. The plastic shrinkage of SCC mixtures was found to be at least two times higher than the ordinary concrete mixtures. As the $w / b$ ratios of the SCC mixtures were lower than that of the ordinary concrete mixtures, difference in pore structure may have contributed to the higher plastic shrinkage. In another study, Turcry and Loukili (2006) conducted plastic shrinkage cracking tests on five SCC mixtures and compared the results with ordinary concretes. They conducted the test in three different environments; one with sealed condition, one with no-wind condition, and the other with wind condition. It was concluded that in moderate evaporation rate plastic shrinkage occurs before and during setting. Drying shrinkage was higher for SCC compared to OC mixtures due to difference in bleeding. At higher evaporation rate, SCC and OC mixtures exhibited the same plastic shrinkage. Restrained shrinkage tests performed in windy condition resulted in less cracking in SCC. It was also suggested that curing of SCC used in horizontal applications should 
be recommended to compensate for the lack of bleeding and subsequently less potential for cracking.

Poppe and Schutter (2005) studied the creep and shrinkage of SCC mixtures made with different parameters like cement type, filler type, and cement to powder ratio. The applicability of the standard creep and shrinkage models were also studied. They found a decrease of the creep deformation. The decrease in the creep coefficient resulted from the increased $\mathrm{w} / \mathrm{c}$ ratio. They also concluded that combination of $\mathrm{w} / \mathrm{c}$ and water to powder ratio (w/p) should be considered for time-dependent deformations. Comparison of the experimental results with traditional models showed that ACI-model was the closest. It was also concluded that shrinkage values of SCC are comparable to that of ordinary concrete.

Hammer (2003) investigated the cracking susceptibility of SCC due to volume changes. Volume changes considered were plastic settlement and shrinkage, autogenous deformation, thermal dilation, and drying shrinkage. It was observed that drying shrinkage cracking of SCC is not significantly different than OC, unless a considerable high amount of paste is used for the SCC. Due to higher cement and filler content, SCC is particularly vulnerable to cracking at early stage compared to OC. Also SCC mixtures designed with high $w / c$ or $w / b$ ratio, risk of "thermal cracking" is higher than ordinary concrete.

Hammer (2001) studied the effect of volume changes as driving forces to selfinduced cracking of Norwegian SCC. Paste content, w/b and binder type are the main parameters behind the risk of plastic shrinkage cracking, thermal cracking, and shrinkage cracking of SCC mixtures. The development work focused at maintaining the above mentioned parameters as close to equivalent traditional concrete as possible. That resulted in similar settlement, plastic shrinkage, autogenous shrinkage, thermal dilation, and drying shrinkage values for SCC and OC mixtures. However lower $\mathrm{w} / \mathrm{b}$ ratio or increased paste volume can lead to higher risk of cracking for the SCC mixtures.

Turcry et al. (2006) evaluated cracking tendency of SCC subjected to restrained shrinkage. Cracking risk is not only dependent on the magnitude and rate of shrinkage, but also on different material properties, such as modulus of elasticity, creep, tensile strength, and fracture properties. (Shah et al., 1998). Three SCC mixtures and three OC mixtures were investigated for shrinkage cracking potential. A comparison was done considering on the age-dependent parameters governing cracking risk, such as shrinkage, viscoelastic properties and fracture properties. 
Restrained shrinkage cracking by ring test was done and a numerical study was performed to simulate the ring test using the material properties. It was found that, when compressive strength was held constant, shrinkage, modulus of elasticity, tensile strength, and specific creep of SCC and OC mixtures were comparable. However, the modulus of elasticity of SCC was found to be smaller than that of OC mixtures, although the difference was insignificant. In the experiment, SCC mixtures had shown a much earlier-age cracking compared to OC mixtures.

Gomez and Landsberger (2007) evaluated the shrinkage prediction models of SCC. An extensive database of shrinkage values for SCC and OC were first generated. The different parameters were cement content, filler content, aggregate content, w/c ratio, $w / p$ ratio and compressive strength. Different standard shrinkage prediction models such as ACI 209R-92 model, CEB-FIP 1990 model, EHE model, B3 model, and GL 2000 models were used to predict and compare the shrinkage values with the database. A residual analysis and coefficient of variation calculation were also done to better interpret the result; the influence of various parameters on mean shrinkage strain and coefficient of variation was also evaluated. The results indicated that despite difference between different models, there were no significant differences in the shrinkage strain values for SCC and OC mixtures. B3 and ACI model were found to be the best models for estimation of shrinkage in SCC mixtures. It was also found that B3 model slightly underestimated the shrinkage strains, whereas ACI model slightly overestimated the strain values. The CEB-FIP 1990, EHE, and GL 2000 models grossly underestimated the shrinkage of the SCC mixtures.

Assie et al. (2003) studied the durability properties of SCC. Durability properties of same strength SCC and vibrated concrete (VC) were tested. It was found that SCC and VC had similar drying and autogenous shrinkage up to 90 days. After 90 days, SCC mixtures showed higher autogenous shrinkage than VC mixtures. Delayed deformation under load or creep, was found to be higher than VC mixtures. SCC had greater basic creep and total creep than VC. For same water-accessible porosity, SCC mixtures presented a lower "dry" intrinsic permeability than that of the VC mixtures.

\subsubsection{Formwork Pressure}

Formwork pressure of SCC might be a problem for SCC due to its highly fluid nature. As per ACI 237, the formwork pressure of SCC is generally higher than normal concrete, especially when the casting rate is higher. Also, the types of forms determine the characteristics and stability of SCC after placement. ACI 347R 
recommend that unless a method based on appropriate experimental data is available, formwork should be designed to withstand the full hydrostatic head of fluid concrete. This provision is problematic for the contractors as they have to use strong forms for the pouring of SCC. Another problem is there are no standard test methods defined to find the formwork pressure in the laboratory. Hence, there is a great need to focus on this topic for this type of highly flowable concrete.

Many laboratory experiments and field tests have shown that SCC pouring do not ncessarily generate full hydrostatic pressure at the bottom of the structure. Tests performed by Vanhove and Djelal (2002) resulted in a maximum pressure $64 \%$ of maximum hydrostatic pressure for a wall placed at $25 \mathrm{~m} / \mathrm{h}$ from above and a maximum of $68 \%$ of maximum hydrostatic pressure for a wall placed at $19.5 \mathrm{~m} / \mathrm{h}$ by pumping from the bottom of the wall. Also, the maximum pressure was not found at the bottom of the wall but at a height of $1.5 \mathrm{~m}$.

Several new techniques are being invented for studying formwork pressure with SCC in the laboratory. One method used by researchers at the University of Sherbrooke and the University of Illinois at Urbana-Champaign (UIUC) used a PVC tube with sensors mounted to the tube. An alternative laboratory set up is used by researchers at Northwestern University. Their testing apparatus utilizes a short column of concrete, $300 \mathrm{~mm}$, in a steel mold.

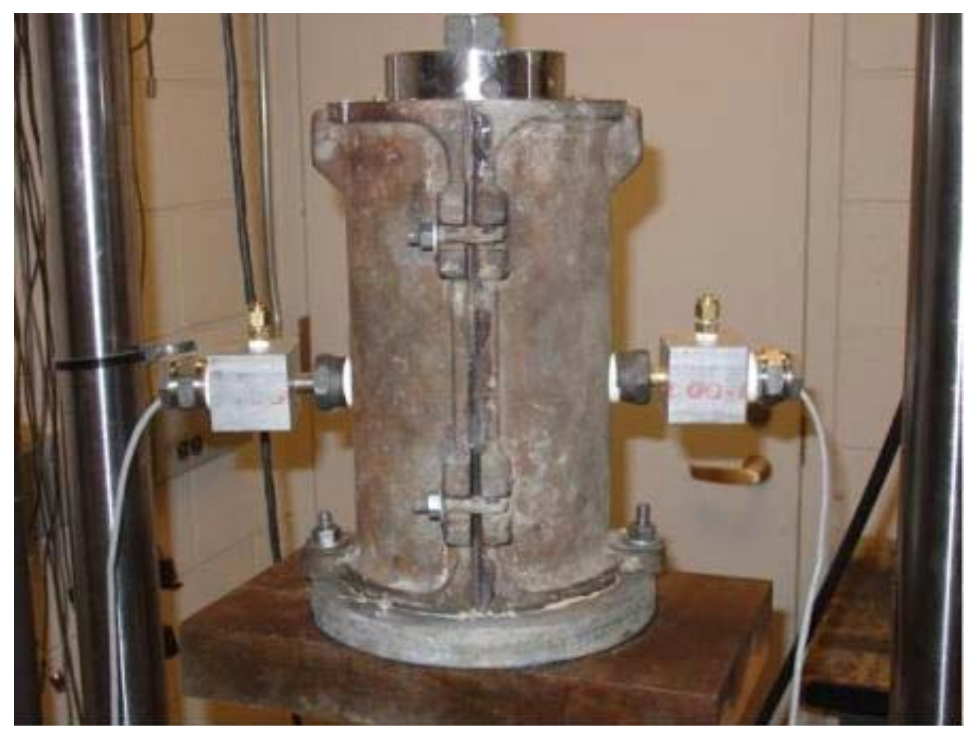

Figure 2.6 Formwork measuring device

(Adopted from: www.selfconsolidatingconcrete.org)

Figure 2.4 is a picture of their test set-up. A loading frame is used to apply a load on the top of the column of concrete to simulate the effect of a larger column of 
concrete. This can also apply increasing loads over time to simulate varying casting rates. The cylinder has two pressure cells mounted on the sides. One is used to measure total horizontal pressure and the second sensor is used to measure pore water pressure.

Assad and Khayat (2006) investigated the effect of casting rate and concrete temperature on formwork pressure exerted by SCC. The initial temperature of the concrete was varied between 10 to $30 \mathrm{C}$ or with high early-strength cement and setaccelerating admixture. The concrete were placed either continuously at casting rate varied between 5 and $25 \mathrm{~m} / \mathrm{h}$ or by intermediate stopping as per some predetermined time. They observed that decrease in casting rate from 25 to $5 \mathrm{~m} / \mathrm{h}$ reduced the maximum initial pressure by $15 \%$ without any considerable effect on the rate of pressure drop with time. It was also concluded that fresh concrete temperature had little or no effect on the maximum developed lateral pressure. They observed that at the end of dormant period of cement hydration, the accelerated rat of formation of hydrates enabled the mixture to becoming self-bearing leading to abrupt drop in pressure.

They also studied (2008) the measurement systems for determining formwork pressure of SCC. They suggested that flush diaphragm milivolt output type pressure sensors can be used to find the lateral pressure of SCC. They had used rigid PVC tubes for their experiment and concluded that $10 \mathrm{~mm}$ thick wall is sufficient for a column height of $2800 \mathrm{~mm}$.

Gregori et al. (2008) investigated experimental simulation of SCC formwork pressure. The effects of casting rate and mixture composition on formwork pressure were investigated by pressurizing a volume of material inside a cylinder and measuring the lateral pressure evolution. They used mixtures with four different $\mathrm{w} / \mathrm{b}$ content and two different casting rates. They concluded that casting rate is the main factor controlling formwork pressure and the mixture composition can also play an important role. They observed that for a given casting rate, reducing the $\mathrm{w} / \mathrm{b}$ ratio reduces the formwork pressure. Also, faster pressure drop was observed when fly ash was used.

\subsubsection{Restrained Shrinkage}

In the previous sections, the mixture proportions, fresh and hardened properties such as compressive strength and shrinkage properties of SCC mixtures were discussed. Those properties are regarded as very important parameters that control performance of SCC. However, for structures like bridge decks, the cracking induced 
by restraints either due to reinforcement or the boundary conditions is of serious concern because of its detrimental effect on service-life performance. A better and more thorough understanding of cracking properties of SCC designated for bridge decks and other important structures is therefore essential to anticipate or prevent crack development. To this end, the restrained shrinkage test is a useful method to evaluate the cracking potential of HPC mixtures. The effect of restrained shrinkage on SCC will be investigated in this section.

\subsubsection{A review of restrained shrinkage test methods}

In order to evaluate the cracking tendency of different concrete mixtures, a number of retrained shrinkage test methods have been developed. These tests are conducted on three different types of specimens: bar, plate, and ring, as described below.

\subsection{Bar test}

The bar specimen test is also called a uniaxial restrained shrinkage test, which provides relatively uniform uniaxial state of stress along the specimen tested. There are two types of uniaxial restrained specimens. One is so-called "dog-bone" specimen, and the other one is prismatic beam specimen.

\subsection{Plate (slab) test}

The plate or slab specimen is usually used for the measurement of plastic shrinkage cracking. However the plate or slab specimen is a good choice to simulate the restraint experienced in an actual structure such as a bridge deck, or an industrial floor.

\subsection{Ring specimen test}

The ring test was first developed by Carlson in early 1940s. His work was first published in 1942 (Carlson, 1942), then subsequently published in 1988 (Carlson and Reading, 1998). In this test, a $25.4 \mathrm{~mm}$ ( 1 in) thick steel ring with an external diameter of $178 \mathrm{~mm}$ (7 in) was used as a restraint source. The concrete or mortar ring specimens were cast around the exterior surface of steel rings. As a result of drying, the concrete ring shrinks, and exerts axisymmetric pressure over the "rigid" steel rings, leading to tension cracking on the outer surface of the concrete ring specimen. The cracking onset depends on the degree of drying of concrete, stiffness of inner steel and concrete material properties.

In 1998, AASHTO approved a provisional standard for the ring test, as "Standard Practice for Estimating the Cracking Tendency of Concrete." The steel ring recommended has a wall thickness of $12.8 \mathrm{~mm}(1 / 2 \mathrm{in})$, an outside diameter of 305 $\mathrm{mm}$ (12 in), and height of $152 \mathrm{~mm}$ (6 in). Four strain gages are suggested to be 
mounted to the interior surface of the steel ring on opposite directions to monitor the onset of concrete cracking. In practice, a smaller size of ring is also sometimes used if aggregate for concrete mixture is small. The detail description of the AASHTO ring test is illustrated in Chapter 6.

A similar test was proposed by the ASTM Committee C09 in ASTM C 1581-04 (Standard Test Method for Determining Age at Cracking and Induced Tensile Stress Characteristics of Mortar and Concrete under Restrained Shrinkage) in 2004. The process is similar to that of AASHTO ring test with some exceptions. One of the exception is the dimension of the steel and concrete ring used. The following figure illustrates the dimensions for the ASTM ring tes ${ }^{+}$
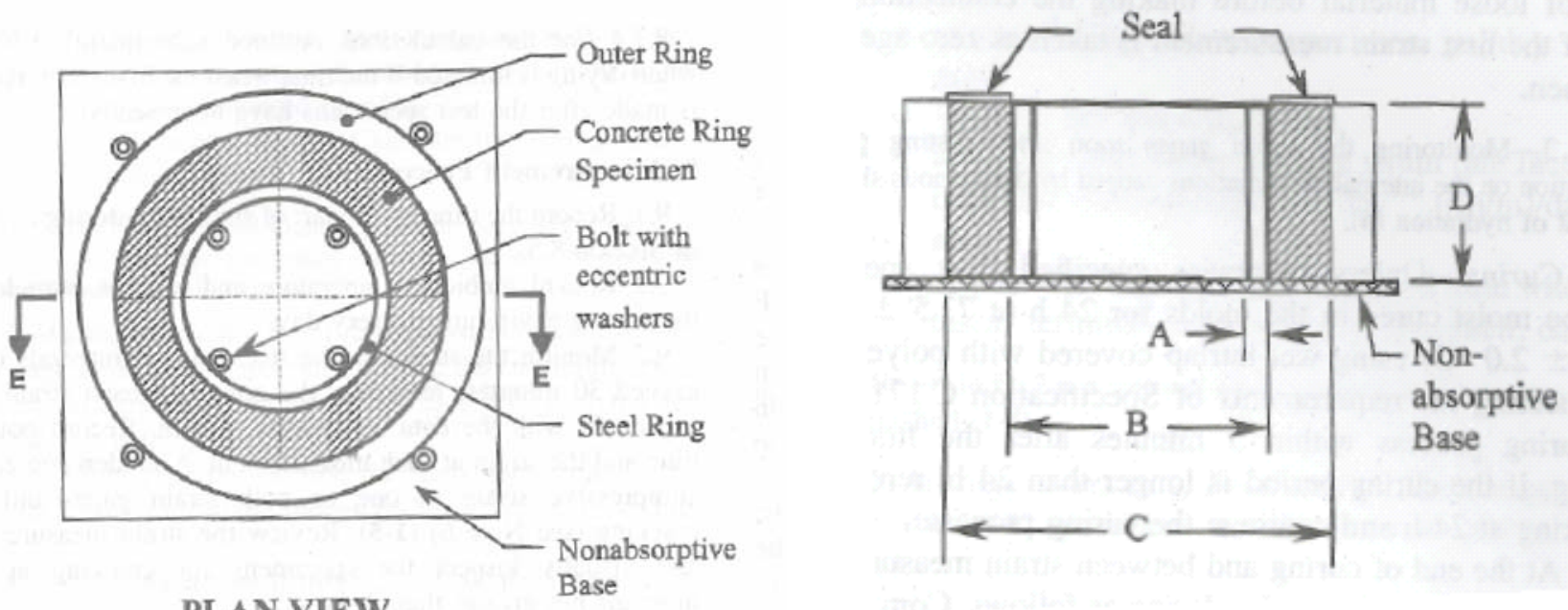

PLAN VIEW

\begin{tabular}{c|c|c}
\hline Figure Dimensions & Inch-Pound Units & SI Units \\
\hline A & $0.50 \pm 0.12$ in. & $12.5 \pm 0.13 \mathrm{~mm}$ \\
B & $13.0 \pm 0.12$ in. & $330 \pm 3 \mathrm{~mm}$ \\
C & $16.0 \pm 0.12 \mathrm{in}$. & $406 \pm 3 \mathrm{~mm}$ \\
D & $6.0 \pm 0.25 \mathrm{in}$. & $150 \pm 6 \mathrm{~mm}$ \\
\hline
\end{tabular}

Figure 2.7 ASTM Ring dimensions

(Adopted from: ASTM C 1581-04)

Apart from the other similarities with the ASTM ring test, this test quantitatively assesses the strain rate factor and stress rate. A classification table for cracking potential based on net time-to-cracking and the average stress rate at cracking is also provided to aid in the comparison of materials. A detail of these calculations is provided in Chapter 6. But one of the limitations of this test is that this method is only applicable to mixtures with aggregates of $13 \mathrm{~mm}$ (0.5 in) maximum nominal size or less. But, most of the time for major structural applications, aggregate size greater than $13 \mathrm{~mm}$ ( $0.5 \mathrm{in})$ is used. Hence this test was not used in this study as 
the mixtures studied contain aggregates above the specified nominal maximum size of $13 \mathrm{~mm}$ (0.5 in) and due to its limited applicability.

Hwang and Khayat (2008) studied the effect of mixture composition on restrained shrinkage cracking of SCC used in repair. The concrete mixtures were prepared with various types and volumes of structural fiber, two types of HRWRAs, and different dosage rates of SRA. A polynapthalene sulfonate (PNS) based HRWRA and polycarboxylate (PC) based HRWRAs were used. Two types of polypropylene synthetic fibers (SyF1 and SyF2) were used. Continuously graded crushed limestone aggregate of $10 \mathrm{~mm}$ (0.39 in) maximum nominal size and well-graded siliceous sand were employed. The workability of SCC was evaluated using the slump flow, L-box, caisson filling capacity, and surface settlement tests. A ring-type test (ASTM C 1581) was used to evaluate the potential for restrained shrinkage cracking and tensile creep behavior of SCC. Time to cracking varied from 4.6 to 17.2 days, with most of the mixtures cracked earlier than 10 days. It was concluded from the experiment that (1) an increase in fiber volume can reduce the cracking potential of SCC due to restrained shrinkage. An increase in fiber volume from 0 to $0.25 \%$ led to $55 \%$ and $65 \%$ increase in tensile creep coefficient of SCC mixtures made with two types of fibers. On average, the increase in fiber volume from 0 to $0.25 \%$ and $0.25 \%$ to $0.50 \%$ lead to a $40 \%$ increase in the elapsed time before crack occurrence. (2) The use of SRA leads to a significant decrease in drying shrinkage. SCC made with high concentration of SRA exhibited longer elapsed time before cracking at 20.7 days compared with 8.8 days for the same concrete prepared without SRA. That was attributed to a $37 \%$ lower drying shrinkage of the former SCC. (3) It was also observed that for a given level of drying shrinkage, a decrease in cracking potential can occur when the concrete develops lower modulus of elasticity at the time of initiation of drying.

Ray et al. (2007) studied the shrinkage and cracking potential of high-performance concrete used in bridge decks. They concluded that cracking properties of regular HPC can be significantly improved by using SRA or latex modified concrete. The use of SRA improved the shrinkage characteristics without affecting the modulus of elasticity, tensile strength, and creep properties.

Turcry et al. (2006) conducted experimental study and modeling of cracking tendency of SCC subjected to restrained shrinkage. Shrinkage cracking potential of SCC was investigated through a comparison of different SCC and OC mixtures, designed with various ingredients and compressive strengths ranging from 35 to 55 
MPa. First, comparison is done by considering age-dependent properties governing cracking risk, such as shrinkage, viscoelastic properties, and fracture parameters. Second, shrinkage cracking is experimentally studied using a restrained shrinkage test, also called the ring test. Third, a numerical study is performed to simulate the ring test using the measured material properties. Three SCC mixtures were compared to three associated OC mixtures, i.e., mixtures designed with the same ingredients and the same compressive strength, and with volume of paste about $20 \%$ lower. The potential for shrinkage cracking was investigated by means of material properties measurements and restrained shrinkage tests (ring tests). Numerical simulations were also performed. When compressive strength is held constant, total shrinkage, modulus of elasticity, tensile strength, and specific creep were observed to be almost equivalent for SCC and OC mixtures designed with the same ingredients. However, although the difference is quite small, modulus of elasticity of SCC was found to be smaller than that of OC, for the tested mixtures. In the same way, total shrinkage of SCC was found to be systematically higher than that of OC. Differences in material properties were not easy to explain with mixdesign parameters. For instance, difference of paste volume could not provide a satisfactory explanation for difference in shrinkage and modulus of elasticity (which was not surprising because the paste of the SCC and the OC is designed differently). Segregation resistance of SCC may be another parameter to justify the differences in behavior, since the SCC mixture with a lack of stability presents certainly poor (i.e., non-uniform) transfer properties. Differences in material properties between SCC and $\mathrm{OC}$ are minor: the risk of cracking due to restrained shrinkage may be analogous for the two types of concrete. Nevertheless, in this study, a SCC mixture showed a much earlier age of cracking in the ring test than the associated OC mixture. A restrained shrinkage test is undoubtedly a more powerful tool for assessing the potential of shrinkage cracking than direct exploitation of material properties. However, material properties can also be used for simulating restrained shrinkage. Indeed, comparison of simulations and experiments of the ring tests was proved to be quite correct. Simulations of the compressive creep tests and of the ring tests confirmed that the CEB-FIP model gives a relevant estimation of the creep for both SCC and OC.

\subsubsection{Robustness}

Robustness is defined by the ability of the mixture to maintain the composition and fresh properties before and after casting of single batch or multiple batches of SCC. 
Robustness depends on various parameters such as mixture composition, shear properties, and application. Because of the low viscosity and yield stress and completely different mixture design, SCC may be more susceptible to changes thus affecting the robustness. The use of different materials, presence of different mineral and chemical admixtures, moisture content, entrapped air, everything plays an important role as the rhelogical properties and robustness of SCC mixtures are concerned. Many researches are gong on currently in this field.

\subsection{Appearance}

SCC is generally a very good choice for structures having aesthetic importance. Although in general, the appearance for SCC is far better than normal concrete and HPC, complete defect free practical and field application is not ensured. Ramsburg (2004) investigated the effects of form material and releasing agent types on the appearance of SCC. It was concluded in the study that plywood forms were the best regarding finish but not durable. Steel forms were the ideal casting surface while the standard textured form liners can also be used with proper cleaning and use of releasing agents. It was also observed that barrier type releasing agents should not be used with SCC when the finishing of the product is important, properly selected reactive type agent should be used instead. Figure 2.8 clearly illustrates the difference in surface aesthetics between SCC and normal concrete.

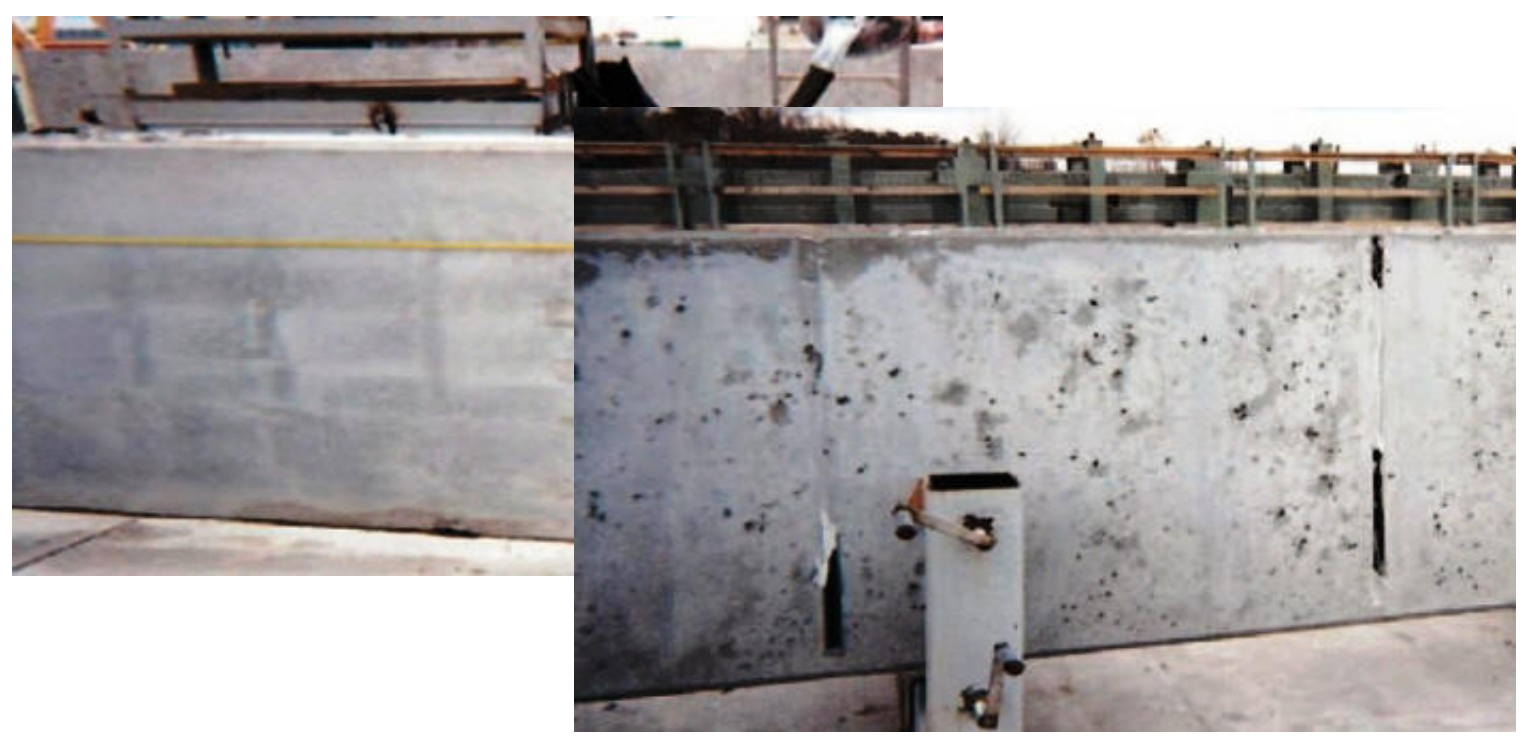

Figure 2.8 Comparison of aesthetics in SCC and OC (Adopted from: www.selfconsolidatingconcrete.org) 


\subsection{Application and Case Studies}

Since the development in the eighties, there were numerous applications of SCC. As stated earlier, the application of SCC is mainly limited to precast and prestressed concrete industry in North America. Apart from that application, cast-in-place applications are also on the rise. Anther major less explored application of SCC is in repair works. SCC can be used for cast-in-place applications such as slabs, abutments, piers and for repair of existing structures, in particular in hard to reach repair projects, with a restricted access to pumping concrete (Paczkowski et al., 2007). In case of ordinary concrete, the major problem for on-site placement is assurance of good quality of material, proper degree of vibration to avoid gaps and reduce shrinkage cracks. SCC offers an excellent solution by improving the quality of concrete structures by eliminating some of the potential for human error. It'll help replace the problems associated with manual compacting. Some application and case studies of projects where SCC were used instead of traditional vibrated concrete are given below.

The first application of SCC was at the towers of a prestressed concrete cable-stayed bridge in 1991 (Sakamoto et al., 1991). In the construction industry, the main reasons for using SCC are:

- To shorten construction period

- To assure compaction to the structure in confined zones where vibration is difficult

- To reduce noise and vibration, especially at concrete production plants.

As of large scale construction, SCC was first used in the anchorages of Akashi-Kaikyo bridge with tha longest suspension of 1991 meters in the world at that time (Tanaka et al., 1993; Okamura and Ozawa, 1996). It was estimated that the use of SCC shortened the anchorage construction period by $20 \%$, from 2 to 2.5 years.

Higashi-Oozu Viaduct, Japan

Precast, prestressed T-girders were used for main girders of the Higashi-Oozu Viaduct. In the beginning of the fabrication, the conventional concrete with slump of $80 \mathrm{~mm}$ was planned. However, it was found that conventional concrete was not capable of forming suitable surface of the girder because of girder dimensions. Also, complaints associated with noise and vibration was occurred from neighbors of the plant. Under this situation, SCC was chosen to fabricate the girders. It was learned after the successful completion of the project that material cost was increased by $4 \%$, labor cost decreased by $33 \%$, and total cost decreased approximately $7 \%$ 
compared to conventional concrete. It was observed that precast, prestressed Tgirders by SCC manufactures the precast factory showed good cost performance although SCC in Japan is still regarded as special concrete because of its cost performance and difficulty in quality control.

In United States of America, choice and application of SCC is growing day by day as stated earlier. Here are some examples of SCC applications in USA (ACI 347R, 2007).

Pedestrian Overpass (I-4), Orlando, Florida

The required concrete mixture was to be placed within an anchor block structure as part of the pedestrian overpass. The $75 \mathrm{~mm}$ ( $3 \mathrm{in}$ ) maximum slump for the class IV FL DOT concrete mixture, combined with two channel sections that ran the length of the sides toward the top of the block, made it impossible to use an immersion vibrator for proper consolidation. Hence, a SCC mixture with a $\mathrm{w} / \mathrm{cm}$ ratio of 0.43 was used with a slump flow of $710 \mathrm{~mm}$ (28 in). The SCC was allowed to free fall for $4.6 \mathrm{~m}$ (15 ft) and no mechanical vibration was needed. The project was a success with excellent aesthetics of the SCC finish.

National Museum of the American India, Washington, D.C.

The main reason to use the SCC mixture was the overcrowded reinforcement and the complicated shapes of the structure. There was little to no room left for the vibrators. SCC enabled the placing of certain elements in one lift and significantly improve the aesthetics. The use of SCC also enabled turnaround times to be reduced from 5 days to 2 days. The quantity of SCC used was greater that 23,000 cubic meter (30,000 cubic yards).

Reaction Wall in Structural Laboratory, Universite de Sherbrooke, Sherbrooke, Quebec, Canada

A strong reaction wall deign to enable dynamic testing of large structural sections was constructed at the structural engineering laboratory at the university using highperformance SCC. The wall measured $9.3 \mathrm{~m}(30.5 \mathrm{ft})$ wide, $7 \mathrm{~m}(23 \mathrm{ft})$ high, and $4 \mathrm{~m}$ $(13 \mathrm{ft})$ thick, and had three hollow sections in the middle. The wall was supported on a $3 \mathrm{~m}$ ( $9.8 \mathrm{ft}$ ) deep foundation system made with a series of highly reinforced beams anchored to rock bed. The use of SCC reduced the noise in the laboratory and facilitated construction activities in a working environment and last but not the least, high quality was secured.

Drilled shaft Applications at Lumber River Bridge Project, South Carolina 
Brown et al. (2007) conducted a study on evaluation of SCC for drilled shaft applications at Lumber Bridge Project, South Carolina. Case studies have shown that when conventional concrete mixture are used in congested drilled shafts, lack of adequate workability or flow between reinforcing bars may lead to trapped laitance or segregation between the inside and outside of the reinforcing cage. SCC was evaluated as a viable material for this kind of applications due to its high flowability and segregation resistance. Several $1.8 \mathrm{~m}$ (6 ft) diameter drilled shafts were constructed using SCC and a high slump gravel aggregate concrete mixture. Observations indicated very good performances can be achieved in difficult construction conditions such as congested cage, tremie placement, and lengthy placement times and it was concluded that SCC is highly feasible for use in congested drilled shaft applications.

\subsection{Concluding Remarks}

In this chapter, the background, history, development, mixture design, and fresh and hardened properties were investigated. The fresh properties of SCC mixtures are quite different than traditional vibrated concrete mixtures. Hence the testing standards and equipments are also quite different for SCC mixtures. The hardened concrete testing for normal concrete and SCC are not much different. As the SCC mixtures generally contain more fines than NC, and due to its higher paste volume and different rhelogical and robustness characteristics, SCC may exhibit some problems. Some of the major concerns for SCC mixtures as learned as robustness, shrinkage cracking, restrained shrinkage behavior and formwork pressure. All of them were studied in detail above. It was impossible to conduct an in-depth study on all of the concerns above; hence shrinkage behavior and restrained shrinkage cracking were selected for an in-depth study in this research program apart from establishing the mixture designs, fresh and hardened properties.

The development of mixture design with the details of the materials, mixing procedure, and curing details are described in detail in the next chapter. 


\section{CHAPTER THREE}

\section{MATERAI LS AND MI XTURE PROPORTI ONS}

This chapter describes the materials and mixture proportions for a total of 17 different SCC mixtures those were developed for the evaluation of fresh, hardened and durability properties.

\subsection{Materials}

\subsubsection{Cement}

Commercially available Type I Portland cement was used, conforming to ASTM C 150 (Standard Specification for Portland cement). The basic physical properties and compound compositions of cement are presented in Table 3.1 and 3.2 respectively.

Table 3.1 Physical properties of Type I Portland cement used

\begin{tabular}{c|c|c|c}
\hline \multirow{2}{*}{ Specific gravity } & \multirow{2}{*}{ Fineness } & \multicolumn{2}{|c}{ Setting time } \\
\cline { 3 - 4 } & & $\begin{array}{c}\text { I nitial } \\
\text { (min.) }\end{array}$ & $\begin{array}{c}\text { Final } \\
\text { (min.) }\end{array}$ \\
\hline 3.15 & $320 \mathrm{~m}^{2} / \mathrm{kg}$ & 90 & 260 \\
\hline
\end{tabular}

$1 \mathrm{~m}^{2} / \mathrm{kg}=703 \mathrm{in}^{2} / \mathrm{lb}$

Table 3.2 - Compound compositions of Portland cement

\begin{tabular}{c|c}
\hline Compounds & Percentage by mass \\
\hline Tricalcium Silicate $\left(\mathrm{C}_{3} \mathrm{~S}\right)$ & 49.0 \\
\hline Dicalcium Silicate $\left(\mathrm{C}_{2} \mathrm{~S}\right)$ & 25.0 \\
\hline Tricalcium Aluminate $\left(\mathrm{C}_{3} \mathrm{~A}\right)$ & 12.0 \\
\hline $\begin{array}{c}\text { Tetracalcium Aluminoferrite } \\
\left(\mathrm{C}_{4} \mathrm{AF}\right)\end{array}$ & 8.0 \\
\hline Gypsum $\left.(\mathrm{CSH})_{2}\right)$ & 2.8 \\
\hline Free Lime $(\mathrm{CaO})$ & 0.8 \\
\hline Free Magnesia $(\mathrm{MgO})$ & 1.4 \\
\hline Others & 2.0
\end{tabular}

\subsubsection{Coarse Aggregate}

Two different types of graded aggregates from Arrow Concrete, WV were used. Aggregates used conformed to ASTM C 33 (Standard Specifications for Concrete Aggregates). Table 3.3 shows few physical properties of the coarse aggregate (CA). 
Table 3.3 - Properties of coarse aggregates

\begin{tabular}{c|c}
\hline Properties & Values \\
\hline Absorption (\%) & 0.53 \\
\hline SSD Specific Gravity & 2.69 \\
\hline Bulk Specific Gravity & 2.68 \\
\hline Apparent Specific Gravity & 2.719 \\
\hline
\end{tabular}

Among the two types of coarse aggregate used, the maximum size of one of the aggregate was $25 \mathrm{~mm}$ ( 1 in) (CA 25) and the maximum size of the other coarse aggregate was $12.5 \mathrm{~mm}$ (3/8 in) (CA 12.5). The sieve analysis data for CA 25 and CA 12.5 are shown in Table 3.4 and Table 3.5, respectively.

Table 3.4 - Sieve analysis result for CA 25

\begin{tabular}{l|l|c|c|c|c}
\hline \multicolumn{2}{c|}{} & $\begin{array}{c}\text { Weight } \\
\text { retained }\end{array}$ & $\begin{array}{c}\text { Amount } \\
\text { retained }\end{array}$ & $\begin{array}{c}\text { Cumulative } \\
\text { amount } \\
\text { retained }\end{array}$ & $\begin{array}{c}\text { Cumulative } \\
\text { amount } \\
\text { passing }\end{array}$ \\
\cline { 3 - 6 } & (gm.) & $(\%)$ & $(\%)$ & $(\%)$ \\
\hline $25 \mathrm{~mm}$ & $1 "$ & 36.30 & 0.88 & 0.88 & 99.12 \\
\hline $19 \mathrm{~mm}$ & $3 / 4 "$ & 626.50 & 15.20 & 16.09 & 83.91 \\
\hline $\begin{array}{l}12.5 \\
\mathrm{~mm}\end{array}$ & $1 / 2 "$ & 1778.40 & 43.16 & 59.25 & 40.75 \\
\hline $\begin{array}{l}12.5 \\
\mathrm{~mm}\end{array}$ & $3 / 8 "$ & 1052.90 & 25.55 & 84.80 & 15.20 \\
\hline $\begin{array}{l}4.75 \\
\mathrm{~mm}\end{array}$ & No. 4 & 587.20 & 14.25 & 99.05 & 0.95 \\
\hline $\begin{array}{l}2.36 \\
\mathrm{~mm}\end{array}$ & No. 8 & 13.20 & 0.32 & 99.37 & 0.63 \\
\hline $\begin{array}{l}1.18 \\
\mathrm{~mm}\end{array}$ & No. 16 & 1.70 & 0.04 & 99.41 & 0.59 \\
\hline
\end{tabular}

$1 \mathrm{~mm}=0.039$ in., $1 \mathrm{gm}=2.205 \times 10^{-3} \mathrm{lb}$

Table 3.5 - Sieve analysis result for CA 12.5

\begin{tabular}{l|l|c|c|c|c}
\hline \multicolumn{2}{c|}{ Sieve Size } & $\begin{array}{l}\text { Weight } \\
\text { retained }\end{array}$ & $\begin{array}{l}\text { Amount } \\
\text { retained }\end{array}$ & $\begin{array}{l}\text { Cumulative } \\
\text { amount } \\
\text { retained }\end{array}$ & $\begin{array}{l}\text { Cumulative } \\
\text { amount } \\
\text { passing }\end{array}$ \\
\cline { 2 - 6 } & (gm.) & (wt. \%) & $\mathbf{( \% )}$ & $\mathbf{( \% )}$ \\
\hline $19 \mathrm{~mm}$ & $3 / 4 "$ & 0.00 & 0.00 & 0.00 & 100.00 \\
\hline $12.5 \mathrm{~mm}$ & $1 / 2 "$ & 4.50 & 0.41 & 0.41 & 912.59 \\
\hline $9.5 \mathrm{~mm}$ & $3 / 8 "$ & 127.20 & 11.45 & 11.86 & 88.14 \\
\hline $4.75 \mathrm{~mm}$ & No. 4 & 827.20 & 74.47 & 86.33 & 13.67 \\
\hline $2.36 \mathrm{~mm}$ & No. 8 & 137.50 & 12.38 & 98.70 & 1.30 \\
\hline $1.18 \mathrm{~mm}$ & No. 16 & 3.10 & 0.28 & 98.98 & 1.02 \\
\hline
\end{tabular}

$1 \mathrm{~mm}=0.039$ in., $1 \mathrm{gm}=2.205 \times 10^{-3} \mathrm{lb}$ 


\subsubsection{Fine Aggregate (FA)}

One type of river sand from Arrow Concrete, WV conforming to ASTM C 33 (Standard Specifications for Concrete Aggregates) was used in this study. Table 3.6 and 3.7 shows the properties of fine aggregate and sieve analysis data, respectively.

Table 3.6 - Properties of fine aggregate

\begin{tabular}{c|c}
\hline \multicolumn{2}{c}{ Source and Basic Properties } \\
\hline Facility Source & Arrow Concrete \\
\hline Type & $\begin{array}{c}\text { Natural river fine } \\
\text { aggregate }\end{array}$ \\
\hline SSD Specific Gravity & 2.61 \\
\hline Bulk Specific Gravity & 2.59 \\
\hline Apparent Specific Gravity & 2.65 \\
\hline Absorption & $1.0 \%$ \\
\hline
\end{tabular}

Table 3.7 - Sieve analysis of fine aggregate

\begin{tabular}{|c|c|c|c|c|c|}
\hline \multicolumn{2}{|c|}{ Sieve size } & \multirow{2}{*}{$\begin{array}{c}\text { Weight. } \\
\text { retained } \\
\text { (gm.) }\end{array}$} & \multirow{2}{*}{$\begin{array}{c}\text { Amount } \\
\text { retained }\end{array}$} & \multirow{3}{*}{$\begin{array}{c}\begin{array}{c}\text { Cumulative } \\
\text { amount } \\
\text { retained }\end{array} \\
(\%) \\
0.00\end{array}$} & \multirow{3}{*}{$\begin{array}{c}\begin{array}{c}\text { Cumulative } \\
\text { amount } \\
\text { passing }\end{array} \\
\mathbf{( \% )} \\
100.00\end{array}$} \\
\hline & & & & & \\
\hline $9.5 \mathrm{~mm}$ & $3 / 8 "$ & 0.00 & 0.00 & & \\
\hline $\begin{array}{l}4.75 \\
\mathrm{~mm}\end{array}$ & No. 4 & 25.50 & 4.98 & 4.98 & 95.02 \\
\hline $\begin{array}{l}2.36 \\
\mathrm{~mm}\end{array}$ & No. 8 & 58.30 & 11.39 & 16.37 & 83.63 \\
\hline $\begin{array}{l}1.18 \\
\mathrm{~mm}\end{array}$ & No. 16 & 55.10 & 10.76 & 27.13 & 72.87 \\
\hline $600 \mu \mathrm{m}$ & No. 30 & 90.80 & 17.74 & 44.87 & 55.13 \\
\hline $300 \mu \mathrm{m}$ & No. 50 & 217.30 & 42.45 & 87.32 & 12.68 \\
\hline $75 \mu \mathrm{m}$ & & 60.30 & 11.78 & 99.10 & 0.90 \\
\hline
\end{tabular}

\subsubsection{Mineral Admixtures}

\subsubsection{Fly ash}

Fly ash (FA) is a finely divided residue resulting from the combustion of ground or powdered coal. It is finer than cement and consists of glassyspherical particles. The Class $F$ fly ash used in this study conforming to AASHTO M 295/ ASTM C 618 (Standard Specification for Coal Fly Ash and Raw Calcined Natural Pozzolan for Use as a Mineral Admixture in Portland 
cement concrete) was hailed from Arrow Concrete, WV. The specific gravity, specific surface area, and oxide composition are listed in Table 3.8.

\subsubsection{Silica fume}

Silica fume (SF) is a by-product for producing silicon or ferrosilicon alloys. Because of its chemical and physical properties, it is highly reactive Pozzolan of very fine nature, and is able to pack between cement particles. The silica fume used in this study was commercially available and supplied by BASF. It conformed to AASHTO M 307/ ASTM C 1240 (Standard Specification for Silica Fume for Use in Hydraulic-Cement Concrete and Mortar). The specific gravity, specific surface area, and oxide composition are listed in Table 3.8.

Table 3.8 - Basic properties of silica fume and fly ash

\begin{tabular}{c|c|c}
\hline & Silica fume & Fly ash \\
\hline Specific gravity & 2.18 & 2.47 \\
\hline Specific surface $\left(\mathrm{m}^{2} / \mathrm{kg}\right)$ & $\begin{array}{c}21400 \text { (Nitrogen } \\
\text { Absorption) }\end{array}$ & 496 \\
\hline Loss of ignition, \% & 1.64 & 3.00 \\
\hline $\mathrm{SiO}_{2}, \%$ & 98 & 49.34 \\
\hline $\mathrm{Al}_{2} \mathrm{O}_{3}, \%$ & 0.20 & 22.73 \\
\hline $\mathrm{CaO}^{2} \%$ & 0.20 & 3.09 \\
\hline $\mathrm{MgO}^{2} \%$ & 0.25 & 1.06 \\
\hline $\mathrm{SO}_{3} \%$ & 0.15 & 0.97 \\
\hline $\mathrm{Na}_{2} \mathrm{O}, \%$ & 0.20 & 1.15 \\
\hline $\mathrm{K}_{2} \mathrm{O}, \%$ & 0.50 & 1.60 \\
\hline $\mathrm{Fe}_{2} \mathrm{O}_{3} \%$ & 0.50 & 16.01 \\
\hline
\end{tabular}

$1 \mathrm{~m}^{2} / \mathrm{kg}=703.07 \mathrm{in}^{2} / \mathrm{lb}$

\subsubsection{Slag}

Ground granulated last furnace slag or simply slag (SL) is defined as a finely ground glassy granular material formed when molten blast-furnace slag is rapidly chilled. Slag is varying in size depending on its chemical composition and method of production as well as that of its iron source. Commercially available slag from Arrow Concrete, WV conforming to AASHTO M 302/ ASTM C 989 (Standard Specification for Ground Granulated Blast-Furnace Slag for Use in Concrete and Mortar) was used for the study. The original source of slag was Essrock, PA. Table 3.9 shows typical properties of Slag. 
Table 3.9 - Basic properties of slag

\begin{tabular}{c|c}
\hline Specific Gravity & 2.88 \\
\hline Specific Surface $\left(\mathrm{m}^{2} / \mathrm{kg}\right)$ & 581 \\
\hline $\mathrm{C}_{3} \mathrm{~S}, \%$ & 48 \\
\hline $\mathrm{C}_{2} \mathrm{~S}, \%$ & 19 \\
\hline $\mathrm{C}_{3} \mathrm{~A}, \%$ & 8 \\
\hline $\mathrm{C}_{4} \mathrm{AF}, \%$ & 7.73 \\
\hline $\mathrm{Na}_{2} \mathrm{O}, \%$ & 0.67 \\
\hline Appearance & White Powder \\
\hline Odor & No Distinct odor \\
\hline Physical State & Solid (powder) \\
\hline pH Value (in water) & 10.5 to 12.7 \\
\hline Solubility in water, \% & Slightly (0.1 to 1.0$)$ \\
\hline Melting Point ( $\left.{ }^{\circ} \mathrm{C}\right)$ & $1300-1350$ \\
\hline
\end{tabular}

$1 \mathrm{~m}^{2} / \mathrm{kg}=703 \mathrm{in}^{2} / \mathrm{lb}$

\subsubsection{Chemical Admixtures}

Chemical admixtures constitute essential ingredients in concrete, in addition to Portland cement, SCM, water, and aggregates. In this research, several different admixtures were used to achieve desired SCC mixtures which have specific properties requirement such as high slump flow, low segregation, proper viscosity and less blocking. Chemical admixtures have much more effect on SCC compared to normal concrete as these admixtures helps to achieve the integral property of SCC, i.e., flow without segregation and blocking. Hence the type and specific objectives of the admixtures are described in details below.

\subsubsection{Water reducing admixture (WRA)}

A commercially available water reducing admixture (WRA) from BASF. was used in the study. It conformed to ASTM C 494/ C 494M and met the requirements for Type $A$, water reducing, Type $B$, retarding, and Type $D$, retarding and water reducing, admixtures.

\subsubsection{High-range water reducing admixture (HRWRA)}

The high range water reducing admixture (HRWRA) used in this project is a commercially available polycarboxylate based full-range water reducing admixture from BASF. The admixture meets the ASTM C 494/ C 494M 
requirements for Type $A$, water reducing, and Type $F$, high range water reducing, admixtures. The admixture is particularly recommended for SCC mixtures where high flowability and less segregation are needed. According to the specification provided by the seller, the maximum dosage is up to 1170 $\mathrm{mL} / 100 \mathrm{~kg}$ of cementitious material (18 fl oz/cwt). However, in some special cases like variation in job condition or materials like silica fume may require dosage outside the recommended range.

\subsubsection{Viscosity-modifying admixture (VMA)}

One of the most important admixtures needed for a successful SCC mixture and uncommon to normal concrete is the viscosity modifying admixture (VMA). Some of the benefits of using the admixture were to control bleeding, reduction of segregation, better surface appearance, and stability of the mixture. A commercially available viscosity modifying admixture from BASF. was used in the study. The VMA used does not affect the air content, setting time, and compressive strength of concrete.

\subsubsection{Shrinkage-reducing admixture (SRA)}

The shrinkage reducing admixture (SRA) used in the project is a commercially available product from BASF. It has been developed specifically to reduce drying shrinkage of concrete and mortar, and the potential for subsequent cracking. It functions by reducing capillary tension of pore water, a primary cause of drying shrinkage.

\subsubsection{Air-entraining admixture (AEA)}

The air entraining admixture (AEA) used in this project is a commercially available air-entraining admixture from BASF. and meeting the requirements of ASTM C 260, AASHTO M 154 and CRD-C 14.

\subsubsection{Mixing Water}

Mixing water used in this study was tap water from the Morgantown city water supply and was assumed to have a density of $100 \mathrm{~kg}$ per cubic meter.

\subsubsection{Limestone Powder (LP)}

Limestone powder was added to some of the mixtures as a filler material. Due to its fine particle size, LP increases the finer content of the concrete to make the mixture more stable against segregation and also adds to the strength. The LP used in this study is a commercially available material from $\mathrm{O}-\mathrm{N}$ 
Minerals, PA. The LP had a reflectance brightness RD of 81.33 and $13.8 \%$ retained on a $44 \mu \mathrm{m}$ sieve. It was in white powder form with a specific gravity of 2.7 .

\subsubsection{Fiber (F)}

For the SCC with steel fibers, a commercially available product CAR-25-CDM with a continuous deformed mild steel fiber of length $25 \mathrm{~mm}$. (1 in.) was used. The fiber fraction was designed as $0.5 \%$ by volume of the concrete mixture. The aspect ratio was 45 .

\subsection{Mixture Proportioning of SCC}

Proper mixture proportioning and mixing is of utmost importance in the production of successful SCC mixtures. A total of 17 mixtures were prepared for the study (Table 3.10 through 3.12). The mix designs were developed by following guidelines given in the report by ACI Committee 237 (2007) and referring to well established literatures. As a starting point, it was assumed that $50 \%$ of the total concrete volume should be filled with the bulk volume of coarse aggregate. The powder content for the mixtures were between $450-500 \mathrm{~kg} / \mathrm{m}^{3}$, where powder included cement, fly ash, slag, limestone fillers, and materials crushed to less than $0.125 \mathrm{~mm}$ (No. 100 sieve), which is suggested for a slump flow of greater than 650 $\mathrm{mm}$. The other parameters were also kept in the permissible range, for example, paste fraction (calculated on volume) were kept between 34 to $40 \%$ of total mixture volume, mortar fraction were between 68 to $72 \%$ of total mixture volume and absolute volume of coarse aggregate were between 28 to $32 \%$. Detail calculations of all the variables and parameters and their permissible values have been documented in Appendix A. It was decided that the effect of aggregate gradation, effect of different mineral admixture, addition of limestone powder, fiber and shrinkage reducing admixture will be studied on different properties of SCC. Hence, it resulted in 17 different mixture proportions with mainly four different categories which are listed below-

- Aggregate gradation

- Addition of filler and mineral admixtures

- Addition of fiber and

- Addition of shrinkage reducing admixture

Among those 17 mixtures, six were selected for further in depth study on shrinkage and cracking of SCC. Table 3.11 shows the aggregate gradation of the 
mixtures and Table 3.12 shows mix design of all 17 mixtures. In Table 3.11 the mixtures are designated as follows: For example, SCC 1 consists of $35 \%$ of $25 \mathrm{~mm}$ CA, $15 \%$ of $12.5 \mathrm{~mm} \mathrm{CA}$ and $50 \%$ of fine aggregate by weight of total aggregates, and limestone powder. The above combination is designated as 0.35/0.15/0.50/LP. Similar designations were followed for other mixtures.

SCC 1 through SCC 3 and SCC 12 consisted of limestone powder with different combinations of coarse and fine aggregate. SCC 4 through SCC 7 and SCC 13 consisted of slag + silica fume with different combinations of coarse and fine aggregate. SCC 14 through SCC 17 consisted of fly ash + silica fume with different combinations of coarse and fine aggregate. SCC 8 and SCC 9 consisted of fiber at a quantity of $39 \mathrm{~kg} / \mathrm{m}^{3}$ with SCC 8 containing limestone powder and SCC 9 containing slag + silica fume. Similarly, SCC 10 and SCC 11 consisted of SRA at a quantity of $4.95 \mathrm{~kg} / \mathrm{m}^{3}$ with SCC 10 containing LP and SCC 11 containing SL + SF. Table 3.10 shows the water to cementitious material ratio $(\mathrm{W} / \mathrm{cm})$, aggregate-paste $(A / P)$ volume, coarse aggregate to fine aggregate ratio (CA/FA), fine aggregate to total aggregate ratio, paste volume in liters, and water to powder ratio (w/p).

Table 3.10 - SCC mixture parameters

\begin{tabular}{c|c|c|c|c|c|c}
\hline SCC & w/ cm & $\begin{array}{c}\text { Agg./ paste } \\
\text { Vol. }\end{array}$ & CA/ FA & $\begin{array}{c}\text { FA/ total } \\
\text { agg. }\end{array}$ & $\begin{array}{c}\text { Paste } \\
\text { vol. } \\
\text { (liters) }\end{array}$ & $\mathbf{w / ~ p}$ \\
\hline SCC 1 & 0.40 & 2.19 & 0.96 & 0.51 & 324.74 & 0.30 \\
\hline SCC 2 & 0.40 & 2.19 & 0.96 & 0.51 & 324.57 & 0.30 \\
\hline SCC 3 & 0.40 & 2.19 & 0.96 & 0.51 & 324.57 & 0.30 \\
\hline SCC 4 & 0.40 & 2.01 & 0.96 & 0.51 & 309.07 & 0.38 \\
\hline SCC 5 & 0.40 & 2.01 & 0.96 & 0.51 & 3012.57 & 0.38 \\
\hline SCC 6 & 0.40 & 2.11 & 1.18 & 0.46 & 300.46 & 0.39 \\
\hline SCC 7 & 0.40 & 2.11 & 1.38 & 0.42 & 300.49 & 0.39 \\
\hline SCC 8 & 0.42 & 2.12 & 0.96 & 0.51 & 333.16 & 0.31 \\
\hline SCC 9 & 0.41 & 1.97 & 0.96 & 0.51 & 315.74 & 0.39 \\
\hline SCC 10 & 0.39 & 2.21 & 0.96 & 0.51 & 326.57 & 0.29 \\
\hline SCC 11 & 0.39 & 2.04 & 0.96 & 0.51 & 310.07 & 0.37 \\
\hline SCC 12 & 0.40 & 2.22 & 0.96 & 0.51 & 320.67 & 0.30 \\
\hline SCC 13 & 0.40 & 2.02 & 0.96 & 0.51 & 311.07 & 0.39 \\
\hline SCC 14 & 0.40 & 1.96 & 0.97 & 0.51 & 318.00 & 0.38 \\
\hline SCC 15 & 0.40 & 1.96 & 0.96 & 0.51 & 318.00 & 0.38 \\
\hline SCC 16 & 0.40 & 1.96 & 0.96 & 0.51 & 317.59 & 0.38 \\
\hline SCC 17 & 0.40 & 1.96 & 0.96 & 0.51 & 317.59 & 0.38 \\
\hline
\end{tabular}

1 liter $=0.264$ gallon 
Table 3.11 - Aggregate gradation of different SCC mixtures

\begin{tabular}{|c|c|}
\hline SCC & Aggregate Fraction \\
\hline SCC 1 & $0.35 / 0.15 / 0.50 / \mathrm{LP}$ \\
\hline SCC 2 & $0.25 / 0.25 / 0.50 / L P$ \\
\hline SCC 3 & $0.15 / 0.35 / 0.50 / \mathrm{LP}$ \\
\hline SCC 4 & $0.35 / 0.15 / 0.50 / \mathrm{SL} / \mathrm{SF}$ \\
\hline SCC 5 & $0.25 / 0.25 / 0.50 / \mathrm{SL} / \mathrm{SF}$ \\
\hline SCC 6 & $0.27 / 0.27 / 0.46 / \mathrm{SL} / \mathrm{SF}$ \\
\hline SCC 7 & $0.29 / 0.29 / 0.42 / \mathrm{SL} / \mathrm{SF}$ \\
\hline SCC 8 & $0.35 / 0.15 / 0.50 /$ LP/Fiber \\
\hline SCC 9 & $0.35 / 0.15 / 0.50 / S L / S F / F i b e r$ \\
\hline SCC 10 & $0.35 / 0.15 / 0.50 / L P / S R A$ \\
\hline SCC 11 & $0.35 / 0.15 / 0.50 / S L / S F / S R A$ \\
\hline SCC 12 & $0.0 / 0.50 / 0.50 / \mathrm{LP}$ \\
\hline SCC 13 & $0.0 / 0.50 / 0.50 / \mathrm{SL} / \mathrm{SF}$ \\
\hline SCC 14 & $0.0 / 0.50 / 0.50 / \mathrm{FA} / \mathrm{SF}$ \\
\hline SCC 15 & $0.35 / 0.15 / 0.50 / \mathrm{FA} / \mathrm{SF}$ \\
\hline SCC 16 & $0.25 / 0.25 / 0.50 / \mathrm{FA} / \mathrm{SF}$ \\
\hline SCC 17 & $0.15 / 0.35 / 0.50 / \mathrm{FA} / \mathrm{SF}$ \\
\hline
\end{tabular}

Table 3.12 - Mixture proportioning for $1 \mathrm{~m}^{3}$ of SCC

\begin{tabular}{|c|c|c|c|c|c|c|c|c|c|c|c|c|}
\hline SCC & $\begin{array}{c}\text { CA } \\
25 \\
\mathrm{~mm} .\end{array}$ & $\begin{array}{c}\text { CA } \\
12 . \\
5 \\
\mathrm{~mm} .\end{array}$ & $\begin{array}{l}\text { Fine } \\
\text { agg. } \\
\text { (FA) }\end{array}$ & $\begin{array}{l}\text { Limestone } \\
\text { Filler ( LF) }\end{array}$ & Cement & $\begin{array}{l}\text { Slag } \\
\text { (SL) }\end{array}$ & $\begin{array}{c}\text { Silica } \\
\text { Fume } \\
\text { (SF) }\end{array}$ & $\begin{array}{l}\text { Fly } \\
\text { Ash } \\
\text { (FA) }\end{array}$ & Water & VMA & $\begin{array}{c}\text { HRWR } \\
\text { A }\end{array}$ & WRA \\
\hline SCC 1 & 563 & 241 & 836 & 112 & 386 & - & - & - & 154 & 0.835 & 4.9 & 1 \\
\hline SCC 2 & 402 & 402 & 836 & 112 & 386 & - & - & - & 154 & 0.835 & 4.725 & 1 \\
\hline SCC 3 & 241 & 562 & 836 & 112 & 386 & - & - & - & 154 & 0.835 & 4.725 & 1 \\
\hline SCC 4 & 565 & 242 & 840 & - & 260 & 130 & 24 & - & 165 & 0.67 & 4.025 & 0.6 \\
\hline SCC 5 & 403 & 403 & 840 & - & 260 & 130 & 24 & - & 165 & 1.33 & 3.85 & 0.6 \\
\hline SCC 6 & 453 & 453 & 771 & - & 250 & 125 & 24 & - & 160 & 0.835 & 4.725 & 1 \\
\hline SCC 7 & 487 & 487 & 705 & - & 250 & 125 & 24 & - & 160 & 0.835 & 4.725 & 1 \\
\hline SCC 8 & 563 & 241 & 836 & 112 & 386 & - & - & - & 161 & 0.835 & 5.6 & 1.9 \\
\hline SCC 9 & 565 & 242 & 840 & - & 260 & 130 & 24 & - & 169 & 0.67 & 5.6 & 2 \\
\hline SCC 10 & 563 & 241 & 836 & 112 & 386 & - & 0 & - & 151 & 0.835 & 4.725 & 1 \\
\hline SCC 11 & 565 & 242 & 840 & - & 260 & 130 & 24 & - & 160 & 0.67 & 4.725 & 1 \\
\hline SCC 12 & - & 804 & 834 & 112 & 380 & - & - & - & 152 & 0.835 & 4.725 & 1 \\
\hline SCC 13 & - & 816 & 846 & - & 260 & 130 & 24 & - & 167 & 0.835 & 3.85 & 0.6 \\
\hline
\end{tabular}




\begin{tabular}{|c|c|c|c|c|c|c|c|c|c|c|c|c|}
\hline scc & $\begin{array}{c}\mathrm{CA} \\
25 \\
\mathrm{~mm}\end{array}$ & $\begin{array}{c}\text { CA } \\
12 . \\
5 \\
\mathrm{~mm} .\end{array}$ & $\begin{array}{l}\text { Fine } \\
\text { agg. } \\
\text { (FA) }\end{array}$ & $\begin{array}{l}\text { Limestone } \\
\text { Filler (LF) }\end{array}$ & Cement & $\begin{array}{l}\text { Slag } \\
\text { (SL) }\end{array}$ & $\begin{array}{c}\text { Silica } \\
\text { Fume } \\
\text { (SF) }\end{array}$ & $\begin{array}{c}\text { Fly } \\
\text { Ash } \\
\text { (FA) }\end{array}$ & Water & VMA & $\begin{array}{c}\text { HRWR } \\
\text { A }\end{array}$ & WRA \\
\hline SCC 14 & - & 808 & 836 & - & 318 & - & 20 & 86 & 168 & 0.835 & 3.5 & 0.6 \\
\hline SCC 15 & 567 & 240 & 840 & - & 318 & - & 20 & 86 & 168 & 0.835 & 3.5 & 0.6 \\
\hline SCC 16 & 404 & 404 & 840 & - & 318 & - & 20 & 85 & 168 & 0.835 & 3.5 & 0.6 \\
\hline SCC 17 & 241 & 566 & 840 & - & 318 & - & 20 & 85 & 168 & 0.835 & 3.5 & 0.6 \\
\hline
\end{tabular}

Notes:

- All the values are in Kilograms.

- Mixtures contained $0.39 \mathrm{~kg} / \mathrm{m}^{3}\left(0.657 \mathrm{lb} / \mathrm{yd}^{3}\right)$ of AEA.

- $1 \mathrm{~kg}=2.205 \mathrm{lb}$.

- $1 \mathrm{~kg} / \mathrm{m}^{3}=1.685 \mathrm{lb} / \mathrm{yd}^{3}$

\subsection{Aggregate Gradation}

\subsubsection{I ntroduction}

As noted in chapter 2, proper aggregate gradation is one of the key for making a successful SCC mixture. In this section, combined aggregate curves will be generated for different aggregate fractions and their effect on certain fresh and hardened properties of SCC will be studied in depth later on.

\subsubsection{Combined Grading Curves}

Sieve analysis had been performed for the CA 25, CA 12.5, and fine aggregate. The combined grading had been done on the basis of their aggregate fraction. The detailed calculation had been shown in Appendix B. Table 3.13 summarizes the grading for different aggregate fractions.

Table 3.13 - Combined aggregate grading

\begin{tabular}{c|c|c|c|c|c|c}
\hline \multirow{2}{*}{$\begin{array}{c}\text { Sieve } \\
\text { Size }\end{array}$} & \multicolumn{6}{|c|}{ Aggregate Fraction (CA 25/ CA 12.5/ FA) } \\
\cline { 2 - 7 } & $\begin{array}{c}\mathbf{3 5 / ~ 1 5 / 5} \\
\mathbf{0}\end{array}$ & $\begin{array}{c}\mathbf{2 5 / 2 5 / 5} \\
\mathbf{0}\end{array}$ & $\begin{array}{c}\mathbf{1 5 / 3 5 / 5} \\
\mathbf{0}\end{array}$ & $\begin{array}{c}\mathbf{0 / 5 0 / 5} \\
\mathbf{0}\end{array}$ & $\begin{array}{c}\mathbf{2 7 / 2 7 / 4} \\
\mathbf{6}\end{array}$ & $\begin{array}{c}\mathbf{2 9} / \mathbf{2 9} / \mathbf{4} \\
\mathbf{2}\end{array}$ \\
\hline $25 \mathrm{~mm}$ & 99.69 & 99.78 & 99.87 & 100.00 & 99.76 & 99.74 \\
\hline $19 \mathrm{~mm}$ & 94.37 & 95.98 & 97.59 & 100.00 & 95.66 & 95.34 \\
\hline $12.5 \mathrm{~mm}$ & 79.20 & 85.09 & 90.97 & 99.80 & 83.89 & 82.70 \\
\hline $12.5 \mathrm{~mm}$ & 68.54 & 75.84 & 83.13 & 94.07 & 73.90 & 71.97 \\
\hline $4.75 \mathrm{~mm}$ & 49.89 & 51.17 & 52.44 & 54.35 & 47.66 & 44.15 \\
\hline $2.36 \mathrm{~mm}$ & 42.23 & 42.30 & 42.36 & 42.46 & 38.99 & 35.68 \\
\hline $1.18 \mathrm{~mm}$ & 36.79 & 36.83 & 36.88 & 36.94 & 33.95 & 31.07 \\
\hline $600 \mu \mathrm{m}$ & 27.56 & 27.56 & 27.56 & 27.56 & 25.36 & 23.15 \\
\hline $300 \mu \mathrm{m}$ & 6.34 & 6.34 & 6.34 & 6.34 & 5.83 & 5.32 \\
\hline $75 \mu \mathrm{m}$ & 0.45 & 0.45 & 0.45 & 0.45 & 0.41 & 0.38 \\
\hline
\end{tabular}

$1 \mathrm{~mm}=0.039$ in., $1 \mu \mathrm{m}=3.937 \times 10^{-5}$ in. 
Aggregate gradation is of utmost importance for successful production and quality control for SCC. As it contains different graded aggregates (coarse and fine), a combined aggregate gradation curve is more appropriate. Figure 3.1 represent the combined aggregate grading curves made with various combinations of $25 \mathrm{~mm}$ coarse aggregate, $12.5 \mathrm{~mm}$ coarse aggregate, fine aggregate for different SCC. The combined aggregate gradation was differentiated by particle size ranges: material equal to and larger than $12.5 \mathrm{~mm}$ (designated as "Q" for quality filter), material smaller than $12.5 \mathrm{~mm}$ and retained on $2.36 \mathrm{~mm}$ (designated as "I" for Intermediate particle) and material smaller than $2.36 \mathrm{~mm}$ (designated as "W"). The larger particles related to strength, intermediate particles are related to mobility of the mix and the particles smaller than $2.36 \mathrm{~mm}$ contributes to workability of the mix. In this study the aggregate gradations for all SCC spanned across three ranges defined above, indicating a combinations of strength, mobility and workability of mix.

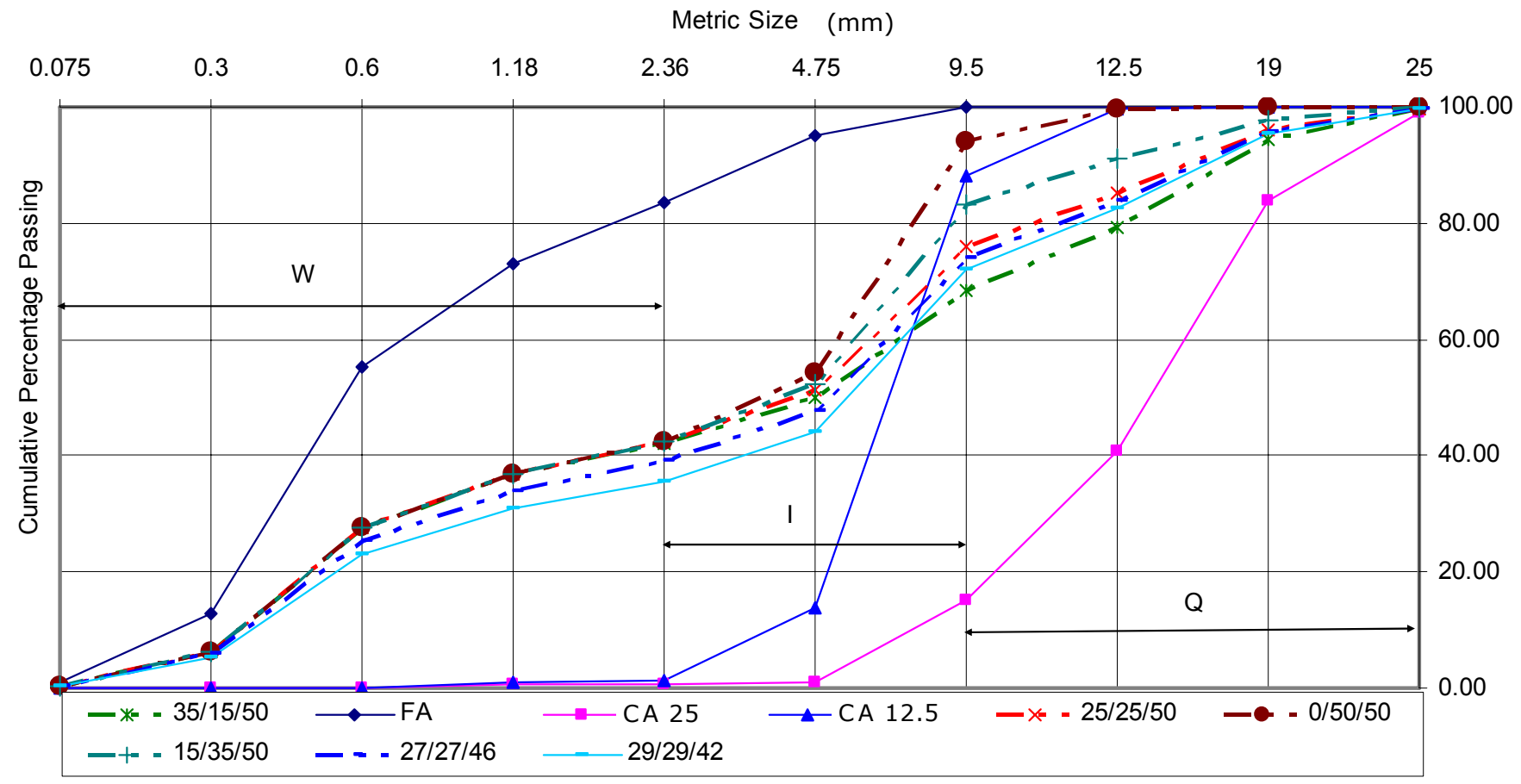

Figure 3.1 Chart showing aggregate gradation

\subsubsection{Coarseness Factor and Workability Factor}

As per Shilstone (1990), concrete mixtures can be optimized using a relationship between a workability factor $(=\mathrm{W} /(\mathrm{Q}+\mathrm{W}+\mathrm{I}))$ and a coarseness factor $(=Q /(Q+I))$. The workability factor (WF) and coarseness factor (CF) had been calculated for all the aggregate fractions and shown in Table 3.14. 
Table 3.14 - Coarseness factor and workability factor

\begin{tabular}{c|c|c|c|c|c}
\hline $\begin{array}{c}\text { Aggregate } \\
\text { Fraction }\end{array}$ & $\mathbf{Q}$ & $\mathbf{I}$ & $\mathbf{W}$ & $\mathbf{W F}$ & $\mathbf{C F}$ \\
\hline $35 / 15 / 50$ & 31.15 & 26.31 & 42.23 & 42.36 & 54.21 \\
\hline $15 / 35 / 50$ & 16.74 & 40.77 & 42.36 & 42.42 & 29.11 \\
\hline $25 / 25 / 50$ & 23.94 & 33.54 & 42.30 & 42.39 & 41.65 \\
\hline $27 / 27 / 46$ & 25.86 & 34.91 & 38.99 & 39.08 & 42.55 \\
\hline $29 / 29 / 42$ & 27.77 & 36.29 & 35.68 & 35.77 & 43.36 \\
\hline $0 / 50 / 50$ & 5.93 & 51.61 & 42.46 & 42.46 & 10.30 \\
\hline
\end{tabular}

According to Shilstone, mixtures within the band shown in Figure 3.2 are expected to be superior in terms of workability and will exhibit the lowest water demand for given cement content. But he developed the relationships for normal range of slump. The coarseness factor and workability factor from aggregate gradation for SCC mixtures used in this study are plotted in the Figure 3.2. It is observed that the trend achieved by these six aggregate gradations is above the Shilstone's band and it is approximately parallel. This means as a starting point of SCC mix design, the aggregate gradation can be chosen in such a way that for a given $\mathrm{CF}$, the WF should be above the band proposed by Shilstone and also the CF preferably be less than 60 . However more data are required to finally recommend the values.

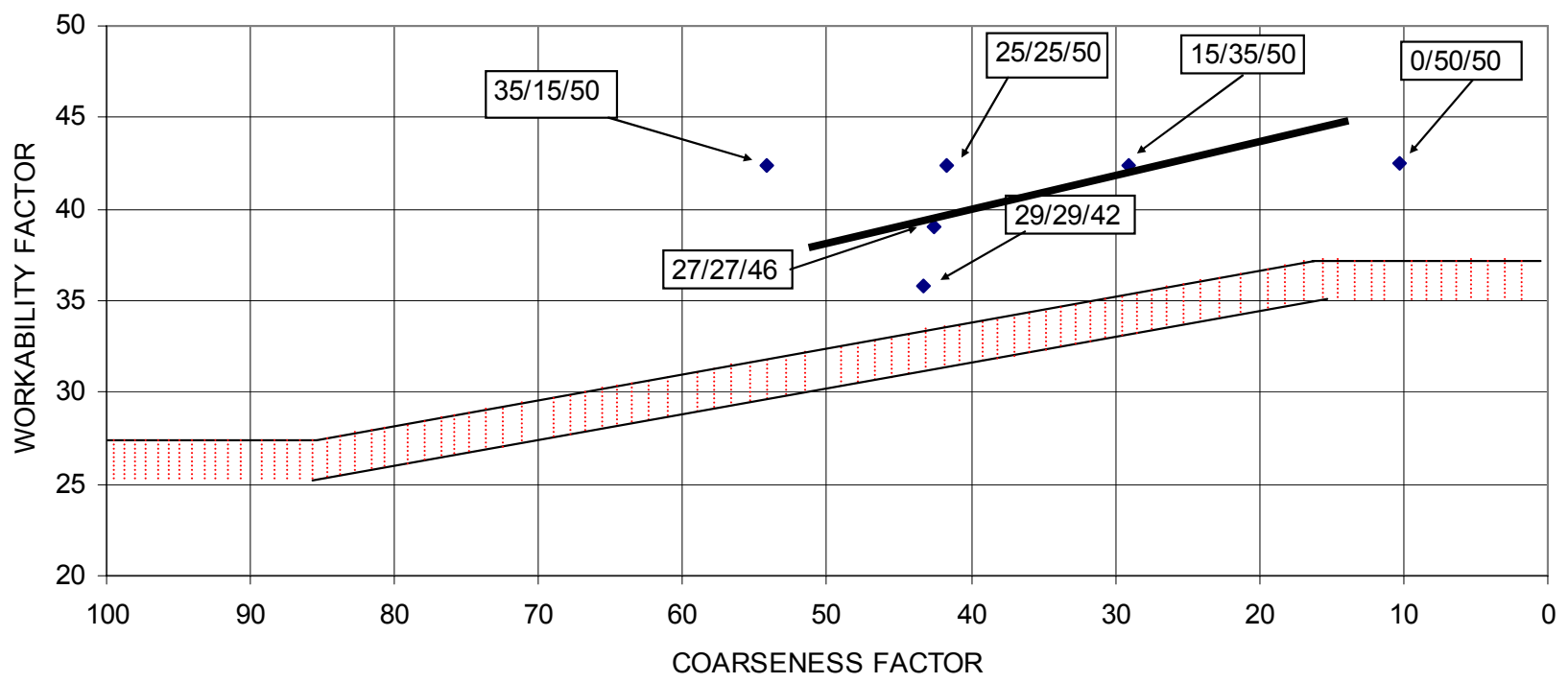

Figure 3.2 Band of aggregate gradation on CF-WF chart 


\subsection{Mixing Procedure}

As the fluctuations in gradation of aggregates and free moisture content can have significant influence on the stability of SCC mixtures, the moisture content of aggregates were maintained strictly and surface moisture quantities were subtracted from the total water quantity to keep the $\mathrm{w} / \mathrm{cm}$ ratios constant. As the level of fluidity has a direct impact on the stability of the mixture, once a suitable mixture has been developed the fluidity level at which the mixture becomes unstable was determined. It was done using the variable dosage of HRWRA to get fluid yet stable mixtures. For the mixing a non-tilting horizontal axis variable speed laboratory mix was used. All the mixing was completed within 15 minutes. All mixtures were prepared in two batches to account for the variations of batching, mixing, placing, and curing of concrete.

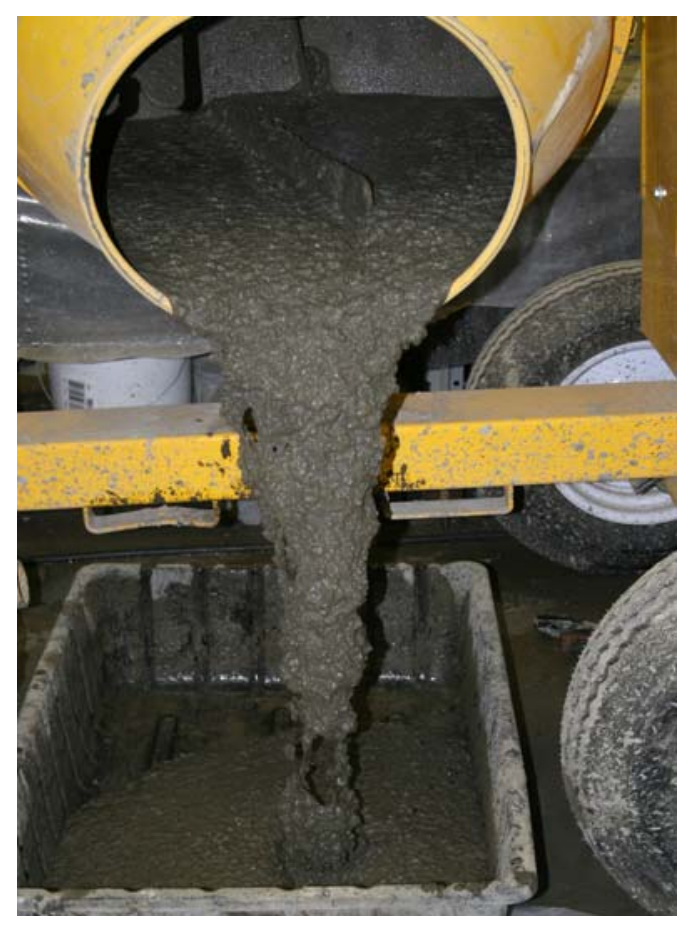

Figure 3.3 Variable speed laboratory mixture machine

Mixing procedures were based on guidelines and sequences recommended by industry experts and established literatures. The detailed mixing sequences are listed as follows:

\subsubsection{Mixing Sequence for SCC with Limestone Powder}

1. Batched the material by weight;

2. Added the AEA to the fine aggregate; 
3. Added the WRA, VMA, and $2 / 3$ of HRWRA to the water, and stirred thoroughly;

4. Cleaned and wetted the mixer;

5. Added the coarse aggregates, $3 / 4$ of the mixing water with the solution of WRA, VMA, and HRWRA and mixed them for 1 minute.

6. Added the fine aggregate to mixer, and mixed it for another 2 minutes;

7. Added cement and limestone powder in one third quantities each and rotated the mixer for some time. The procedure was repeated for three times;

8. Added remaining water to the mixture and rotated for 1 minute;

9. Added the remaining HRWRA and mixed for about 3 minutes;

10. Rotated the mixer till the target slump flow was achieved.

\subsubsection{Mixing Sequence for SCC with Slag and Silica Fume}

1. Batched the material by weight;

2. Added the AEA to the fine aggregate;

3. Added the WRA, VMA, and $2 / 3$ of HRWRA to the water, and stirred thoroughly;

4. Cleaned and wetted the mixer;

5. Added the coarse aggregates, silica fume, and $3 / 4$ of the mixing water with the solution of WRA, VMA, and HRWRA and mixed them for 1 minute.

6. Added the fine aggregate to mixer, and mixed it for another 2 minutes;

7. Added cement and slag in one third quantities each and rotated the mixer for some time. The procedure was repeated for three times;

8. Added remaining water to the mixture and rotated for 1 minute;

9. Added the remaining HRWRA and mixed for about 3 minutes;

10. Rotated the mixer till the target slump flow was achieved.

\subsubsection{Mixing Sequence for SCC with Fiber}

Similar procedure as listed above was followed for the fiber-reinforced SCC mixtures except the fact that fibers were added to the mixer at the starting of mixing with the coarse aggregates. Also it may be noted here that for SCC with fibers have more water demand than the other SCC mixtures for the same slump flow. Hence the quantity of HRWRA and water must be properly adjusted to maintain the desired slump flow yet produce a stable mixture. 


\subsubsection{Mixing Sequence for SCC with SRA}

SRA had been added to the mixing water prior to mixing and stirred thoroughly. Rest of the process was same as described above.

\subsection{Curing}

Immediately after casting (within 5 minutes), the molded specimens were covered with wet barlap and kept for about 24 hours at room temperature. After 24 hours, the specimens for compressive strength test and splitting tensile tests were cured under lime saturated water at $23 \pm 2{ }^{\circ} \mathrm{C}\left(73 \pm 3^{\circ} \mathrm{F}\right)$ until testing age.

\subsection{Concluding Remarks}

In this chapter the materials and mixture proportions for 17 SCC mixtures are described in details. The 17 mixtures were divided into different categories based on their aggregate gradation, filler content, mineral admixture content, fiber content, and SRA content. Combined aggregate gradation curves, CF and WF of each mixture were calculated. The combined aggregate gradation curve was differentiated by particle size ranges as quality filter (Q), intermediate particles (I), and materials smaller that $2.36 \mathrm{~mm}(\mathrm{~W})$. The aggregate gradation for the developed SCC mixtures spanned across three ranges defined above, indicating a combination of strength, mobility and workability of the mixture. The coarseness factor and workability factor was also calculated for each mixture depending on their aggregate gradation and plotted in CF-WF chart. It was observed that the trend achieved by the SCC mixtures developed, was above the Shilstones's band in CF-WF chart. That signifies that, as a starting point of SCC mixture design, the aggregate gradation can be fixed such a way that for a given $\mathrm{CF}$, the WF should be above the band proposed by Shilstone and also the CF preferably be less than 60. The mixing procedure for each type of SCC was described in detail. It was observed that SCC required longer mixing time than normal vibrated concrete as reported by many other researchers. In the next chapter the fresh properties of the 17 SCC mixtures are described in detail. 


\section{CHAPTER FOUR}

\section{FRESH PROPERTIES OF SCC}

\subsection{I ntroduction}

This chapter contains detail description of the different test methods adopted for testing the fresh properties of the 17 mixtures. It also lists the results obtained by the test methods in the laboratory and detailed analysis and correlation of the results with certain parameters.

As the SCC is completely different in rheological and robustness from normal concrete, the fresh property measurement is radically different than the normal concrete. As described in Chapter 2, there are many methods to quantify the fresh properties of SCC. As stated early, the main parameters to measure the properties of SCC at fresh stage are flow rate, viscosity, stability, passing ability, and segregation. The fresh concrete tests those were performed were (a) slump flow test according to ASTM C 1611/C 1611M-05( Standard Test Method for Slump Flow of SelfConsolidating Concrete) (b) Passing ability of SCC by J-ring conforming to ASTM C 1621/C 1621M-06 ( Standard Test Method for Passing Ability of Self-Consolidating Concrete by J-Ring) (c) Static segregation of SCC using column technique according to ASTM C 1610/C 1610M-06 and (Standard Test Method for Static Segregation of Self-Consolidating Concrete Using Column Technique) (d) L-box test according to "The European Guidelines for Self Compacting Concrete" (Annex B: Test Methods; Annex B.3; Testing fresh concrete - Part B3: L-box test). The L-Box test was done with two bars, although three bar test could have been done to simulate more congested reinforcement. The detailed description of the test methods are as follows.

\subsection{Test Methods}

\subsubsection{Slump Flow Test}

ASTM C 1611/C 1611M-05 was followed for the slump flow test. The purpose of the test is to monitor the consistency of fresh, unhardened SCC and its unconfined flow potential. The rate at which the concrete spreads is directly related to its viscosity. This test method also covers a non-mandatory procedure that was used to evaluate an indication of relative viscosity of the SCC mixture.

The test method consist of the same slump cone for determining slump of normal concrete and a base plate of minimum diameter of $915 \mathrm{~mm}$ (36 in.). The 
slump flow is the average diameter measured after raising the slump cone at the centre of the base plate and after the flow of the concrete stop completely. At the time of performing the slump flow test, the time it takes for the outer edge of the concrete mass, to reach a diameter of $500 \mathrm{~mm}$ (20 in.) provides a relative assessment of the unconfined flow rate of the concrete mixture. This time period, termed as $T_{50}$, gives an indication of the relative viscosity of the SCC mixture. The stability of the concrete can be observed visually by inspecting the concrete mass. Table 4.1 contains Visual Stability Index (VSI) values to qualitatively assess the stability of the SCC.

\section{Table4.1 - Visual Stability Index Values}

\begin{tabular}{l|l}
\hline \multicolumn{1}{c|}{ VSI Value } & \multicolumn{1}{c}{ Criteria } \\
\hline $0=$ Highly Stable & No evidence of segregation or bleeding. \\
\hline $1=$ Stable & $\begin{array}{l}\text { No evidence of segregation and slight bleeding observed as a } \\
\text { sheen on the concrete mass. }\end{array}$ \\
\hline $2=$ Unstable & $\begin{array}{l}\text { A slight mortar halo } \leq 0.5 \mathrm{in.}(\leq 10 \mathrm{~mm} \text { ) and/or aggregate } \\
\text { pile in the center of the concrete mass. }\end{array}$ \\
\hline $3=$ Highly Unstable & $\begin{array}{l}\text { Clearly segregating by evidence of a large mortar halo }>0.5 \\
\text { in. }(>10 \mathrm{~mm}) \text { and/or a large aggregate pile in the center of } \\
\text { the concrete mass. }\end{array}$ \\
\hline
\end{tabular}

(Reproduced from: ASTM C 1611/C 1911M - 05)

Figure 4.1(a) shows a schematic diagram of the base plate and Figure 4.1(b) depicts the slump flow test going on in the laboratory.
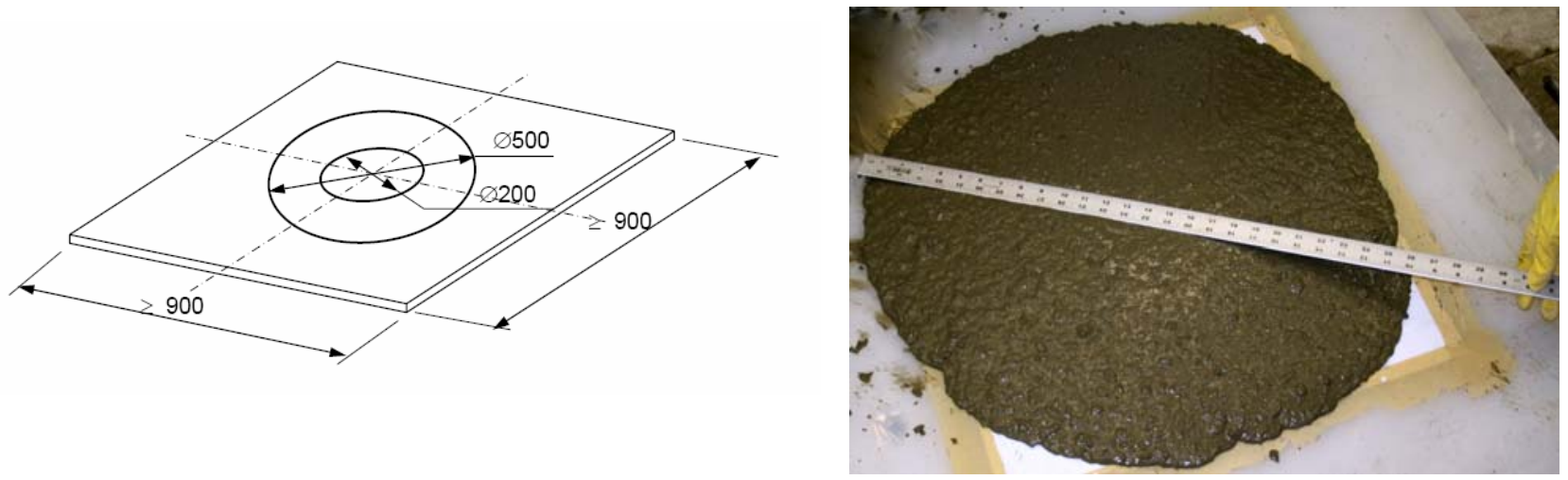

Figure 4.1 (a) Base plate for slump flow test Figure (b) Slump flow measurement (Reproduced from: The European Guidelines for Self Compacting Concrete) 


\subsubsection{J-Ring Test}

ASTM C 1621/C 1621M-06 was followed for the J-ring test. The purpose of the test is to determine the passing ability of fresh SCC mixtures. Passing ability is defined as the ability of the SCC to flow under its own weight without vibration and completely fill all spaces within the formwork. Difference between the slump flow and the J-ring flow indicates the extent of the passing ability of a particular mixture.

Same procedure should be followed as the slump flow test, only added feature will be a J-ring placed at the center of the base plate. The dimensions of the J-ring are shown in figure 4.2(a). A slump flow should be conducted without the Jrind in accordance with Test Method C 1611/C $1611 \mathrm{M}$; the two tests shall be completed within 6 minutes. The difference between the slump flow and the J-ring flow will provide the blocking assessment. A difference less than $25 \mathrm{~mm}$ (1 in.) indicates good passing ability, whereas, a difference greater than $50 \mathrm{~mm}$ (2 in.) indicates poor passing ability. Table 4.2 quantifies the blocking assessment.

\section{Table4.2 - Blocking Assessment}

\begin{tabular}{l|l}
\hline $\begin{array}{c}\text { Difference Between Slump } \\
\text { Flow and J-Ring Flow }\end{array}$ & \multicolumn{1}{c}{ Blocking Assessment } \\
\hline 0 to $25 \mathrm{~mm}$ (0 to $1 \mathrm{in.})$ & No visible blocking \\
\hline$>25$ to $50 \mathrm{~mm}(>1$ to $2 \mathrm{in.})$ & Minimal to noticeable blocking \\
\hline$>50 \mathrm{~mm}$ (>2 in.) & Noticeable to extreme blocking \\
\hline \multicolumn{2}{c}{ (Reproduced from: ASTM C 1621/C 1921M - 06) }
\end{tabular}
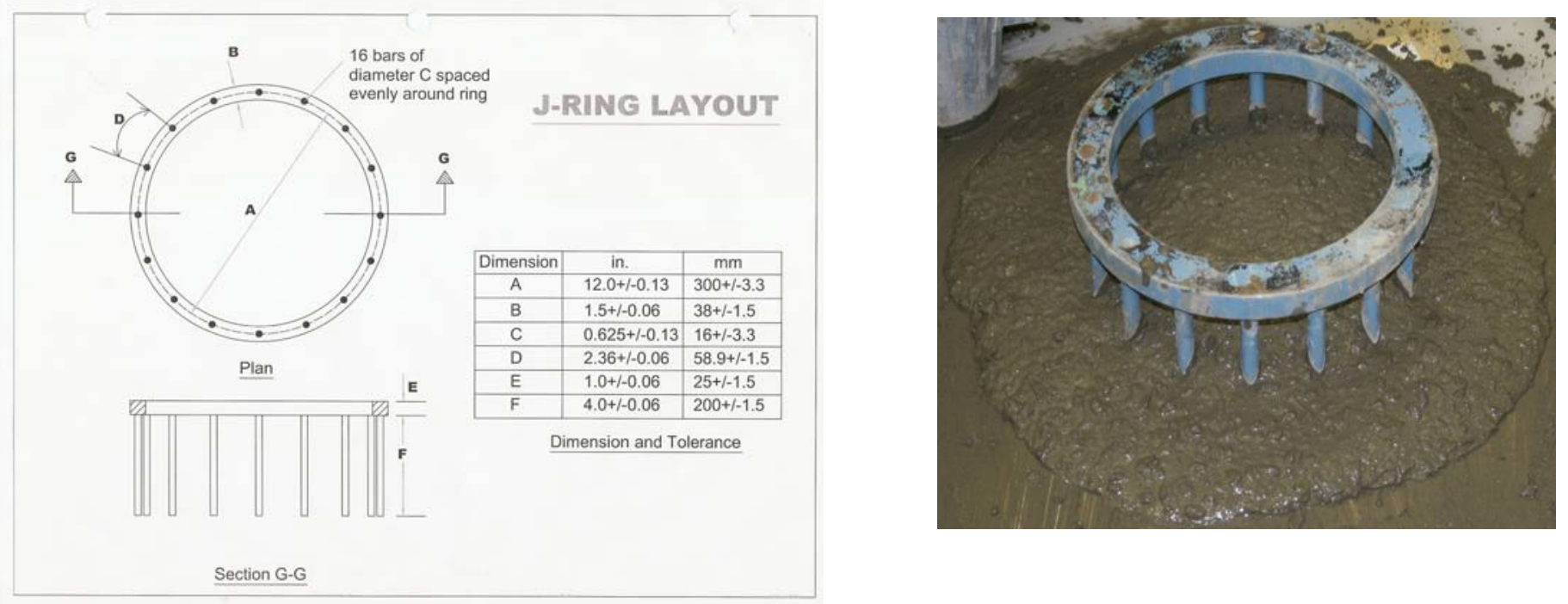

Figure 4.2 (a) J-ring dimensions (b) J-ring test in laboratory 


\subsubsection{Column Segregation Test}

ASTM C 1610/C 1610M-06 was followed for measuring the static segregation of SCC using column technique. The test provides necessary ways is to determine the potential static segregation for fresh SCC mixtures. Static segregation is meant by the segregation of the mortar from the coarse aggregate that occurs after the placement of the concrete while it is in plastic state. As SCC is a fluid concrete, it may prone to segregation unless proportioned properly to design a cohesive SCC mixture. Application of SCC is very much dependent on its cohesiveness and especially critical for deep vertical sections like wall and columns. As this test method measures the degree of segregation of a mixture, it can be used to identify the suitability of a mixture for a particular application.

The mold used for this test has been shown in Figure 4.3. The column mold should be completely filled with the concrete and let stand for around 15 minutes. After that, the concrete from the top and bottom part should be washed on a 4.75 $\mathrm{mm}$ No. 4) sieve. Finally the coarse aggregates retained on the sieve should be brought to saturated-surface-dry condition. The calculation of the percent static segregation is as below:

$S=2\left[\frac{\left(C A_{B}-C A_{T}\right)}{\left(C A_{B}+C A_{T}\right)}\right] * 100$, if $C A_{B}>C A_{T}$

$S=0$, if $C A_{B} \leq C A_{T}$

where:

$S=$ static segregation, percent

$C A_{T}=$ mass of coarse aggregate in the top section of the column, gms.

$C A_{B}=$ mass of coarse aggregate in the bottom section of the column, gms.

Figure 4.6 below shows a column segregation test in process in the laboratory.

There is no specified maximum limit listed in the standard for the percent segregation. $15 \%$ was assumed as a starting value for this research after consulting established literatures and industry experts as stated in Chapter 2. Figure 4.3 shows an ongoing column segregation test in the laboratory. 


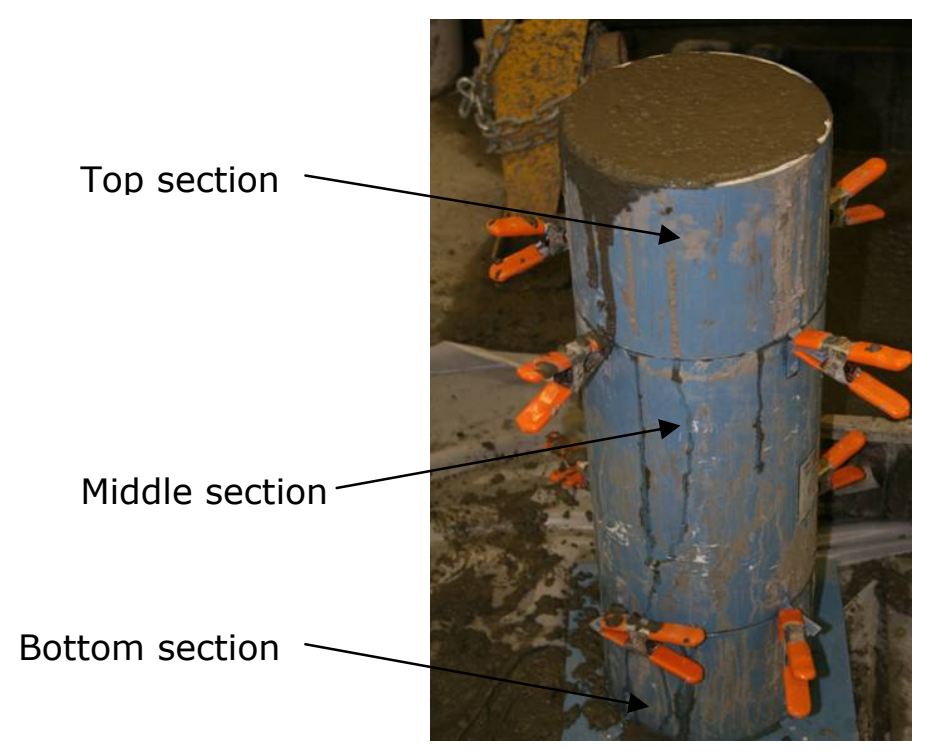

Figure 4.3 Column segregation test

\subsubsection{L-box Test}

This test had been done following The European Guidelines for Self Compacting Concrete, Annex B.3. The test is used to assess the passing ability of SCC to flow through small openings like highly congested reinforcements and other obstructions without blocking or segregation. The principle of the test is to measure the difference in height of concrete after a measured volume of fresh concrete is allowed to flow horizontally through the gaps between vertical reinforcements.

The assembly of the test set-up is shown in Figure 4.4. Concrete is poured from a container to the filling hopper and let stand for around $60 \pm 10$ seconds. Then the gate near the reinforcement is raised and concrete is allowed to flow until it completely comes to rest. The heights $\mathrm{H} 1$ and $\mathrm{H} 1$ are measured to get the required passing ability $(P A)=\mathrm{H} 2 / \mathrm{H} 1$. Figure 4.5 shows an L-box test going on in the laboratory.

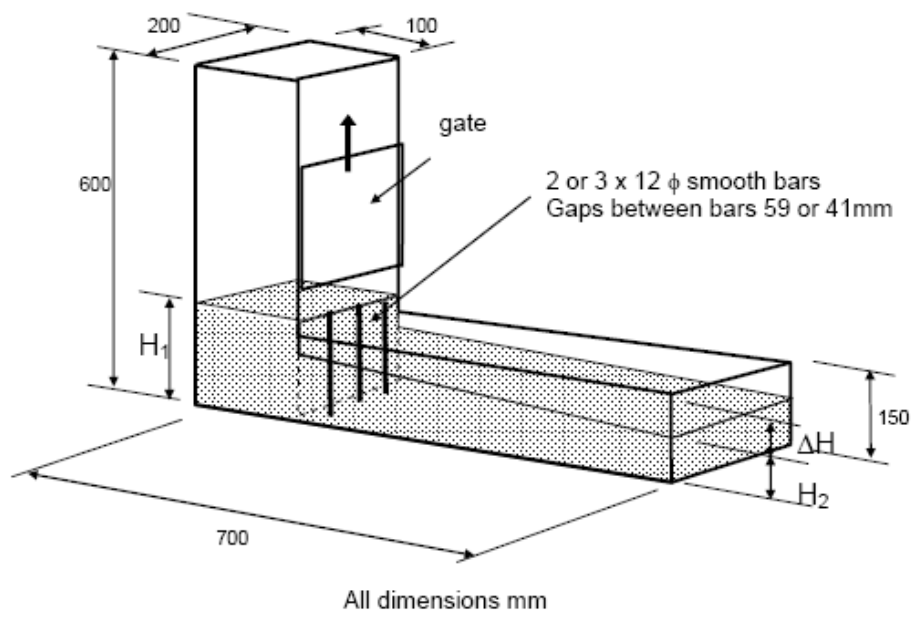



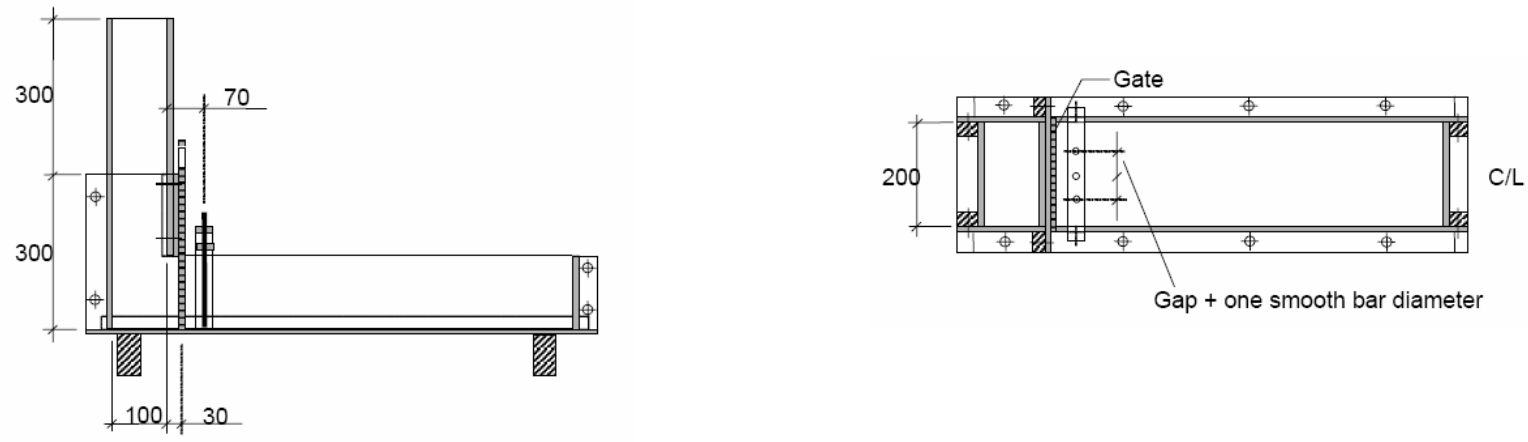

Figure 4.4 L-box test set-up

(Reproduced from: The European Guidelines for Self Compacting Concrete)

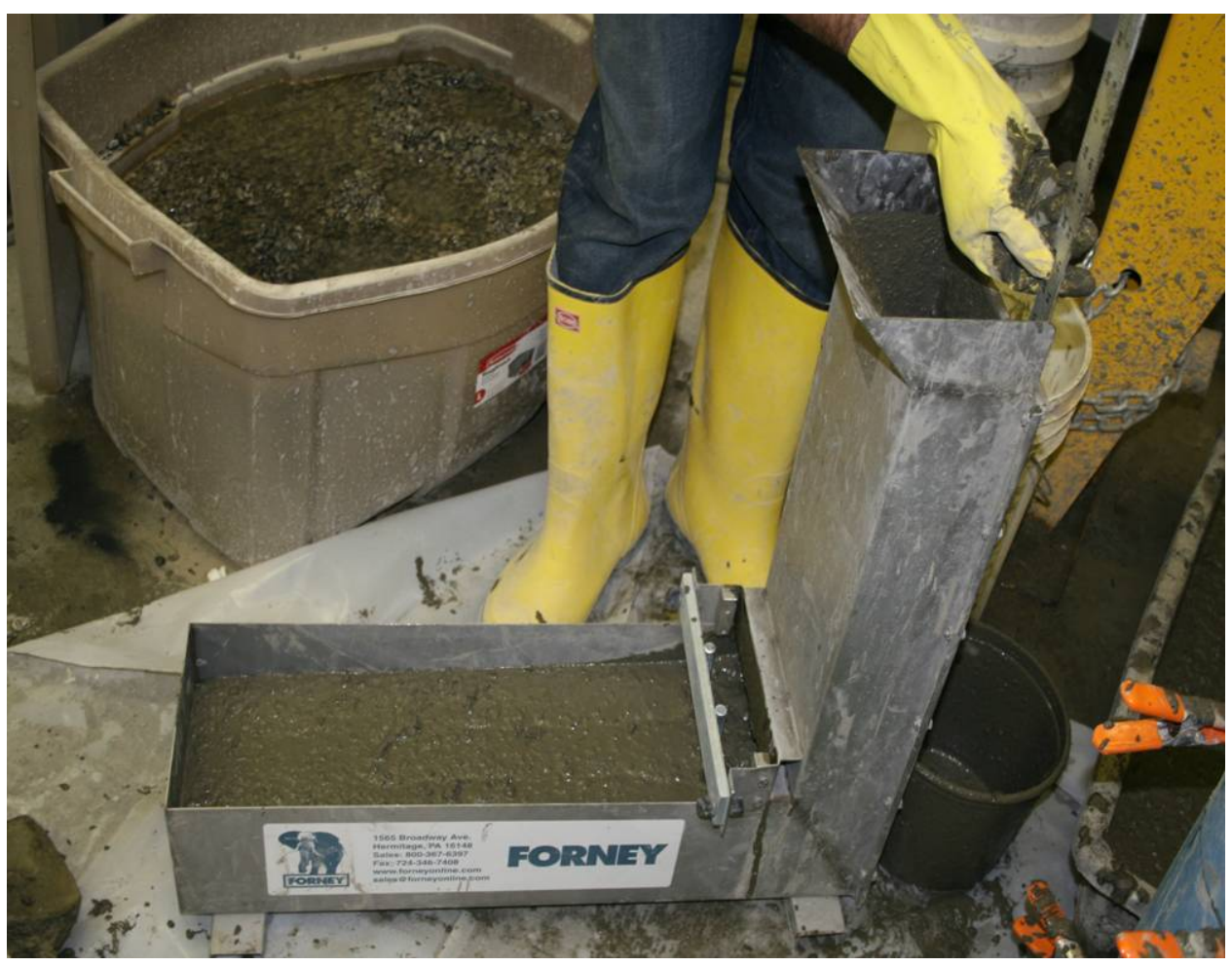

Figure 4.5 L-box test in laboratory

\subsection{Test Results and Discussion}

\subsubsection{VSI and T50 Results}

The VSI values are representative values of the SCC stability and the $T_{50}$ provides information on the relative viscosity of the SCC mixtures. Higher $T_{50}$ values correspond to increased viscosity which resists the flow properties of the SCC. Table 4.3 quantifies the VSI values and $T_{50}$ values of the 17 SCC mixtures. 
Table4.3 - VSI Values and $\mathbf{T}_{50}$ Values for SCC Mixtures

\begin{tabular}{c|c|c}
\hline SCC & $\begin{array}{c}\text { VSI } \\
\text { Value }\end{array}$ & $\begin{array}{c}\mathbf{T}_{\mathbf{5 0}} \\
\text { (Seconds) }\end{array}$ \\
\hline SCC 1 & 1 & 2.3 \\
\hline SCC 2 & 1 & 1.9 \\
\hline SCC 3 & 1 & 1.9 \\
\hline SCC 4 & 1 & 2.3 \\
\hline SCC 5 & 1 & 2.4 \\
\hline SCC 6 & 1 & 2.3 \\
\hline SCC 7 & 1 & 2.3 \\
\hline SCC 8 & 1 & 2.6 \\
\hline SCC 9 & 1 & 2.5 \\
\hline SCC 10 & 1 & 2.0 \\
\hline SCC 11 & 1 & 2.1 \\
\hline SCC 12 & 1 & 1.2 \\
\hline SCC 13 & 1 & 1.3 \\
\hline SCC 14 & 1 & 1.2 \\
\hline SCC 15 & 1 & 2.4 \\
\hline SCC 16 & 1 & 2.2 \\
\hline SCC 17 & 1 & 2.0 \\
\hline
\end{tabular}

It is observed from the above table is that all the SCC mixtures were stable in terms of their VSI values which supports the fact of no segregation was observed and slight bleeding was observed as a sheen on the concrete mass. $T_{50}$ varied from 1.2 seconds to 2.6 seconds. The differences are very less but one observation was $\mathrm{T}_{50}$ was higher for the mixture containing higher fraction of CA 25 than CA 9.5. Mixtures containing the fibers were the most viscous ones with $T_{50}$ of 2.5 and 2.6 seconds respectively.

\subsubsection{Slump Flow Test Results}

Figure 4.6 represents the slump flow achieved in the laboratory for the 17 SCC mixtures. The target minimum slump flow had been fixed as $650 \mathrm{~mm}$ (25.6 in.). As per ACI Committee 237 (2007), a common range of slump flow for SCC is 450 to $750 \mathrm{~mm}$ (18 to $30 \mathrm{in.}$ ). The higher the slump flow, the further the SCC can travel from the discharge point and the faster it can fill up the mold or form. From that point of view, our initial target was in the higher side and can be used in many ranges of application. 


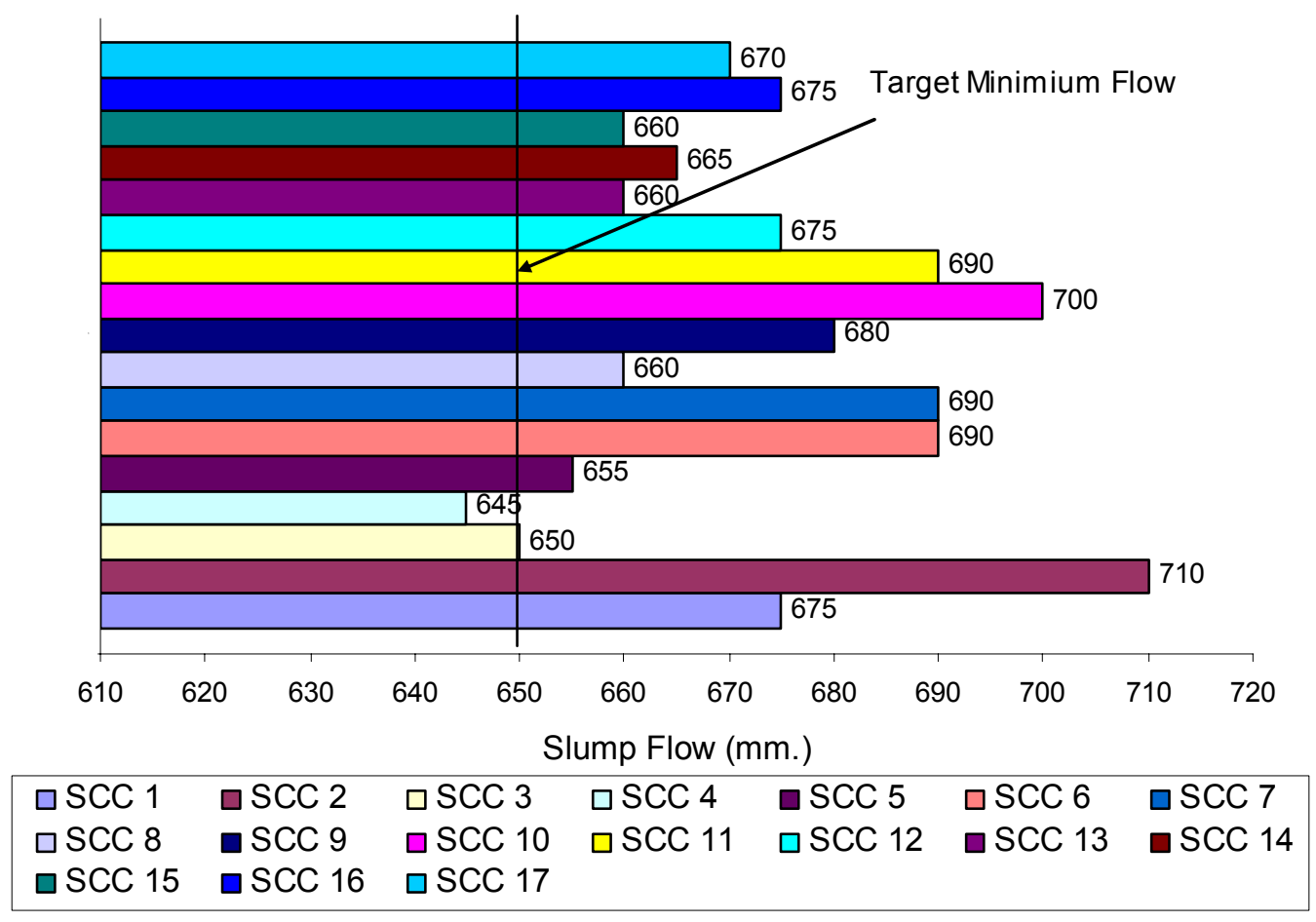

$1 \mathrm{~mm}=0.039 \mathrm{in}$.

Figure 4.6 Slump flow test result for 17 SCC mixtures

From Figure 4.6 it is clearly visible that almost all the SCC made the initial requirement of the target slump flow except SCC 4 which just missed the target flow.
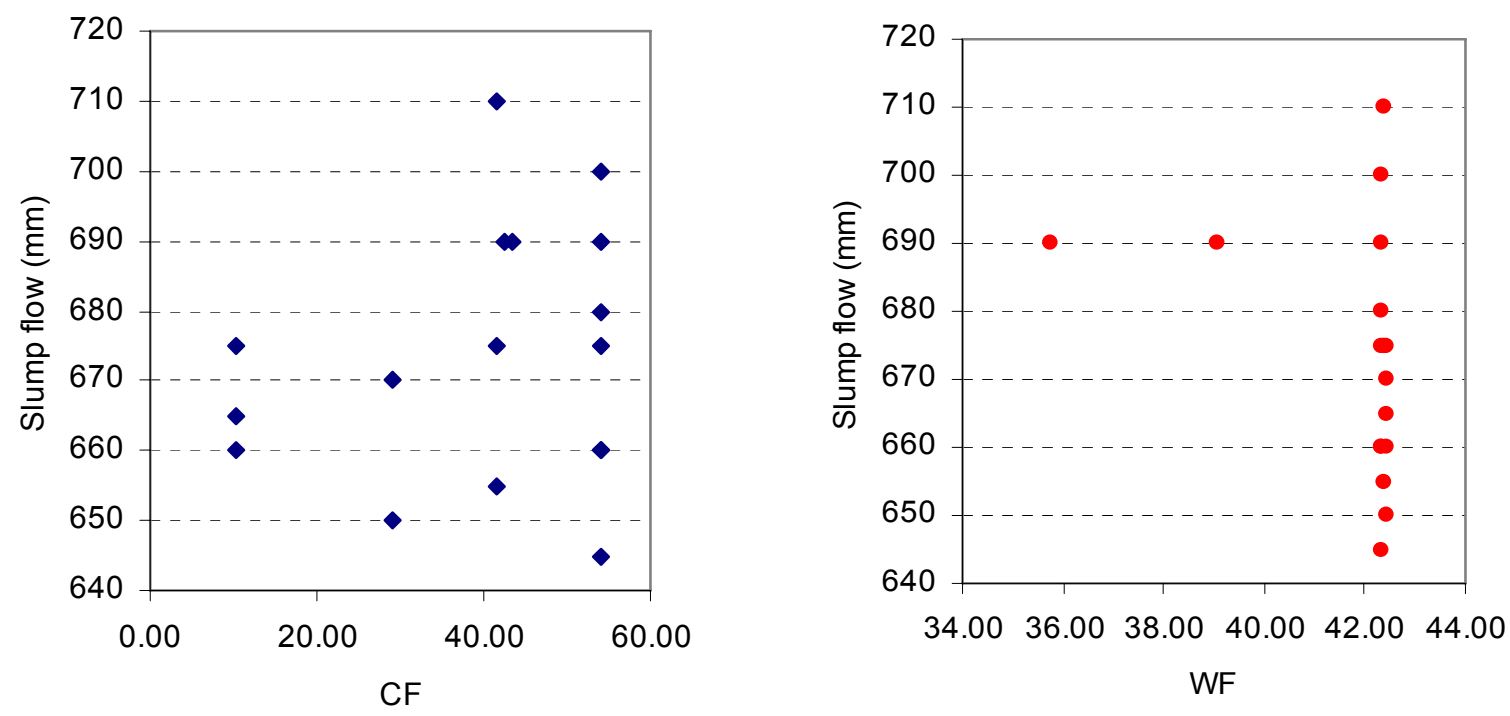

Figure 4.7 Slump flow vs. (a) coarseness factor (b) workability factor by few millimeters. Also this shortfall can be overcome by adjusting and/ or increasing the HRWRA quantity for that particular mixture. As per the above figure, the filler and mineral admixture on the slump flow of the mixture have little or no 
effect. The slump flow of the mixture containing LP varied between $650 \mathrm{~mm}$ (25.6 in.) to $710 \mathrm{~mm}$ (28 in.) and are on the higher side compared to other mixtures. Slump flow values of the mixtures containing SL + SF were pretty consistent and varied between $645 \mathrm{~mm}$ (25.4 in.) to $690 \mathrm{~mm}$ (27.2 in.). The slump flow values for the FA + SF mixtures varied between $665 \mathrm{~mm}$ (26.2 in.) to $675 \mathrm{~mm}$ (26.6 in.) and on a little bit lower side compared to other mixtures. The negligible effect of filler and mineral admixtures on the slump flow values of the SCC mixtures were due to various factor like use of different chemical admixtures including WRA, HRWRA, AEA, and VMA. To study the effect of CF and WF on the slump flow values, the above figures are drawn. It may be interpreted from Figure 4.7 that CF and WF do not have any major role in the slump flow values. Although for higher $\mathrm{CF}$, higher slump flow values are observed. There are no correlation between WF and the slump flow as seen in Figure 4.7. This is also due to the fact that the effects of different mineral admixtures, fillers, and chemical admixtures are inter combined and it is very difficult to relate only one parameter to the properties.

\subsubsection{J-Ring Flow Test Results}

As stated earlier blocking is the difference between slump flow and J-ring flow and it is the parameter to assess the flowability of the SCC through congested

reinforcements. No visible blocking

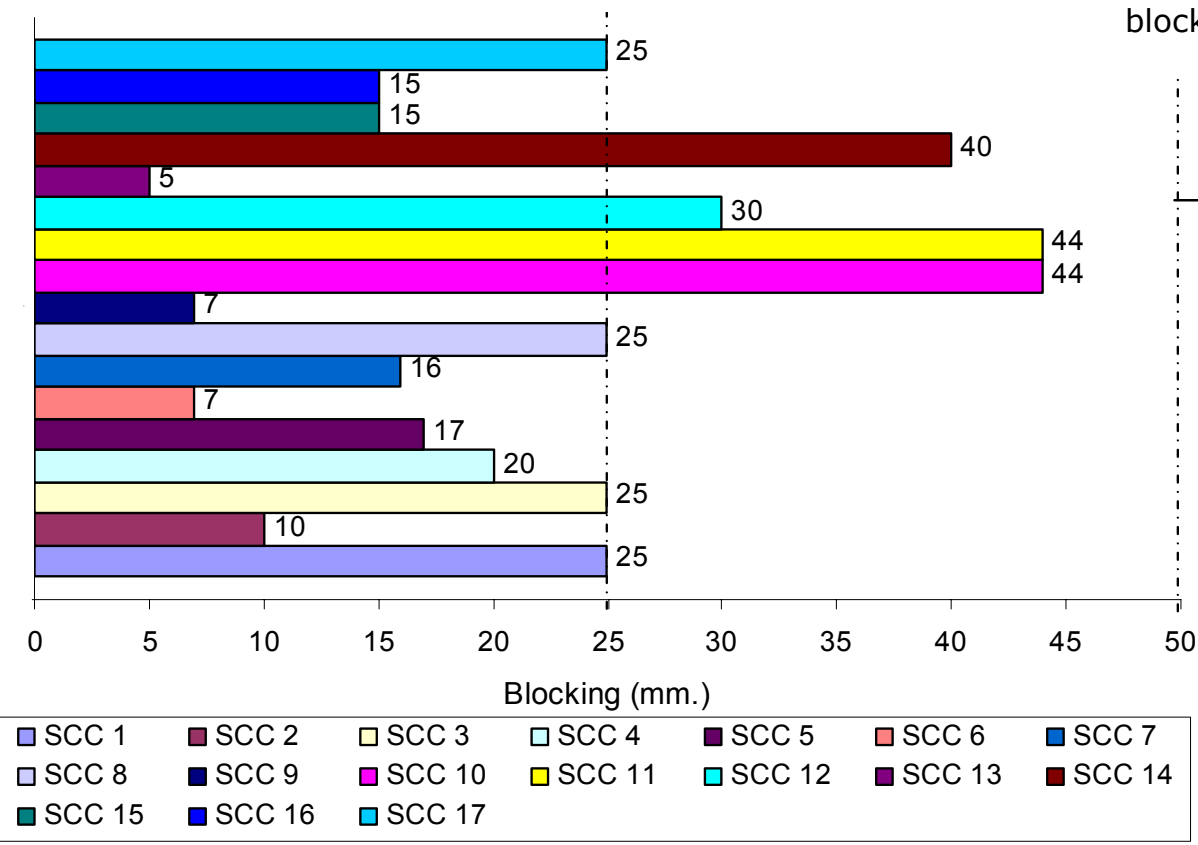

$1 \mathrm{~mm}=0.039 \mathrm{in}$.
Minimal to noticeable blocking

Noticeable to extreme blocking

Figure 4.8 Blocking assessments for 17 SCC mixtures 
Figure 4.8 illustrates the blocking assessment of the 17 SCC mixtures prepared in the laboratory. As most of the blocking assessment calculated, as seen from the figure, is less than $25 \mathrm{~mm}$ ( $<1$ in.) it is clear that the SCC mixtures developed were superior in terms of blocking.

SCC mixtures made with SL + SF had the least blockage in comparison with the SCC mixtures made with LP or FA + SF. Minimal to noticeable blocking were observed for SCC 10, SCC 11, SCC 12, and SCC 14 mixtures. It may be noted here that slump flow values of the above listed SCC mixtures are also on higher side. This problem may be fixed by adjusting the VMA quantity. Also it may not need any change at all depending upon the type of application and project specification.
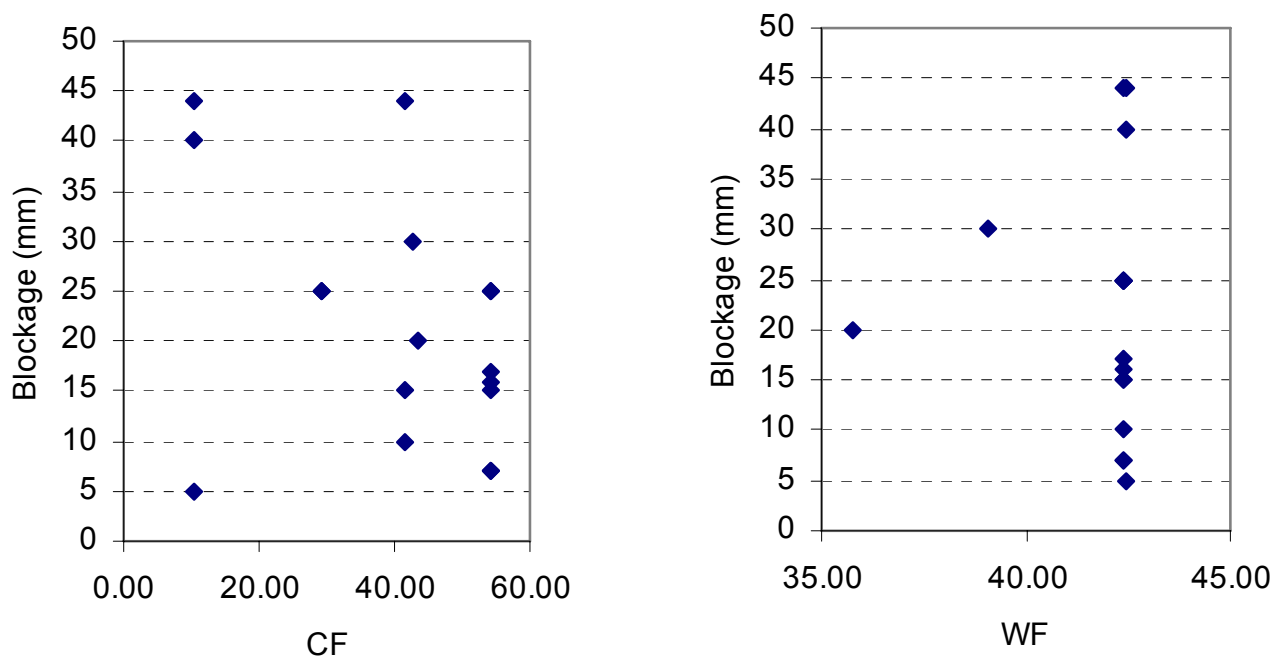

Figure 4.9 Blocking assessments vs. coarseness factor and workability factor

Figure 4.9 shows the relation between blocking assessment and CF and WF. As seen from the earlier case, there are no correlations at all. Different blocking values at same CF or same WF are the direct effect of the admixtures, fillers, and mineral admixtures as explained earlier.

\subsubsection{Column Segregation Test Results}

Figure 4.10 represents the static segregation (\%) of the 17 SCC mixtures prepared in the laboratory. There are no target limits set for this test in the relevant ASTM. It is entirely dependent upon the scope and application of the project where the mix is going to be used. 

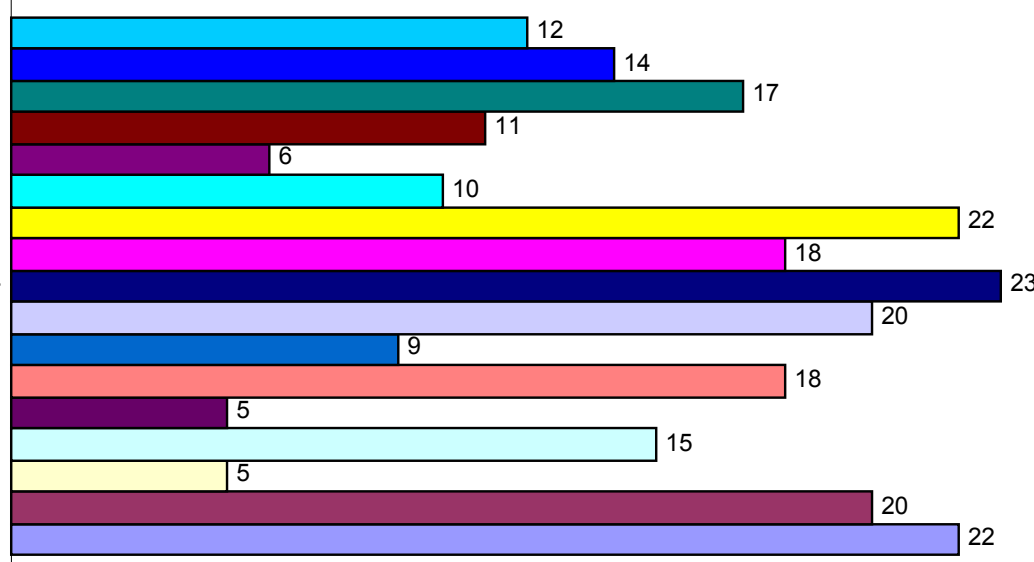

0

5

10

15

20

25

Static Segregation (\%)

\begin{tabular}{|c|c|c|c|c|c|c|}
\hline$\square \operatorname{SCC} 1$ & 口SCC 2 & 口SCC 3 & $\square \operatorname{SCC} 4$ & $\square \operatorname{SCC} 5$ & 口SCC 6 & $\square \operatorname{SCC} 7$ \\
\hline$\square \operatorname{SCC} 8$ & घSC 9 & $\square \operatorname{SCC} 10$ & 口SCC 11 & 口SCC 12 & a SCC 13 & USCC 14 \\
\hline$\square$ SCC 15 & $\square \operatorname{SCC} 16$ & $\square$ SCC 17 & & & & \\
\hline
\end{tabular}

Figure 4.10 Static segregation as per column segregation for 17 SCC mixtures

It is seen from the figure that for some of the SCC mixtures, the static segregation values are little bit higher. It may be noted here that most of the mixtures which exceeded the $20 \%$ value, have a greater percentage of CA 25 in total coarse aggregate. Due to its higher particle size and weight, mixture containing CA 25 is more prone to segregation than the mixture which contains more CA 12.5 and less CA 25. Increased use of the VMA should invalidate the problem.

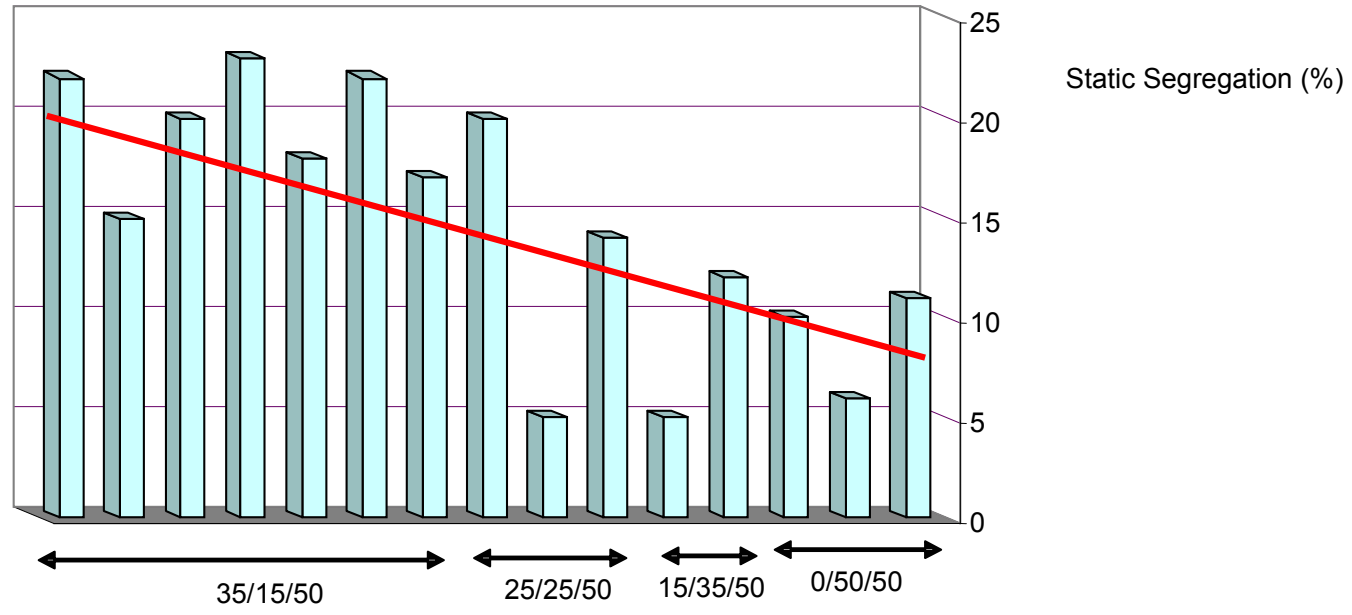

Figure 4.11 Aggregate fractions vs. static segregation 
Figure 4.11 shows the relation between coarse aggregate fraction and static segregation. The red line clearly marks the trend of the graph. Greater the amount of CA 25 in the mixture, greater is the static segregation.
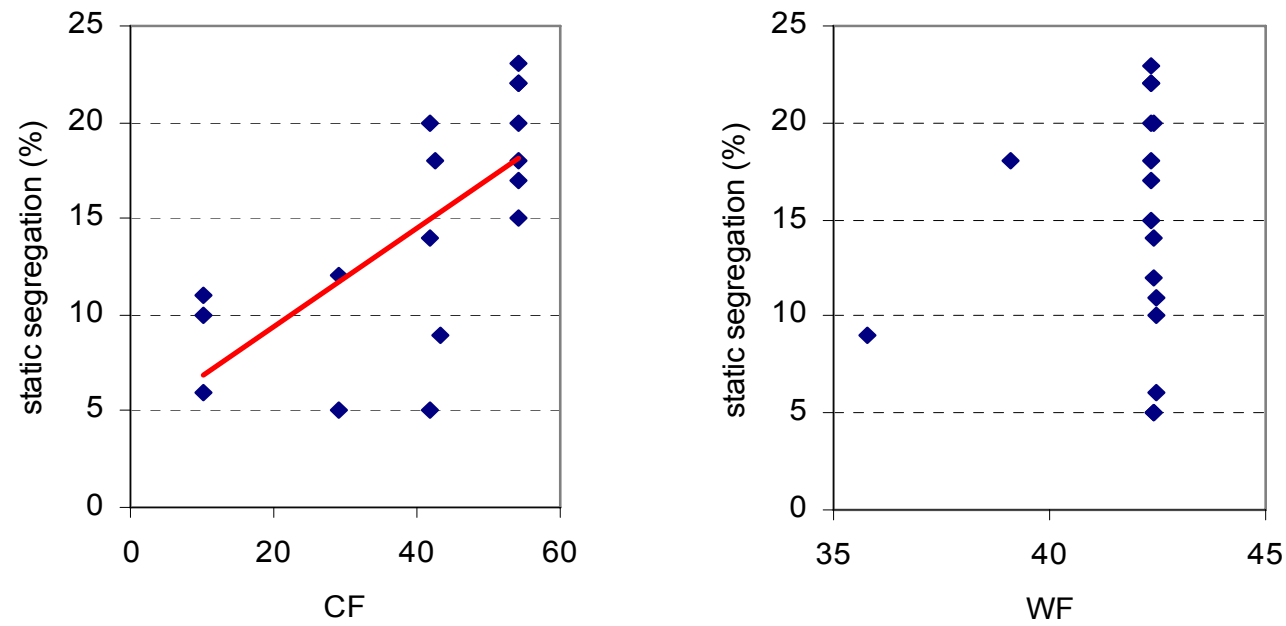

Figure 4.12 Static segregations vs. (a) coarseness factor (b) workability factor

Figure 4.12 shows the effects of coarseness factor and workability factor on static segregation of the SCC mixtures. As seen from the figure, same slump flow can be achieved at different CF below a CF of 45 approximately with the help of chemical admixtures. But when the CF value exceeds 45 , more VMA is needed to keep the mixture stable. The workability factor had not any effect on the static segregation of the mixtures as seen from the figure 4.12 (b).

\subsubsection{L-box Test Results}

Figure 4.13 represents the L-box passing ability achieved in the laboratory for the 17 SCC mixtures. The target minimum L-box passing ability had been set up as 0.7 . No target limit had been proposed in the relevant standard but 0.7 was chosen after consultation with industry experts and well established literature. 


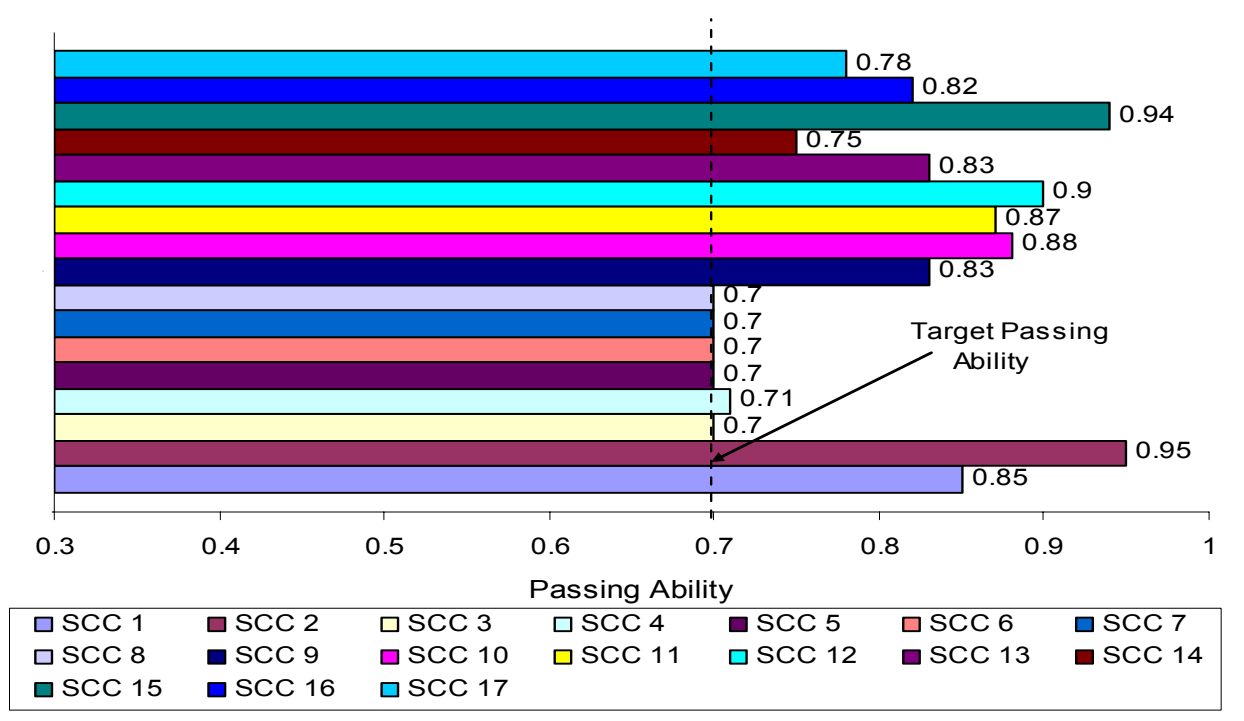

Figure 4.13 L-box test result for 17 SCC mixtures

All the SCC mixtures were above the target limit of 0.7 as seen from the figure. That means mixtures are well enough to flow through congested reinforcements. If some project demands flow through highly congested reinforcements, an L-box PA value greater than 0.8 or 0.9 may be used depending the project specification.

Figure 4.14 shows the plot between coarseness factor and workability factor versus L-box passing ability. It can be concluded from the figures that there are no correlation between CF and WF with the L-box passing ability.
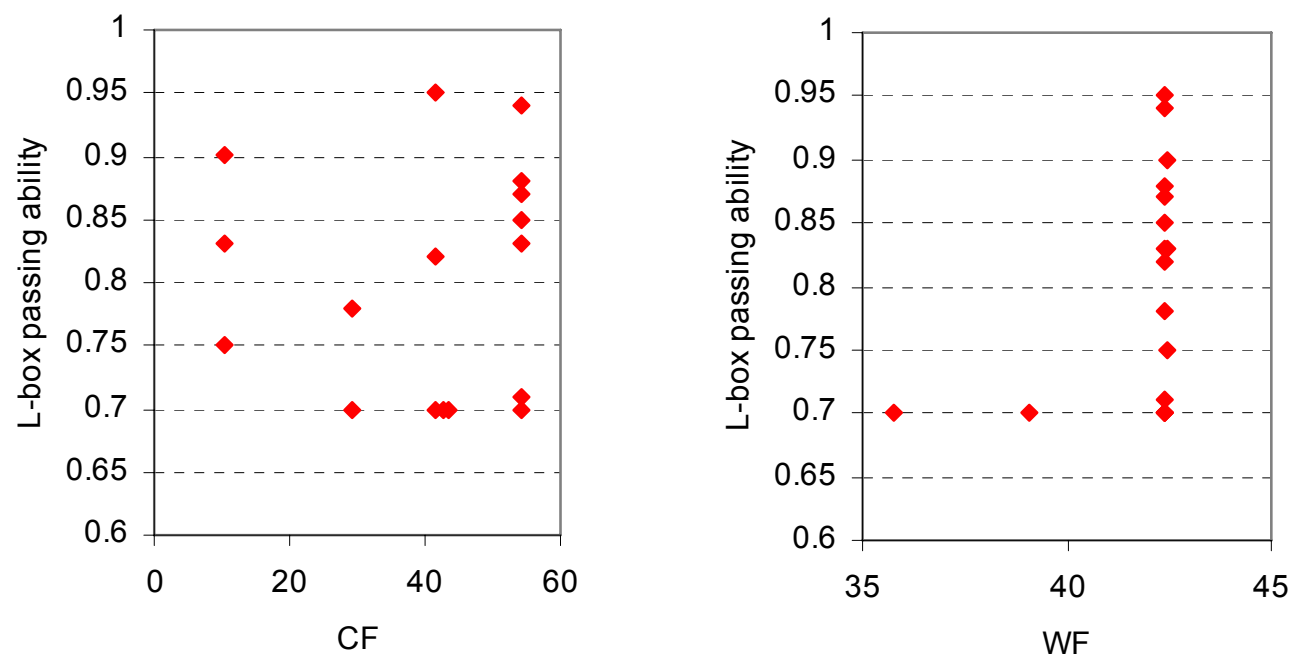

Figure 4.14 L-box PA vs. (a) coarseness factor (b) workability factor 


\subsection{Concluding Remarks}

Different fresh concrete tests were performed on the 17 developed SCC mixtures in this chapter. The details of the test methods and the analysis and correlation of the results with different parameters were also listed in the chapter. The visual stability index (VSI) values which are representative of the SCC mixture stability were found to be stable for all the mixtures. The T50 values varied from 1.2 seconds to 2.6 seconds; higher values were obtained for mixtures containing higher CA 25 . Slump flow values for all the mixtures found to be satisfactory with almost all of them exceeded the target limit of $650 \mathrm{~mm}$. The effect of filler and mineral admixtures on the effects of the slump flow values was not clear enough due to the combine effect of fillers, mineral admixtures, HRWRA, WRA, AEA, VMA, different paste volumes, different $w / p$ ratios and $w / b$ ratios. Blocking assessment results for the SCC mixtures as predicted by the J-ring test indicated that most of the blocking was less than 25 $\mathrm{mm}$ signifying that the SCC mixtures developed were superior in terms of blocking. Static segregation by column segregation test result varied from a value of $5 \%$ to $23 \%$ indicating a wide range of segregation values between the mixtures. Higher value means higher segregation and vice versa. Due to the higher particle size, mixtures made with greater percentage of CA 25, showed higher segregation values. It was also observed that higher CF resulted in higher static segregation. Very good L-box passing ability values were observed for all the SCC mixtures. All of them exceeded the target limit value of 0.7 . Values greater than 0.9 was also achieved by some of the mixtures, indicating very good passing ability and can be of great application where flow through congested reinforcement is needed. The next chapter describes the hardened properties such as compressive strength and splitting tensile strength in detail for the developed SCC mixtures. 


\section{CHAPTER FI VE}

\section{HARDENED PROPERTIES OF SCC AND MI XTURE SELECTI ON}

\subsection{I ntroduction}

In this chapter the compressive strength of different mixtures has been compared. The ACI prediction equation for compressive strength has been investigated and compared with the compressive strength results for the selected $\mathrm{SCC}$ mixtures. Also the effects of $\mathrm{w} / \mathrm{cm}$ ration, $\mathrm{w} / \mathrm{p}$ ratio, $\mathrm{CF}, \mathrm{WF}$, and paste volume on compressive strength has been investigated.

\subsection{Compressive Strength Measurement}

Compressive strengths of $101.6 \mathrm{~mm}$ diameter $\times 203.2 \mathrm{~mm}$ long (4 in. diameter $x 8$ in. long) cylinder specimens were measured in accordance with ASTM C 39 (Standard Test Method for Compressive Strength of Concrete Specimens). Tests were conducted at 7 and 28 days after casting. On an average compressive strength of four specimens were tested and the average values are reported here.

\subsection{Compressive Strength of 17 Mixtures}

Figure 5.1 shows the 7-day and 28-day compressive strength of the 17 SCC mixtures prepared in the laboratory.

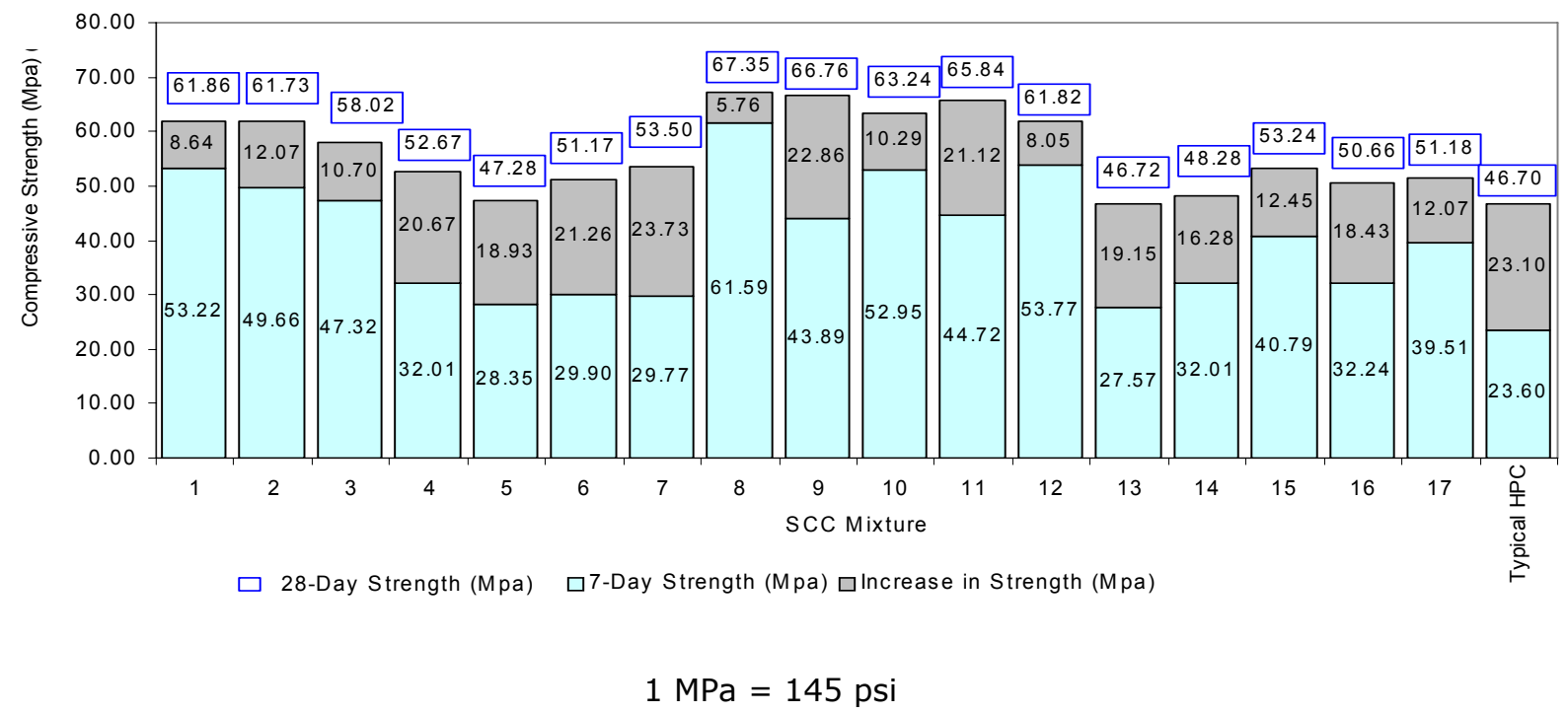

Figure5.1 Compressive strength of SCC mixtures 


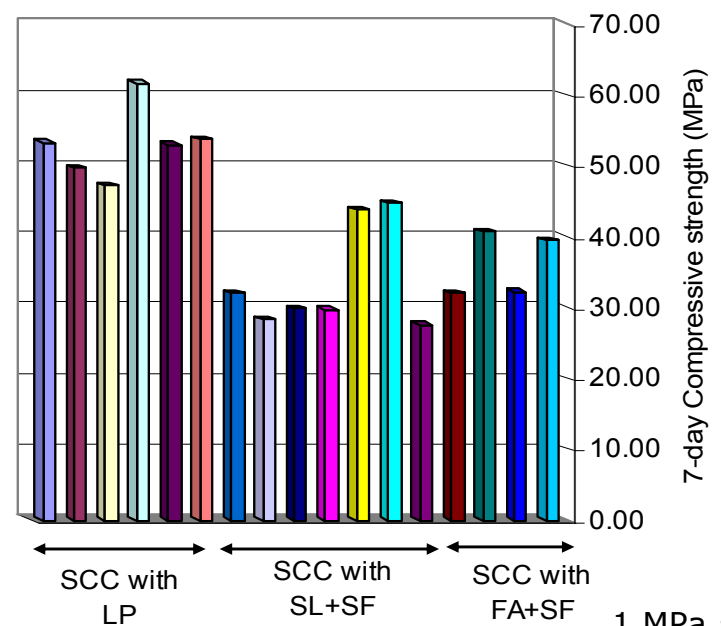

$1 \mathrm{MPa}=145.04 \mathrm{psi}$

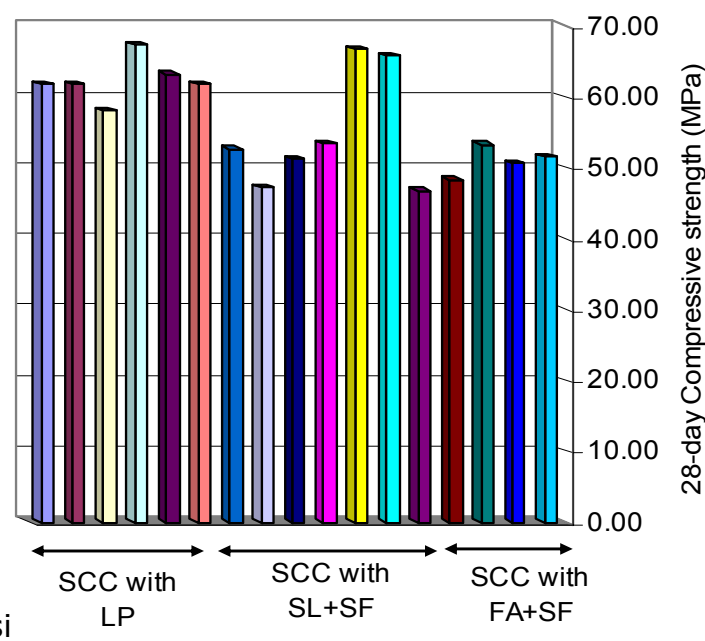

Figure 5.2 Compressive strength comparisons case-I (a) 7-day (b) 28-day
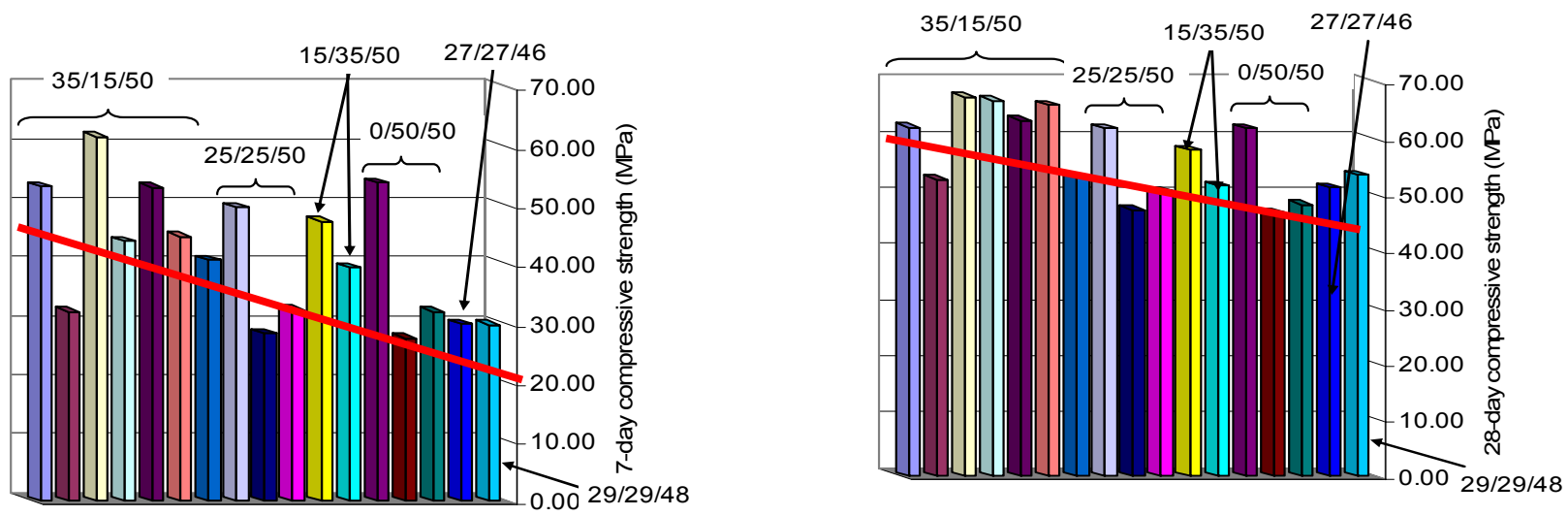

$1 \mathrm{MPa}=145.04 \mathrm{psi}$

Figure 5.3 Compressive strength comparisons case-II (a) 7-day (b) 28-day
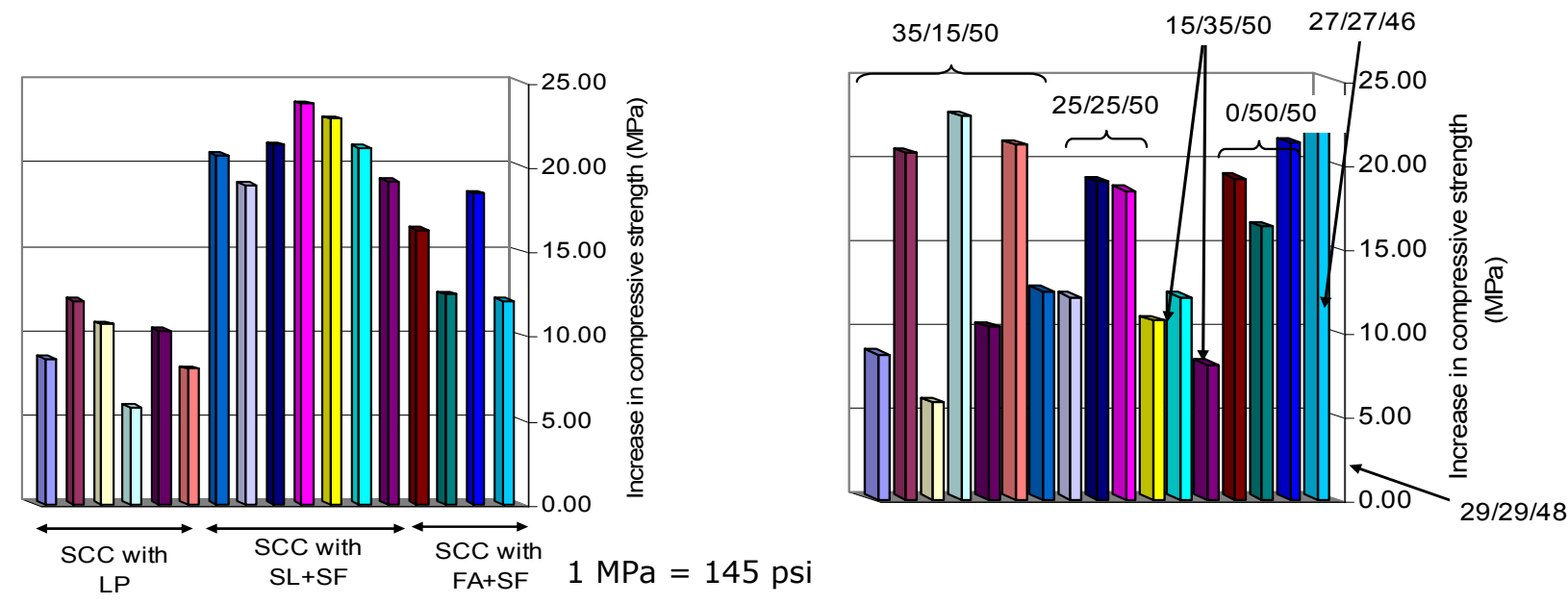

Figure 5.4 Increase in strength (a) case-I (b) case-II 
Figure 5.2(a) shows the 7-day compressive strength comparison between different mixtures. The mixtures are grouped according to their mineral admixture and filler content; group I contain LP, group II contain SL+SF, and group III contain FA+SF. The three separate groups are marked on the figure. Figure 5.2(b) shows the 28-day strength comparison between different mixtures, other parameters remaining the same. Figure 5.3(a) compares the 7-day compressive strength between the 17 mixtures. The mixtures are grouped according to their aggregate fraction. For example, the first group contains $35 \%$ of CA $25,15 \%$ of CA 9.5 , and $50 \%$ of FA by weight and termed as 35/15/50. Similar nomenclature has been followed for the other groups. Figure 5.3(b) compares the 28-day compressive strength between the mixtures grouped according to their aggregate fraction. Figure 5.4(a) shows in increase in compressive strength from 7-day to 28-day for all the mixtures grouped based on their mineral admixture and filler content. 5.4(b) compares the increase in strength from 7-day to 28-day for all the mixtures grouped based on their aggregate fraction. From Figure 5.1 it is observed that SCC 8 containing fibers had the highest 28-day compressive strength among all the mixtures with a value of $67.35 \mathrm{MPa}$ ( 9770 psi) followed by SCC 9 and SCC 11 with values of $66.76 \mathrm{MPa}$ (9680 psi) and 65.84 MPa (9550 psi) respectively. If the mixtures without the fiber and SRA are considered, then SCC 1 had the highest 28-day strength of $61.86 \mathrm{MPa}$ (8970 psi) followed by SCC 12 and SCC 3 with compressive strength values of $61.82 \mathrm{MPa}$ (8965 psi) and $61.73 \mathrm{MPa}(8950 \mathrm{psi}$ ) respectively. It is observed from the above discussion that mixtures containing limestone powder developed higher compressive strengths at both 7-day and 28-day compared to those mixtures with slag + silica fume or fly ash + silica fume. Similar observations have been made by Zhu and Gibbs (2005). SCC 1, SCC 12, and SCC 3 all of them had LP in common. It is also evident from Figure 5.1 that the compressive strength developed in the SCC mixtures were comparable or higher in most cases when compared to the strength value of a typical HPC mixture. This opinion is clearly supported from Figure 5.2 where the compressive strengths are grouped according to their mineral admixture and filler content. Another important fact noted from Figure 5.2(a) is that the early age compressive strength development is much higher for the mixtures containing LP than the mixtures containing SL+SF or FA+SF. The average 7-day compressive strength values for the mixtures containing LP were $53 \mathrm{MPa}$ (7690 psi), whereas the average 7-day compressive strength of the mixtures containing SL+SF and FA+SF was $34 \mathrm{MPa}$ (4930 psi) and $36 \mathrm{MPa}$ (5220 psi) respectively. Group I containing the 
LP had a highest 7-day compressive strength of $61.59 \mathrm{MPa}$ (8935 psi) and the lowest 7-day compressive strength was 47.32 $\mathrm{MPa}$ (6865 psi). Group II containing the SL+SF had a highest 7-day compressive strength of $44.72 \mathrm{MPa}$ (6490 psi) and the lowest 7-day compressive strength was 27.57 MPa. (4000 psi) Group III containing the FA+SF had a highest 7-day strength of $40.79 \mathrm{MPa}$ (5915 psi) and the lowest 7day compressive strength was $32.01 \mathrm{MPa}$ (4645 psi). It may be also noted that within the individual groups, apart from the mixtures containing fiber and SRA, strength development is maximum for the mixtures which contains larger CA 25 percentage. For example in Group II, the highest 7-day compressive strength (neglecting mixtures with fiber and SRA) of a value of $32.01 \mathrm{MPa}$ (4645 psi) was achieved by the mixture containing an aggregate fraction of 35/15/50 and the lowest was 27.57 MPa (4000 psi) with an aggregate fraction of 0/50/50. Similar conclusion can be drawn for Group III also; it has a highest 7-day compressive strength (neglecting mixtures with fiber and SRA) of a value of $40.79 \mathrm{MPa}$ (5915 psi) was achieved by the mixture containing an aggregate fraction of 35/15/50 and the lowest was $32.01 \mathrm{MPa}$ (4645 psi) with an aggregate fraction of 0/50/50. Similar trends were also observed for the 28-day compressive strength for the mixtures. Figure 5.3 shows the 7-day and 28-day compressive strength figures for all the mixtures grouped according to their aggregate fractions. These figures support the earlier proposed fact that the mixtures with higher CA 25 fraction containing the LP gained the maximum strength compared to the other mixture combinations. The trend line is marked as red in both the figures. Figure 5.4 shows the increase in strength from 7-day to 28-day for both the categories, one grouped based on their mineral admixture content, and the other based on their aggregate fraction content. Some interesting facts are observed from Figure 5.4(a). The mixtures containing SL+SF and $\mathrm{FA}+\mathrm{SF}$ gained much more strength in those days compared to mixtures containing LP. The maximum strength increase in case of a mixture containing LP was $24.31 \%$ and the minimum strength increase was $9.35 \%$. Whereas, the maximum strength increase in case of a mixture containing SL+SF was $79.72 \%$ and the minimum strength increase was $47.24 \%$ and the maximum strength increase in case of a mixture containing $\mathrm{FA}+\mathrm{SF}$ was $57.16 \%$ and the minimum strength increase was $30.52 \%$. This observation leads to the conclusion that LP contributes to accelerated hydration compared to mineral admixtures like SL+SF or FA+SF. Also, due to its finer particle size, strength values are more for the mixtures containing LP compared to the mixtures containing SL+SF and FA+SF. 

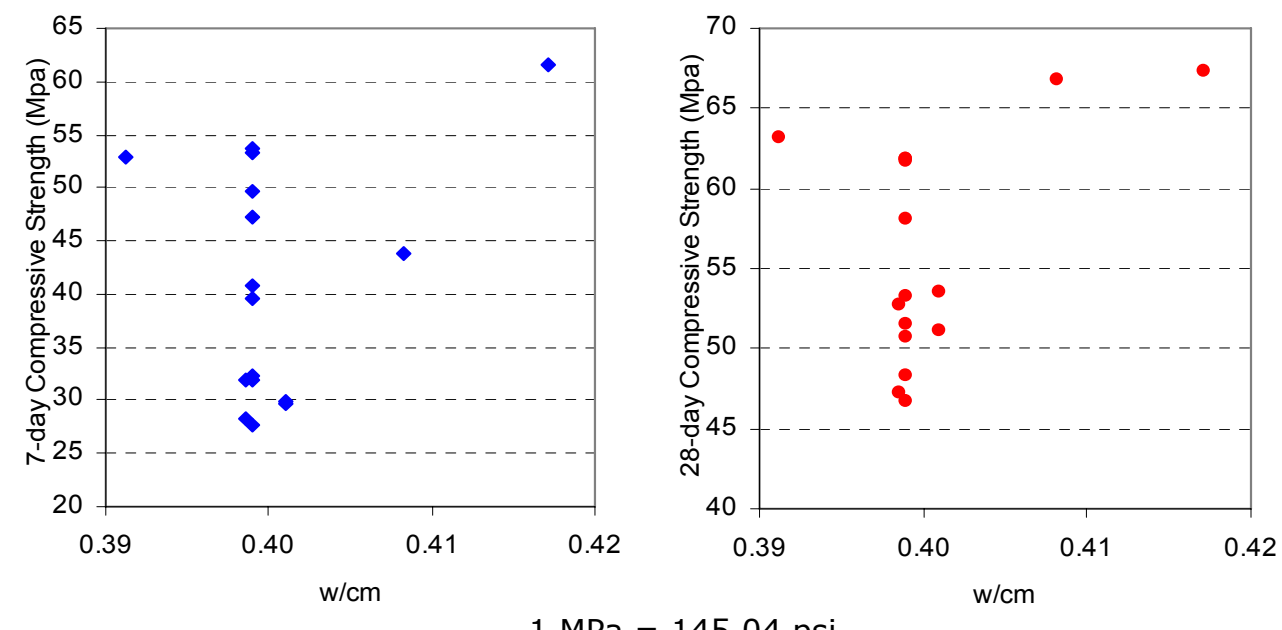

$1 \mathrm{MPa}=145.04 \mathrm{psi}$

Figure 5.5 w/cm versus (a) 7-day (b) 28-day Compressive strength
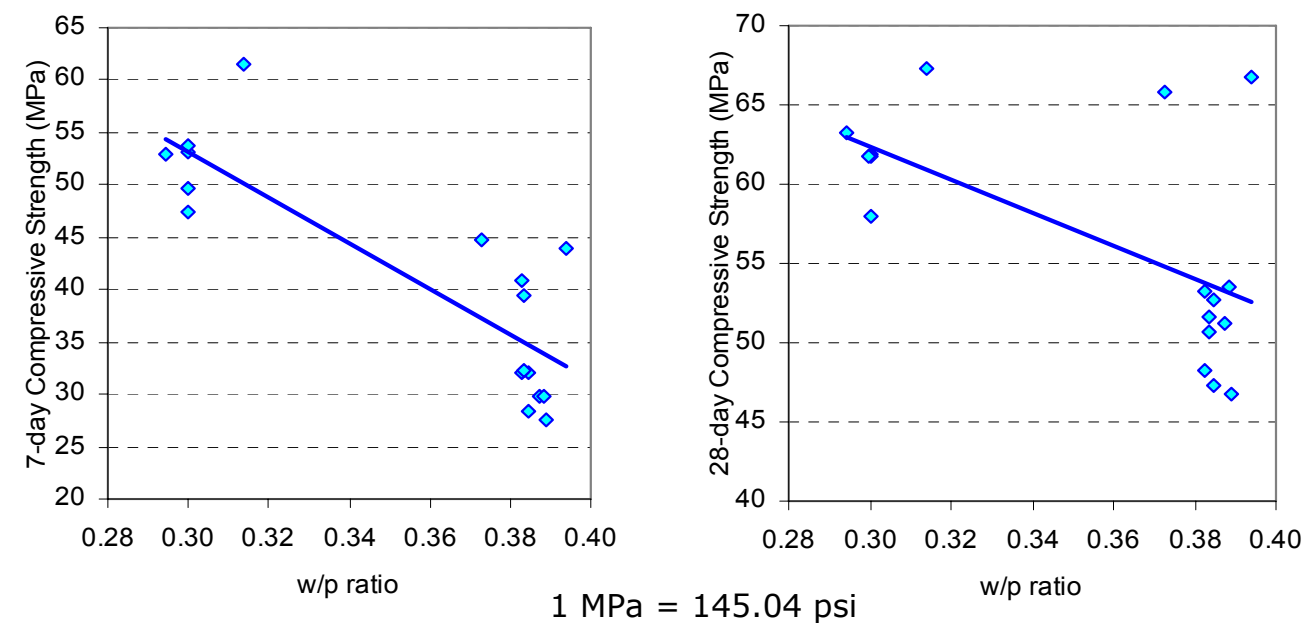

Figure5.6 w/p versus (a) 7-day (b) 28-day Compressive strength
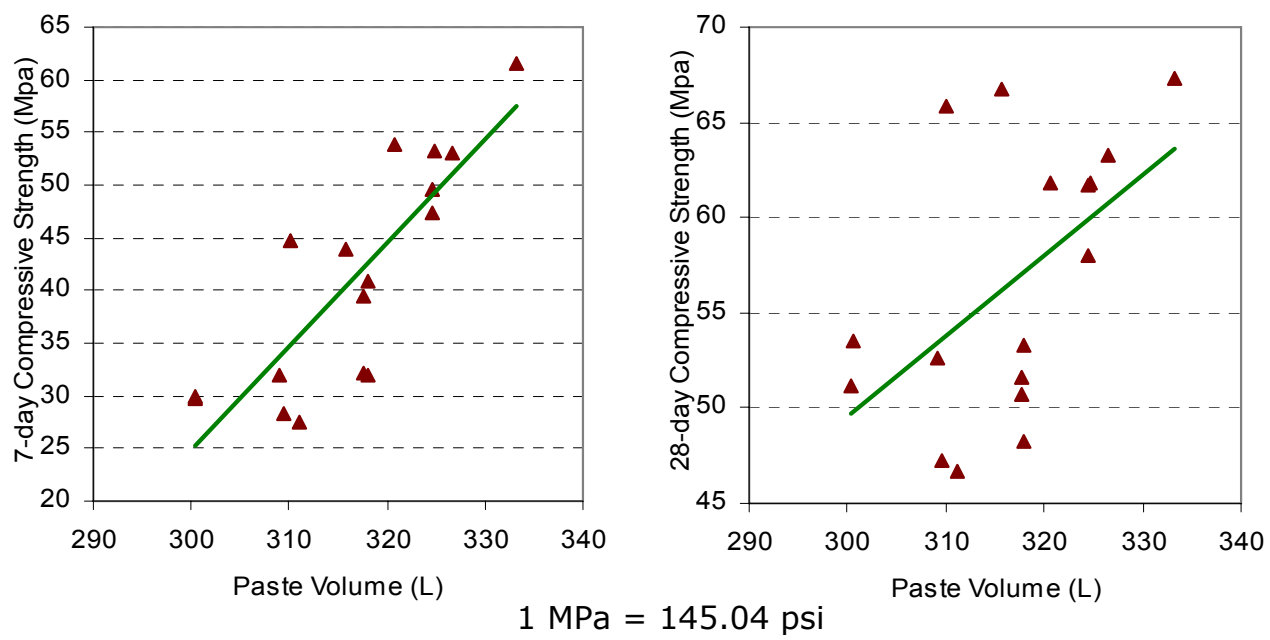

Figure5.7 Paste volume versus (a) 7-day (b) 28-day Compressive strength 

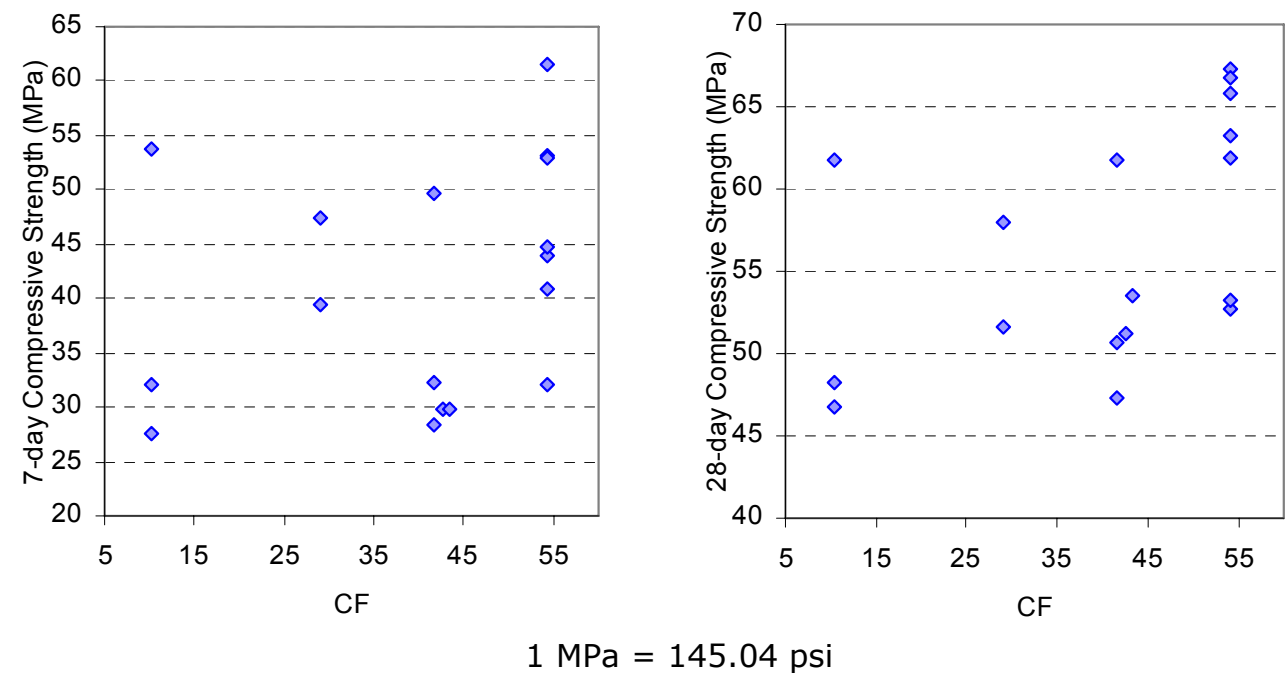

Figure5.8 CF versus (a) 7-day (b) 28-day Compressive strength
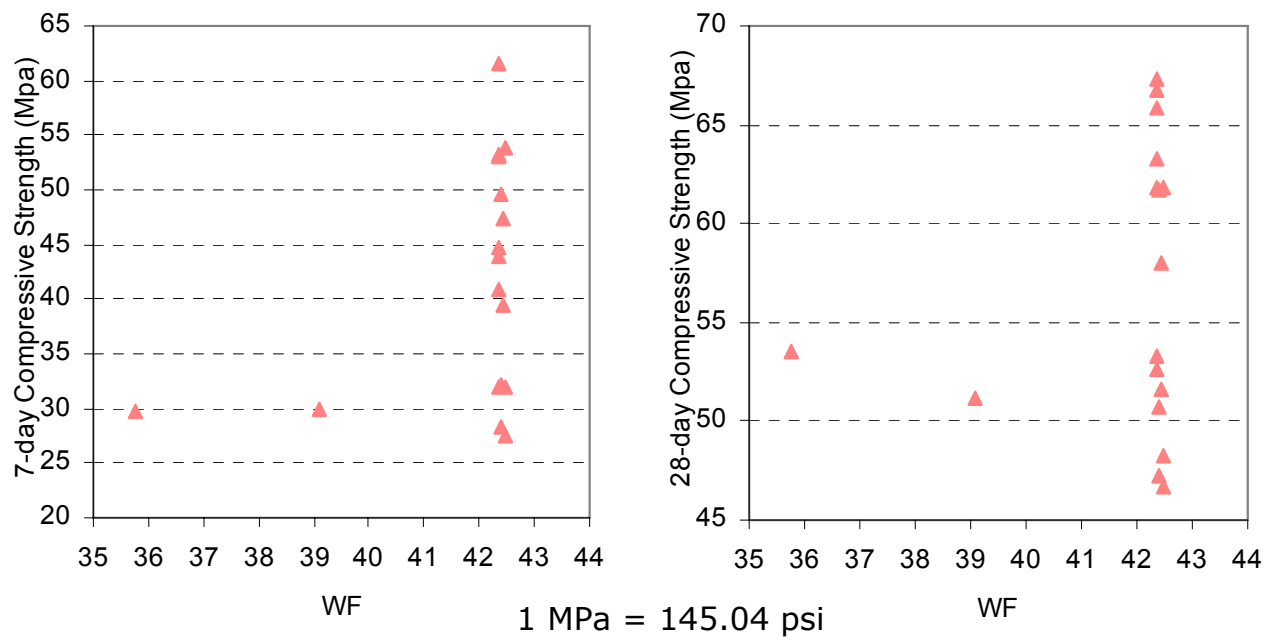

Figure5.9 WF versus (a) 7-day (b) 28-day Compressive strength

Figure 5.5 through Figure 5.9 tries to establish relation between the 7-day and 28-day compressive strengths with different parameters like $\mathrm{w} / \mathrm{cm}$ ratio, $\mathrm{w} / \mathrm{p}$ ratio, paste volume, coarseness factor, and workability factor. Figure 5.5(a) and Figure 5.5(b) shows the plot of $\mathrm{w} / \mathrm{cm}$ ratio to 7-day compressive strength and 28day compressive strength respectively. As observed from the figures, there is no correlation between the $\mathrm{w} / \mathrm{cm}$ ratio and the compressive strength of the mixtures. This may be due to the fact that, amount of powders governs the compressive strength much more than the cementitious materials. It is found from the figures that at same $\mathrm{w} / \mathrm{cm}$ ratio there mixtures with varied strength were possible. Though the $\mathrm{w} / \mathrm{cm}$ ratios of all the mixtures were kept approximately same, the range of compressive strength varied greatly among the mixtures. This is due to the fact that 
the paste volume and powder content have significant effect on the compressive strength.

Figure 5.6(a) and Figure 5.6(b) show the plot of $w / p$ ratio to 7 -day compressive strength and 28-day compressive strength respectively. As observed from the figures, there is definite correlation between the $\mathrm{w} / \mathrm{p}$ ratio and the compressive strength of the mixtures. The material of size $125 \mu \mathrm{m}$ or smaller are considered as powder. As LP was a very fine filler material and was included in the powder calculation, the $\mathrm{w} / \mathrm{p}$ ratio for SCC with LP was lowest and the value was 0.29 , whereas $w / p$ ratio for rest of the mixtures was around 0.39 . For further investigation, the mixtures without the fiber and SRA are plotted against the $\mathrm{w} / \mathrm{p}$ ratios in Figure 5.10 below.

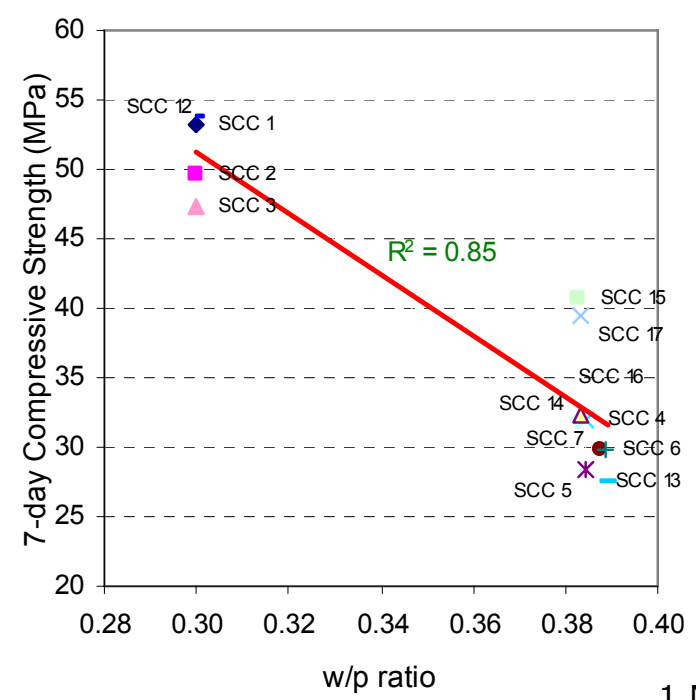

$1 \mathrm{MPa}=145.04 \mathrm{psi}$

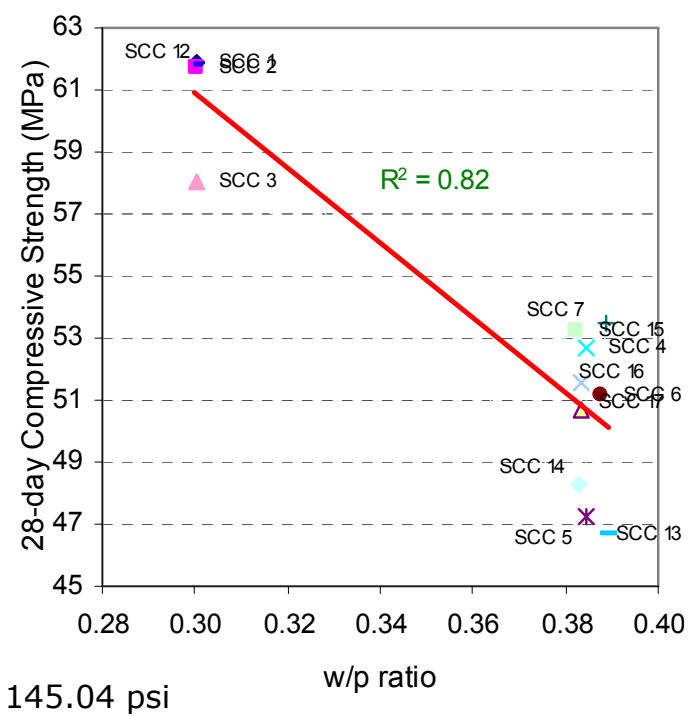

Figure $5.10 \mathrm{w} / \mathrm{p}$ versus (a) 7-day Compressive strength (b) 28-day Compressive strength (excluding mixtures containing fiber and SRA)

There is a definite trend between $\mathrm{w} / \mathrm{p}$ ratio and compressive strength as evident from the figures with a regression co-efficient of 0.85 and 0.82 respectively. However due to strong influence of admixtures on SCC, for a given $w / p$, different level of compressive strengths were possible.

Paste volume is another important criterion for SCC as it is designed with a higher paste volume than normal concrete. Flowability of SCC increases with higher volume of paste but it may have detrimental effects on mechanical properties, timedependent deformations and cracking susceptibility (Roziere et. al., 2007). Paste volume of all the mixtures has been calculated as the total volume of all the mixture minus those from coarse and such ass. The paste volumes were highest for the 
mixtures made with LP $\left(321 \sim 333\right.$ liters $\left./ \mathrm{m}^{3}\right)$ followed by the FA+SF mixtures (318 liters $\left./ \mathrm{m}^{3}\right)$. The paste volumes of the SL+SF were the least $\left(300 \sim 316\right.$ liters $\left./ \mathrm{m}^{3}\right)$. The paste volume has been plotted against 7-day and 28-day compressive strengths in Figure 5.7. As seen from the figures, there exist correlations between compressive strength and paste volume for all the mixtures. Compressive strength was higher for the concretes made with higher paste volume. For example, SCC 1 through SCC 4 was made with highest paste volume of around 330 liters $/ \mathrm{m}^{3}$ of concrete and these four mixtures exhibited high 7-day and 28-day compressive strengths. Conversely, SCC 7 through SCC 10 made with low paste volume (varied between 300 310 liters $/ \mathrm{m}^{3}$ ) was characterized by low 7-day and 28-day compressive strength compared to other mixtures. As in this study the paste volume varied between $300 \sim 330 \mathrm{~L} / \mathrm{m}^{3}$ of concrete, more strength data with wider range of paste volume are required to support the fact.

Figure 5.8(a) and Figure 5.8(b) shows the plot of CF to 7-day compressive strength and 28-day compressive strength respectively. Similarly, Figure 5.9(a) and Figure 5.9(b) shows the plot of WF to 7-day compressive strength and 28-day compressive strength respectively. As seen from the figures that there are no definite correlation between the parameters. From the figures it may be concluded that it is possible to design mixtures with different strength having same CF or WF. This is possible due to the effect of $w / p$ ratio, paste volume, and chemical admixtures on the compressive strength of SCC. 


\subsection{Mixture Selection}

\subsubsection{I ntroduction}

Out of 17 mixtures designed and established earlier six mixtures were selected for further in depth study. In this section the basis of selection of mixtures, fresh properties, and hardened properties of the mixtures are described.

\subsubsection{Basis of Selection}

Six mixtures were selected from the 17 mixtures for further study on durability. The six mixtures selected are shown in Table 5.1 below with tick marks.

Table5.1 - Selected Six Mixtures

\begin{tabular}{|c|c|c|c|}
\hline Mixture & Aggregate Fraction & & Nomenclature \\
\hline SCC 1 & $0.35 / 0.15 / 0.50 / \mathrm{LP}$ & $\sqrt{ }$ & $\operatorname{SCC} A(70-30)$ \\
\hline SCC 2 & $0.25 / 0.25 / 0.50 / \mathrm{LP}$ & $\sqrt{ }$ & SCC B (50-50) \\
\hline SCC 3 & $0.15 / 0.35 / 0.50 / \mathrm{LP}$ & $\sqrt{ }$ & $\operatorname{SCC} C(30-70)$ \\
\hline $\operatorname{SCC} 4$ & $0.35 / 0.15 / 0.50 / S L / S F$ & & \\
\hline SCC 5 & $0.25 / 0.25 / 0.50 / S L / S F$ & & \\
\hline SCC 6 & $0.27 / 0.27 / 0.46 / S L / S F$ & & \\
\hline SCC 7 & $0.29 / 0.29 / 0.42 / S L / S F$ & & \\
\hline $\operatorname{SCC} 8$ & $0.35 / 0.15 / 0.50 / \mathrm{LP} / \mathrm{F}$ & $\sqrt{ }$ & $\operatorname{SCC} E(F)$ \\
\hline SCC 9 & $0.35 / 0.15 / 0.50 / \mathrm{SL} / \mathrm{SF} / \mathrm{F}$ & & \\
\hline SCC 10 & $0.35 / 0.15 / 0.50 / L P / S R A$ & $\sqrt{ }$ & SCC F (SRA) \\
\hline SCC 11 & $0.35 / 0.15 / 0.50 / S L / S F / S R A$ & & \\
\hline SCC 12 & $0.0 / 0.50 / 0.50 / \mathrm{LP}$ & $\sqrt{ }$ & SCC D $(0-100)$ \\
\hline SCC 13 & $0.0 / 0.50 / 0.50 / \mathrm{SL} / \mathrm{SF}$ & & \\
\hline SCC 14 & $0.0 / 0.50 / 0.50 / \mathrm{FA} / \mathrm{SF}$ & & \\
\hline SCC 15 & $0.35 / 0.15 / 0.50 / \mathrm{FA} / \mathrm{SF}$ & & \\
\hline SCC 16 & $0.25 / 0.25 / 0.50 / \mathrm{FA} / \mathrm{SF}$ & & \\
\hline SCC 17 & $0.15 / 0.35 / 0.50 / F A / S F$ & & \\
\hline
\end{tabular}

Table 5.1 shows the six mixtures were selected on the following basis. To study the effects of aggregate distribution, fibers, and SRA on durability in a limited time, it was necessary to omit some parameters which affect directly the hardened concrete behavior. Also, SCC mixtures are generally designed with limestone fillers as discussed in Chapter 2. The importance of fillers like limestone powder in SCC mixtures is due to the fact that it provides stability to the mixture preventing segregation and providing better rheology to the paste. Also, SCC with limestone fillers performed consistently better than SL+SF and FA+SF mixtures in terms of strength development. Due to this reason, the mixtures with limestone powder were 
given preference. These six mixtures contain different aggregate gradations as well as one of the contains fiber and the other contains SRA. Four different kind of aggregate distributions such as 35/15/50, 25/25/50, 15/35/50, and 0/50/50 were present in the selection which will help to understand the effect of aggregate distribution on the cracking and durability properties of SCC. Also the presence of the mixtures containing fiber and SRA will help comparison between different SCC mixtures from shrinkage and cracking point of view. The nomenclature of the selected mixtures are as follows. SCC A contained 35\% CA 25, 15\% CA 9.5, and $50 \%$ fine aggregate by weight of total aggregate As the amount of CA 25 is $70 \%$ of the total coarse aggregate by weight, it was designated as SCC A (70-30). Similar nomenclature were followed for SCC B through SCC D. SCC E and SCC F both had an aggregate fraction of 35/15/50; the only difference was that SCC E contains fiber and SCC F contains SRA. Hence the nomenclature for them was decided as SCC E (F) and SCC F (SRA) respectively.

\subsubsection{Tests on Selected Mixtures}

Tests for fresh properties were already performed on these mixtures as described in Chapter 4. The main purpose of the selection was to study certain hardened property and durability characteristics of the mixtures. Hence extensive testing was done on the samples of the selected mixture. The main tests which were performed on the SCC mixtures are listed below:

- Compressive strength test at ages 1,3,7,14,28, and 56 days after casting;

- Splitting tensile strength at ages $1,3,7,14,28$, and 56 days after casting;

- Drying and autogenous shrinkage at different ages up to 90 days after casting;

- Restrained shrinkage cracking of ring specimens made by selected SCC mixtures;

- Air-void stability of hardened SCC samples at 28 days after casting;

- Chloride permeability of selected SCC mixtures after 28 days of casting; and

- Freeze-thaw resistance of the selected SCC mixtures.

Between the above mentioned tests, compressive strength and splitting tensile strength results are discussed in this chapter. Shrinkage and cracking potential studies are discussed in Chapter 6 . The remaining test results and discussions are described in Chapter 7. 


\subsubsection{Compressive strength results for selected mixtures}

Compressive strength was measured as described earlier in this chapter. Similar procedure was followed for curing also. Four identical specimen of the same mixture were used for each age and the average value is reported here. Figure 5.11 shows the compressive strength of the six selected mixtures at different ages.

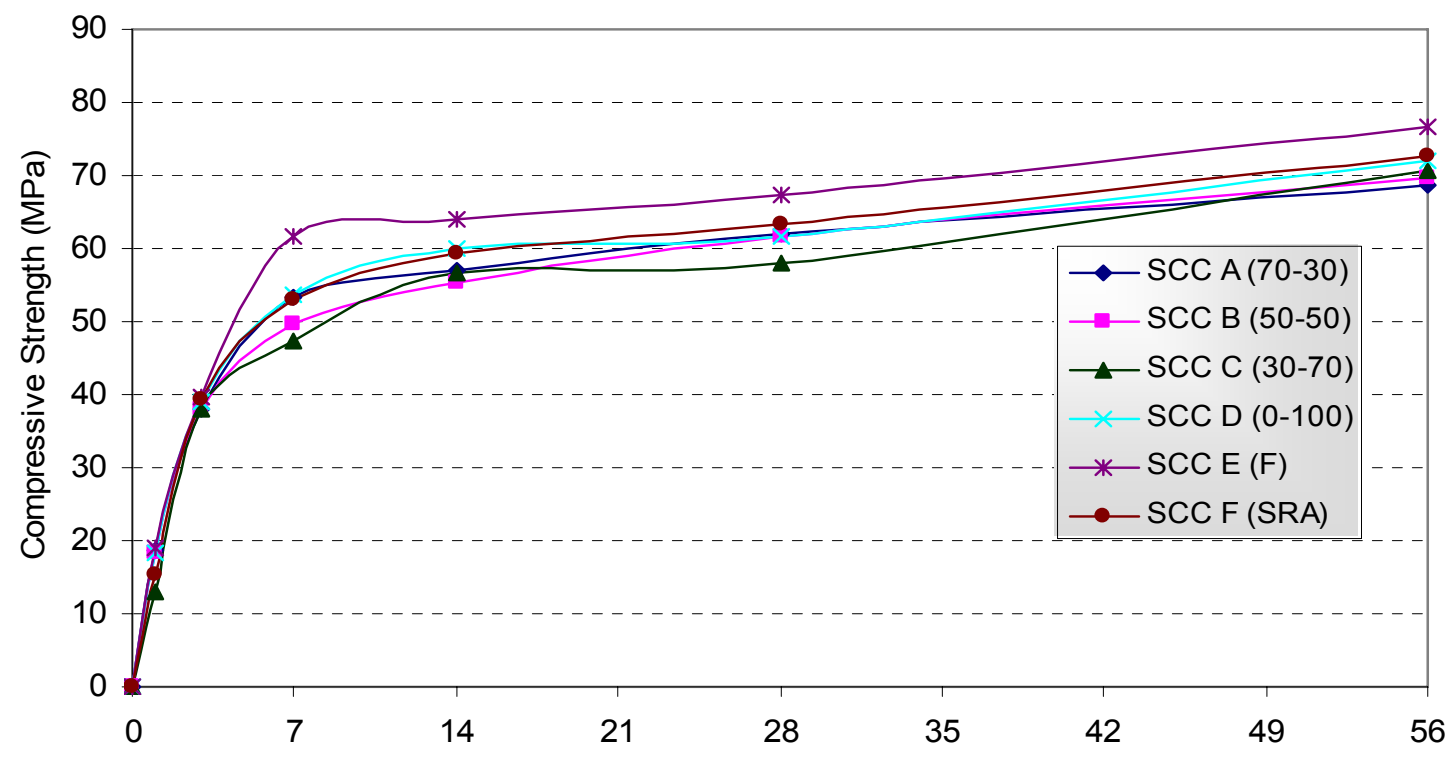

Age (Days)

$1 \mathrm{MPa}=145.04 \mathrm{psi}$

Figure5.11 Compressive strength for selected mixtures

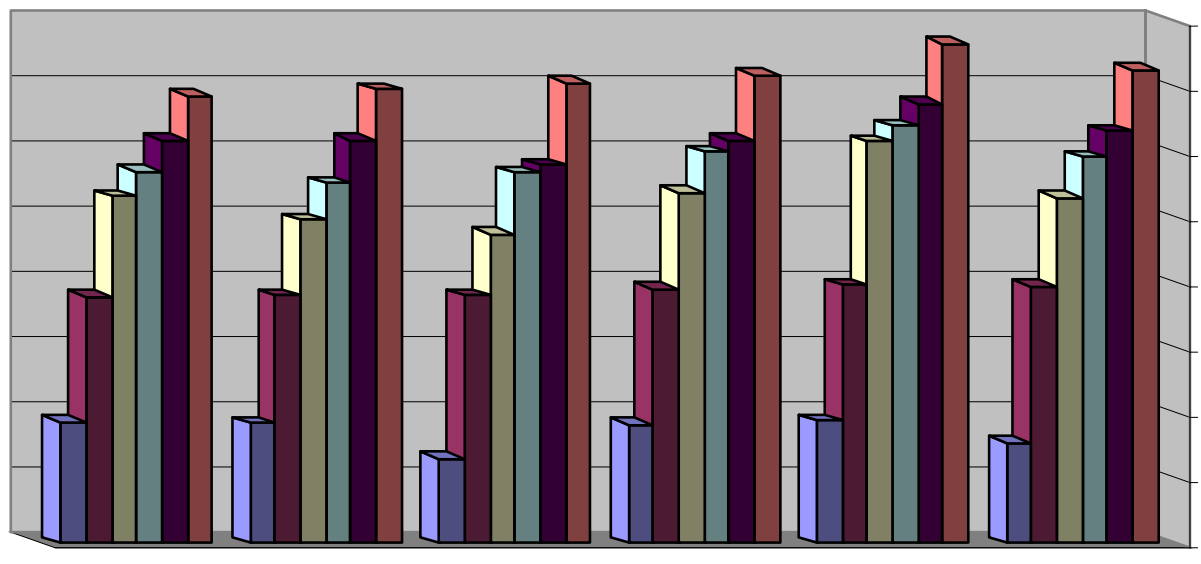

80.00

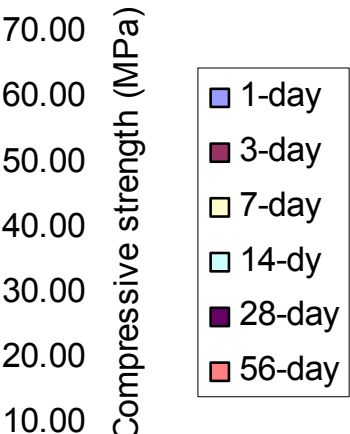

0.00

$1 \mathrm{MPa}=145.04 \mathrm{psi}$

$\operatorname{SCC} A(70-30) \operatorname{SCC} B(50-50) \quad \operatorname{SCC}(30-70) \operatorname{SCCD}(0-100) \quad \operatorname{SCC} E(F) \quad \operatorname{SCC} F(\operatorname{SRA})$

Figure5.12 Relative comparison of compressive strength for selected mixtures Figure 5.12 represents a relative comparison of compressive strength for selected mixtures at different ages. It is observed from the figures that the differences of 
compressive strengths of the mixtures at different ages are minimal. The 7-day compressive strength varied between 47.32 MPa (6865 psi) to $61.59 \mathrm{MPa}$ (8935 psi). The 28-day strengths between the six mixtures varied from $58.02 \mathrm{MPa}$ (8415 psi) to 67.35 $\mathrm{MPa}(9770 \mathrm{psi}$ ) and the 56-day compressive strengths varied from $68.59 \mathrm{MPa}$ (9950 psi) to $76.53 \mathrm{MPa}(11,100 \mathrm{psi})$. The difference between the compressive strengths at different ages became lower with the days. SCC E (F) had the highest compressive strength at all ages followed by SCC F (SRA). If the mixtures containing fiber and SRA are excluded from the comparison, compressive strengths of the remaining 4 mixtures were almost same and varied only between 58 62 MPa (8410 8990 psi) at 28-day and 69 72 MPa $(10,010 \sim 10,440 \mathrm{psi})$ at 56-day. This is due to the fact that all of them contained LP and also the $w / p$ ratios and paste volumes were similar.

\subsubsection{Comparison with ACI Prediction Eqn. for Compressive strength}

ACI 209 R (Prediction of Creep, Shrinkage, and Temperature Effects in Concrete Structures) provides the equation for prediction of compressive strength at any time ' $t$ ' with respect to 28 -day compressive strength, $f_{c}$ '. Following is the equation:

$$
\left(f^{\prime}{ }_{C}\right)_{t}=\frac{t}{a+\beta t}\left(f^{\prime}\right)_{28}
$$

Where for Type I concrete with moist curing, $\alpha=4.0$, and $\beta=0.85$

Figure 5.13(a) through 5.13(f) compare the ACI predicted model for strength at different ages with the actual values for SCC A (70-30) through SCC F (SRA).

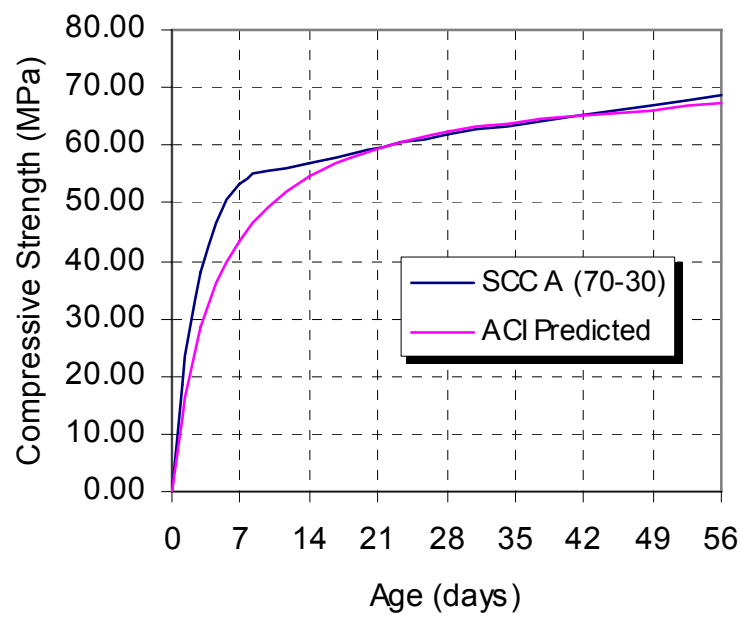

(a)

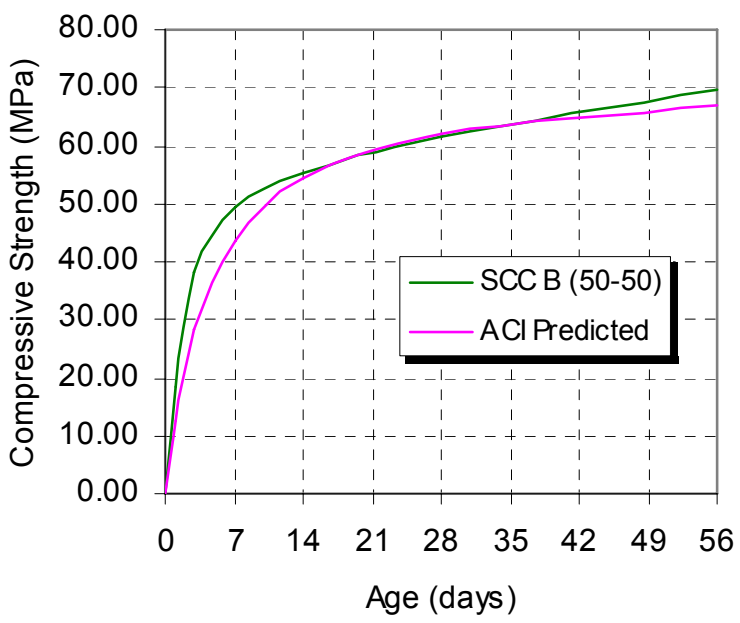

(b) 


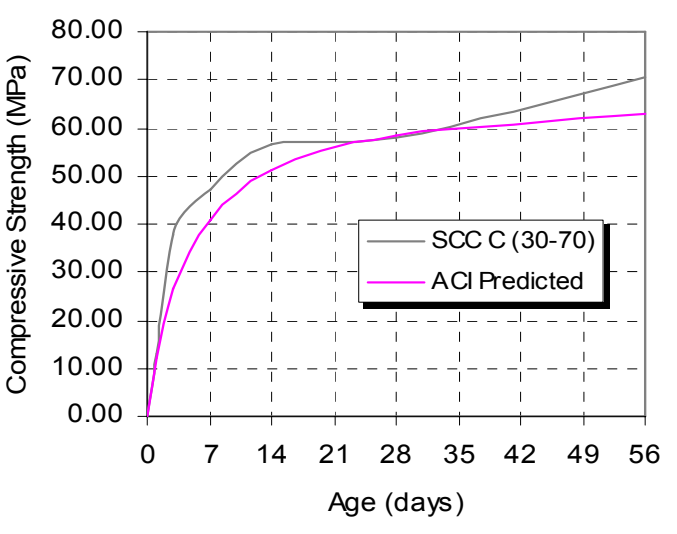

(c)

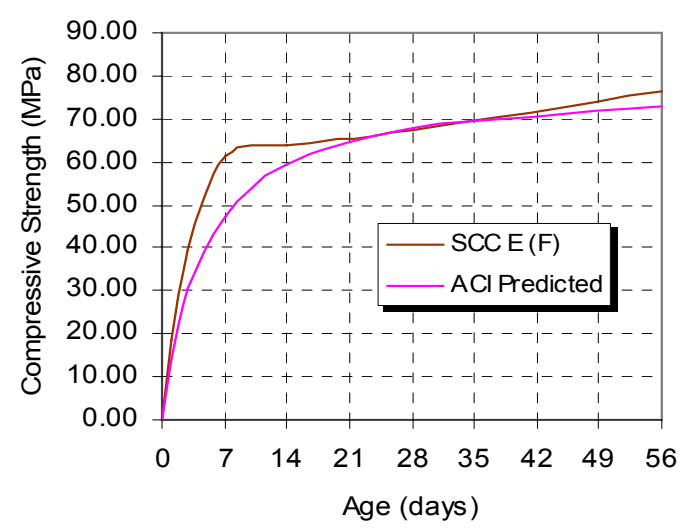

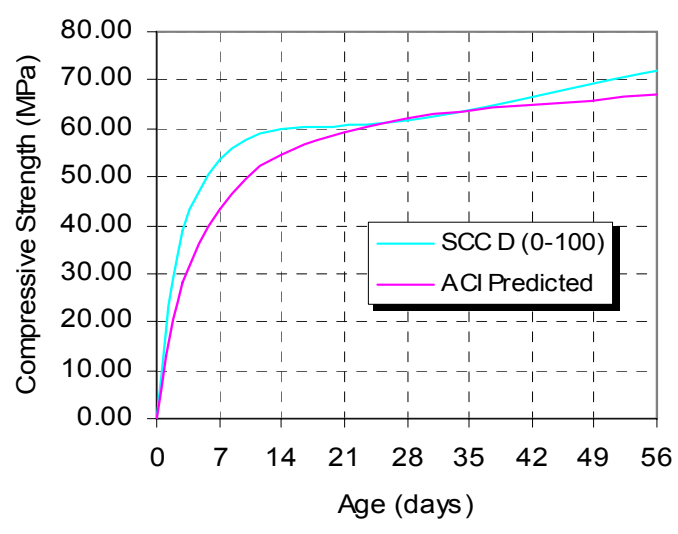

(d)

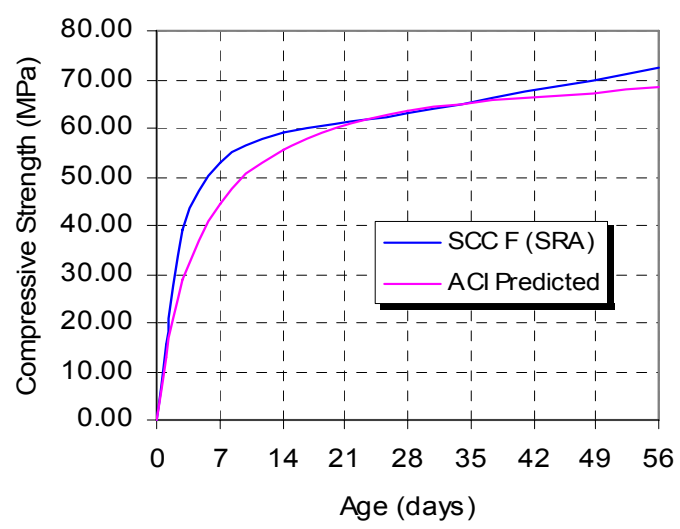

(f)

Figure5.13 Comparison of compressive strengths at different ages predicted by ACI 209 R and (a) SCC A (70-30); (b) SCC B (50-50); (c) SCC C (30-70); (d) SCC D (0100); (e) SCC E (F) and (f) SCC F (SRA)

It is observed from the above figures that ACI prediction equation holds good for the SCC also. As it is a new type of concrete with entirely different rheology and robustness characteristics than normal concrete, it was necessary to calibrate SCC with the available equation for normal concrete. The ACI predicted values are less than the actual values generated by the SCC mixtures in almost all the ages, and almost for all the SCC mixtures and hence conservative. The main difference as seen from the figures is the early age strength gain for the SCC mixtures compared to the prediction equation. This may be due to the presence of limestone powder in the mixture. The difference of strength at later ages are minimal and the ACI equation is conservative hence acceptable. The increase in strength due to the presence of LP is prevalent at 0 to 21 days for every mixture. Hence a correction factor $\gamma_{C F}$ can be applied to this type of SCC mixtures containing LP for determination of early age compressive strengths from the ACI predicted equation. The correction factor is valid 
for only 0 to 21 days, after 21 days the original formula holds well. The value of the factor have been determined as 1.20 for ages from 0 to 7 days and 1.10 for ages greater than 7 days and up to 21 days. Hence the proposed formula for strength is:

$$
\left(f^{\prime}{ }_{C}\right)_{t}=\frac{t}{a+\beta t}\left(f^{\prime}{ }_{C}\right)_{28} * \gamma_{C F}
$$

Where for Type I concrete with moist curing

$\alpha=4.0$, and $\beta=0.85$

$\gamma_{\mathrm{CF}}=$ correction factor for SCC containing limestone powder

$$
\begin{aligned}
& =1.2 \text { for } 0-7 \text { days } \\
& =1.1 \text { for } 8-21 \text { days } \\
& =1.0 \text { for }>21 \text { days }
\end{aligned}
$$

Figure 5.14 shows the new set of curves for different SCC mixtures following the proposed formula.

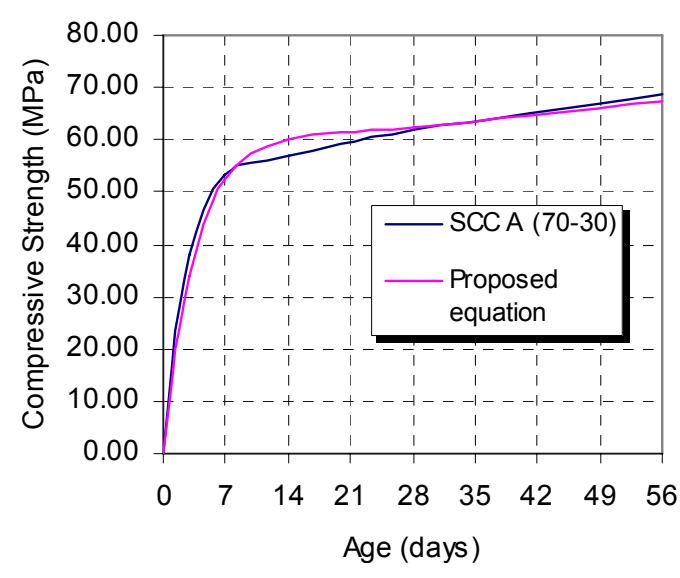

(a)

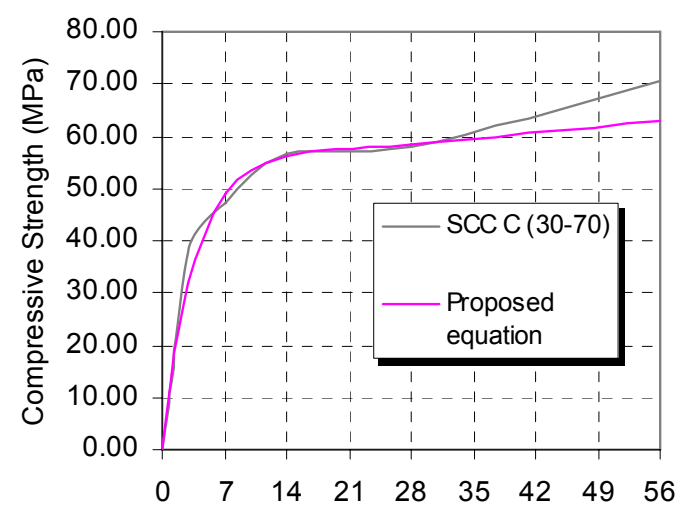

(c) s)

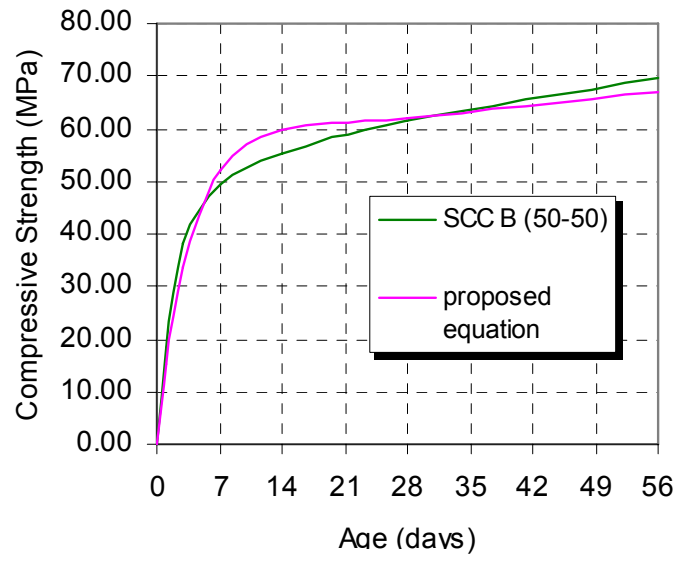

(b)

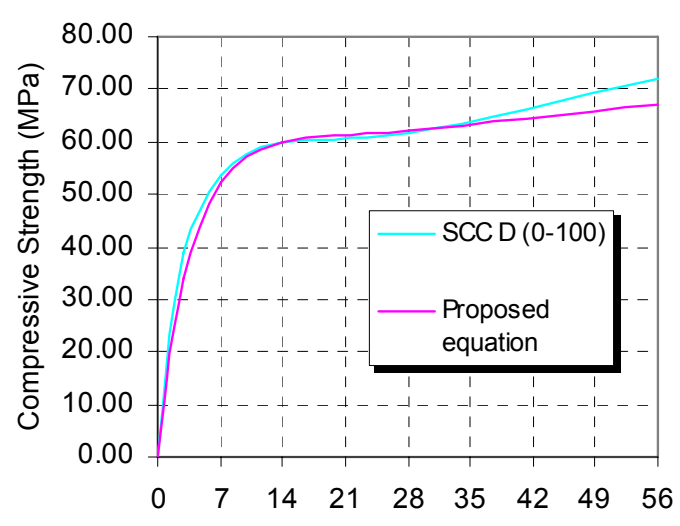

(d) s) 


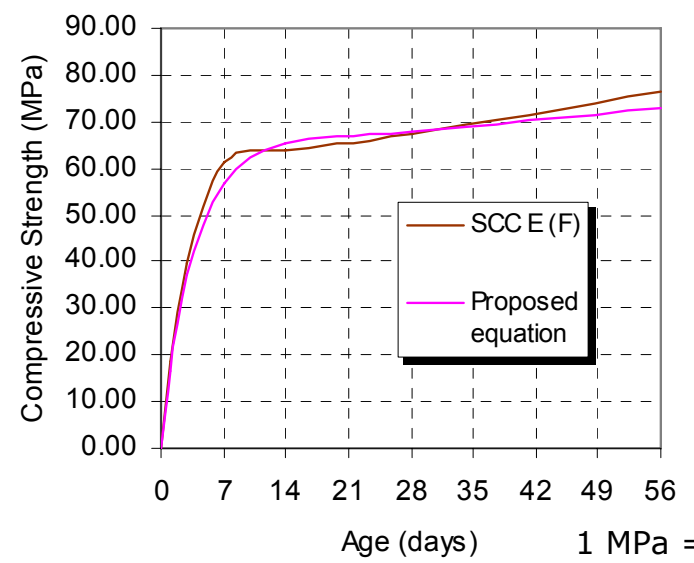

(e)

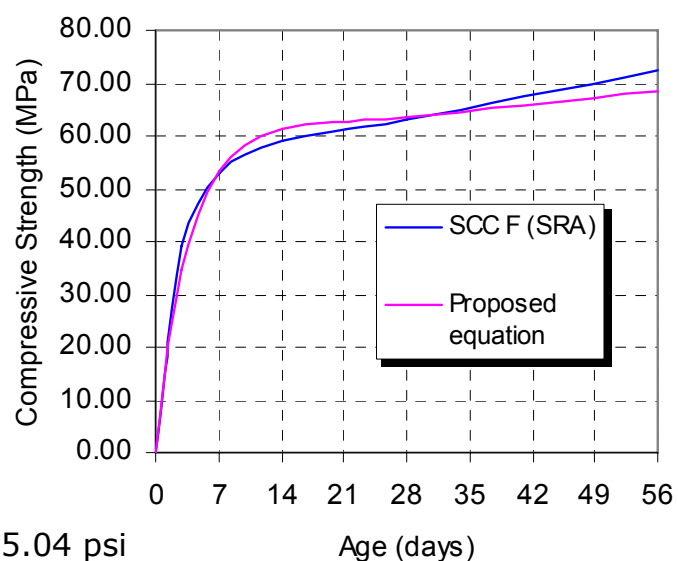

(f)

Figure5.14 Comparison of compressive strengths at different ages predicted by modified ACI equation and (a) SCC A (70-30); (b) SCC B (50-50); (c) SCC C (3070); (d) SCC D (0-100); (e) SCC E (F) and (f) SCC F (SRA)

\subsubsection{Splitting tensile strength test}

Splitting tensile (ST) strengths of $101.6 \mathrm{~mm}$ diameter x $203.2 \mathrm{~mm}$ long (4 in. diameter $x 8$ in. long) cylinder specimens were measured in accordance with ASTM C 496/C 496M-04 (Standard Test Method for Splitting Tensile Strength of Cylindrical Concrete Specimens). Each specimen was cured under water as described earlier in Chapter 3. Tests were conducted at 1, 3, 7, 14, 28 and 56 days after casting. On an average splitting tensile strength of four specimens were tested and the average values are reported here.

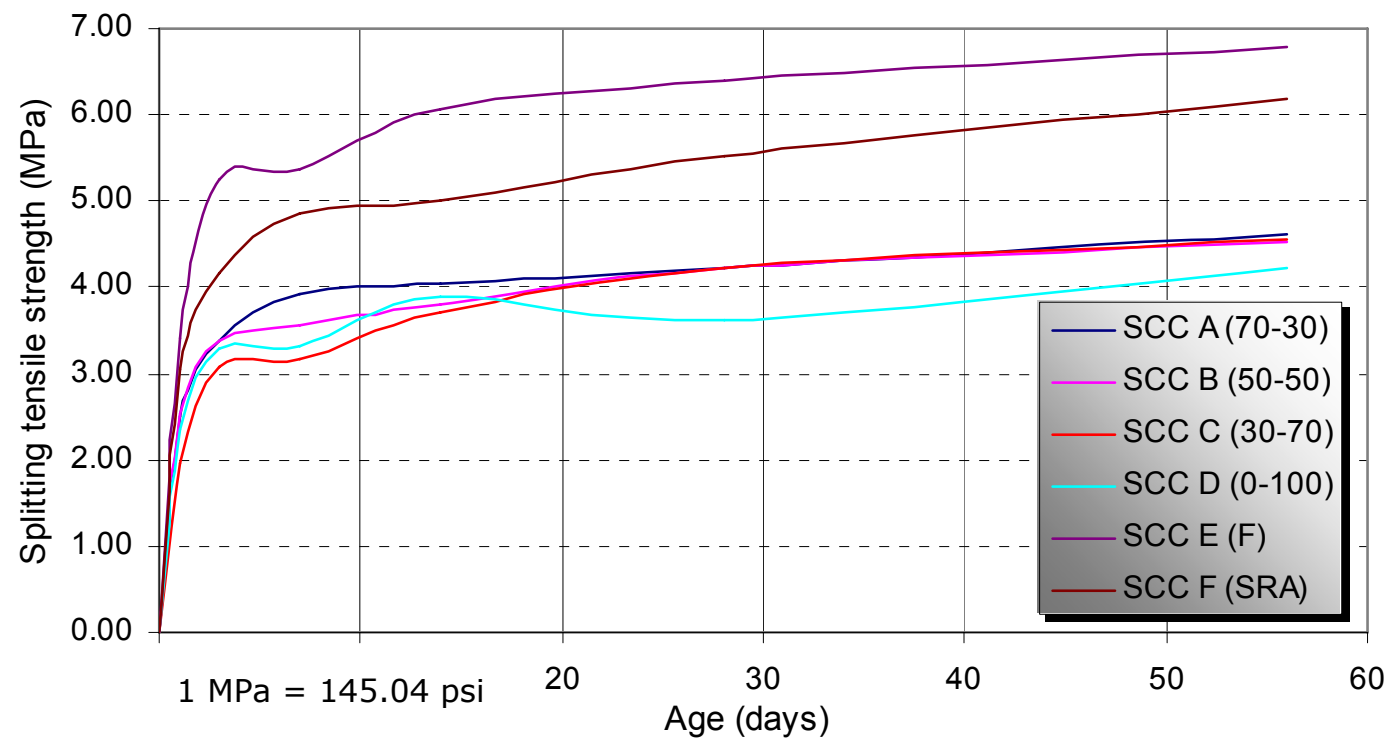

Figure5.15 Splitting tensile strength of selected mixtures with time 
Figure 5.15 shows the splitting tensile strength of the selected six mixtures at different ages up to 56 days after casting. It is evident from the figure that the trend is similar for all the mixtures. The highest splitting tensile value was reached by SCC $\mathrm{C}(\mathrm{F})$ with a value of $6.80 \mathrm{MPa}$ (985 psi) and the least splitting tensile strength was achieved by SCC D (0-100) with a value of $4.24 \mathrm{MPa}(615 \mathrm{psi})$. Because of the presence of the fiber, the splitting tensile strength was highest for SCC E (F). If the mixtures containing fiber and SRA are neglected, the splitting tensile strength of the remaining four mixtures had almost similar values with SCC A (70-30) being the highest and SCC D (0-100) being the lowest. The effect of aggregate gradation had its effect on the splitting tensile strength too.

As per ASTM C 496/C 496M-04, splitting tensile strength is generally stated as greater than the direct tensile strength and lower than the modulus of rupture. It was decided to verify the validation of the statement for SCC mixtures. ACI 209 R (Prediction of Creep, Shrinkage, and Temperature Effects in Concrete Structures) provides the equation for modulus of rupture $f_{r}$ and direct tensile strength $f_{t}^{\prime}$. Following is the equation:

$$
\begin{aligned}
& f_{r}=g_{r}\left[w\left(f_{c}{ }^{\prime}\right)_{t}\right]^{1 / 2} \\
& f_{t}{ }^{\prime}=g_{t}\left[w\left(f_{c}{ }^{\prime}\right)_{t}\right]^{1 / 2}
\end{aligned}
$$

Where,

$\left(\mathrm{f}_{\mathrm{c}}{ }_{\mathrm{c}}\right)_{\mathrm{t}}=$ Compressive strength at age ' $\mathrm{t}$ ' days, $\mathrm{MPa}$

$\mathrm{w}=$ Unit weight of concrete, $\mathrm{Kg} / \mathrm{m}^{3}$

$g_{r}=0.012$ to 0.021

$g_{t}=0.0069$

A unit weight of $2400 \mathrm{~kg} / \mathrm{m}^{3}$ was assumed for all the SCC mixtures. Although $\mathrm{g}_{\mathrm{r}}$ had a lowest value of 0.012 , a value of 0.013 to 0.014 is more realistic in most cases. A value of 0.013 was selected for this project. Direct tensile modulus and modulus of rupture are computed using the above equations and from the compressive strength values previously computed. Splitting tensile strength, estimated direct tensile strength and estimated modulus of rupture are plotted for each of the mixtures and shown below in Figure 5.16. 


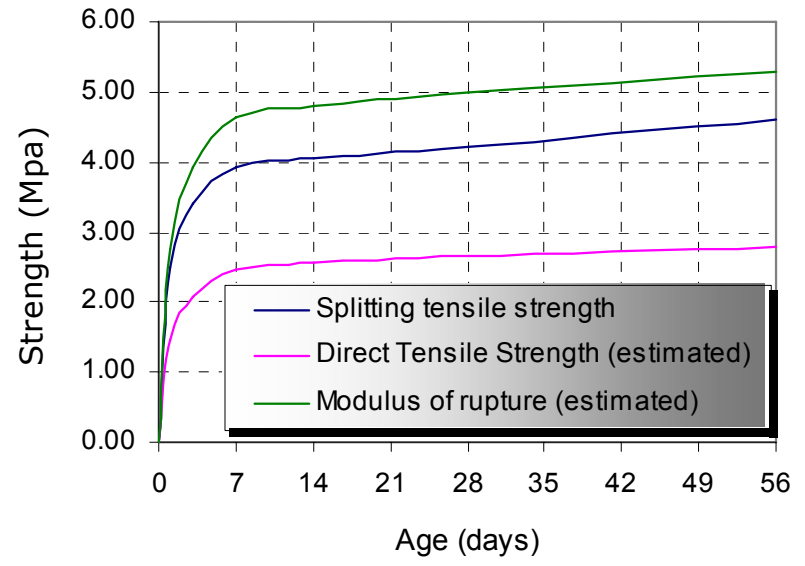

(a)

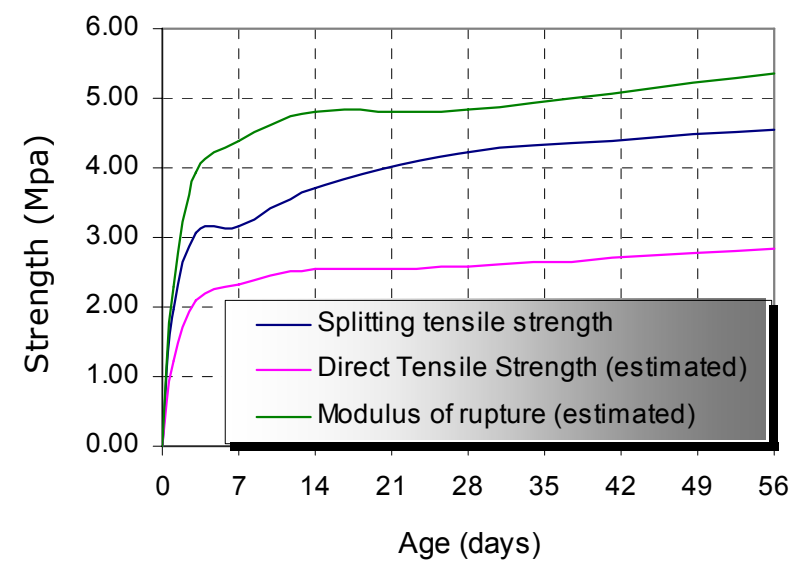

(c)

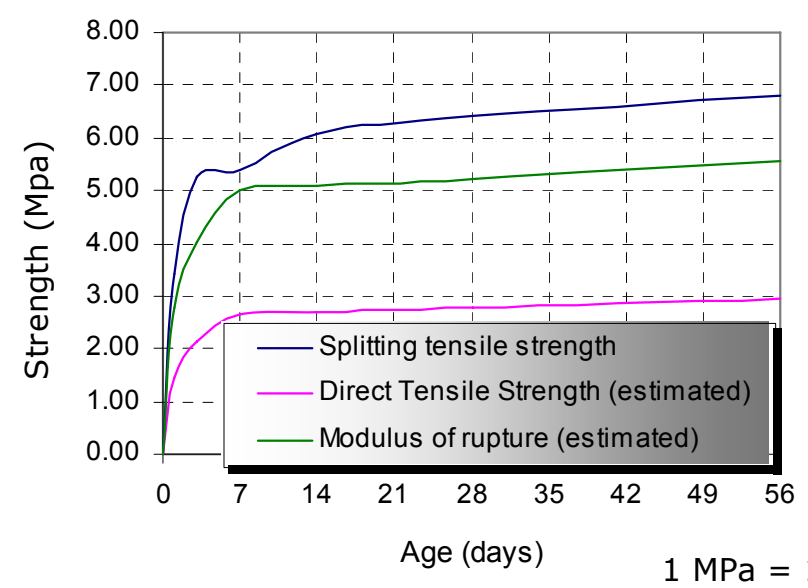

(e)

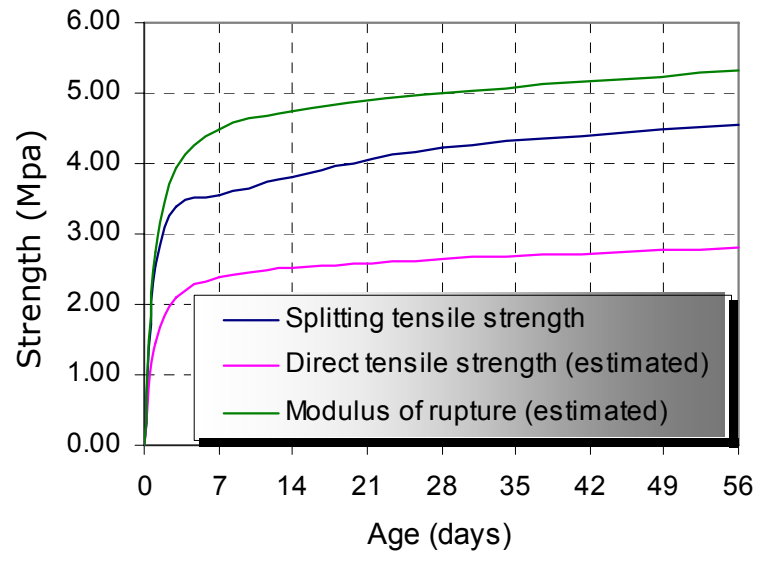

(b)

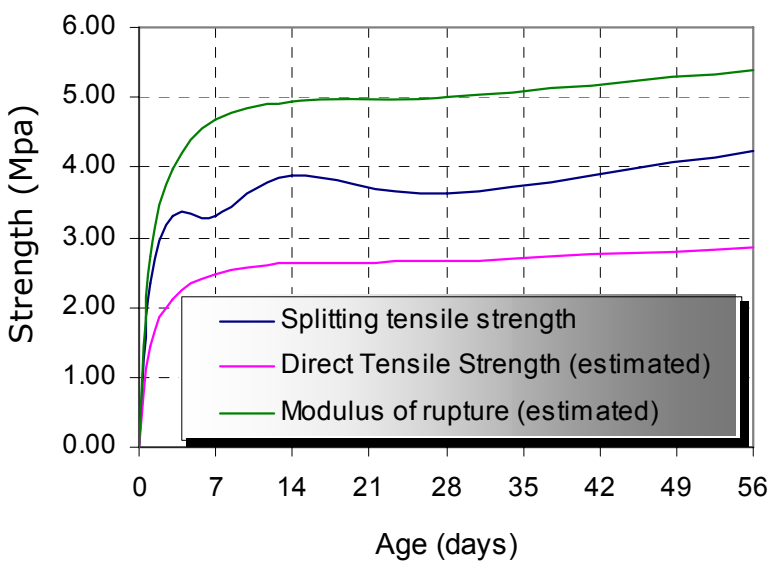

(d)

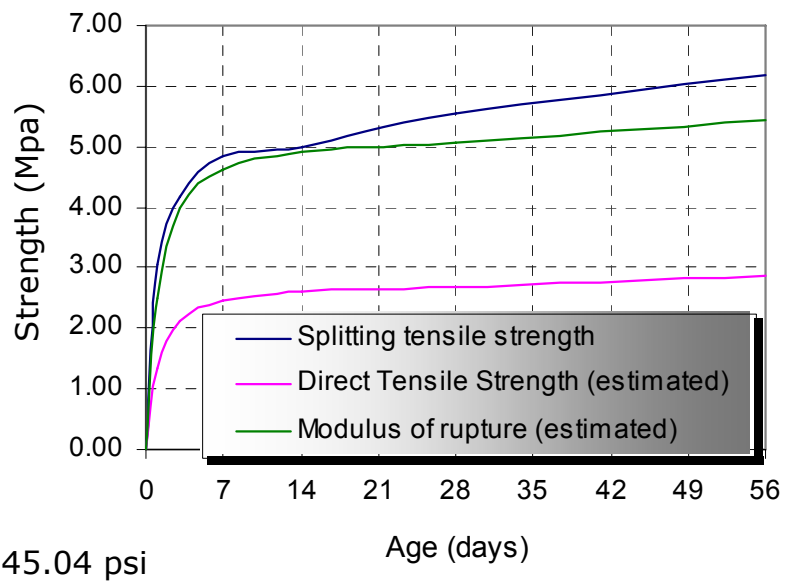

(f)

Figure5.16 Comparison of splitting tensile strength, direct tensile strength and modulus of rupture for (a) SCC A (70-30); (b) SCC B (50-50); (c) SCC C (30-70); (d) SCC D (0-100); (e) SCC E (F) and (f) SCC F (SRA) 
From the above figures, it is observed that splitting tensile strength is higher than direct tensile strength and lower than the flexural strength (modulus of rupture) for the mixtures SCC A (70-30) through SCC D (0-100). Splitting tensile strength for SCC E (F) and SCC F (SRA) are higher than both the direct tensile strength and the modulus of rupture. As the mixtures contained fiber and SRA, it may be possible for them to deviate from the general trend. Other than these two mixtures, others were quite consistent in their relation to direct tensile strength and modulus of rupture.

To study the relation between compressive strength and splitting tensile strength, the ratio of splitting tensile strength and compressive strength were found out at different ages and listed in Table 5.2 below.

\section{Table5.2 - Ratio of splitting tensile strength to compressive strength}

\begin{tabular}{|c|c|c|c|c|c|c|}
\hline \multirow[b]{2}{*}{ Days } & \multicolumn{6}{|c|}{$\begin{array}{c}\text { Ratio of splitting tensile strength to compressive } \\
\text { strength }\end{array}$} \\
\hline & $\begin{array}{c}\text { SCC A } \\
(70-30)\end{array}$ & $\begin{array}{l}\text { SCC B } \\
(50-50)\end{array}$ & $\begin{array}{c}\text { SCC C } \\
(30- \\
70)\end{array}$ & $\begin{array}{l}\text { SCC D } \\
(0-100)\end{array}$ & $\begin{array}{l}\text { SCC E } \\
\text { (F) }\end{array}$ & $\begin{array}{l}\text { SCC F } \\
\text { (SRA) }\end{array}$ \\
\hline 1 & 0.13 & 0.14 & 0.15 & 0.13 & 0.18 & 0.20 \\
\hline 3 & 0.09 & 0.09 & 0.08 & 0.08 & 0.13 & 0.11 \\
\hline 7 & 0.07 & 0.07 & 0.07 & 0.06 & 0.09 & 0.09 \\
\hline 14 & 0.07 & 0.07 & 0.07 & 0.06 & 0.09 & 0.08 \\
\hline 28 & 0.07 & 0.07 & 0.07 & 0.06 & 0.10 & 0.09 \\
\hline 56 & 0.07 & 0.07 & 0.06 & 0.06 & 0.09 & 0.09 \\
\hline
\end{tabular}

It is observed from the above table is the same ratio of splitting tensile strength to compressive strength for SCC mixtures SCC A (70-30) through SCC D (0100) for 7-day, 14-day, 28-day, and 56-day. All of them had a value of $0.06 \sim 0.07$. The ratios for the early age are greater than 0.07. For the SCC mixtures with fiber and SRA the ratio of splitting tensile strength to compressive strength for 7-day, 14day, 28-day, and 56-day were 0.08 0.10. The early age strength for SCC E (F) and SCC F (SRA) varies from 0.11 to 0.20 .

Hence it can be concluded that the ratio for splitting tensile strength to compressive strength for ordinary SCC mixtures can be safely assumed as 0.06 . Here ordinary meant mixtures without fibers or SRA or any special type of materials. This proposition is valid at 7 or more days after casting. The ratio of 0.06 can be assumed for 0 through 7 days but it'll be highly conservative. It is to be noted here that these values originated from the test results on only six mixtures that contained LP. Hence more test results are required to validate the proposed statements. 


\subsection{Concluding Remarks}

In this chapter the compressive strength of all the 17 SCC mixtures were evaluated at 7 days and 28 days after casting. Six SCC mixtures based on their performance and other criteria's were selected among these 17 mixtures. Detailed analysis regarding the compressive strength and splitting tensile strength of these selected six mixtures were presented in this chapter. The compressive strengths of the 17 mixtures were very high compared to normal vibrated concrete mixtures. In general, mixtures containing LP showed very high early strength compared to other mixtures. Mixtures containing fiber and SRA gained maximum strength among all the mixtures. When compared to the aggregate fraction, it was observed that mixtures containing higher CA 25 with LP gained maximum strength compared to any other combination of aggregate gradation. Mixtures containing LP gained high early strength but strength increment from 7-day to 28-day was highest for SL+SF mixtures followed by FA+SF mixtures. There was a definite trend between the $w / p$ ratio and the compressive strength. Higher the $\mathrm{w} / \mathrm{p}$ ratio, lower the strength and vice versa. There exist definite correlations between compressive strength and paste volume for all the mixtures. Compressive strength was higher for the concretes made with higher paste volume. No definite correlation between CF or WF and compressive strength was observed which may be attributed to the fact that there were interrelated effects of $w / p$ ratio, paste volume, and chemical admixtures on the compressive strength of SCC. The compressive strength values of the selected SCC mixtures were compared with the ACI prediction equation of compressive strength and it was observed that $\mathrm{ACI}$ equation underestimates the early age compressive strength of the LP mixtures. A correction factor $\gamma_{C F}$ was developed to calibrate the ACI equation for the LP mixtures. Splitting tensile strength values were found to be higher than direct tensile strength and lower than the flexural strength (modulus of rupture) with exceptions of the mixture containing fiber and the mixture containing SRA. It can be also concluded that the ratio for splitting tensile strength to compressive strength for ordinary SCC mixtures containing LP, can be safely assumed as 0.06. The drying shrinkage, autogenous shrinkage, and restrained shrinkage properties of the selected SCC mixtures are studied in detail in the next chapter. 


\section{CHAPTER SIX}

\section{SHRI NKAGE AND CRACKI NG OF SELECTED SCC MI XTURES}

\subsection{I ntroduction}

In this chapter the free and autogenous shrinkage of the selected SCC mixtures will be investigated. There are many conflicting observations on shrinkage of SCC. Some researchers reported that shrinkage of SCC is comparable to that of normal concrete; other researchers observed that drying and autogenous shrinkage in SCC is higher than normal concrete as detailed in Chapter 2 . The increase in shrinkage may be due to higher finer contents, higher paste volume, different admixture effects, and different water-powder ratios compared to normal concrete. Also, an investigation of the early age mechanical behavior of SCC by Ambrosia et al. (2005) has revealed a potentially high risk for cracking at early age. The main factors which contribute to the cracking risk are stress developed by autogenous shrinkage at early age and diminished creep capacity in low $\mathrm{w} / \mathrm{cm}$ ratio materials. Hence, in this chapter the total, drying and autogenous shrinkage of the selected SCC mixtures will be evaluated. The shrinkage values will be compared with few existing models and will be calibrated to a model which is the closest one to the values generated from the experiment. Restrained shrinkage test is a useful method to evaluate the cracking potential of concrete mixtures. As the test setup is relatively simple and easy to implement; more and more researchers are

increasingly using this test. Additionally, ring test can provide sustained and sufficient restraint to induce the cracking for common size specimens which makes it more suitable for laboratory use. As the ring specimen is axisymmetric, it helps in the analysis part too.

In this study, the AASHTO type ring specimen test was adopted to investigate the restrained cracking behavior of the selected mixtures with LP. Also the effect of aggregate gradation, compressive strength, effect of fiber and SRA on cracking will be investigated. Cracking potential of the mixtures will be investigated using ASTM C 1581-04. 


\subsection{Free Shrinkage of SCC Mixtures}

In this section the shrinkage of the selected six mixtures will be investigated as described earlier. The shrinkage values from the experiment will be compared to different standard existing models and will be calibrated with the closest model among them. The effect of autogenous shrinkage on total shrinkage of SCC will also be investigated.

\subsubsection{Test Procedure}

Free shrinkage test was conducted as per ASTM C 157/ AASHTO T 160. For every selected mixture, four $76.2 \mathrm{~mm} \times 76.2 \mathrm{~mm} \times 311.2 \mathrm{~mm}$ ( 3 in $\times 3$ in $\times 11.75$ in) prisms were cast. Two of them were used to evaluate free shrinkage and the rest of them were used to evaluate autogenous shrinkage. After one day curing under wet burlap, the prisms were demolded and kept in a environmental chamber with the temperature of $23 \mathrm{C}(73 \mathrm{~F})$ and relative humidity of $50 \%$. The onset of drying after one day was selected to capture shrinkage from early age.

Strain measurements were performed by embedding vibrating wire strain gauges (VWSG) of gauge length $100 \mathrm{~mm}$ (4 in) in the center of the molds. The main reason for using the VWSG was to eliminate human error in recording the strains through the length comparator and due to its high sensitivity. Vibrating wire principle is used in this type of strain gauges; a length of steel wire is tensioned between two end blocks that are embedded in concrete. Strain changes of the concrete mass results in relative movement of the end blocks, which in turn causes tension in the steel wire. This tension is measured by plucking the wire and the resonant frequency is measured by using an electro magnetic coil. The other advantages of this type of strain gauges are excellent long term stability, maximum resistance to the effects of moisture and suitable for transmission over long ranges. The VWSG was also used to measure the autogenous shrinkage and temperature right from the begining of the tests. the VWSG was suspended in the center of the prism mold using metal ties connected to the rigid part of the mold in both the free shrinkage and the autogenous shrinkage specimens. The autogenous specimens were carefully wrapped in plastic and aluminum foils to prevent loss of moisture in the surrounding. The specimens were demolded after 24 hours of casting and left dry in the humidity chamber in order to measure the shrinkage. The VWSG was connected to a data logger which recorded strains for every 10 minutes until 90 days after casting. Figure 6.1 shows the molds for free shrinkage and autogenous shrinkage with the VWSG. Figure 6.2 shows the storage and entire test set up for the shrinkage test. 


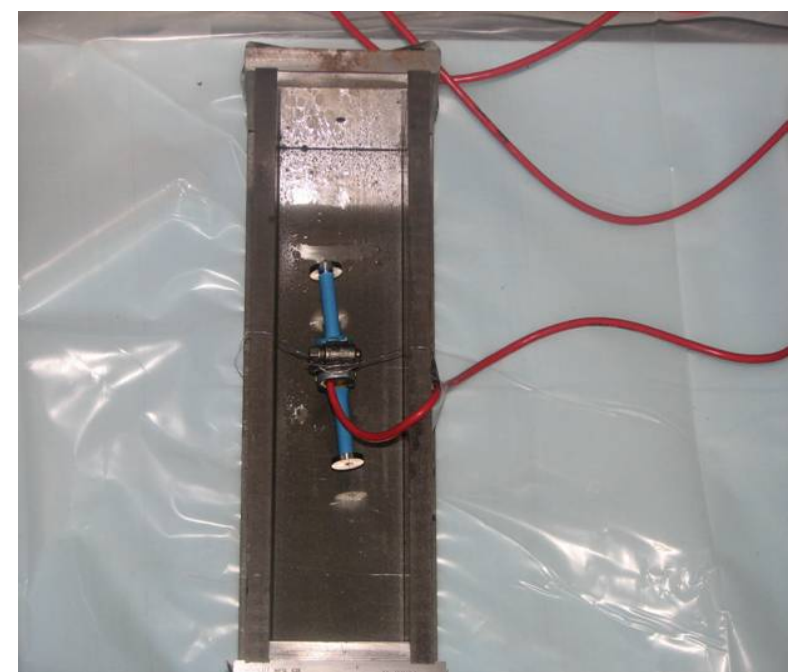

(a)

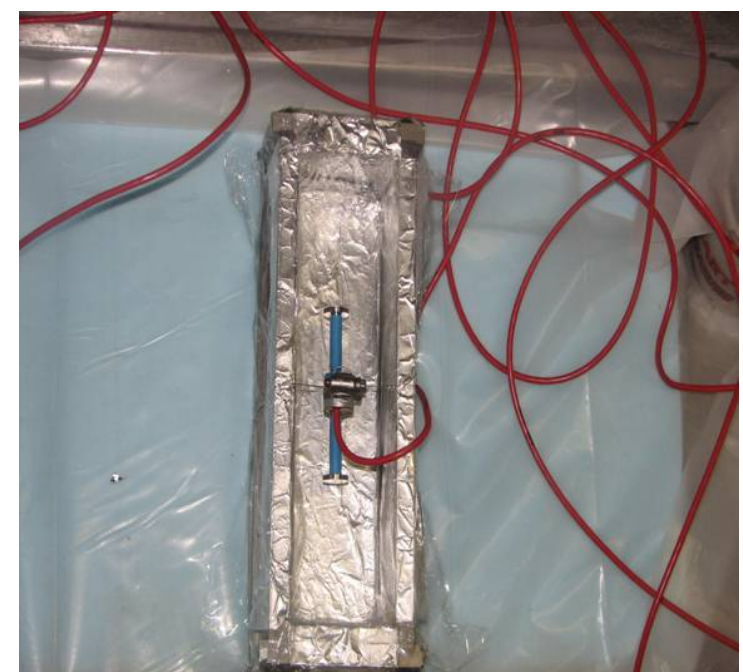

(b)

Figure6.1 Test set up for (a) drying shrinkage (b) autogenous shrinkage

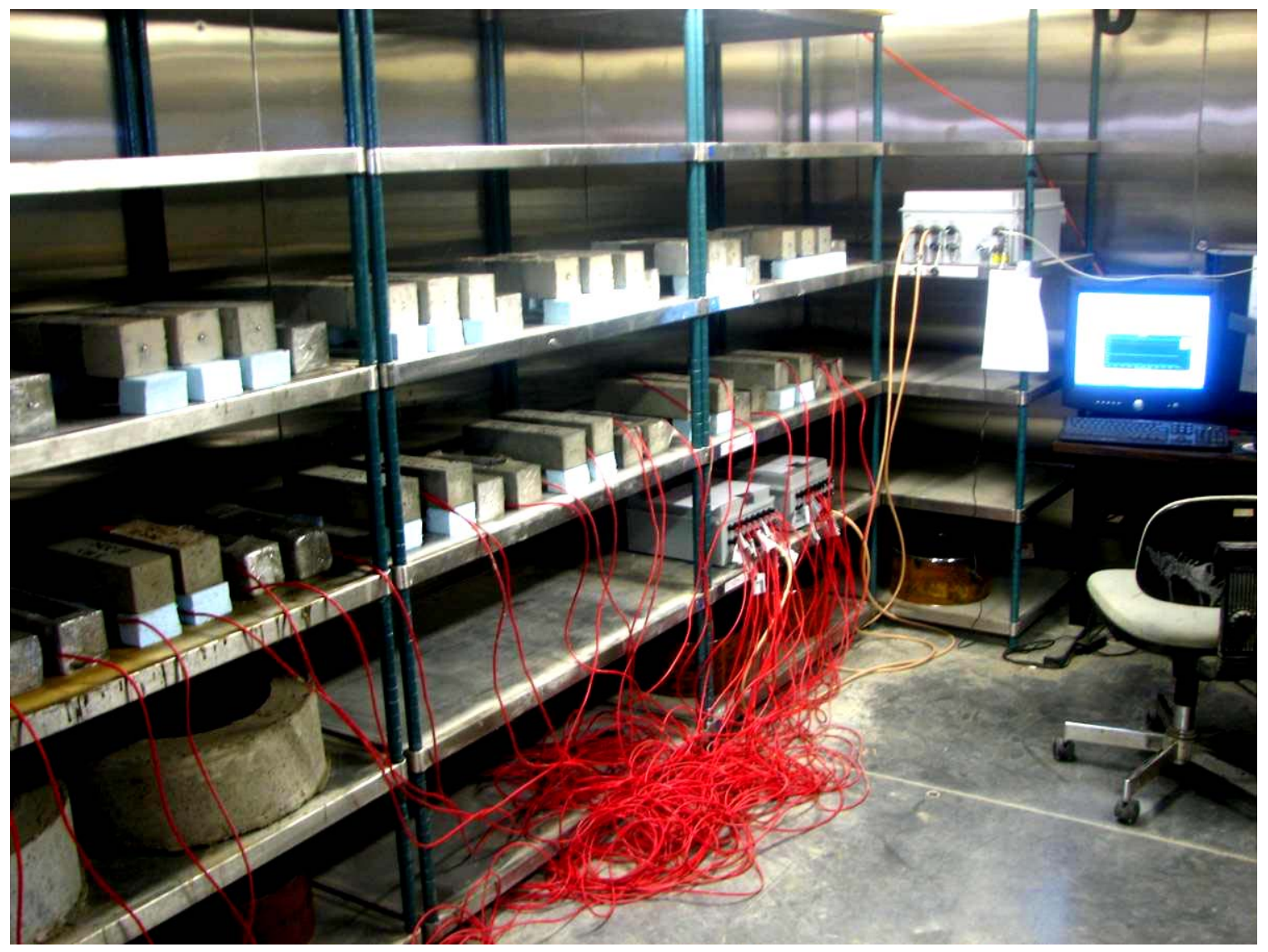

Figure6.2 Test set up for shrinkage test in the laboratory 


\subsubsection{Test Results}

Figure 6.3 shows the free shrinkage and autogenous shrinkage graphs for the six SCC mixtures. Two lines were drawn for the two free shrinkage samples and another two for the autogenous shrinkage sample. The average values for these two are also plotted in the graphs for free and autogenous shrinkage both.

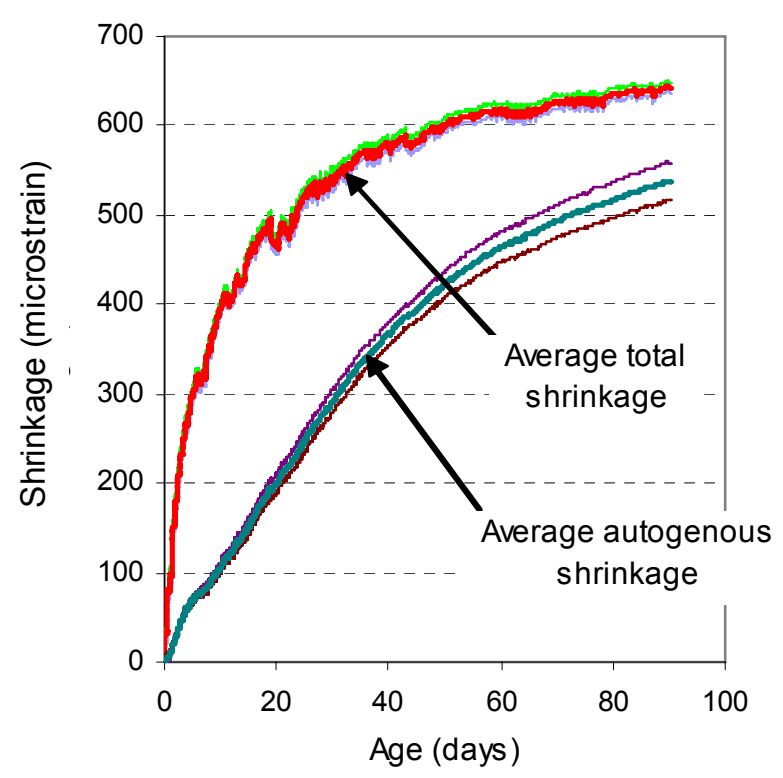

(a)

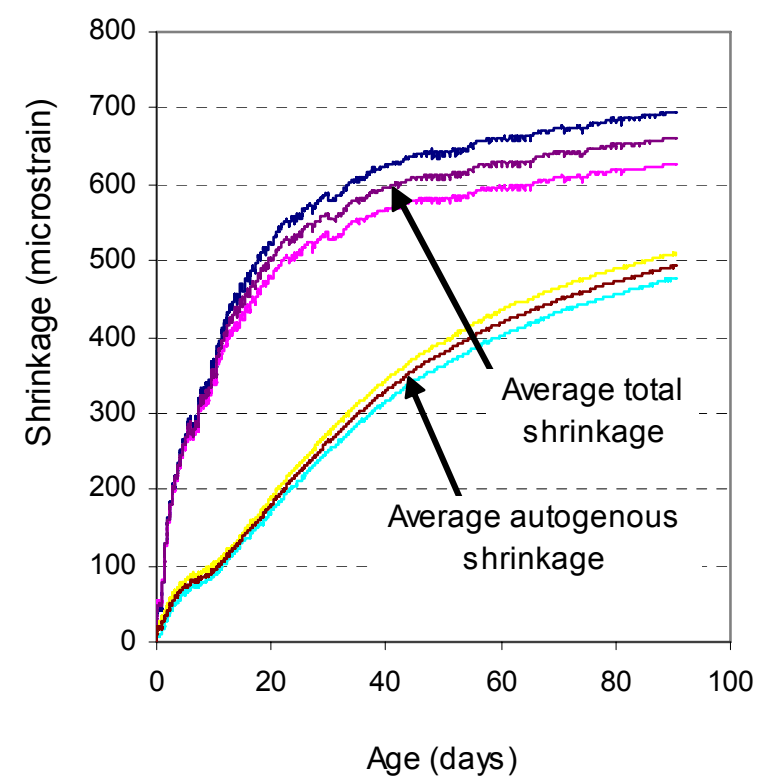

(c)

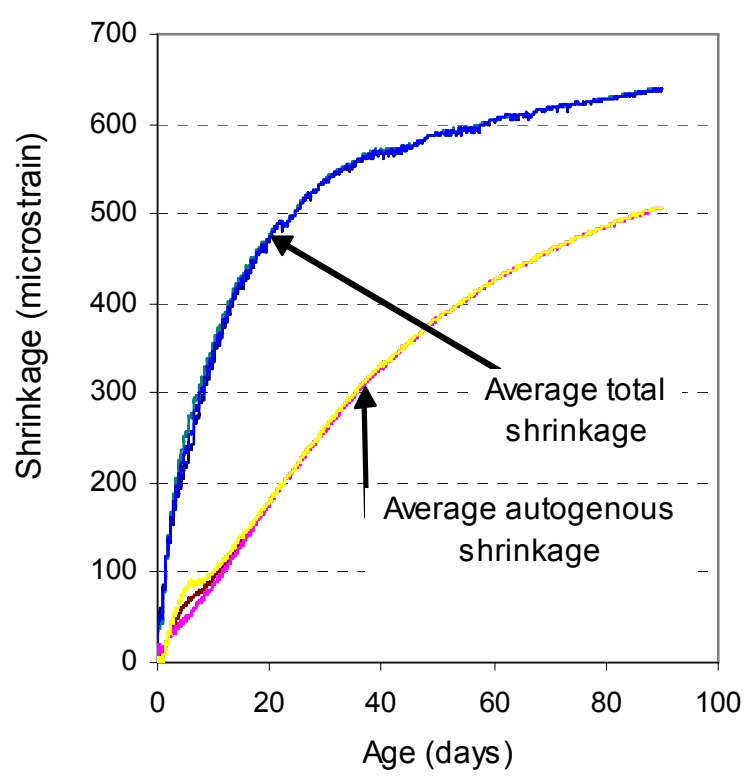

(b)

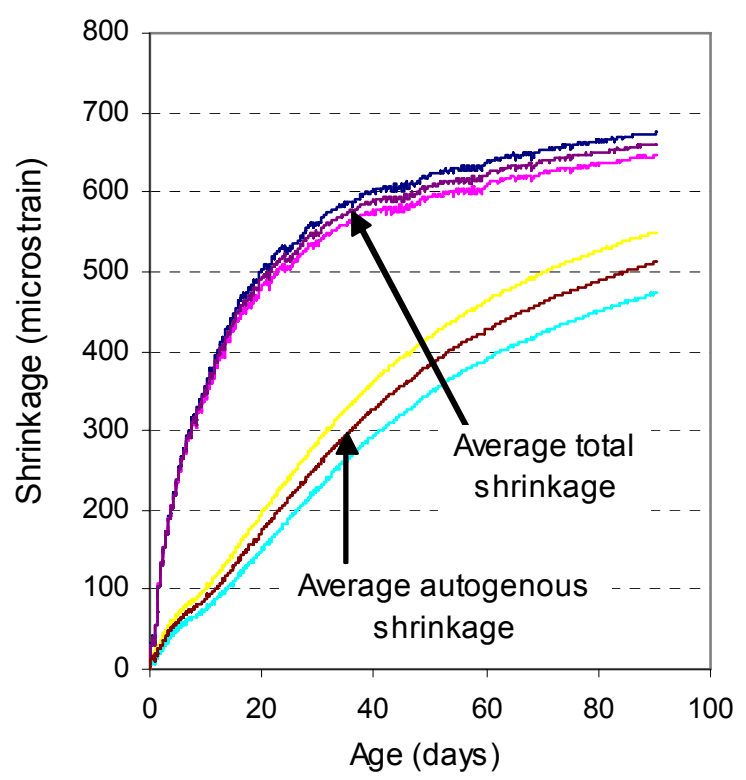

(d) 


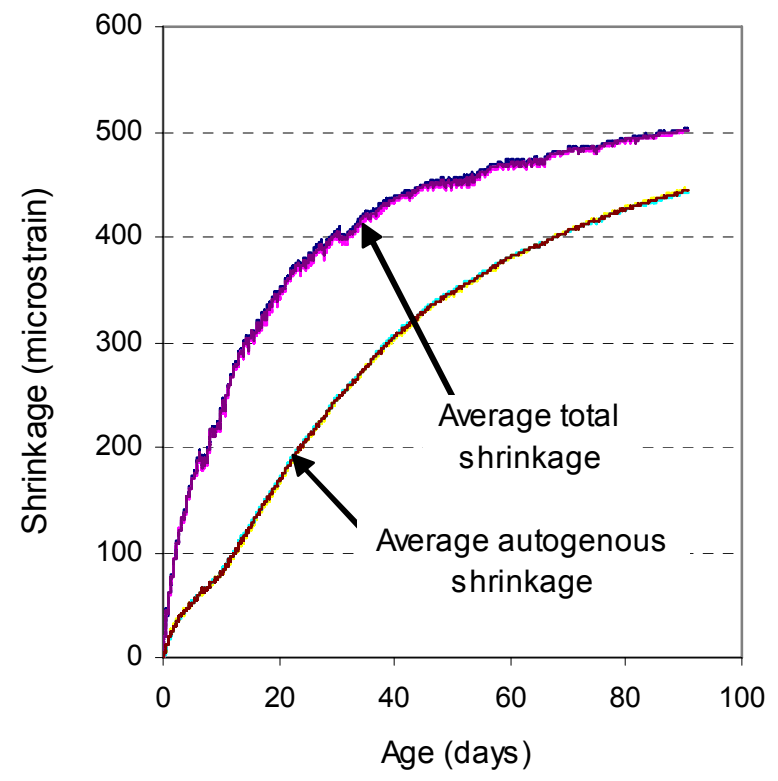

(e)

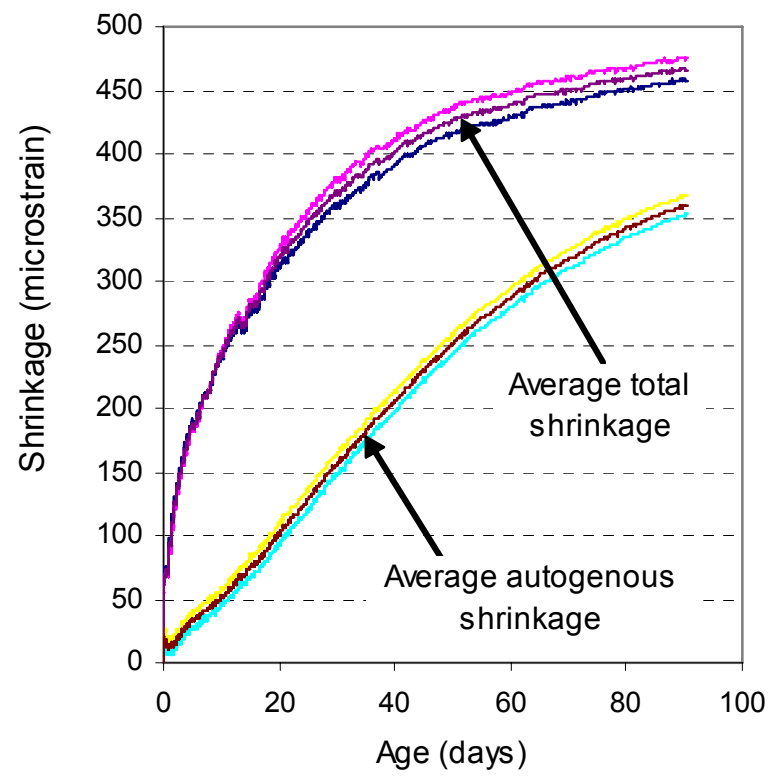

(f)

Figure6.3 Total and autogenous shrinkage test results for (a) SCC A (70-30) (b) SCC B (50-50) (C) SCC C (30-70) (d) SCC D (0-100) (e) SCC E (F) (f) SCC F (SRA)

Figures 6.3(a) through (f) show that the shrinkage values obtained from duplicate specimens were very consistent for all cases. From the above figures it was observed that SCC C (30-70) and SCC D (0-100) achieved a highest shrinkage of 660 micro strains in 90 days compared to 640 micro strains achieved by SCC A and SCC B. As the $\mathrm{w} / \mathrm{cm}$ ratio, $\mathrm{w} / \mathrm{p}$ ratio, paste volume, aggregate-paste volume, CA/FA ratio, S/A ratio of the above mentioned four SCC mixtures are almost same; the 90-day shrinkage values of the mixtures were very close. The SCC mixtures containing fiber and SRA behaved differently than the other mixtures. SCC E (F) had a very low shrinkage value of 500 micro strains and SCC F (SRA) had the lowest shrinkage value of 465 micro strains after 90 days. The shrinkage reducing admixture had a huge impact on the shrinkage strains as it has been reduced by almost $1 / 3^{\text {rd }}$ compared to the other mixtures. It is noted from the above figures that autogenous shrinkage contributed immensely on the total shrinkage of the concrete. As stated earlier, the total shrinkage contains autogenous shrinkage and drying shrinkage due to external drying both. To find out the nature of drying shrinkage, autogenous shrinkage values were deducted from the free shrinkage values. The following figures were plotted to compare the different shrinkage values among the concretes and also to compare the behavior of the mixtures subjected to drying and autogenous shrinkage. 


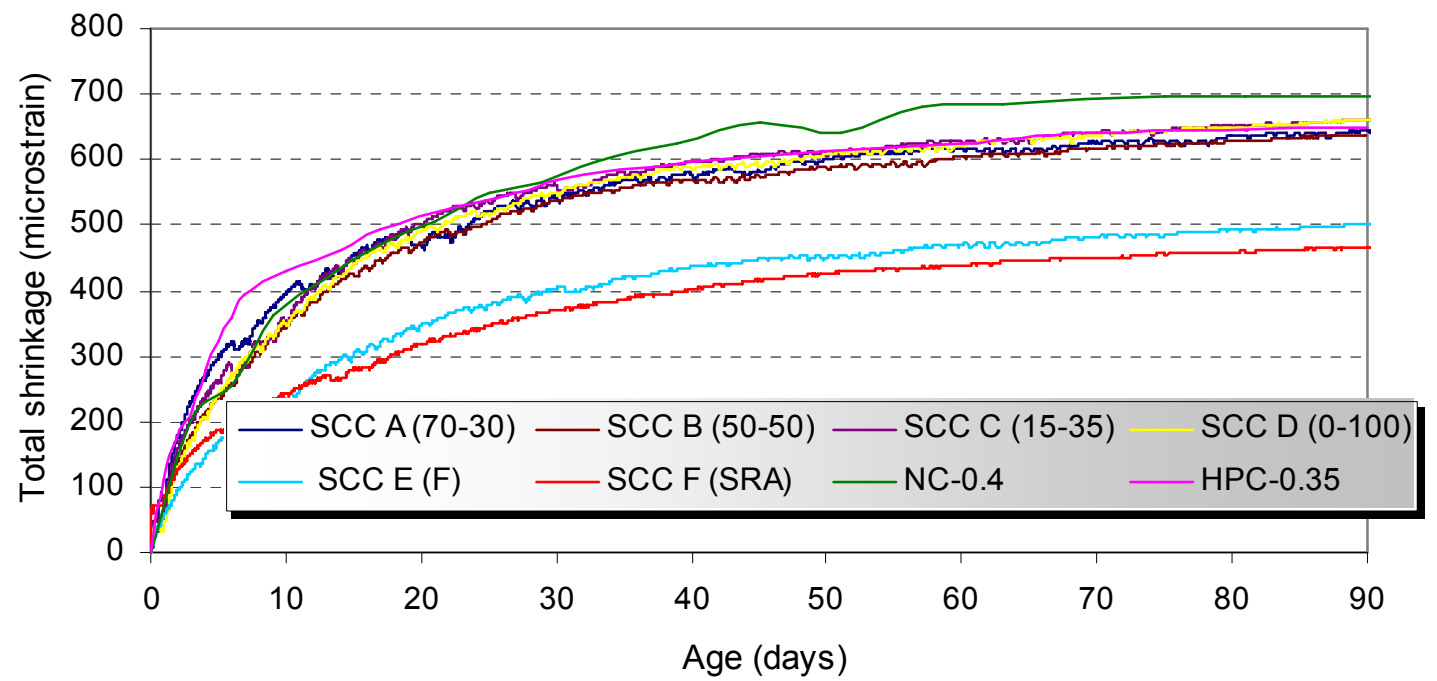

Figure 6.4 Total shrinkage test results for selected SCC mixtures

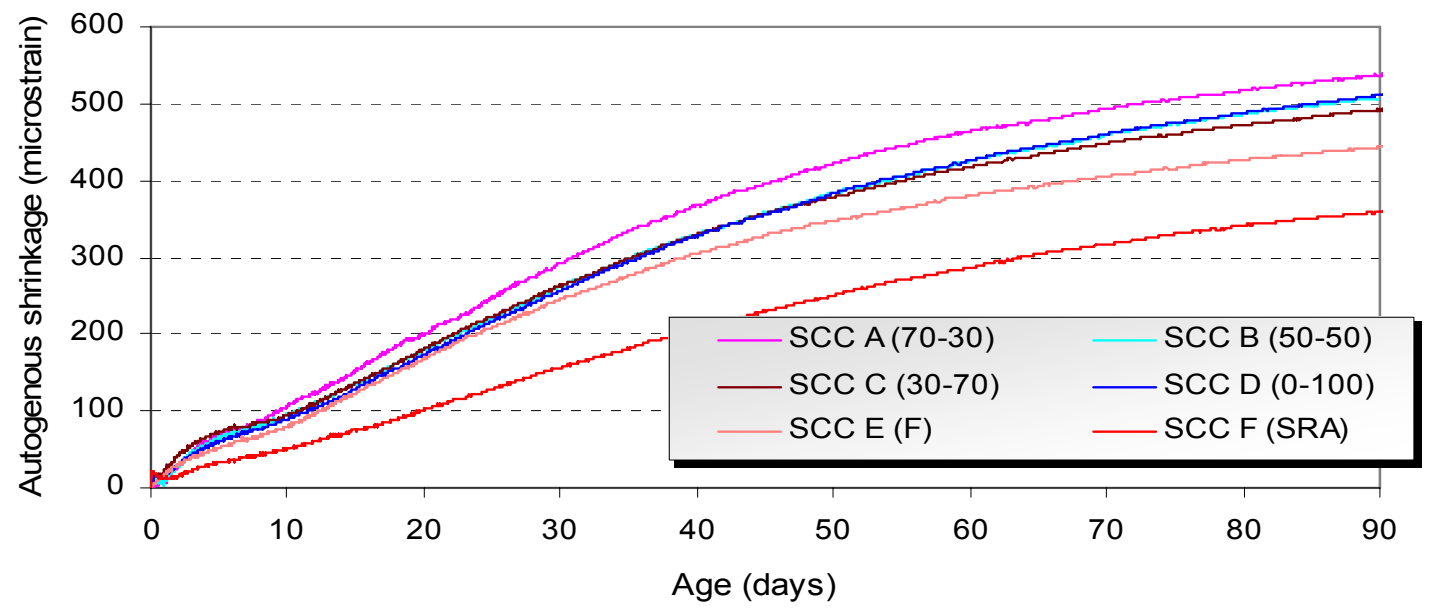

Figure 6.5 Autogenous shrinkage test results for selected SCC mixtures

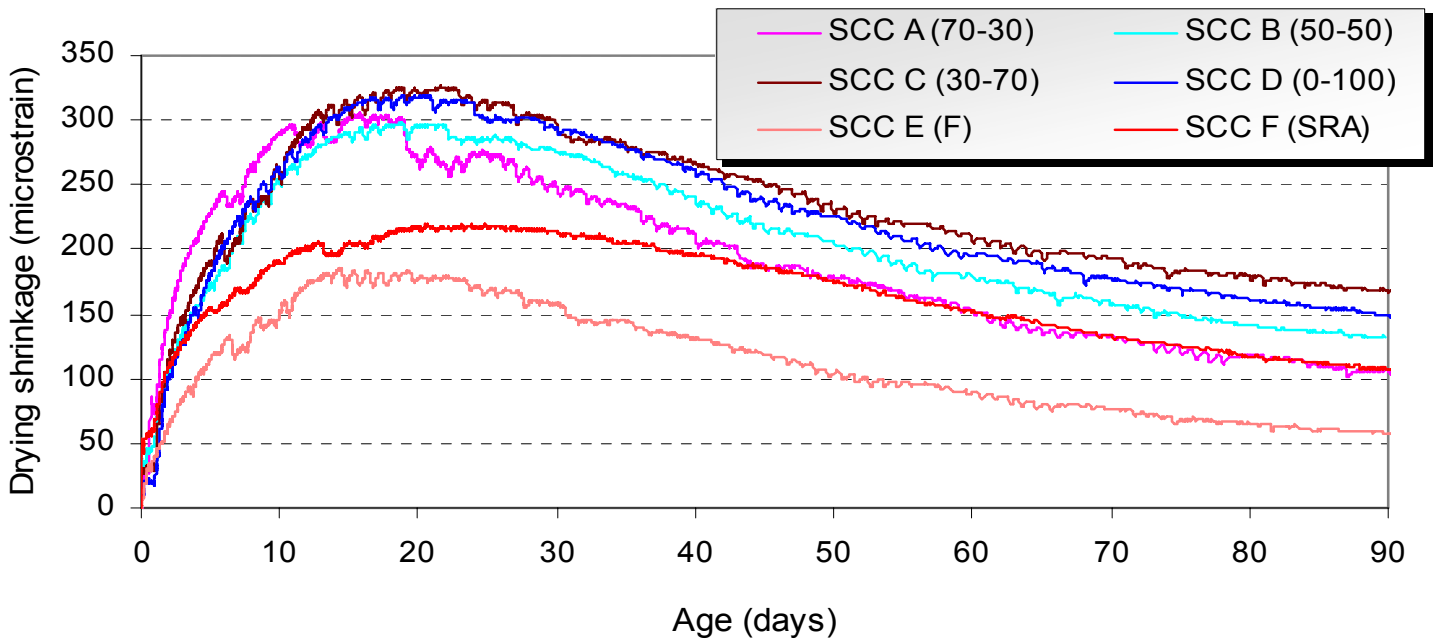

Figure6.6 Drying shrinkage (due to external drying) test results for selected SCC mixtures 
Figure 6.4 shows the total shrinkage against time for the six selected mixtures. Also the shrinkage values for a typical normal concrete (NC) (Chatterjee, 2004) and a high-performance concrete (HPC) (Gong, 2006) were incorporate in Figure 6.4 for comparison purpose. It is noted from the figure that total shrinkage of all the SCC mixtures followed the similar pattern with SCC D (0-100) having the highest value and SCC F (SRA) being the lowest. Though the total shrinkage values of all the mixtures were similar, a comparison relative to their aggregate gradation reveals the fact that the mixtures containing higher CA $25 \mathrm{~mm}$ resulted in less shrinkage compared to the mixtures which contain more CA $12.5 \mathrm{~mm}$. This is due to the restraining effect of the coarse aggregates as discussed in Chapter 2. Similar observations can be made comparing the total shrinkage values to the CF. Figure 6.7 shows the plot between CF and total and autogenous shrinkage. It can be seen that higher the $\mathrm{CF}$, lower the shrinkage. As the number of sample were very low, more experiments should be conducted before coming to a general conclusion, but there was definitely a trend between them as shown by the red line in the following figure.

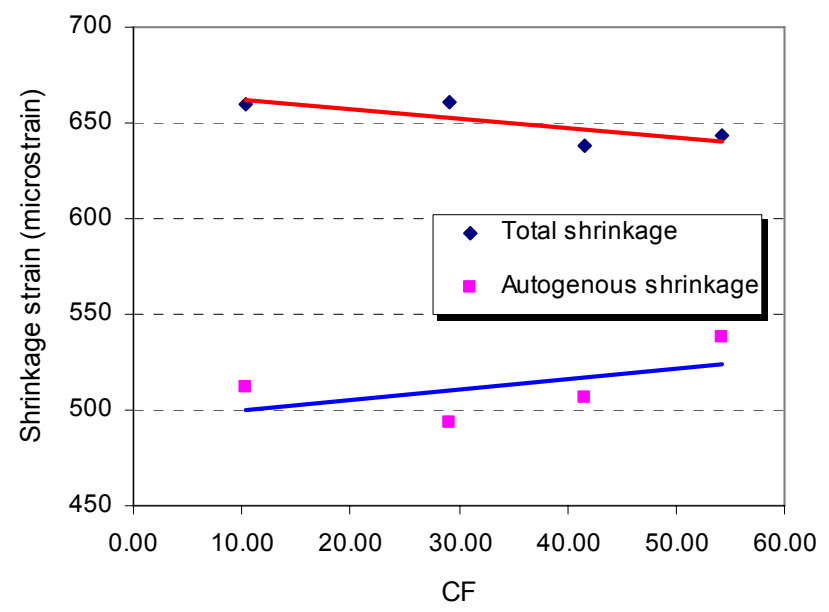

Figure6.7 CF versus Total and autogenous shrinkage

Figure 6.5 shows the autogenous shrinkage of all the six SCC mixtures prepared in the laboratory. Some interesting facts are revealed by studying the graph as follows: SCC A (70-30) had the highest autogenous shrinkage, though the total shrinkage of SCC A is less than SCC D (0-100) and SCC C (30-70). The long term autogenous shrinkage values of all SCC mixtures were very high. This may be due to the lower $w / c m$ and lower $w / p$ ratio responsible for higher self-desiccation. SCC F (SRA) had the lowest autogenous shrinkage followed by SCC E (F) among all the mixtures. It may be noted that the mixture containing fiber not only had a lower 
total shrinkage but also was superior in terms of autogenous shrinkage compared to other SCC mixtures except the one with SRA. There may exist a relation between autogenous shrinkage and CF as seen from Figure 6.7. Increased CF resulted in increased autogenous shrinkage which is shown by the blue trend line in the figure. More data will be required to support the fact. Another important fact revealed from the tests was the percentage of autogenous shrinkage over the total shrinkage at 90 days after casting. The ratio of autogenous shrinkage and total shrinkage varied between 0.75 and 0.80 for all the mixtures except SCC E (F) which had a high ratio of 0.88 . This is due to the fact that the concrete containing fibers were less porous and higher self-desiccation caused high autogenous shrinkage. Another important observation could be the development of autogenous shrinkage and temperature change in mixture due to hydration. The VWSG used in the study were able to monitor the temperature along with the strains facilitating the investigation.

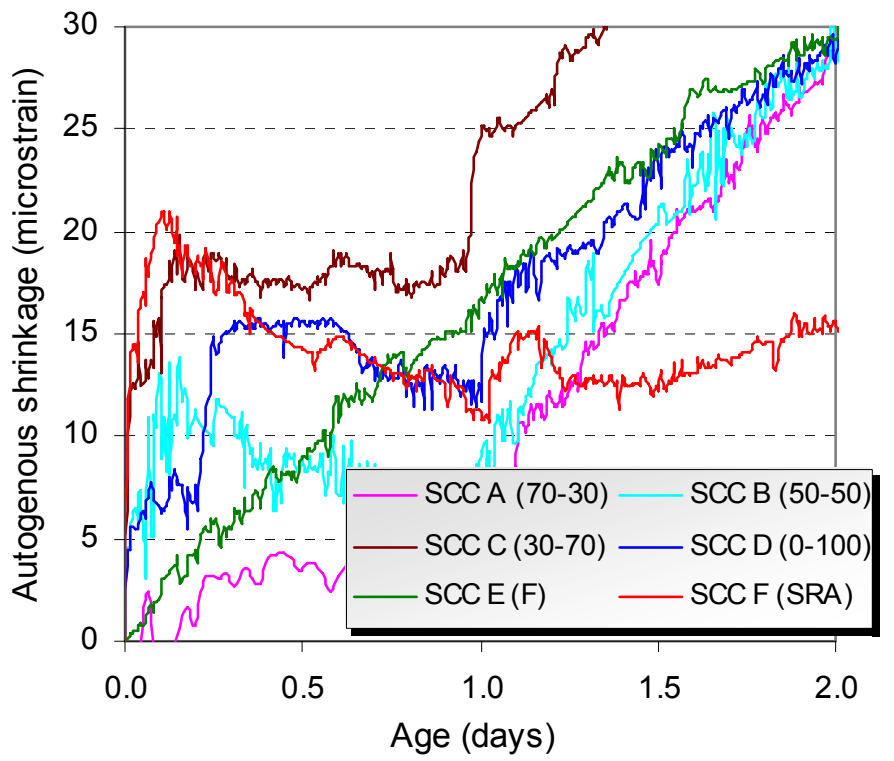

(a)

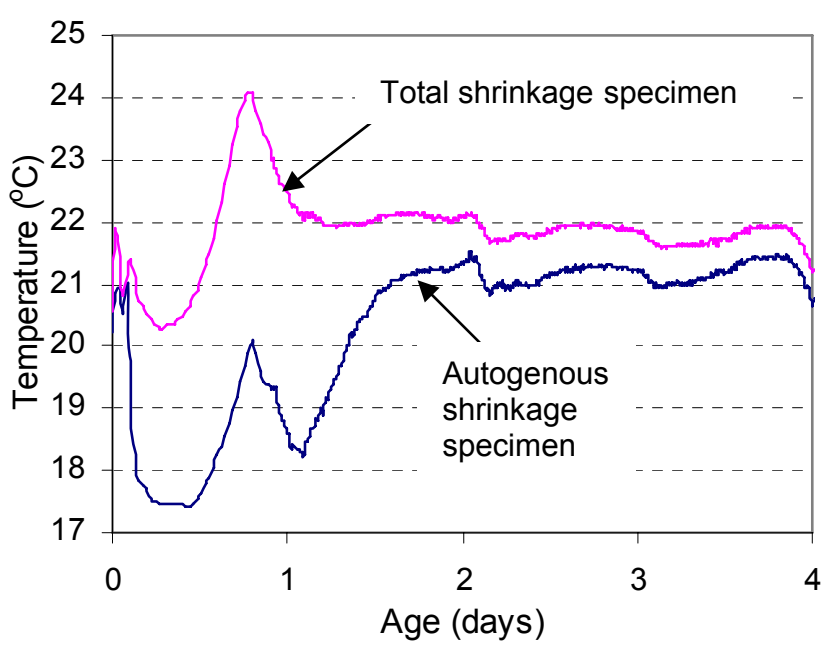

(b)

Figure6.8 (a) Early age autogenous shrinkage (b) Temperature change within concrete after casting

Figure 6.8 (a) shows the early age autogenous shrinkage of the SCC mixtures with time. All of them had an initial hump at around 12 hours and then a gradual incremental phase. SCC E (F) did not follow that path, instead followed in a straight path right from the beginning. All the mixtures after one day followed an upward 
path except from SCC F (SRA) which followed a path parallel to the time axis initially. That was the effect of SRA which reduced the autogenous shrinkage.

Figure 6.8 (b) shows the change in temperature after casting for the total shrinkage specimen and the autogenous shrinkage specimen for a typical mixture. In the initial stages, the rate of heat evolution was much less for an autogenous shrinkage specimen as it was wrapped in plastic to prevent moisture loss to outside. The less rate of heat evolution signified less shrinkage. Figure 6.9 shows a typical curve showing rate of heat evolution during hydration of Portland cement.

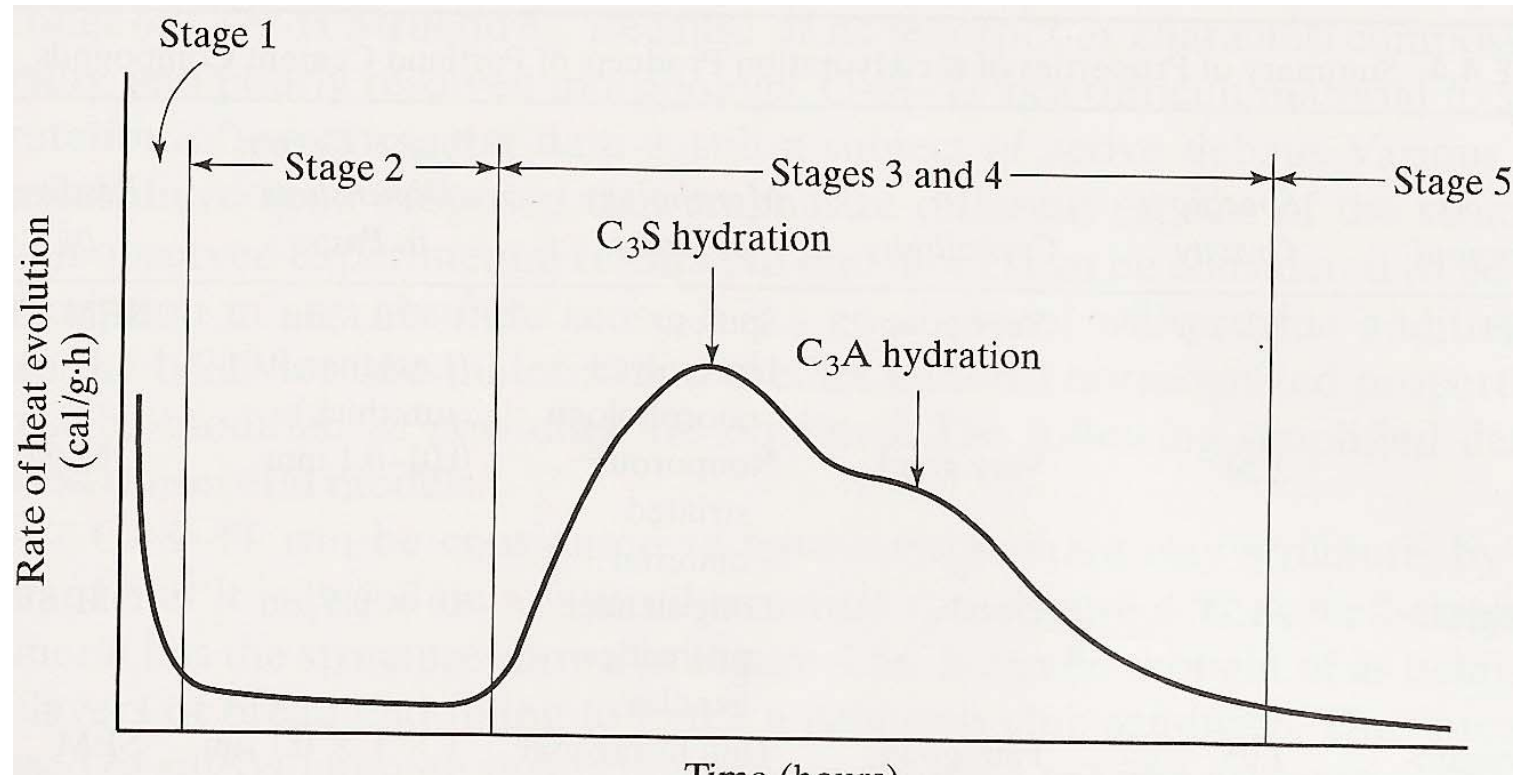

Time (hours)

Figure6.9 Rate of heat evolution for typical portland cements (Reproduced from Mindess et al., 2003)

As temperature is a direct measurement of heat, figure 6.8 (b) can be compared with figure 6.9 above. It is seen that the two curves resemble very closely and each stage can be identified from the data achieved from the experiments. Stage 1 is period of rapid evolution of heat which is followed by a period of relative inactivity. This period is called as induction or dormant period (stage 2). Stage 3 is termed as acceleration period reaching a maximum rate of heat evolution. The next phase is termed as deceleration period (stage 4) and the last stage is called steady state (stage 5). From Figure 6.8 , it is also noted that steady state is achieved for the autogenous shrinkage samples after a jump in temperature from stage 4. This combined with stage 3 and stage 4 may attribute to the early age strength gain of the LP mixtures. 


\subsubsection{Comparison and discussion of experimental values with NC, HPC and SCC mixtures from other studies}

It can be seen from Figure 6.4 that the 90-day value of shrinkage for NC, HPC and the SCC mixtures were close. SCC E (F) and SCC F (SRA) were excluded from this discussion as they contain fiber and SRA. Instead other SCC mixtures can be compared in general with other values. NC shrinkage value was the highest and the shrinkage value for the HPC and the SCC mixtures were really close. The 90-day shrinkage value for the SCC mixtures varied between 640 microstrains to 660 microstrains. An extensive database of shrinkage values for SCC presented by Gomez and Landsberger (2007) reveal that experimental shrinkage strains for SCC vary between 40 and 1210 microstrains with an average mean value of 540 microstrains. In case of NC, the strains vary between 253 and 980 microstrains with a mean value of 581 microstrains. The experimental values were well within that range and close to the average. Also, Ambrosia et al. (2005) reported a free shrinkage value varied between 500 to 800 microstrains with a w/cm ratio varied from 0.34 to 0.41 . It is also observed that the shrinkage of NC, HPC and the SCC mixtures were similar. There were many contradictory opinions regarding the shrinkage of SCC mixtures due to its higher fine content and different paste volume fraction compared to NC. A strict comparison of the shrinkage values is problematic due to the differences in formulation, admixture types, pozzolan types, procedure and specimen size, humidity condition, and type of fillers (Bomen and Shah, 2005). They reported that the shrinkage of SCC tends to be greater than ordinary concrete. However, substitution of cement by non-pozzolanic filler substantially decreases the drying shrinkage.

It is very difficult to correctly predict and compare the shrinkage values of SCC due to its wide variability as discussed above. But one thing can be concluded from the results that the shrinkage values for SCC A (70-30) through SCC D (0-100) are not significantly different from the normal concrete and the HPC. Similar observation was also reported by Gomez and Landsberger (2007). 


\subsubsection{Comparison and Prediction of Free Shrinkage}

Several models exist associated with the prediction of shrinkage of concrete. Among those models, the ACI 209R (1992), CEB MC90-99, B3 model by Bazant (1996) and AASHTO Specification (2000) are the most widely used models in practice. The following section lists the equations for those four models as well as the prediction model for HPC proposed by Gardner and Lockman, 2001. Then, a comparison between these predictions and the present experimental data is given, followed by a proposed model developed in this study following ACI 209R.

\subsubsection{Shrinkage models}

\subsubsection{1 $\mathrm{ACl}$ prediction equation}

ACI prediction equation for is in the following form-

$\left(\varepsilon_{s h}\right)_{t}=\frac{t^{\alpha}}{f+t^{\alpha}}\left(\varepsilon_{s h}\right)_{u}$

where $\mathrm{f}$ is in days and $\alpha$ is a constant and $\left(\alpha_{s h}\right)_{u}$ is the ultimate shrinkage strain and $t$ is time from the end of initial curing. Normal ranges of the above mentioned constants are-

$\alpha=.9$ to 1.3

$f=20$ to 130 days

$\left(\alpha_{s h}\right)_{u}=$ is ultimate shrinkage with values between 415 to $1070 \times 10^{-6}$ in/in $(\mathrm{m} / \mathrm{m})$

$\mathrm{t}=$ time from end of initial curing

Based on normal weight, sand light weight and all light weight concretes using both moisture and steam curing the appropriate value of $\alpha$ and $\left(\alpha_{s h}\right)_{u}$ were determine as 1 and $780 \times 10-6 \mathrm{~m} / \mathrm{m}$ respectively. These values are presented by ACI 209R. Therefore the recommended equation for shrinkage under standard conditions is $\left(\alpha_{s h}\right)_{t}=\frac{t}{35+t}\left(\varepsilon_{h}\right)_{u}$ for shrinkage after 7 days of moist cured concrete.

$\left(\alpha_{s h}\right)_{t}=\frac{t}{55+t}\left(\varepsilon_{h}\right)_{u}$ for shrinkage after 1-3 days of steam cured concrete.......

ACI has also recommended different correction factors to ultimate shrinkage strain value when the conditions are different than the ones mentioned above. 
Different corrections are described below:

1. Differential shrinkage: For shrinkage considered for other than 7 days for moist cured concrete and other than 1-3 days for steam cured concrete, the difference in equations 2.11 and 2.12 (as the case may be) is determined for any period starting after this time.

2. Initial moist curing: To determine shrinkage of concrete moist cured other than 7 days moist curing a $\mathrm{cp}$ y factor is used. Table 2.1 shows $\mathrm{cp}$ y factor corresponding to different moist curing duration.

Table6.1 - Correction for $\gamma_{c p}$

\begin{tabular}{c|c}
\hline $\begin{array}{c}\text { Moist curing } \\
\text { duration, days }\end{array}$ & $\gamma_{\mathbf{c p}}$ \\
\hline 1 & 1.2 \\
3 & 1.1 \\
7 & 1.0 \\
14 & 0.93 \\
28 & 0.86 \\
90 & 0.75 \\
\hline
\end{tabular}

3. Ambient relative Humidity: If ambient relative humidity is greater than $40 \% \gamma_{\lambda}$ is used as a correction factor for ultimate shrinkage-

$\gamma_{\lambda}=1.4-.01 \lambda$, for $40 \leq \lambda \leq 80$

$$
=3.0-.03 \lambda \text {, for } 80 \leq \lambda \leq 100
$$

Where, $\lambda=$ relative humidity in $\%$

For ambient humidity lower than $40 \%$ a value higher than 1 should be used for $\gamma_{\lambda}$

4. Correction for size and shape:

(a). Avg. thickness method correction $\left(\gamma_{h}\right)$

Table 6.2 shows the correction factors for members having average thickness less than $150 \mathrm{~mm}$ 
Table6.2 - Correction factors for average thickness method of members less than $150 \mathrm{~mm}$

\begin{tabular}{c|c}
\hline $\begin{array}{c}\text { Average thickness } \\
\text { of member }\end{array}$ & Shrinkage, $\boldsymbol{\gamma}_{\mathbf{h}}$ \\
\hline $\mathrm{mm}$ & $\leq 1$ year \\
\hline 51 & 1.35 \\
\hline 76 & 1.25 \\
\hline 104 & 1.17 \\
\hline 127 & 1.08 \\
\hline
\end{tabular}

For average thickness of members greater than $150 \mathrm{~mm}$ and up to $300 \mathrm{~mm}$ to $375 \mathrm{~mm}$ the following equations are used for correction

During the first year of drying:

Shrinkage $\gamma_{\mathrm{h}}=1.23-.00015 \mathrm{~h}$

where $\mathrm{h}$ is the avg. thickness of the member in $\mathrm{mm}$

For ultimate values

Shrinkage $\gamma_{\mathrm{h}}=1.17-.00114 \mathrm{~h}$

where $\mathrm{h}$ is the avg. thickness of the member in $\mathrm{mm}$

(b). Volume-surface ratio method $\left(\gamma_{v s}\right)$ (more accurate method)

Shrinkage $\gamma_{v s}=1.2 \exp (-.12 \mathrm{v} / \mathrm{s})$

Where $\mathrm{v} / \mathrm{s}$ is the volume-surface ratio of the member in inches

Shrinkage $\gamma_{v s}=1.2 \exp (-.00472 \mathrm{v} / \mathrm{s})$

Where $\mathrm{v} / \mathrm{s}$ in $\mathrm{mm}$

In either method $\gamma_{s h}$ should not be taken less than 0.2. Also $\gamma_{s h}\left(\varepsilon_{s h}\right)_{u} \geq 100 \times 10^{-6}$ in./in. $(\mathrm{m} / \mathrm{m})$ is used if concrete is under seasonal wetting and drying cycles and $\gamma_{s h}\left(\varepsilon_{s h}\right)_{u} \geq 150 \times 10^{-6} \mathrm{in.} / \mathrm{in} .(\mathrm{m} / \mathrm{m})$ if concrete is under sustained drying condition.

5. Temperature other than 70F (21C): This effect is usually considered to be less important than relative humidity since the operating range of most structures is small.

6. Correction Factors for Concrete Composition: 
(a). Slump:

Shrinkage $\gamma_{s}=0.89+.00161 \mathrm{~s}$

Where $\mathrm{s}$ is observed slump in inches

(b). Fine aggregate percentage:

For $\psi \leq 50$ percent

Shrinkage $\gamma_{\psi}=0.30+0.14 \psi$

For $\psi>50$ percent

Shrinkage $\gamma_{\psi}=0.90+0.002 \psi$

$\psi$ is the ratio of the fine aggregate to total aggregate by weight expressed as percentage.

(c) Cement Content:

Shrinkage $\gamma_{c}=0.75+.00061 \mathrm{c}$

where $\mathrm{c}$ is cement content in $\mathrm{Kg} / \mathrm{m}^{3}$

(d) Air Content:

Shrinkage $\gamma_{\alpha}=.95+.008 \alpha$

where $\alpha$ is the air content in percent

5. Shrinkage ratio of concrete with equivalent paste quality: Shrinkage strain is mainly a function of shrinkage characteristic of the cement paste and of the aggregate volume concentration.

$\frac{\left(\varepsilon_{s h}\right)_{u 1}}{\left(\varepsilon_{s h}\right)_{u 2}}=\frac{1-\left(v_{1}\right)^{1 / 3}}{1-\left(v_{2}\right)^{1 / 3}}$

where $\left(\varepsilon_{s h}\right)_{u 1} /\left(\varepsilon_{s h}\right)_{u 2}$ is the ratio of shrinkage strain of two mixes with different content of paste with equivalent paste quality and $v_{1}$ and $v_{2}$ are the total aggregate solid volumes per unit volume of concrete for each one of the mixes. 


\subsection{Bazant model (1996)}

He proposed what is called B3 model which is as followingMean Shrinkage strain in the cross section:

$\varepsilon_{\text {sh }}\left(t, t_{0}\right)=-\varepsilon_{\text {shoo }} k_{h} S\left(t-t_{c}\right)$

Time curve:

$S\left(t-t_{c}\right)=\tanh \left(\frac{t-t_{0}}{\tau_{s h}}\right)^{1 / 2}$

Humidity Dependence:

$$
\begin{array}{rlrl}
k_{h} & =1-h^{3} & & \text { for } h \leq .98 \\
& =-0.2 & & \text { for } h=1 \text { (swelling in water) } \\
& =\text { linear interpolation for } .98 \leq h \leq 1
\end{array}
$$

Size dependence:

$$
\begin{aligned}
\tau_{\text {sh }} & =0.085 \mathrm{t}_{\mathrm{c}}{ }^{-0.08} \mathrm{f}_{\mathrm{cm} 28}{ }^{-0.25}\left[2 \mathrm{k}_{\mathrm{s}}(\mathrm{V} / \mathrm{S})\right]^{2} \text { in SI unit } \\
& =190.8 \mathrm{t}_{\mathrm{c}}{ }^{-0.08} \mathrm{f}_{\mathrm{cm} 28}{ }^{-0.25}\left[2 \mathrm{k}_{\mathrm{s}}(\mathrm{V} / \mathrm{S})\right]^{2} \text { in in.-lb units }
\end{aligned}
$$

where $\mathrm{V} / \mathrm{S}$ is the volume to surface area ration and $\mathrm{k}_{\mathrm{s}}$ is the effective cross-section shape factor

$$
\begin{aligned}
\mathrm{k}_{\mathrm{s}} & =1.00 & & \text { for infinite slab } \\
& =1.15 & & \text { for infinite cylinder } \\
& =1.25 & & \text { for infinite square prism } \\
& =1.30 & & \text { for sphere } \\
& =1.55 & & \text { for a cube } \\
\varepsilon_{\text {sh }} & =-\varepsilon_{\text {so }} \frac{E_{c m 607}}{E_{c m\left(t_{c}+\tau_{s h}\right)}} & &
\end{aligned}
$$

typical values of $\varepsilon_{\text {shoo }}$ range from $300 \times 10^{-6}$ to $1100 \times 10^{-6}$

$$
\begin{aligned}
E_{c m t} & =E_{c m 28}\left(\frac{t}{4+0.85 t}\right) \\
\varepsilon_{s \infty} & =\alpha_{1} \alpha_{2}\left[26 w^{2.1}\left(f_{c}^{\prime}\right)^{-.28}+270\right] \quad\left(\text { in } 10^{-6}\right) \\
k_{1} & =190.8 t_{0}^{-.28} f_{c}^{\prime} \quad \text { days } i^{-2} \\
\alpha_{q} & =1.0 \text { for Type I cement } \\
& =.85 \text { for Type II cement } \\
& =1.1 \text { for Type III cement }
\end{aligned}
$$


and $\alpha_{2}=.75$ for steam cured specimens

$=1.0$ for $100 \% \mathrm{RH}$

$=1.2$ for specimens sealed during curing

\subsection{Gardner and Lockman model (2001)}

They proposed a design office procedure for calculating shrinkage. They used 28 day compressive strength and a factor $\mathrm{K}$ for accommodating different types of cement. They suggested by using different values of $\mathrm{K}$ it is also possible to include the effects of Fly Ash and Ground Granulated Blast Furnace Slag. According to there model shrinkage can be estimated using the following equation-

$\varepsilon_{\text {sh }}\left(t, t_{c}\right)=\varepsilon_{\text {shu }} \beta(h) \beta\left(t-t_{c}\right)$

$\beta(h)=\left(1-1.18 h^{4}\right)$

$\varepsilon_{\text {shu }}=900 \cdot K \cdot\left(\frac{30}{f_{c m 28}}\right)^{1 / 2} \cdot 10^{-6}$

$\beta\left(t-t_{c}\right)=\left[\frac{\left(t-t_{c}\right)}{\left(t-t_{c}\right)+0.12(V / S)^{2}}\right]^{1 / 2}$

where

$\mathrm{h}=$ humidity expressed as a decimal;

$\mathrm{t}=$ age of concrete, days;

$\mathrm{t}_{\mathrm{c}}=$ age drying commenced, end of moist curing, days;

$\mathrm{K}=1$ for Type I cement;

$\mathrm{K}=.70$ Type II cement

$\mathrm{K}=1.15$ Type III cement;

$\mathrm{V} / \mathrm{S}=$ volume-surface ratio, $\mathrm{mm}$;

$\mathrm{f}_{\mathrm{cm} 28}=$ concrete mean compressive strength at 28 days, $\mathrm{MPa}$

They also proposed an equation to predict the mean compressive strength at $t$ days.

$$
f_{c m t}=f_{c m 28} \frac{t^{3 / 4}}{a+b \cdot t^{3 / 4}}
$$

for

Type I cement concretes, $a=2.8$ and $b=0.77$

Type II cement concretes, $a=3.4$ and $b=0.72$

Type III cement concretes, $a=1.0$ and $b=0.92$ 
For Blended cement concretes containing Fly Ash or Slag the measured concrete strengths should be used to determine which of the equations (5a), (5b) or (5c) best represents the test results to determine the value of $K$ to be used in the shrinkage prediction equation.

\subsection{The AASHTO specification model (2000)}

$\varepsilon_{\text {sh }}=k_{s} k_{h}\left(\frac{t}{35+t}\right) \cdot 0.51 \times 10^{-3}$

For moist cured concrete,

$k_{s}=\frac{\frac{t}{26 e^{0.0142(V / S)}+t}}{\frac{t}{45+t}} \times \frac{1064-3.70(V / S)}{923}$

where, $\mathrm{V} / \mathrm{S}$ is the volume to surface ratio and

$k_{h}=\frac{140-H}{70}$ For $\mathrm{H}<80 \%$

$k_{h}=\frac{3(100-H)}{70}$ For $\mathrm{H} \geq 80 \%$

where $\mathrm{H}=$ relative humidity $(\%)$

\subsection{CEB MC90-99 model}

The CEB MC90 model was originally proposed by Muller and Hilsdorf (1990) and was intended to predict the time-dependent behavior of a concrete member. The concept was similar to that of ACI 209R-92.For high performance concrete a new approach subdivides the total shrinkage into autogenous shrinkage and drying shrinkage. This model is regarded as CEB MC90-99; where the drying shrinkage component is closely related to the CEB MC90 (CEB 1993) model.

The total shrinkage $\varepsilon_{\mathrm{sh}}\left(\mathrm{t}, \mathrm{t}_{\mathrm{c}}\right)$ can be calculated from Eq. (6.31)

$\varepsilon_{s h}\left(t, t_{c}\right)=\varepsilon_{c a s}(t)+\varepsilon_{c d s}\left(t, t_{c}\right)$

Where $\varepsilon_{\text {sh }}\left(t, t_{c}\right)$ is the total shrinkage, $\varepsilon_{\text {cas }}(t)$ the autogenous shrinkage, and $\varepsilon_{c d s}\left(t, t_{c}\right)$ is the drying shrinkage of concrete at $t$ (days) after beginning of drying. The autogenous part is calculated according to the following equation:

$\varepsilon_{\text {cas }}(t)=\varepsilon_{\text {caso }}\left(f_{c m 28}\right) \beta_{\text {as }}(t)$

where,

$\varepsilon_{\text {caso }}\left(f_{c m 28}\right)=-\alpha_{a s}\left(\frac{f_{c m 28} / f_{c m o}}{6+f_{c m 28} / f_{c m o}}\right)^{2.5} \times 10^{-6}$

and, 
$\beta_{\text {as }}(t)=1-\exp \left[-0.2\left(\frac{t}{t_{1}}\right)^{0.5}\right]$

where,

$\mathrm{f}_{\mathrm{cm} 28}=28$-day mean compressive strength of concrete (MPa or psi)

$\mathrm{f}_{\mathrm{cmo}}=10 \mathrm{MPa}(1450 \mathrm{psi})$

$\mathrm{t}=$ age of concrete

$\mathrm{t}_{1}=1$ day

$\alpha_{\text {as }}=$ coefficient depending upon type of cement (Table 6.3)

Table6.3 - Coefficients for CEB MC90-99 model

\begin{tabular}{l|c|c|c}
\hline Type of cement & $\alpha_{\text {as }}$ & $\alpha_{\text {ds1 }}$ & $\alpha_{\text {ds2 }}$ \\
\hline SL (slowly-hardening cements) & 800 & 3 & 0.13 \\
\hline N or R (normal or rapid hardening cements) & 700 & 4 & 0.12 \\
\hline RS (rapid hardening high-strength cements) & 600 & 6 & 0.12 \\
\hline
\end{tabular}

The drying shrinkage is calculated from the following equation.

$\varepsilon_{c d s}\left(t, t_{c}\right)=\varepsilon_{c d s o}\left(f_{c m 28}\right) \beta_{R H}(h) \beta_{d s}\left(t-t_{c}\right)$

Where $\varepsilon_{\mathrm{cdso}}\left(\mathrm{f}_{\mathrm{cm} 28}\right)$ is the notional drying shrinkage coefficient and the factor $\beta_{\mathrm{RH}}(\mathrm{h})$ takes into account the effect of relative humidity. $\beta_{\mathrm{ds}}\left(t-t_{c}\right)$ is a time function from equation (6.38).

$\varepsilon_{c d s o}\left(f_{c m 28}\right)=\left[\left(220+110 \alpha_{d s 1}\right) \exp \left(-\alpha_{d s 2} f_{c m 28} / f_{c m o}\right)\right] \times 10^{-6}$

$\beta_{R H}(h)=-1.55\left[1-\left(\frac{h}{h_{0}}\right)^{3}\right]$

$\beta_{d s}\left(t-t_{c}\right)=\left[\frac{\left(t-t_{c}\right) / t_{1}}{350\left[(V / S) /(V / S)_{0}\right]^{2}+\left(t-t_{c}\right) / t_{1}}\right]^{0.5}$

$\beta_{s 1}=\left(\frac{3.5 f_{c m o}}{f_{c m 28}}\right)^{0.1}$

where $\alpha_{\mathrm{ds} 1}$ and $\alpha_{\mathrm{ds} 2}$ are coefficients depending on the type of cement (Table 6.3). $\beta_{\mathrm{s} 1}$ takes into account the effect of self-desiccation in high-performance concrete.

$\mathrm{h}=$ ambient relative humidity in decimal

h0 $=1$

$\mathrm{V} / \mathrm{S}=$ Volume to surface ratio in $\mathrm{mm}$ (in)

$(\mathrm{V} / \mathrm{S}) 0=50 \mathrm{~mm}(2 \mathrm{in})$ 
$\mathrm{f}_{\mathrm{cmo}}=10 \mathrm{MPa}(1450 \mathrm{psi})$

tc $=$ age of concrete at beginning of drying (days)

$\mathrm{t}_{1}=1$ day

\subsubsection{Comparison with models}

Comparisons of the experimental values of shrinkage for the six mixtures with the above discussed models are shown in Figure 6.10.

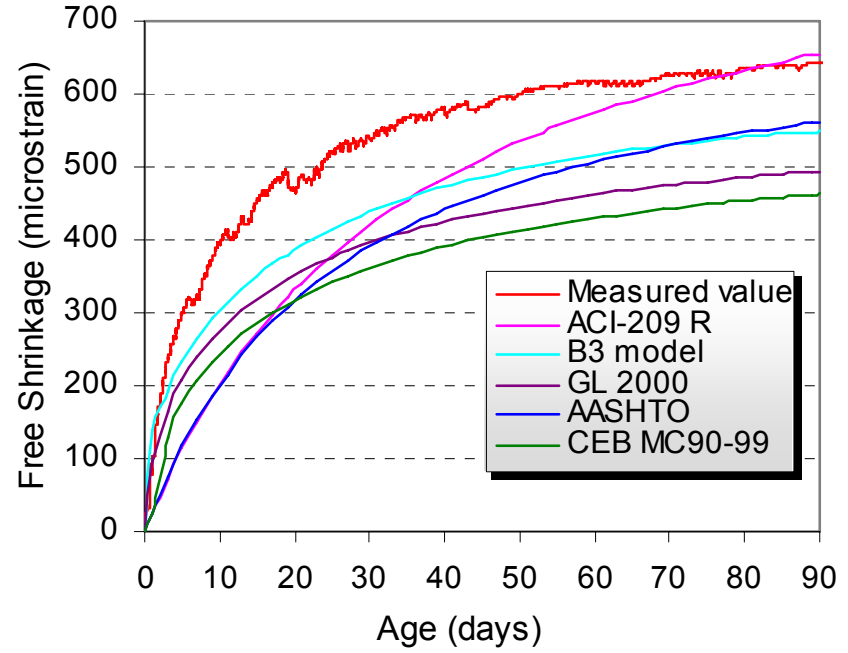

(a)

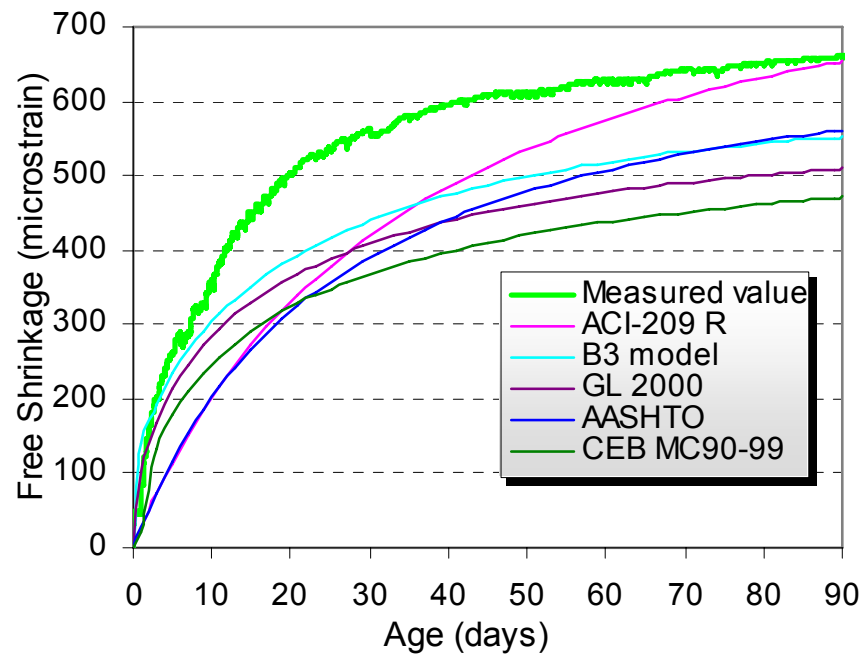

(c)

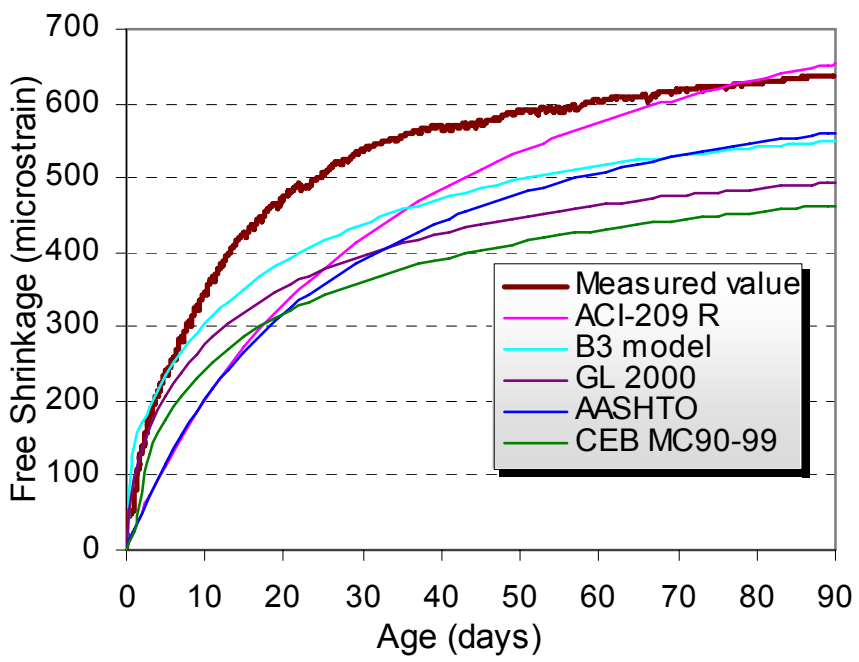

(b)

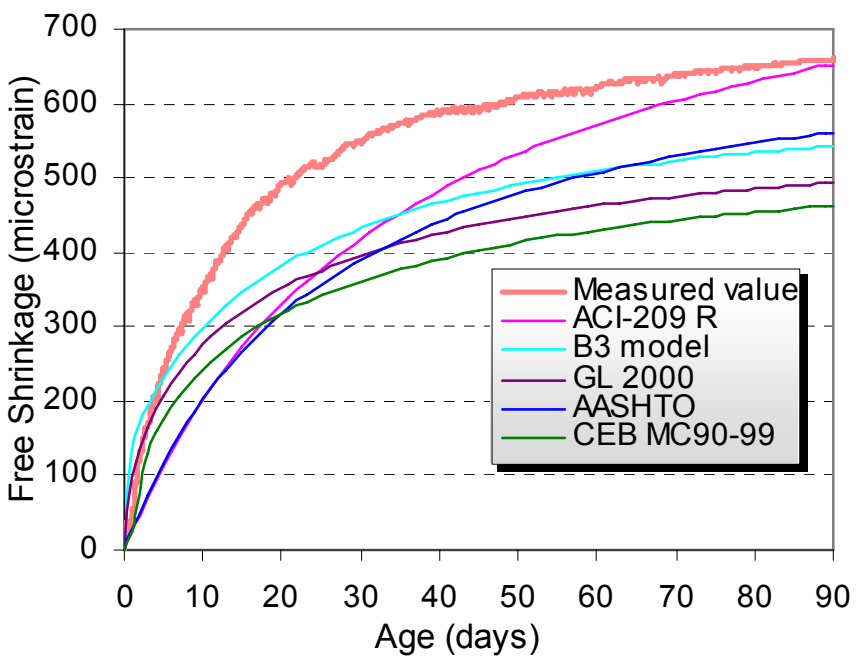

(d) 


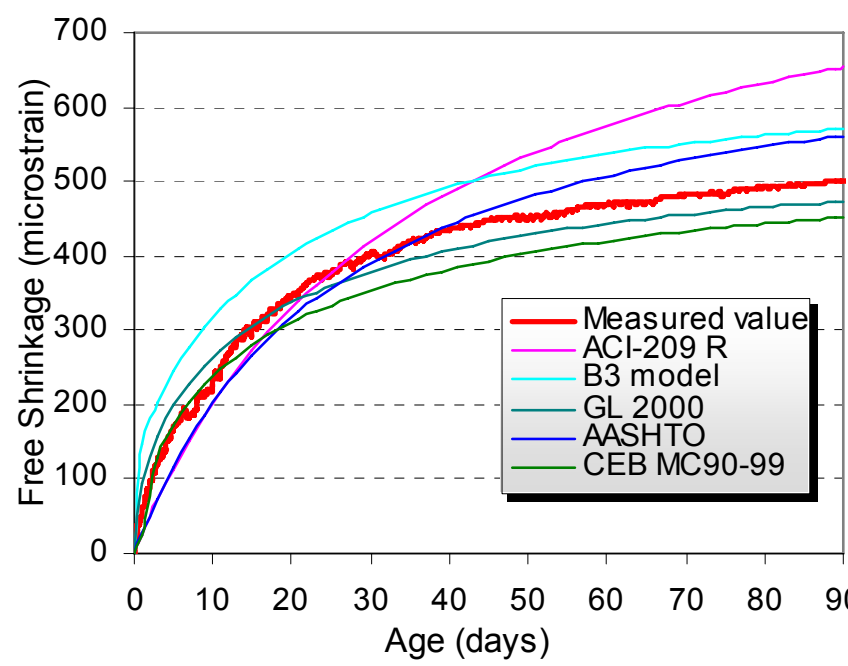

(e)

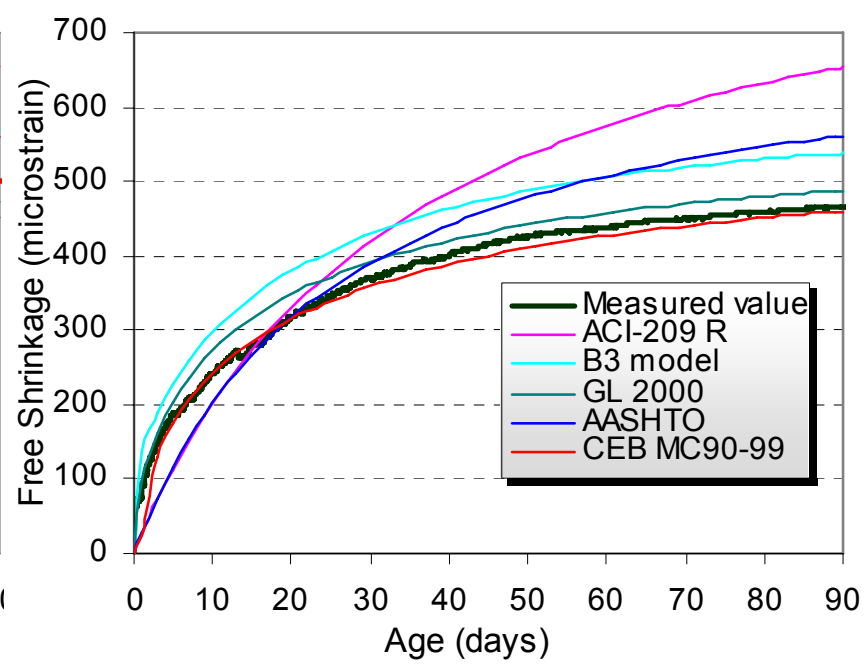

(f)

Figure6.10 Comparison of free shrinkage with different available models for (a) SCC A (70-30) (b) SCC B (50-50) (C) SCC C (30-70) (d) SCC D (0-100) (e) SCC E (F) (f) SCC F (SRA)

From the above figures the following conclusions can be made:

1. All the prediction models grossly under estimate the free shrinkage values for SCC mixtures at early age except for SCC E (F) and SCC F (SRA).

2. For SCC A (70-30) through SCC D (0-100), the 90-day shrinkage value was best predicted by ACI $209 \mathrm{R}$ model. Almost all of them have similar shrinkage values at the age of 90 days after casting. Similar results were obtained by Poppe and Schutter (2005).

3. Other models grossly under estimate the shrinkage value at early age as well as at later stages for SCC A (70-30) through SCC D (0-100).

4. CEB MC90-99 model under estimated the shrinkage values in all the cases and predicted the lowest shrinkage values.

5. The B3 and AASHTO model shrinkage were close at later stage and predicted closest to the values given by ACI 209R model and the values for SCC mixtures.

6. SCC E (F) and SCC F (SRA) behaved differently than other SCC mixtures due to the fiber and SRA content. The GL and CEB MC90-99 models were closest to the final shrinkage value for SCC E (F) and all the other models over estimated the shrinkage values.

7. Due to the effect of SRA the shrinkage values for SCC F (SRA) was the lowest and when compared to the models, it was closest to the values 
predicted by CEB MC90-99 followed by the GL model. All the other models over estimate the shrinkage values for SCC F (SRA).

ACI 209.2R-08 explained that due to wide variation between material, mixtures, pouring, admixtures and other effects, it is unrealistic to expect results from the prediction models to be within $\pm 20 \%$ of the test data. Also, the prediction models were calibrated only for normal concrete with typical compositions but not for concrete containing slag, silica fume, fly ash or limestone powders. Hence models for concretes made with such materials should be calibrated by testing.

As seen from the figures, the shrinkage values predicted by ACI 209R model resembles most closely to the experimental results, it was decided to calibrate the ACI model for SCC A (70-30) through SCC D (0-100) which were normal SCC mixtures without any addition of fibers or SRA. As SCC E (F) and SCC F (SRA) shrinkage values were close to the CEB MC90-99 and the GL model, any one of them can be used to predict the ultimate free shrinkage values.

\subsubsection{Proposed model}

In this study, the inverse best-fit method as recommended by ACI 209R was adopted to find the prediction equation on the basis of the experimental values obtained in this research. The ACI prediction equation was given by Eq. (6.1). By inversing the equation the following equation is achieved.

$$
\frac{1}{\varepsilon_{\text {sh }}(t)}=\left(\frac{f}{\varepsilon_{\text {shu }}}\right) \frac{1}{t}+\frac{1}{\varepsilon_{\text {shu }}}
$$

Equation (6.40) is a linear equation of the form $y=m x+c$. As all the mixtures had a same $w / p$ ratio of 0.30 , same $w / c m$ ratio of 0.40 and all the mixtures contained LP, they can be grouped together on shrinkage point of view. Hence, the experimental data were manipulated using equation (6.40) and a linear bestfit curve was obtained. The typical plot and the equation of the best-fit curve results is illustrated in the Figure 6.11. From the slope and intercept of the fitting curve, the values of $f$ and $\varepsilon_{\text {shu }}$ were calculated. The computed values for $f$ and $\varepsilon_{\text {shu }}$ were 9.25 and 715 respectively. 


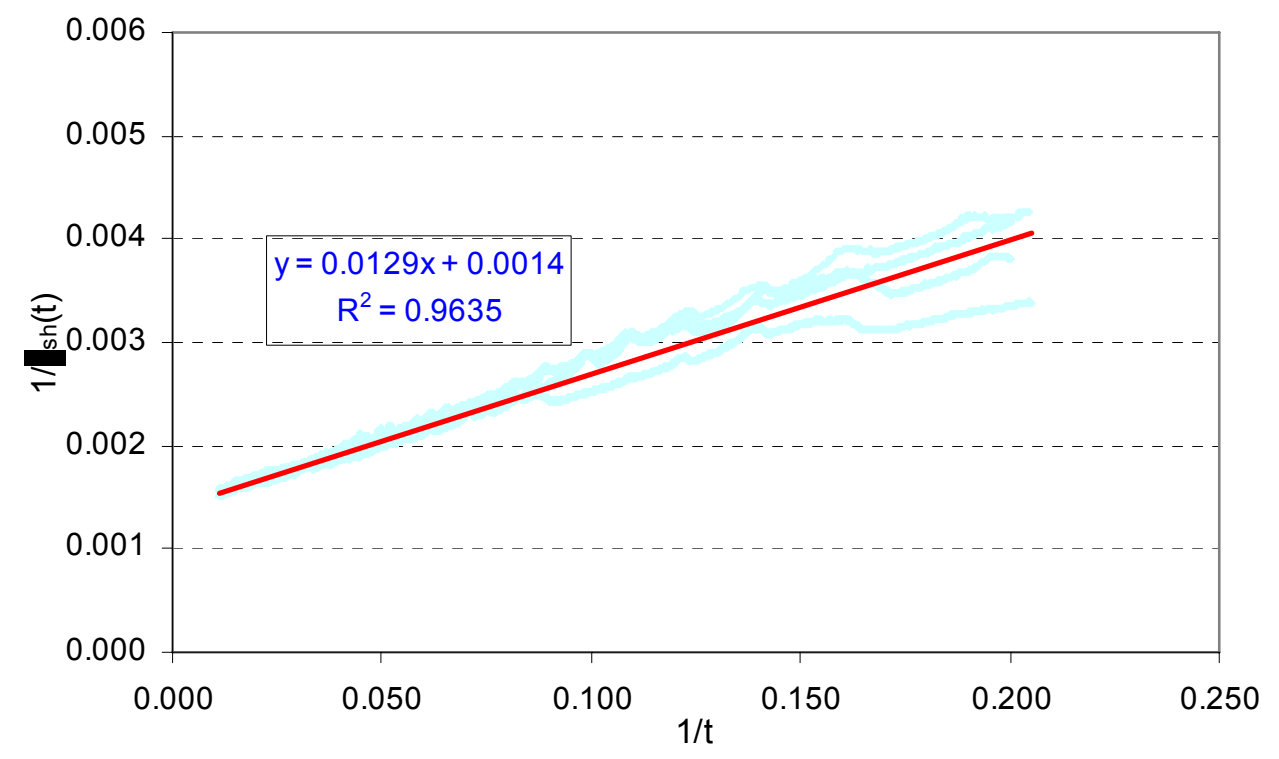

Figure6.11 Typical plot of the best-fit curve

The proposed prediction curve as well as the experimental values is plotted in Figure 6.12.

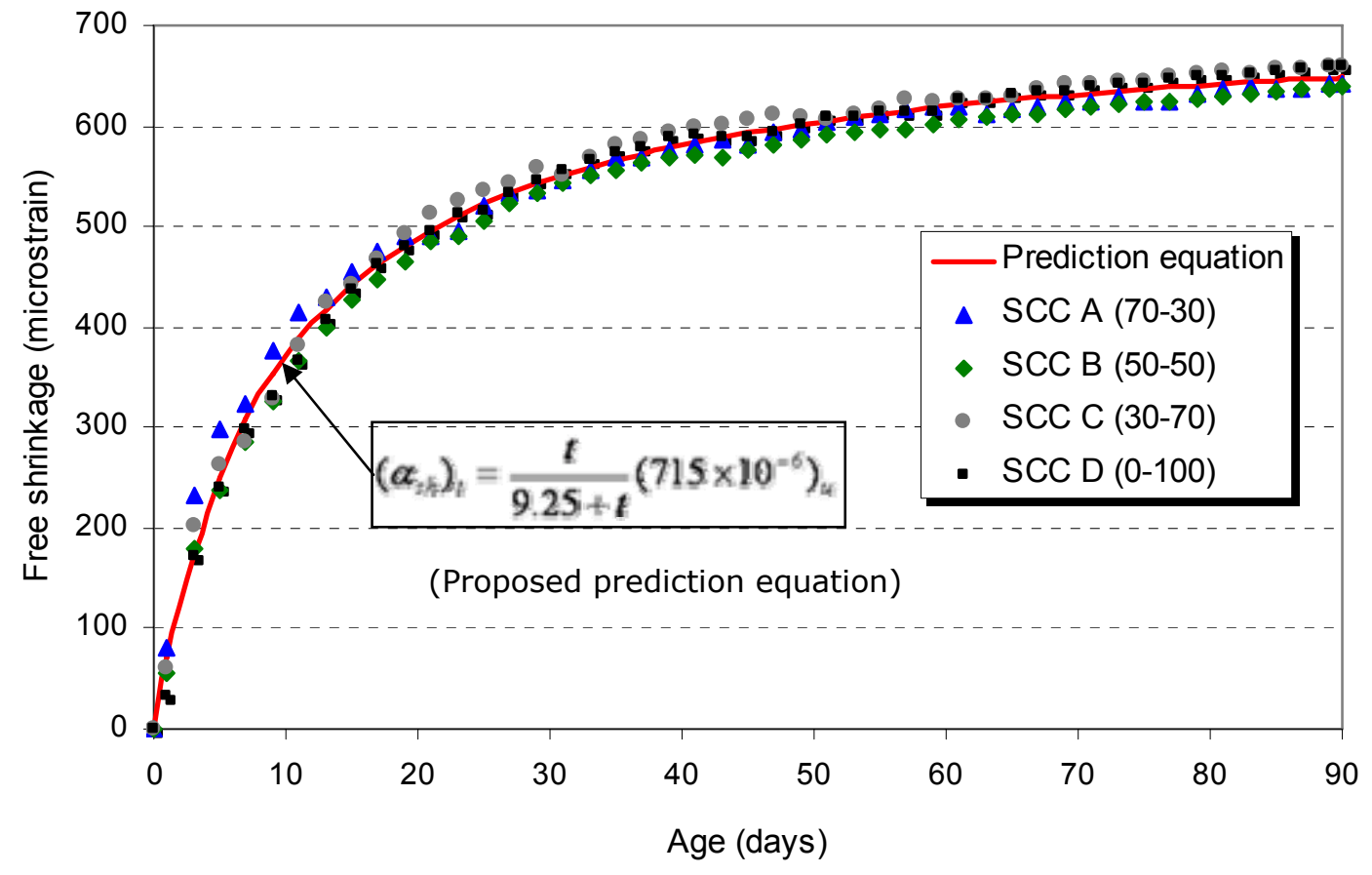

Figure6.12 Comparative plots of proposed model and experimental values 
McDonald and Roper (1993) mentioned that a residual plot can give a good idea about the accuracy of a prediction model. Positive residuals indicates that the model overestimated the values and negative residuals indicate that the model underestimate the results. A model is said to be better if the values are closer to the zero axis and evenly distributed in the positive and negative ranges. Figure 6.13 shows the residual plots for the model and the SCC mixtures. As seen from the figure, almost all the values are closer to the zero axis and are evenly oriented along the axis signifying a good model.

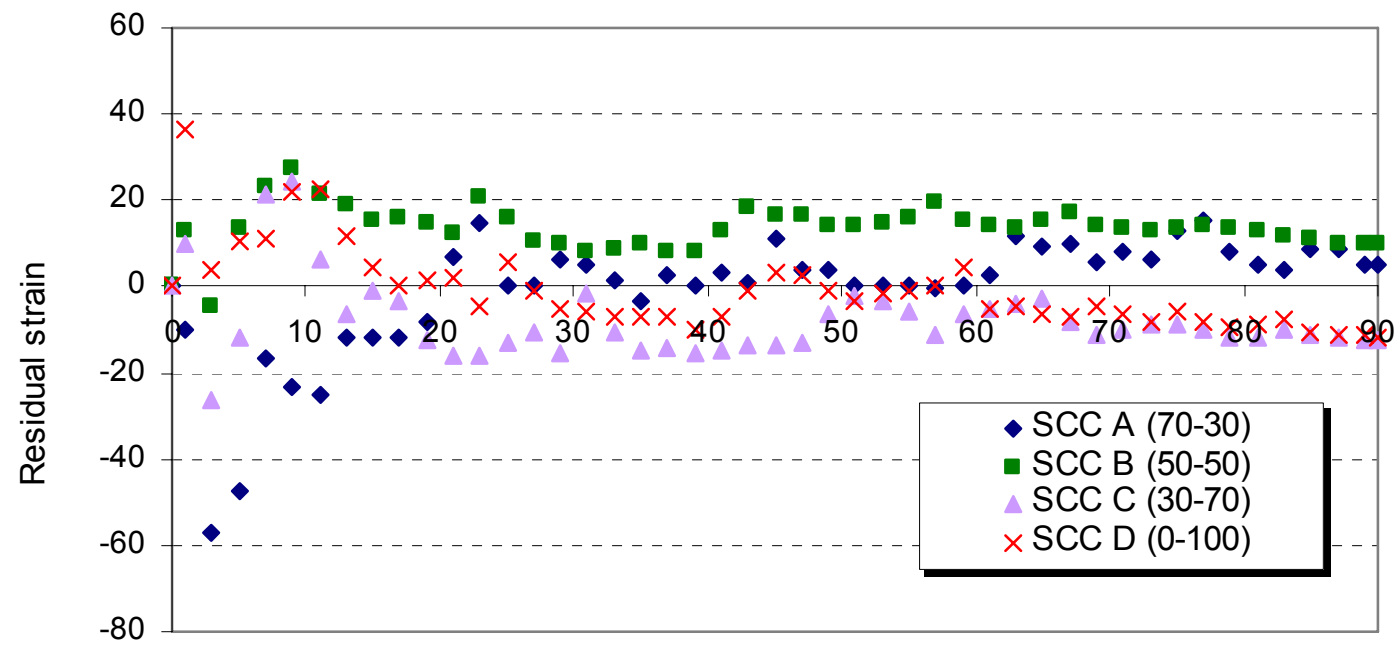

Age (days)

Figure6.13 Residual plot of the proposed model

As seen from the above figures, the model gives fairly good results for all the SCC mixtures. This model can be used for SCC mixtures with LP and having a w/p ratio of 0.30 . As the number of data was very less for this study, more experiments will be conducted in the future to validate the model. 


\subsection{Restrained Shrinkage of SCC Mixtures}

\subsubsection{I ntroduction}

In the previous chapters and sections, the fresh properties, compressive strength, splitting tensile strength and free shrinkage properties of different SCC mixtures were investigated. Those properties are regarded as very important parameters with respect to the performance criteria of SCC. However, for different structures like bridge decks, the cracking is induced by restraints from the reinforcements or the boundary condition which can have direct impact on their safety and service life. Also, as SCC is a new type of concrete, the cracking tendencies may be different than the normal concrete or the HPC due to the effect of higher fines, different rheology or different admixture contents. Hence, a better understanding of cracking properties of SCC is essential to anticipate or prevent crack development. The restrained shrinkage test had been so far a useful test method to evaluate the cracking potential of concrete mixtures.

Between the different restrained shrinkage tests available as discussed in Chapter 2, ring test is being used by the researchers very often due to its simplicity and ease of implementation. Also, the ring test provides sustained and sufficient restrain to induce cracking for an affordable size specimen. In 1998, AASHTO adopted the ring test as a provisional test standard test (AASHTO 1998). ASTM C 1561-04 (Standard Test Method for Determining Age at Cracking and Induced Tensile Stress Characteristics of Mortar and Concrete under Restrained Shrinkage) proposed a very similar standard for determination and estimation of restrained shrinkage cracking potential of concrete mixtures. Recently, several researchers have used the ring test to investigate the restrained properties of concrete (Gong, 2006). Hwang and Khayat (2008) recently investigated the effect of mixture composition on restrained shrinkage cracking of self-consolidating concrete used in repair. Turcry et. al. (2006) investigated the cracking tendency of self-compacting concrete subjected to restrained shrinkage. They all have used ring test to study the restrained shrinkage cracking behavior.

In this study, the AASHTO type ring test was adopted to investigate the restrained shrinkage cracking behavior of the selected SCC mixtures. ASTM type ring test is very similar except some dimensional variation of the ring and the concrete thickness compared to AASHTO ring test. The ASTM ring test limits the applicability of the test for aggregates of $13 \mathrm{~mm}$ ( $0.5 \mathrm{in}$ ) maximum nominal size or less. There was no such restriction for AASHTO ring test. This may be due to the reduced 
concrete thickness in case of the ASTM ring test. As in this experimental study, the nominal maximum size of the aggregated in some of the mixtures exceeded the limiting value provided in the ASTM; AASHTO ring test was followed instead of the ASTM ring test. ASTM ring test additionally provide some formulas to calculate the stress rate in the ring specimens and also gives a potential for cracking classification among the samples based on net time to cracking and average stress rate. These formulas will be modified for the AASHTO ring test based on the revised dimensions and the cracking potential of the selected six SCC mixtures will be investigated in this chapter.

\subsubsection{Testing Procedure}

The testing was conducted as per "Standard Practice for Estimating the Cracking Tendency of Concrete (AASHTO Designation: PP 34-pp (2006)) which was originally approved in December 1997. This provisional standard was first published in June 1998, reconfirmed in 2005 and again in 2006. The details of the test method are described as follows:

a) The test specimen was made of a concrete ring cast around a steel ring. The outside diameter of the concrete ring was $457 \mathrm{~mm}$ (18 in) and the outside diameters of the steel ring were $305 \mathrm{~mm}$ (12 in) and $280 \mathrm{~mm}$ (11 in), respectively. The inner and outer faces of the steel ring were machined to a smooth polished surface. The height of the ring was $152 \mathrm{~mm}$ (6 in). The set up is shown in figure 6.14. Although, structural steel pipe conforming to ASTM A 501 or A 53M/ A 5312 -in extra-strong with an outside diameter of $324 \mathrm{~mm}\left(12^{3} / 4\right.$ in) and a wall thickness of $13 \mathrm{~mm}(1 / 2 \mathrm{in})$ may be used, if the inner and outer faces are machined to a smooth, polished surface. In this experiment, the second set of dimensions was used.

b) The types of mixtures in this test are the same as those used in the free shrinkage tests. For each mixture, three replicate rings were cast. Two for the measurement of strain versus time and the remaining for the temperature measurement. The preparation of the concrete followed the relevant requirements of ASTM M 210 an ASTM R 39. A total of 18 ring samples were tested.

c) The concrete ring was cast within an exterior plastic mold and steel ring, placed over a plywood board. After 24 hours curing under wet burlap, the specimens were demolded and coated with silicon caulk on the top surface. Care was taken to seal the top and bottom face of the concrete ring so that 
evaporation of moisture can not take place through the surfaces. All the specimens were then moved to a controlled environmental chamber with a constant temperature of $23{ }^{\circ} \mathrm{C}\left(73^{\circ} \mathrm{F}\right)$ and relative humidity of $50 \%$, which was same as the environmental conditions for the free shrinkage test.

d) Four strain gauges were used for each ring specimen. They were used to measure the strain inside the steel rings and automatically capture the cracking onset time. Strain gauges were bonded at four equidistant midheight locations on the interior surface of the steel ring.

e) A highly sensitive data acquisition system was used in this study. The strain readings were automatically recorded every 2 minutes.

f) A strain decrease of more than 30 microstrains in one or more gauges usually indicates cracking as per the AASHTO standard. Though all the cracking occurred before 35 days, strain readings were continued until 90 days after casting to study the behavior of the post-cracking strain in the rings.

Figure 6.15 shows a typical specimen with strain gauges bonded to the interior surface of the steel ring, and Figure 6.16 shows an overview of the test setup in the environmental chamber.
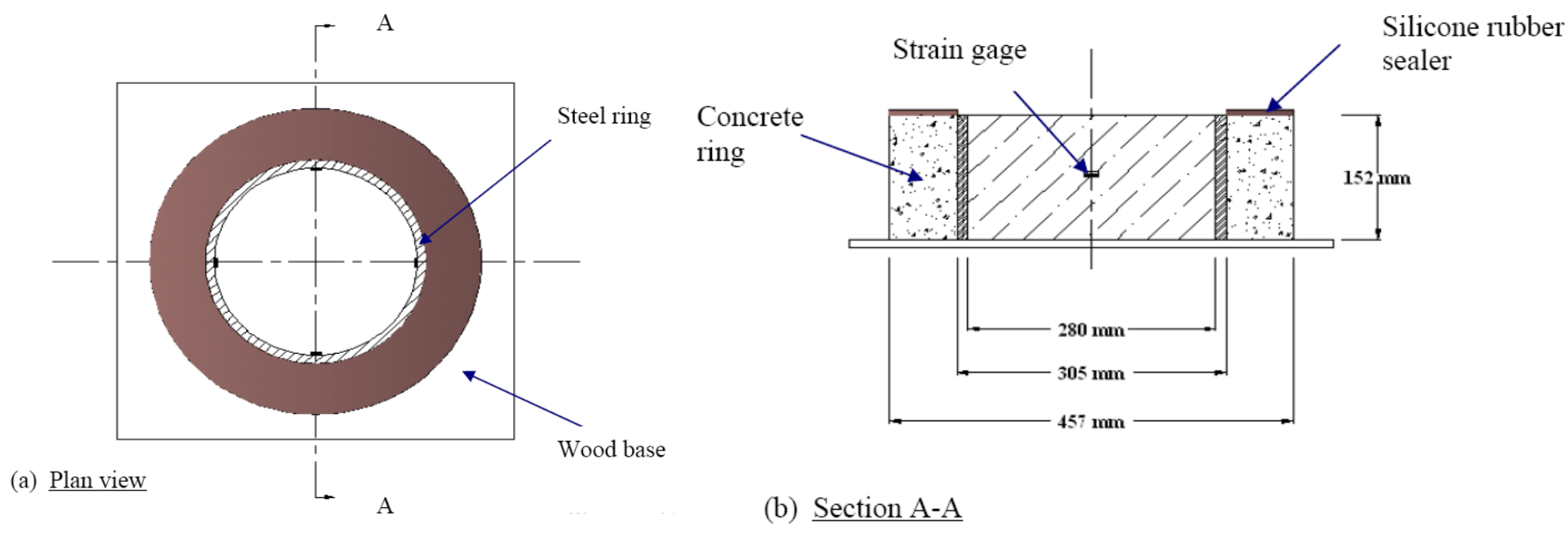

$$
(1 \mathrm{~mm}=0.03937 \mathrm{in})
$$

Figure6.14 Schematic view of a ring specimen 


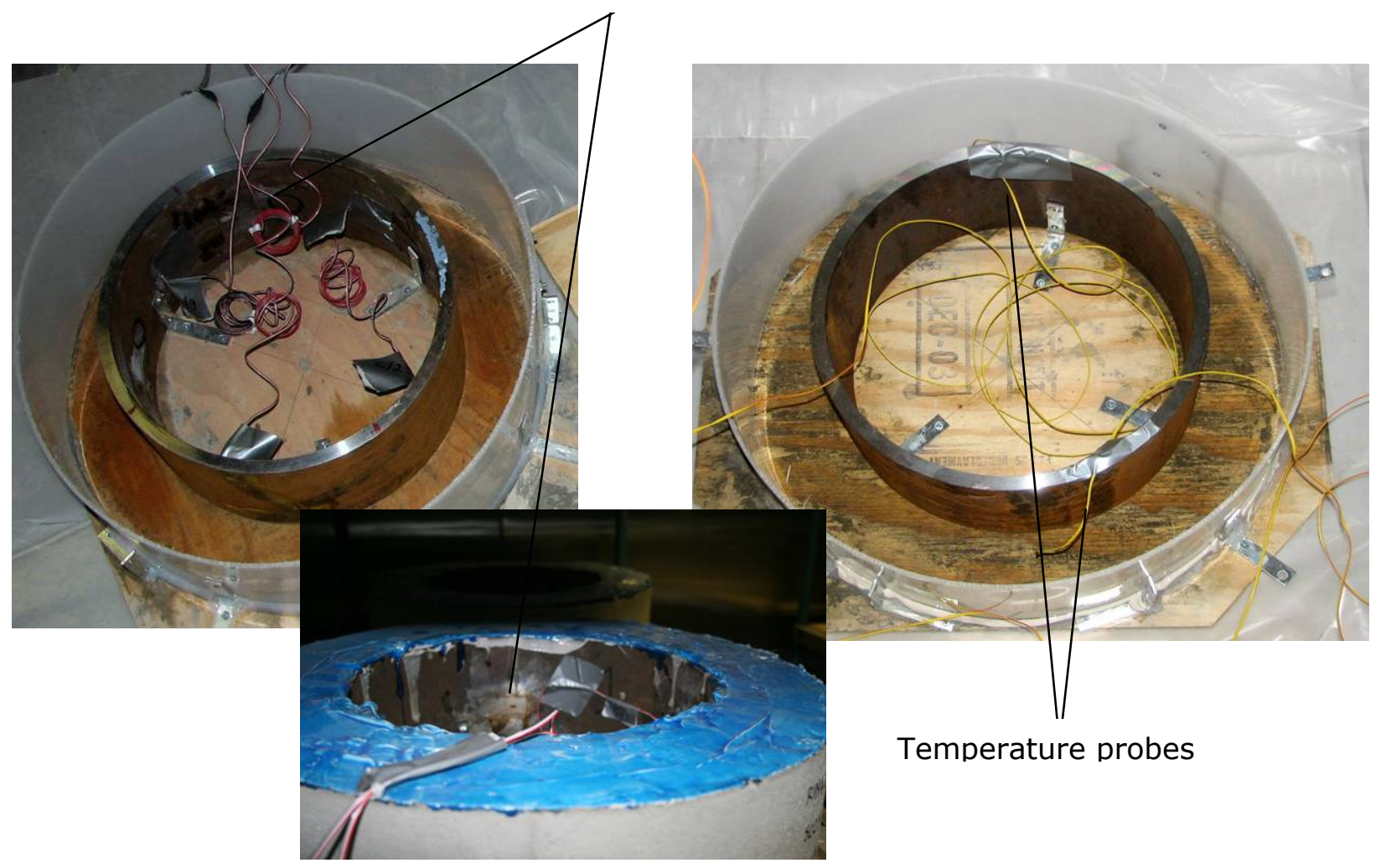

Figure6.15 Close view of a typical ring specimen with strain gauges

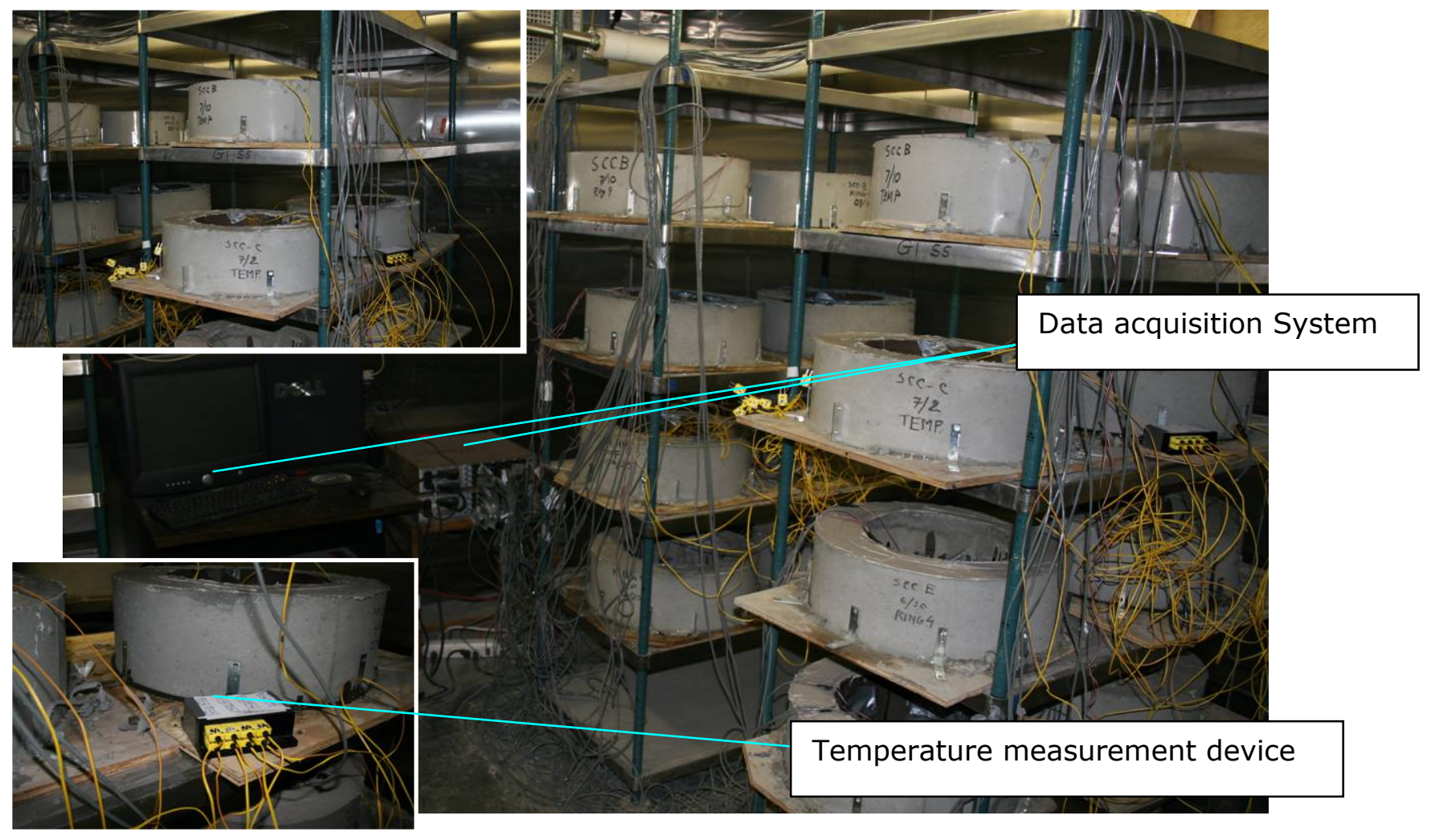

Figure6.16 Overview of test setup 


\subsubsection{Results and Discussions}

\subsubsection{Strain versus time for ring specimens}

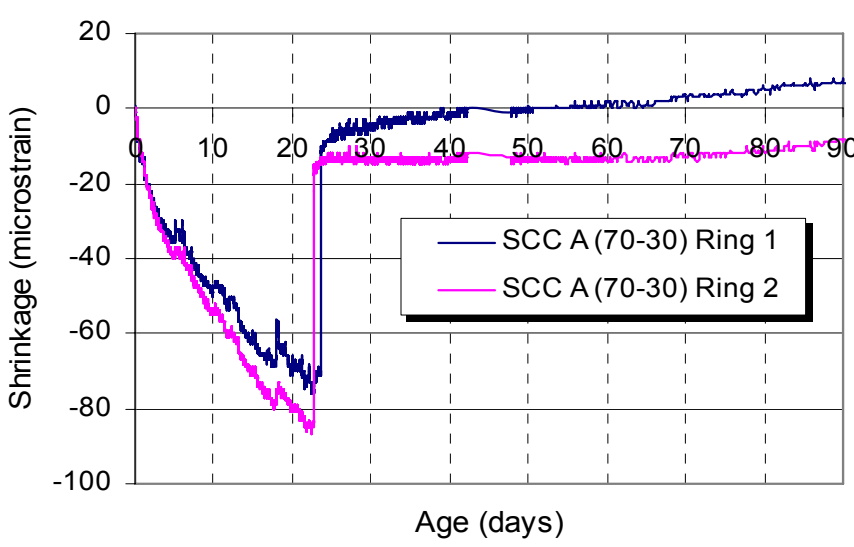

(a)

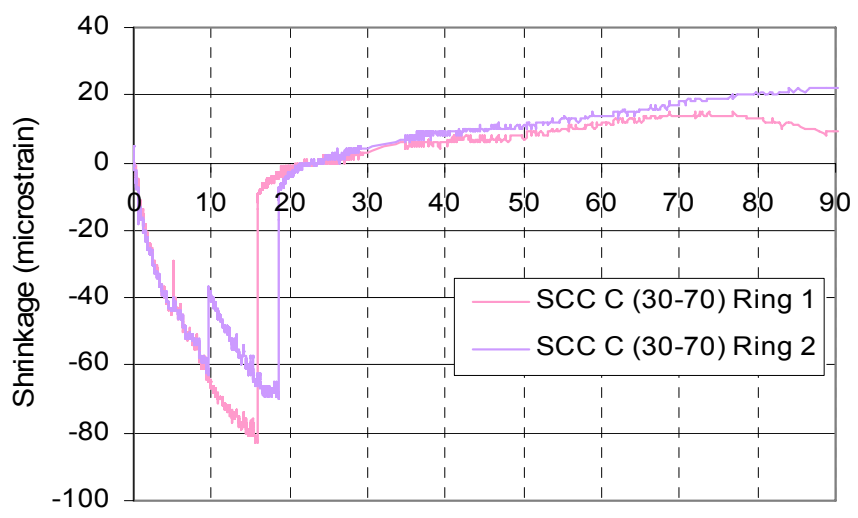

Age (days)

(c)

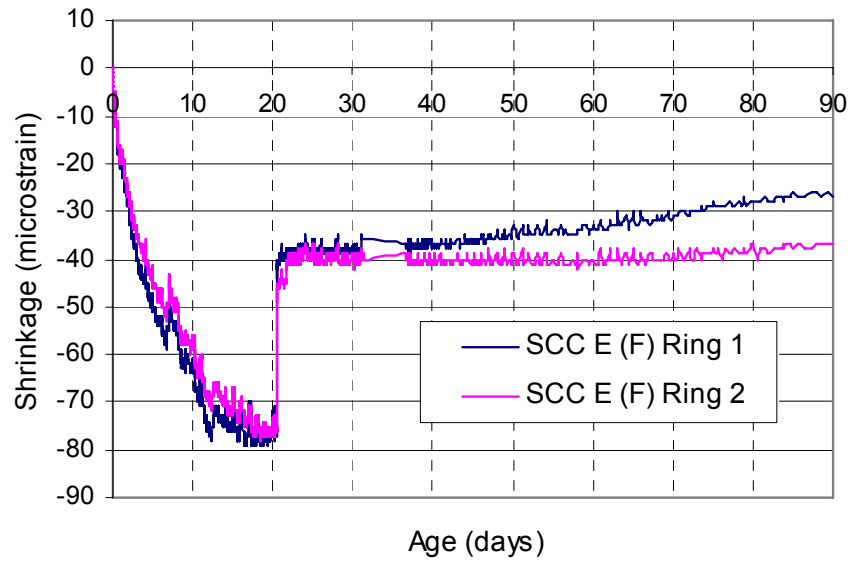

(e)

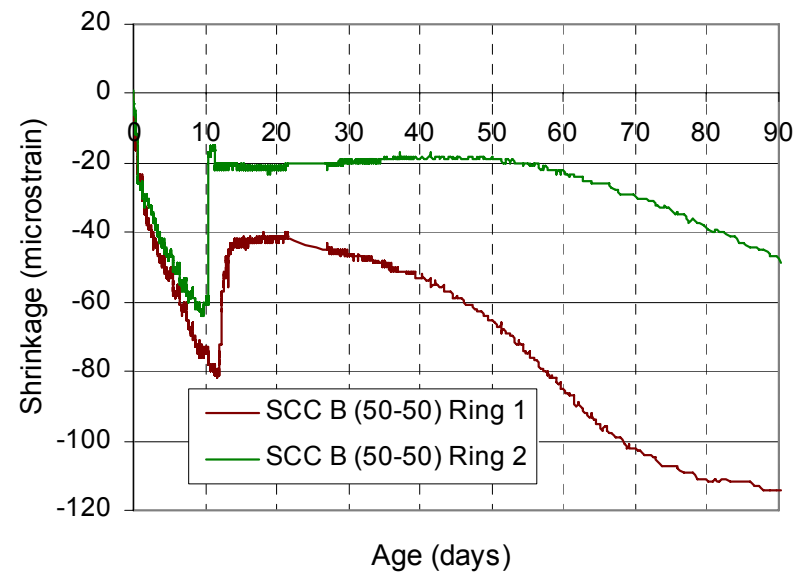

(b)

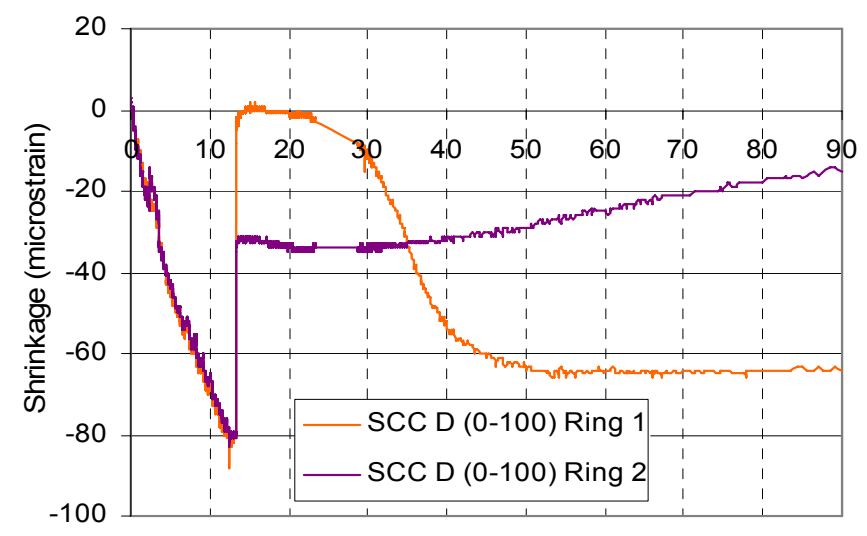

Age (days)

(d)

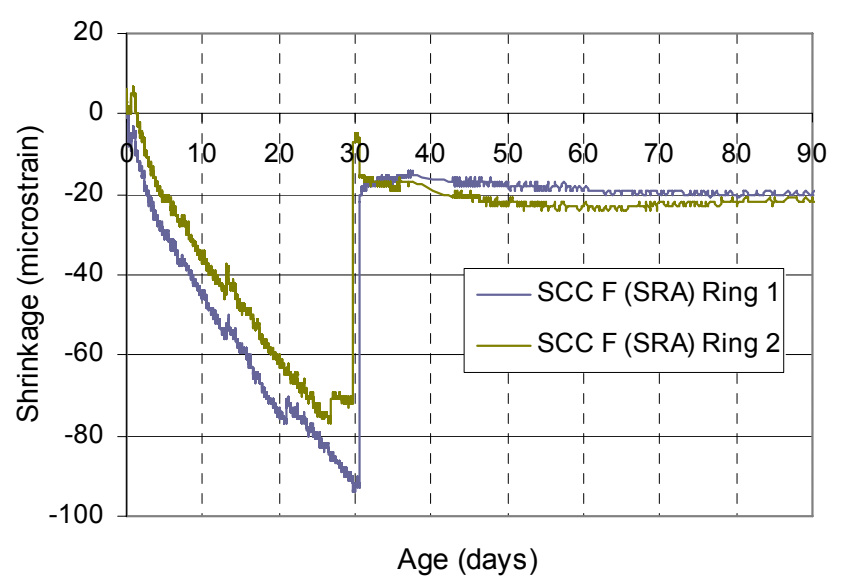

(f)

Figure 6.17 Strain developments with time inside steel ring 
Figure 6.17 illustrates the strain development inside the steel ring with time for the selected six SCC mixtures. As stated earlier, two rings were monitored for the strains; average for each ring were calculated and plotted in the above figures. As seen from the figure, the two rings for each concrete cracked almost at the same age. The cracking point can be seen very clearly from the figures where the strain abruptly changed and moved vertically upward. The following table lists the cracking age of individual rings and the average cracking days for all the mixtures.

\section{Table6.4 - Cracking age for selected SCC mixtures}

\begin{tabular}{c|l|c|c|c}
\hline \multirow{2}{*}{ SCC } & Aggregate Fraction & Cracking Age & \multirow{2}{*}{$\begin{array}{c}\text { Avg. } \\
\text { Cracking } \\
\text { Age (t }\end{array}$} \\
\cline { 3 - 5 } & & Ring 1 & Ring 2 & \\
\hline SCC A (70-30) & $0.35 / 0.15 / 0.50 / L P$ & 23.52 & 22.67 & 23.10 \\
\hline SCC B (50-50) & $0.25 / 0.25 / 0.50 / L P$ & 11.89 & 10.54 & 11.21 \\
\hline SCC C (30-70) & $0.15 / 0.35 / 0.50 / L P$ & 15.80 & 16.76 & 16.28 \\
\hline SCC D (0-100) & $0.0 / 0.50 / 0.50 / L P$ & 13.21 & 13.21 & 13.21 \\
\hline SCC E (F) & $0.35 / 0.15 / 0.50 / L P / F$ & 20.47 & 20.46 & 20.47 \\
\hline SCC F (SRA) & $0.35 / 0.15 / 0.50 / L P / S R A$ & 30.69 & 29.81 & 30.25 \\
\hline
\end{tabular}

As seen from the above table, SCC F (SRA) cracked after 30.25 days after starting of drying which is the highest and SCC B (50-50) cracked after 11.21 days after initiation of drying and is the lowest value among all the mixtures. Figure 6.12 shows typical cracks on the ring surface.

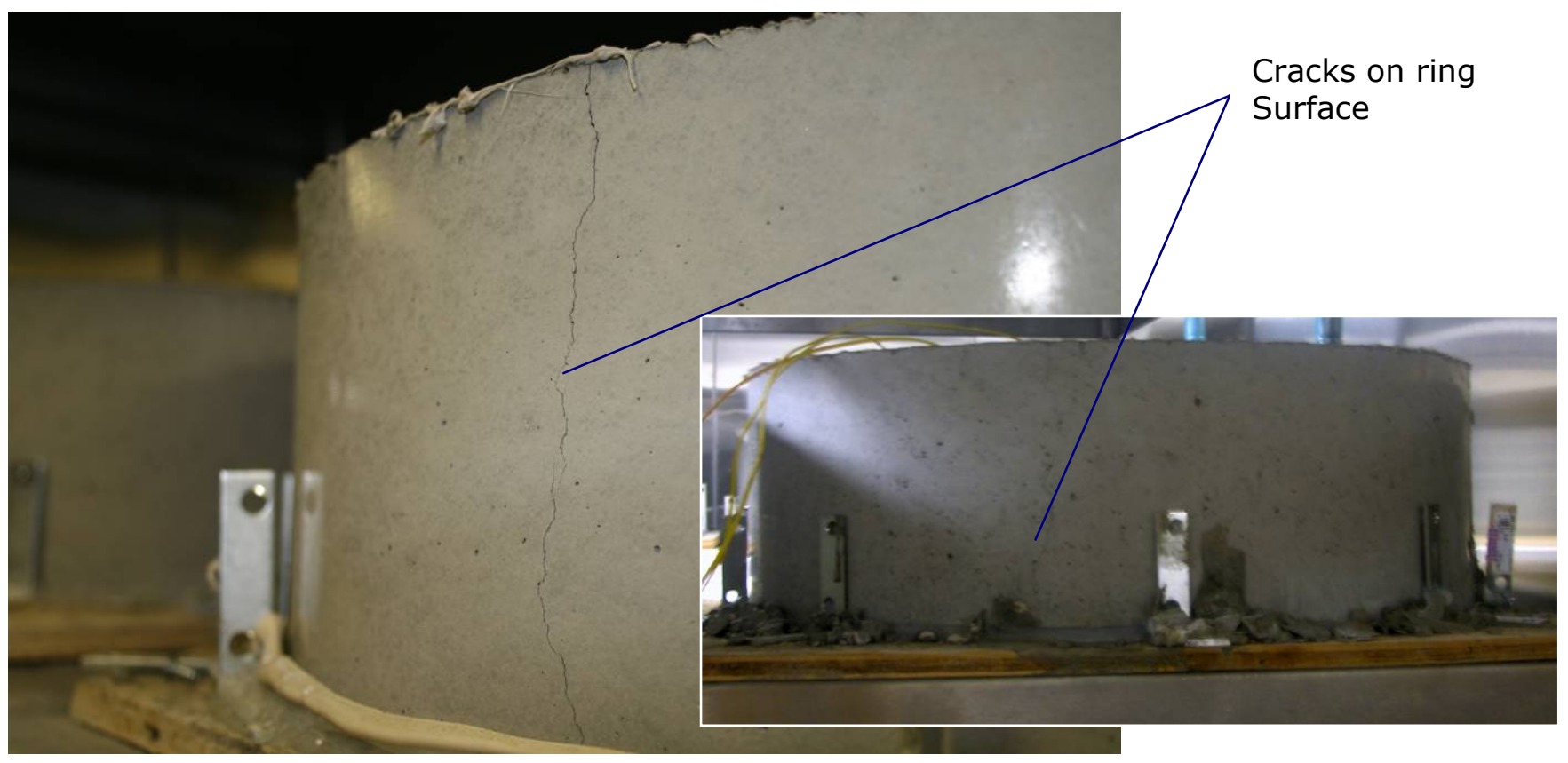

Figure6.18 Typical crack on ring surface 
The mixture containing the SRA cracked last as expected followed by the mixture SCC A (70-30) and the mixture containing fiber. These mixtures cracked between 20 to 30 days after initiation of drying. In the other three remaining mixtures, cracking occurred between 11 and 16 days which are substantially lower than the previous three mixtures. This may be due to the effect of SRA, fiber and aggregate gradation. SCC F (SRA) showed minimum free shrinkage compared to other mixtures and this is one of the main reasons that it cracked last. SCC E (F) contained fibers and its free shrinkage was also next to SCC F (SRA) owing to higher age of cracking. SCC A does not contained SRA or the fiber but still had a higher cracking onset day. This may be due to its higher CA 25 content. The w/cm ratio is the most important parameter affecting strength and the effect of the aggregate is generally ignored. But in case of tensile and fracture properties its effect can not be ignored (Mindess et. al., 2003). An increase in coarse aggregate size and quantity generally results in an increase in tensile strength and fracture energy due to the greater tendency toward crack bridging and the greater path length as cracks pass around the aggregate particles. As the fracture properties are improved by the higher CA size and content, SCC A (70-30) which had a highest percentage of CA 25 $\mathrm{mm}$ compared to other concretes cracked at a later stage. Similar observation can be made for SCC C (30-70) and SCC D (0-100). Due to higher percentage of CA 25 in SCC C (30-70) it cracked at a later day than SCC D (0-100). Although SCC B (50-50) is an exception of the above mentioned justification, the cracking onset day was really close to that of SCC C (30-70) and SCC D (0-100). To strengthen the justification, the following figure is plotted.
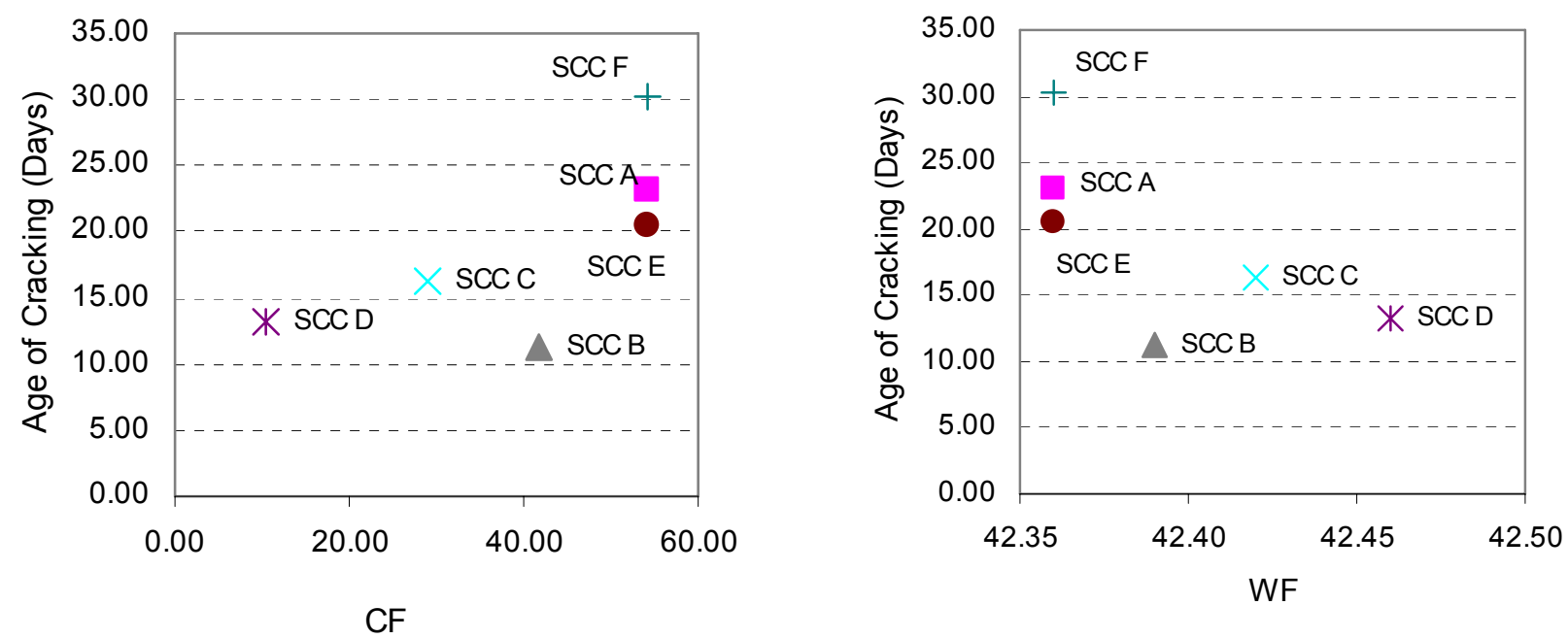

Figure6.19 Average age of cracking versus (a) CF (b) WF 
Figure 6.19 illustrates the relation between average age of cracking and CF and WF. As seen from the figure, there is definitely a trend between the two. Higher the CF, higher was the age when cracks developed. It supports the facts concluded above. Relation between WF and the age of cracking is just a mirror image of the plot between CF and age of cracking. Higher the WF, higher is the tendency to develop cracks early.

\subsubsection{Relation between free shrinkage and restrained shrinkage}

To investigate the relation between free, autogenous and drying shrinkage with the restrained ring shrinkage the following figures are plotted.

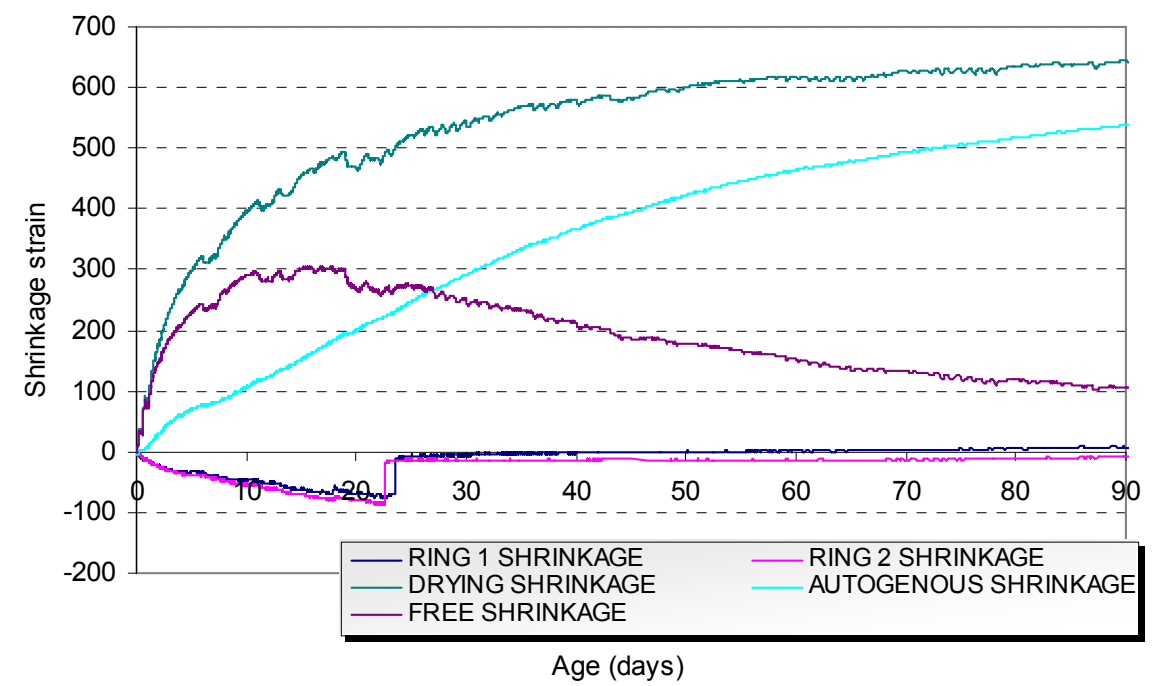

(a)

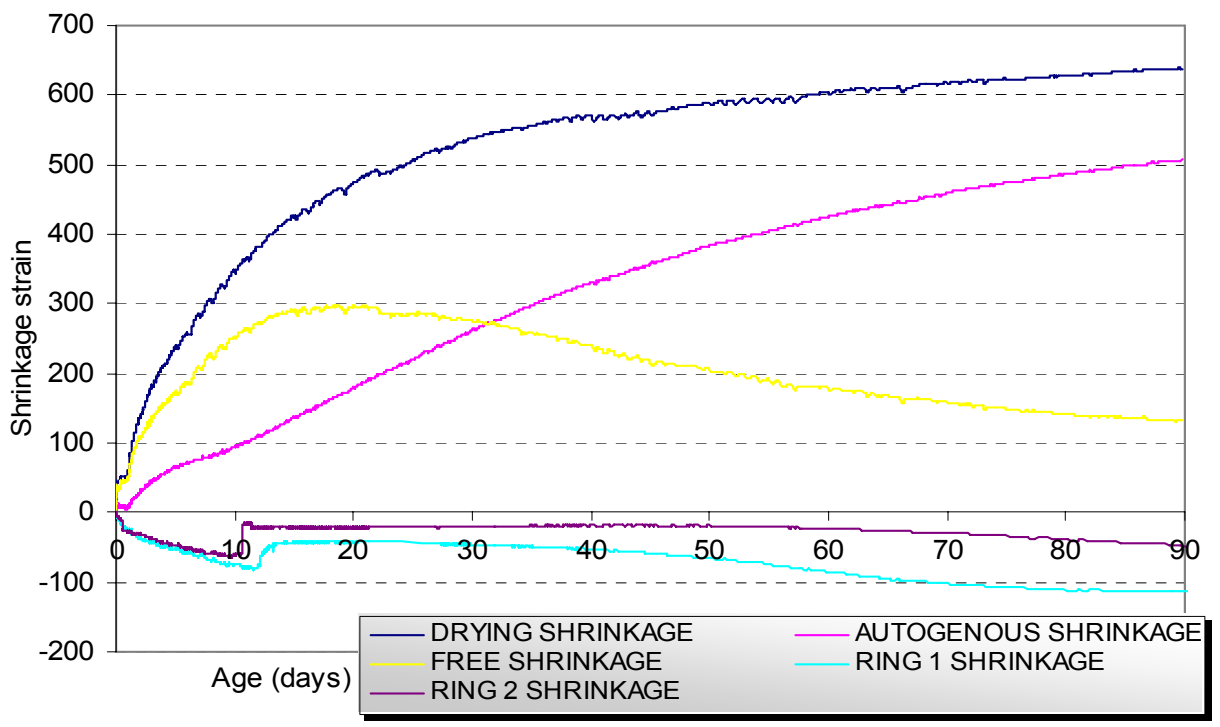

(b) 


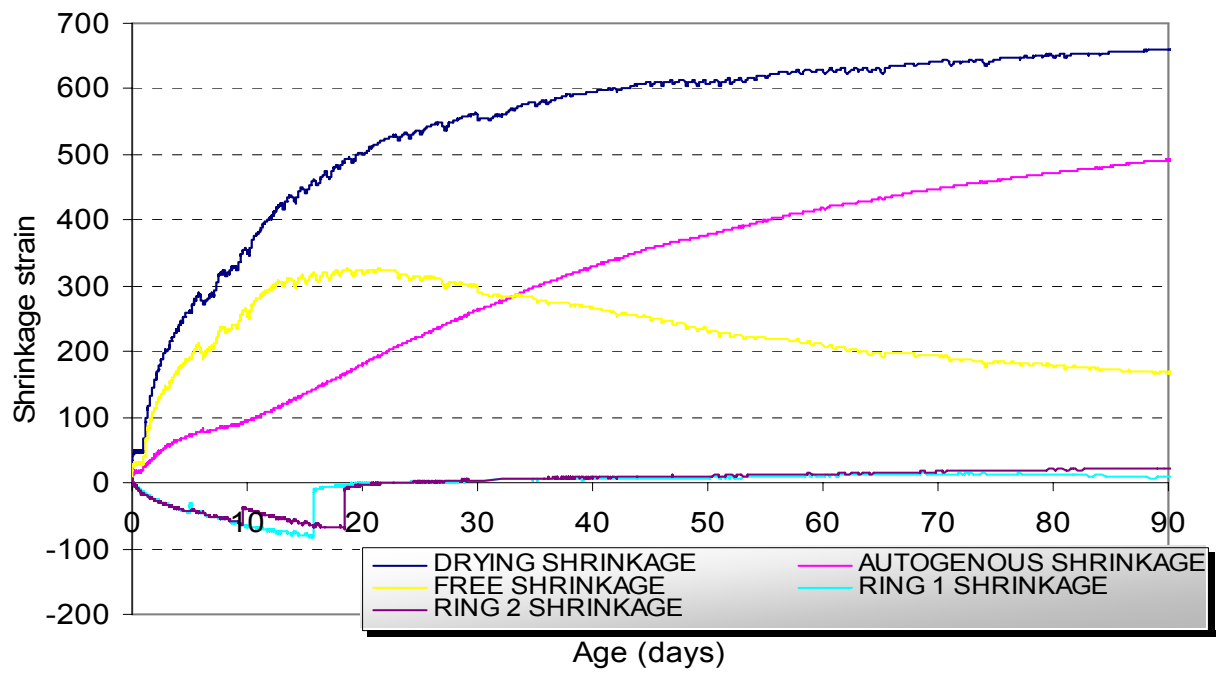

(c)

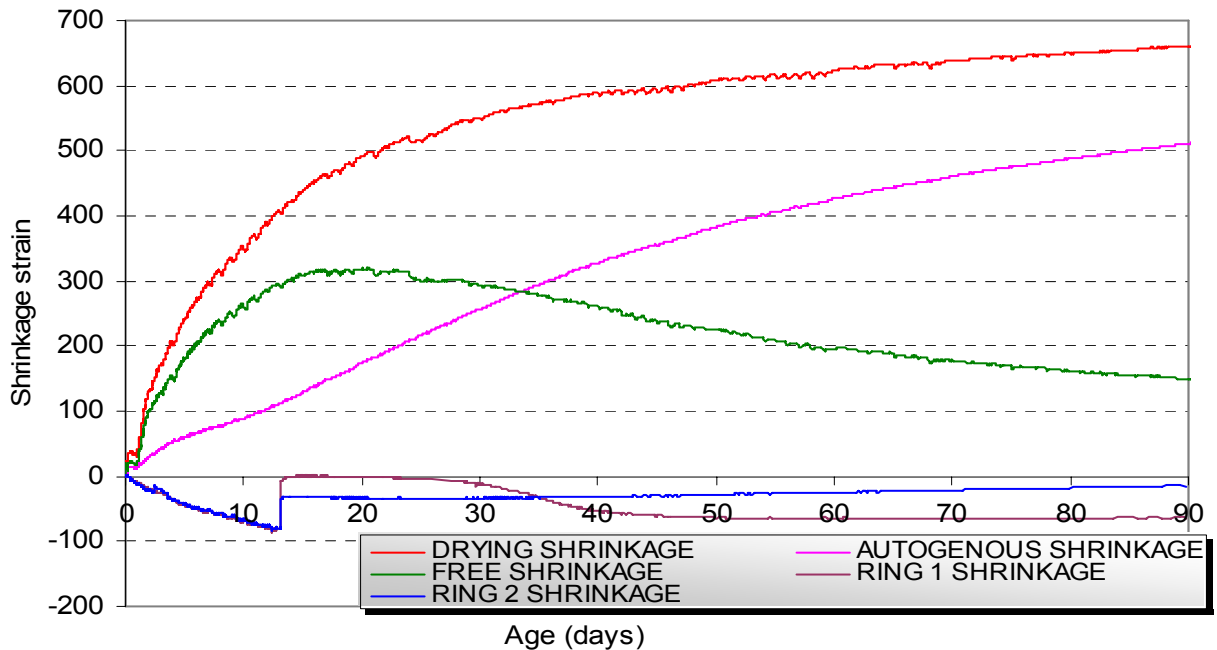

(d)

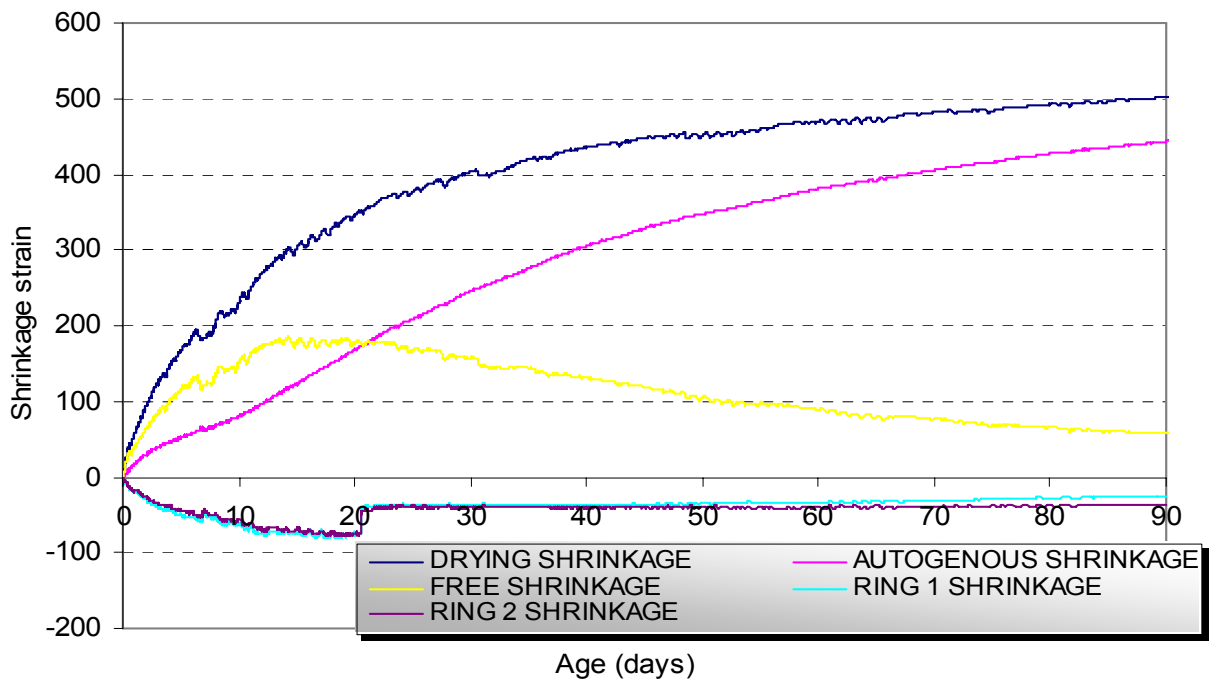

(e) 


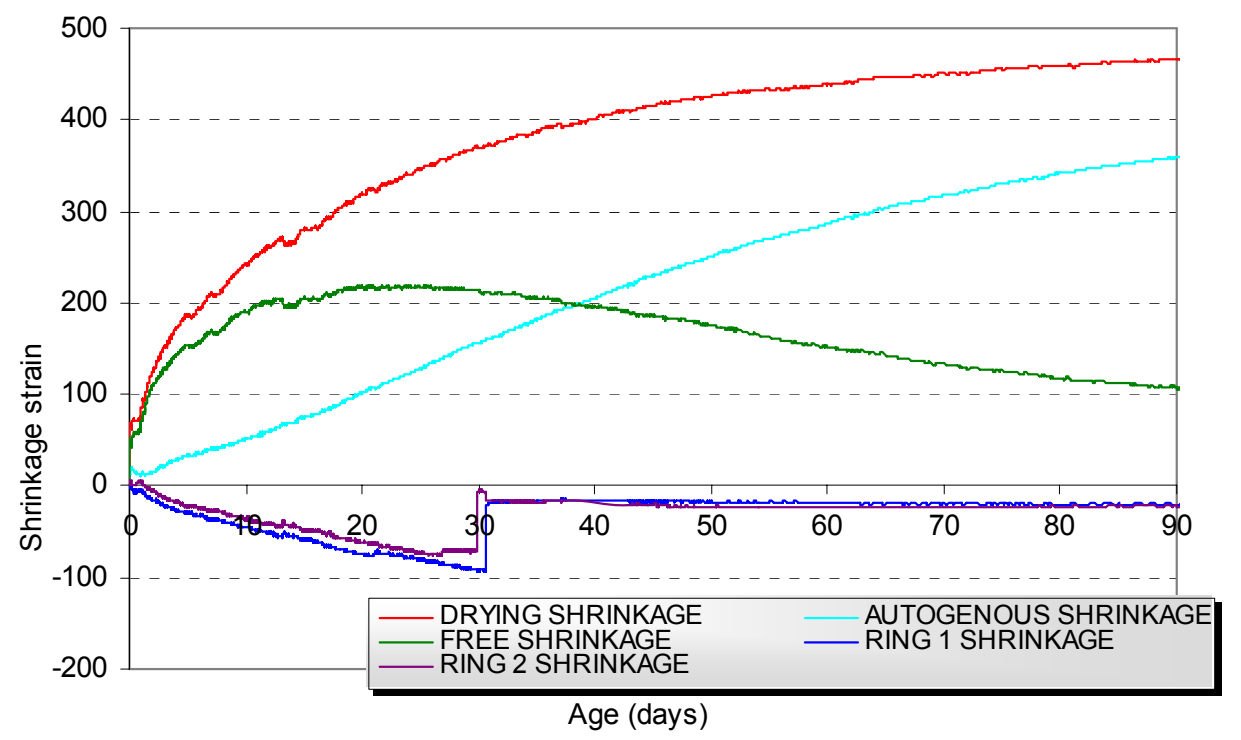

(f)

Figure6.20 Shrinkage comparisons for (a) SCC A (70-30) (b) SCC B (50-50) (C) SCC C (30-70) (d) SCC D (0-100) (e) SCC E (F) (f) SCC F (SRA)

Figure 6.20 illustrates the nature of different shrinkage curves for each SCC mixtures I this experiment. It is observed from the figures that cracking occurred at a period which is very near to the zone when the drying shrinkage values were maximum. It is also observed that SCC A (70-30) through SCC D (0-100) cracked when the drying shrinkage reached a maximum value around 300 microstrains. SCC E (F) and SCC F (SRA) cracked at a much lower drying shrinkage values of the shrinkage specimens. Another observation can be made that the mixtures which cracked at a later stage like SCC A (70-30), SCC E (F), and SCC F (SRA), the specimens cracked after the drying shrinkage reached its highest value. While SCC B (50-50), SCC C (30-70), and SCC D (0-100) cracked at the time when the drying shrinkage reach its peak value or just before that.

\subsubsection{Comparison with HPC}

Comparison can be made with a similar work made by Gong (2006) for HPC mixtures. The result of the ring test has been presented in Table 6.5. SL-SF0.35 represents the mixture contains SL and SF with a $\mathrm{w} / \mathrm{cm}$ ratio of 0.35 . Similar nomenclature was followed for all the mixtures. MK represents Metakaoline. The results for $\mathrm{w} / \mathrm{cm}$ ratios of $0.30,0.35$, and 0.40 are presented below and compared with the results for the SCC mixtures in this experiment. 
Table6.5 - Cracking onset days for different HPC mixtures

\begin{tabular}{c|c}
\hline Mixtures & $\begin{array}{c}\text { Average onset } \\
\text { of cracking } \\
\text { (days) }\end{array}$ \\
\hline SL-SF-0.40 & 13 \\
\hline FA-SF-0.40 & 13 \\
\hline MK-0.40 & 12 \\
\hline SL-SF-0.35 & 10 \\
\hline FA-SF-0.35 & 11 \\
\hline MK-0.35 & 12 \\
\hline SL-SF-0.30 & 8 \\
\hline FA-SF-0.30 & 9 \\
\hline MK-0.30 & 8 \\
\hline
\end{tabular}

(Adopted from Gong, 2006)

As seen from the above table that average cracking onset was less for low $\mathrm{w} / \mathrm{cm}$ ratios and vice versa. This may be due to the higher powder content of the low $\mathrm{w} / \mathrm{cm}$ mixtures. It is observed that the values varied between 8 and 13 days. Where as the cracking onset day for the SCC mixtures varied from 11 to 30 days. Most importantly the water to binder ratio of the SCC mixtures was around 0.30 . When compared to the HPC mixtures with $\mathrm{w} / \mathrm{cm}$ of 0.30 , it was no doubt superior in terms of restrained shrinkage cracking. This may be due to the advantageous effect of the admixtures, fiber, and also may be due to the presence of LP. Hence it may be concluded that these SCC mixtures are superior in terms of restrained shrinkage cracking compared to typical HPC mixtures. Though, due to variation in different parameters and test procedure, more experiments should be conducted before coming to any conclusion.

\subsubsection{Post-cracking ductility of FRSCC}

Plain concrete is a brittle material with low tensile strength and strain capacities. To overcome these disadvantages, fibers are added to the matrix. Fiber reinforced concrete may be defined as concrete incorporating short, discrete, and discontinuous fibers (Mindess, 2003). The purpose of fibers is not to increase the strength but to control the cracking and then to modify the behavior of the material once the concrete matrix has cracked. Fibers provide post-cracking ductility by bridging across the cracks as they begin to open. Hence, addition of fibers may or may not significantly increase the strength, but they have enormous effect on the 
toughness of the concrete mixture. The increase in toughness occurs in the postcracking parts of the curves. Hence addition of fibers does not necessarily mean that cracking potential of the concrete mixture is higher but it signifies that the post cracking behavior of the concrete will be definitely better and the ductility provided by the fibers will resist any sudden failure of the member.

The cracking and post cracking behavior of the fiber reinforced SCC (FRSCC) mixture can be compared with the other mixtures for this experiment. As seen from Figure 6.17, the strains in the concrete rings just before and after cracking were closest for SCC E (F). The differences in strains for the SCC mixture containing fibers were around 30 microstrains, whereas for all the other SCC mixtures it was more than 50 microstrains. It supports the crack-bridging principle of the fibers as stated earlier.

The post cracking strains of the SCC mixtures other than SCC E (F) shows an irregular pattern with high variation and random pattern of strains. Although, SCC F (SRA) showed a better post cracking strain behavior, the sudden decrease in strains just before and after cracking indicates very low ductility and chances of sudden failure. Whereas, SCC E (F) showed a very ductile nature of strain pattern after the cracking onset. The strain values after cracking onset were very consistent and varied only between 30 and 40 microstrains, thus indicting a very good ductility. Hence it may be concluded from the above discussion, that though SCC E (F) does not developed a very good resistance to initial crack occurring compared to SCC F (SRA) and SCC A (70-30), but it developed a very good postcracking behavior and ductility compared to the other mixtures. Further study may be conducted on the beneficial role of fibers on SCC by measuring the crack growth and conducting fracture tests.

\subsubsection{Potential for cracking for different SCC mixtures}

ASTM C 1581-04 describes a process to calculate the stress rate $q$ for each test specimen and the net time to cracking and $\mathrm{q}$ are correlated to potential for cracking of concrete mixtures. The basic equation is as follows:

$\varepsilon_{\text {net }}=\alpha \sqrt{ } \mathrm{t}+\mathrm{k}$

where,

$\varepsilon_{\text {net }}=$ net strain, $\mathrm{m} / \mathrm{m}$ (in/in)

$\alpha=$ strain rate factor for each strain gage on the test specimen, $(\mathrm{m} / \mathrm{m}) / \mathrm{day}^{1 / 2}$ ((in/in)/day $\left.{ }^{1 / 2}\right)$ 
$\mathrm{t}=$ elapsed time, days, and

$\mathrm{k}=$ regression constant

The stress rate $\mathrm{q}$,

$q=\frac{G\left|\alpha_{\text {avg }}\right|}{2 \sqrt{t_{r}}}$

where,

$\mathrm{q}=$ stress rate in each test specimen, $\mathrm{MPa} /$ day (psi/day),

$\mathrm{G}=72.2 \mathrm{GPa}\left(10.47 \times 10^{6} \mathrm{psi}\right)$ is a constant based on the ring dimensions

$\left|\alpha_{\text {avg }}\right|=$ absolute value of the average strain rate factor for each test specimen,

$(\mathrm{m} / \mathrm{m}) /$ day $^{1 / 2}\left((\right.$ in/in $) /$ day $\left.^{1 / 2}\right)$, and

$t_{r}=$ elapsed time at cracking, days

The net strain is defined as the difference between the recorded strain starting from the age of drying in the steel ring and the initial strain. To find the strain rate factor $\alpha$, net strain and square root of elapsed time were plotted. Linear regression analysis was done to fit a straight line through the data. The strain rate factor was the slope of the line. A typical example of calculating the strain rate factor is described below. Figure 6.21 shows a typical plot for net strain and square root of time.

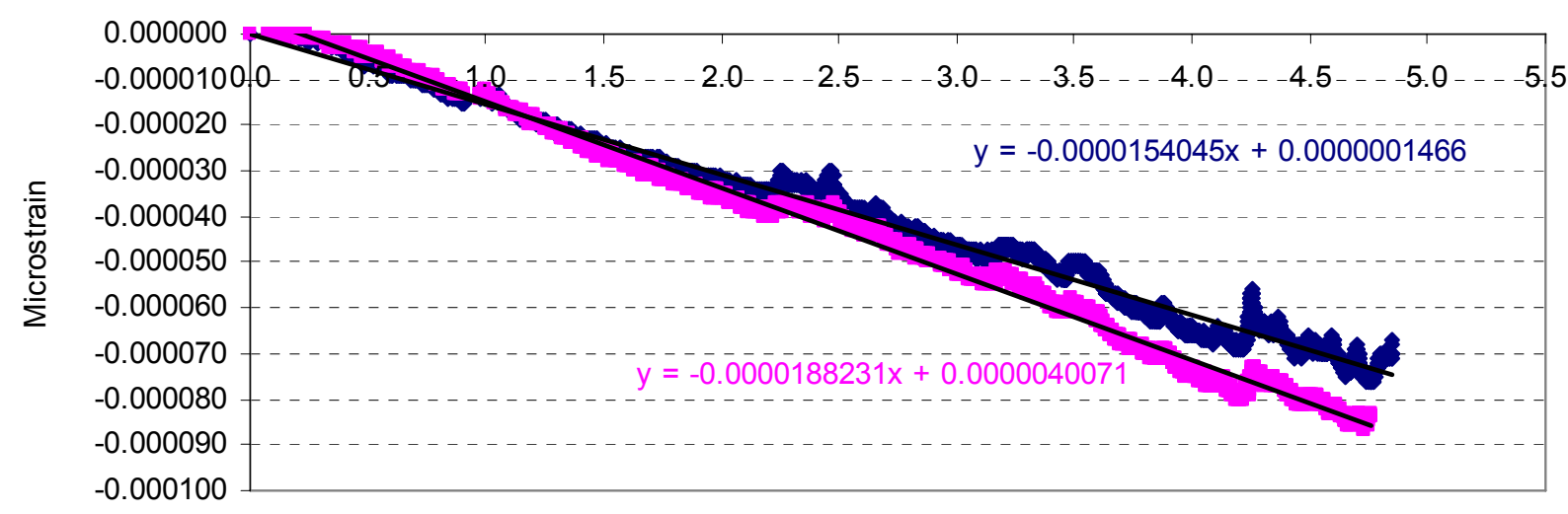

Sqrt (t)

Figure6.21 Net strain versus square root of time for SCC A (70-30) In Figure 6.21, net strain for SCC A (70-30) was plotted against square root of elapsed time. Two curves were obtained for two rings. Then linear regression analysis was performed to fit two straight lines. The equations of the straight lines are shown in the figure. From the equations, the $\alpha$ and $k$ values were computed. 
Similar procedure was followed for each SCC mixtures. The results for $\left|\alpha_{\text {avg }}\right|$ and $|k|$ for all the mixtures are shown in Table 6.6 below:

Table6.6 - Strain rate factor for different SCC mixtures

\begin{tabular}{|c|c|c|c|}
\hline & & \multirow{2}{*}{$\begin{array}{c}\left|\alpha_{a v g}\right| \\
\left.(\mathbf{m} / \mathbf{m}) / \mathbf{d a y}^{\mathbf{1} / \mathbf{2}}\right)\end{array}$} & $|k|$ \\
\hline & & & \\
\hline \multirow{2}{*}{ SCC A (70-30) } & Ring Specimen 1 & $1.54045 \mathrm{E}-05$ & $1.5 \mathrm{E}-07$ \\
\hline & Ring Specimen 2 & $1.88231 \mathrm{E}-05$ & $4 \mathrm{E}-06$ \\
\hline \multirow{2}{*}{ SCC B (50-50) } & Ring Specimen 1 & 0.00002329 & $5.1 \mathrm{E}-06$ \\
\hline & Ring Specimen 2 & $1.85127 \mathrm{E}-05$ & $1.5 \mathrm{E}-06$ \\
\hline \multirow{2}{*}{ SCC C (30-70) } & Ring Specimen 1 & $2.29183 \mathrm{E}-05$ & $8.3 E-06$ \\
\hline & Ring Specimen 2 & $3.19655 \mathrm{E}-05$ & $7.2 \mathrm{E}-06$ \\
\hline \multirow{2}{*}{ SCC D $(0-100)$} & Ring Specimen 1 & $2.67081 \mathrm{E}-05$ & $1.7 \mathrm{E}-05$ \\
\hline & Ring Specimen 2 & $2.76598 \mathrm{E}-05$ & $1.8 \mathrm{E}-05$ \\
\hline \multirow{2}{*}{ SCC E (F) } & Ring Specimen 1 & $1.70046 \mathrm{E}-05$ & $8.2 E-06$ \\
\hline & Ring Specimen 2 & 0.000017225 & $3.8 \mathrm{E}-06$ \\
\hline \multirow{2}{*}{ SCC F (SRA) } & Ring Specimen 1 & $1.85336 \mathrm{E}-05$ & $1.2 \mathrm{E}-05$ \\
\hline & Ring Specimen 2 & $1.74687 \mathrm{E}-05$ & $1.8 \mathrm{E}-05$ \\
\hline
\end{tabular}

The above values are the average strain rate factor for each test specimen. The $\alpha_{\text {avg }}$ values will be used to calculate the stress rate factor, q. As described in Equation (6.43), the stress rate, $q$ depends on a constant $G$ that depends on the ring dimensions. As the ring dimensions in the ASTM and the AASHTO ring test is different, this factor should be modified properly if the equation is applied for the AASHTO ring specimens as tested in this experiment.

\subsubsection{Modification of the constant, $G$}

To modify the value of the constant, G, basic stress-strain behavior of the ring specimens was reviewed. Since the concrete ring is restrained against horizontal movement by the steel ring, internal pressure $\mathrm{p}$ will be developed as the concrete shrinks. The steel ring will experience deformation under compression. The interaction between the steel ring and the concrete ring can be illustrated in Figure 6.22 . 

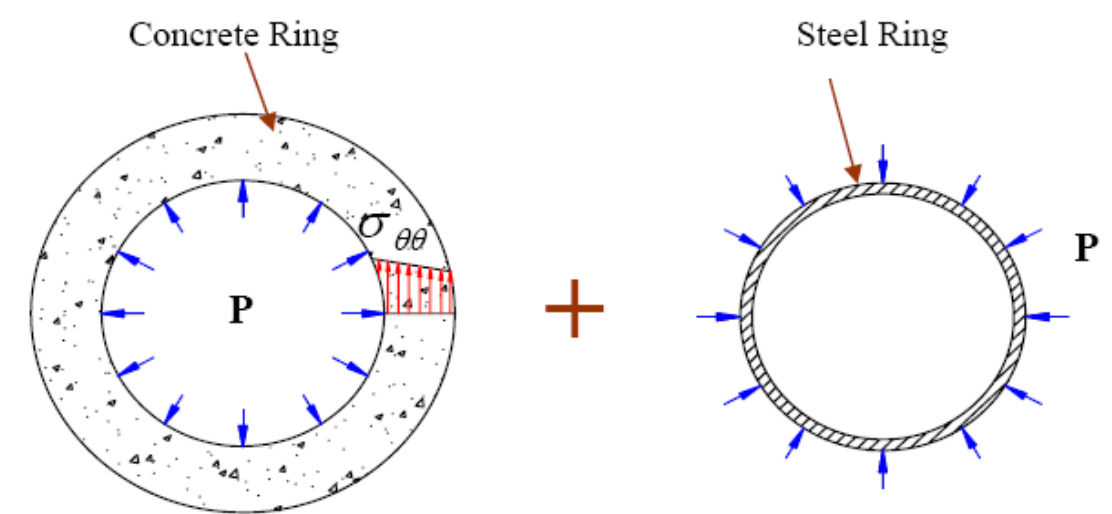

Figure6.22 Interaction between concrete ring and steel ring

The actual stress in the ring is first derived using

$$
\begin{aligned}
& \left.\sigma_{\text {actual-max }}(t)=-\varepsilon_{\text {steel }}\right)\left.(t)\right|_{r=R_{I S}} E_{S} \frac{\left(R_{O S}{ }^{2}-R_{I S}{ }^{2}\right)}{2 R_{O S}{ }^{2}} \frac{R_{O S}{ }^{2}+R_{O C}{ }^{2}}{R_{O C}{ }^{2}-R_{O S}{ }^{2}}=-\left.\varepsilon_{\text {steel }}(t)\right|_{r=R_{I S}} G \\
& G=E_{S} \frac{\left(R_{O S}{ }^{2}-R_{I S}{ }^{2}\right)}{2 R_{O S}{ }^{2}} \frac{R_{O S}{ }^{2}+R_{O C}{ }^{2}}{R_{O C}{ }^{2}-R_{O S}{ }^{2}}
\end{aligned}
$$

Where,

$\mathrm{R}_{\mathrm{IC}}=$ the inner radius of concrete ring

$\mathrm{R}_{\mathrm{OC}}=$ the outer radius of the concrete ring

$\mathrm{R}_{\mathrm{IS}}=$ the inner radius of the steel ring

$\mathrm{E}_{\mathrm{S}}=$ the Young's modulus of steel

The stress rate, $\mathrm{q}$ in Equation (6.43) can be derived by differentiating Equation (6.44) with respect to time and equating $-\varepsilon_{\text {steel }}(t)$ in Equation (6.44) to $\varepsilon_{\text {net }}$ as

$$
q=\frac{d \sigma}{d t}=G \frac{d(\alpha \sqrt{t}+k)}{d t}=\frac{G\left|\alpha_{\text {avg }}\right|}{2 \sqrt{t_{r}}}
$$

If the values of the parameters as per ASTM ring tests are applied to Equation (6.45), the resulting value of $\mathrm{G}$ becomes $72.2 \mathrm{GPa}\left(10.47 \times 10^{6} \mathrm{psi}\right)$. The input parameters for the ASTM ring tests are shown in Table 6.7 below:

\section{Table6.7 - G for ASTM ring geometry}

\begin{tabular}{c|cc}
\hline$E_{S}$ & 199947.96 & $\mathrm{MPa}$ \\
\hline $\mathrm{R}_{\mathrm{OS}}$ & 165.1 & $\mathrm{~mm}$ \\
\hline $\mathrm{R}_{\mathrm{IS}}$ & 152.4 & $\mathrm{~mm}$ \\
\hline $\mathrm{R}_{\mathrm{OC}}$ & 203.2 & $\mathrm{~mm}$ \\
\hline \multicolumn{3}{|c}{$\mathrm{G}=72.244 \mathrm{GPa}$} \\
\hline
\end{tabular}

Since the values for the AASHTO ring dimensions are different than the ASTM ring dimensions, the same formula is applied to calculate the $G$ value for the AASHTO 
ring test also. The input parameters for this experiment are shown in Table 6.8 below:

Table6.8 - G for AASHTO ring geometry

\begin{tabular}{c|cl}
\hline$E_{\mathrm{s}}$ & 199947.96 & $\mathrm{MPa}$ \\
\hline $\mathrm{R}_{\mathrm{OS}}$ & 161.9 & $\mathrm{~mm}$ \\
\hline $\mathrm{R}_{\mathrm{IS}}$ & 149.2 & $\mathrm{~mm}$ \\
\hline $\mathrm{R}_{\mathrm{OC}}$ & 238.1 & $\mathrm{~mm}$ \\
\hline \multicolumn{3}{|c}{$\mathrm{G}=40.986 \mathrm{GPa}$} \\
\hline
\end{tabular}

$(1 \mathrm{MPa}=145 \mathrm{psi}, 1 \mathrm{~mm}=0.039 \mathrm{in}))$

After using the modified values for AASHTO ring dimension as illustrated in Table 6.7 , the value of $\mathrm{G}$ obtained as $40.986 \mathrm{GPa}\left(5.9446 \times 10^{6} \mathrm{psi}\right)$. This value of $\mathrm{G}$ will be used in the Equation (6.43) to evaluate the stress rate factor, $q$.

The values of $G, \alpha_{a v g}$, and $t_{r}$ were used as input for Equation (6.43) and the resulting values of $q$ were tabulated in Table 6.9. The average stress rates, $\mathrm{S}$ were calculated for the test specimens to the nearest MPa/day (psi/day).

Table6.9 - Stress rate factors for different SCC mixtures

\begin{tabular}{|c|c|c|c|c|}
\hline & \multirow{3}{*}{$\frac{q}{\text { ( MPa/ day) }}$} & \multirow{3}{*}{$\begin{array}{c}t_{c r} \\
\text { (days) }\end{array}$} & \multirow{3}{*}{$\begin{array}{c}\text { Savg }_{\text {(MPa/ day) }} \\
\text { (Mal }\end{array}$} \\
\hline & & & & \\
\hline & & & & \\
\hline \multirow{2}{*}{$\operatorname{SCC} A(70-30)$} & Ring Specimen 1 & 0.07 & \multirow{2}{*}{23} & \multirow{2}{*}{0.07} \\
\hline & Ring Specimen 2 & 0.08 & & \\
\hline \multirow{2}{*}{ SCC B (50-50) } & Ring Specimen 1 & 0.14 & \multirow{2}{*}{11} & \multirow{2}{*}{0.13} \\
\hline & Ring Specimen 2 & 0.12 & & \\
\hline \multirow{2}{*}{$\operatorname{SCC} C(30-70)$} & Ring Specimen 1 & 0.12 & \multirow{2}{*}{16} & \multirow{2}{*}{0.14} \\
\hline & Ring Specimen 2 & 0.16 & & \\
\hline \multirow{2}{*}{ SCC D (0-100) } & Ring Specimen 1 & 0.15 & \multirow{2}{*}{13} & \multirow{2}{*}{0.15} \\
\hline & Ring Specimen 2 & 0.16 & & \\
\hline \multirow{2}{*}{ SCC E (F) } & Ring Specimen 1 & 0.08 & \multirow{2}{*}{20} & \multirow{2}{*}{0.08} \\
\hline & Ring Specimen 2 & 0.08 & & \\
\hline \multirow{2}{*}{ SCC F (SRA) } & Ring Specimen 1 & 0.07 & \multirow{2}{*}{30} & \multirow{2}{*}{0.07} \\
\hline & Ring Specimen 2 & 0.07 & & \\
\hline
\end{tabular}

$(1 \mathrm{MPa} /$ day $=145 \mathrm{psi} /$ day $)$

To study the effect of CF on the average stress rate, Figure 6.23 is plotted as shown below. 


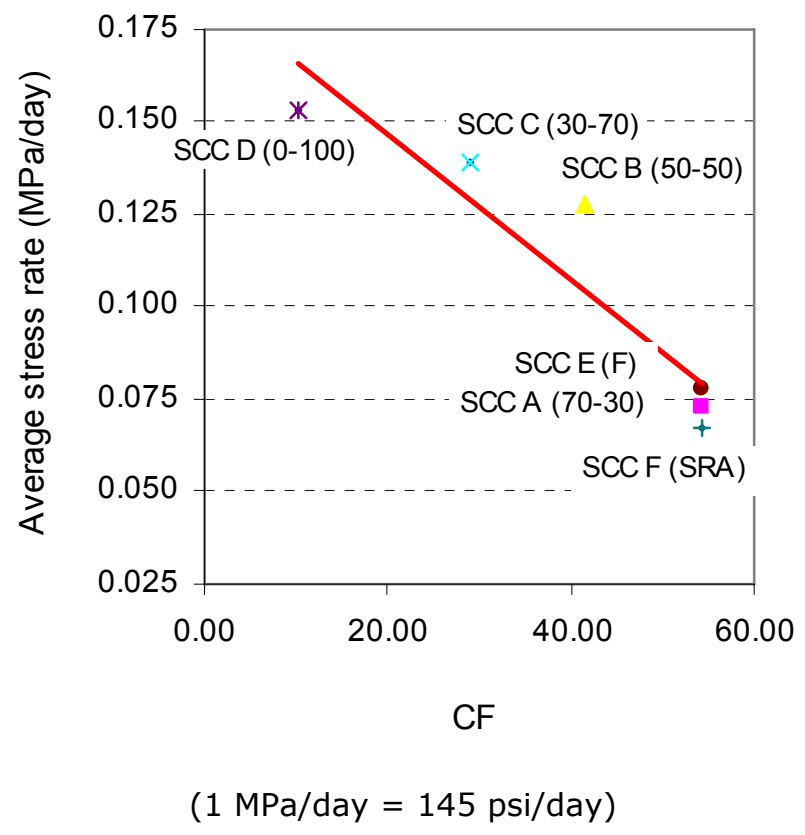

Figure6.23 CF versus average stress rate

As seen from the above figure, average stress rate were lowest for higher CF and vice versa.

ASTM C 1581-04 furnishes a table to calculate the potential for cracking classification based on the values of net time-to-cracking and average stress rate, $\mathrm{S}$. The following Table 6.10 illustrates the potential for cracking classification:

Table6.10 - Potential for cracking classification

\begin{tabular}{|c|c|c|c|}
\hline $\begin{array}{c}\text { Net Tim-to-Cracking, } \\
\mathbf{t}_{\mathrm{cr}} \text { days }\end{array}$ & $\begin{array}{c}\text { Average } \\
\text { Stress Rate, } \\
\text { (psi/ day) }\end{array}$ & $\begin{array}{c}\text { Average Stress } \\
\text { Rate, } \mathbf{S} \\
\text { ( MPa/ day) }\end{array}$ & $\begin{array}{c}\text { Potential for } \\
\text { Cracking }\end{array}$ \\
\hline $0<\mathrm{t}_{\mathrm{cr}} \leq 7$ & $\mathrm{~S} \geq 50$ & $\mathrm{~S} \geq 0.34$ & High \\
\hline $7<\mathrm{t}_{\mathrm{cr}} \leq 14$ & $7 \leq \mathrm{S}<14$ & $0.17 \leq \mathrm{S}<0.34$ & Moderately-High \\
\hline $\mathrm{t}_{\mathrm{cr}} \leq 28$ & $14 \leq \mathrm{S}<25$ & $0.10 \leq \mathrm{S}<0.17$ & Moderately-Low \\
\hline $\mathrm{t}_{\mathrm{cr}} \geq 28$ & $\mathrm{~S}<15$ & $\mathrm{~S}<0.10$ & Low \\
\hline
\end{tabular}

$(1 \mathrm{MPa} /$ day $=145 \mathrm{psi} /$ day $)$

(Adopted from ASTM C 1581-04)

Table 6.10 can be used to assess the relative performances of the concrete mixtures. The values for the selected SCC mixtures can be compared from Table 6.9 to assess the relative potential for cracking of the developed mixtures. Table 6.11 shows the 
potential for cracking of the selected SCC mixtures based on net time-to-cracking and average stress rate, $\mathrm{S}$.

Table6.11 - Potential for cracking for selected SCC mixtures

\begin{tabular}{c|c|c}
\cline { 2 - 3 } & $\begin{array}{c}\text { Potential for cracking } \\
\text { based on net time-to- } \\
\text { cracking (t } \text { crr }_{\text {days) }}\end{array}$ & $\begin{array}{c}\text { Potential for cracking based } \\
\text { on average stress rate (S, } \\
\text { MPa/ day) }\end{array}$ \\
\hline SCC A (70-30) & Moderately-Low & Low \\
\hline SCC B (50-50) & Moderately-High & Moderately-Low \\
\hline SCC C (30-70) & Moderately-Low & Moderately-Low \\
\hline SCC D (0-100) & Moderately-High & Moderately-Low \\
\hline SCC E (F) & Moderately-Low & Low \\
\hline SCC F (SRA) & Low & Low \\
\hline
\end{tabular}

It is observed from the above table that all the SCC mixtures had moderately-low to low cracking potential based on average stress rate. SCC F (SRA), SCC E (F), and SCC A (70-30) had the lowest average stress rate, hence it had the lowest potential for cracking as expected. All the other mixtures had a moderatelylow potential for cracking based on the average stress rate.

Potential for cracking based on net time-to-cracking indicates a low to moderately-high cracking potential for the SCC mixtures. SCC F (SRA) had a low potential for cracking followed by SCC A (70-30) and SCC F (SRA) which had moderately-low potential for cracking. SCC B (50-50) and SCC D (0-100) had a moderately-high possibility of cracking when compared to the net time-to-cracking.

From the above discussion, it may be concluded that all the SCC mixtures were good against cracking with SCC F (SRA) having the lowest potential for cracking and SCC B (50-50) and SCC D (0-100) having moderately-high potential for cracking. All the other mixtures had moderately-low potential for cracking. Hence it is recommended that SCC B (50-50) and SCC D (0-100) may not be used where cracking can be a crucial factor like tanks, bridge decks and other important structures.

It may be also concluded from Figure 6.23 and Table 6.8 that the mixtures having higher CF had the lowest average stress rate subsequently lower potential for cracking. SCC A (70-30), SCC E (F), and SCC F (SRA) had the highest 
CF and subsequently the lowest potential for cracking. SCC D (0-100) had the lowest CF factor and developed highest average stress rate which ultimately led to a moderately-high possibility of cracking. SCC B (50-50) was the only exception. More test results are needed to support the fact.

\subsection{Concluding Remarks}

In this chapter the free and autogenous shrinkage of the selected SCC mixtures were investigated. In this study, the AASHTO type ring specimen test was adopted to investigate the restrained cracking behavior of the selected mixtures with LP. Also the effects of aggregate gradation, compressive strength, effect of fiber and SRA on cracking were investigated. Cracking potential of the mixtures was also investigated using ASTM C 1581-04. Total shrinkage values for the SCC mixtures were found to be similar to that of normal concrete mixtures and the HPC mixtures. Autogenous shrinkage had played a big part in the shrinkage values for all the SCC mixtures. SCC F (SRA) followed by SCC E (F) showed best performance regarding shrinkage. When compared to standard shrinkage prediction models, ACI model best predicted the shrinkage values for the SCC mixtures. The ACI equation was then calibrated for the mixtures containing LP. Restrained shrinkage tests illustrated that SCC mixtures were superior when compared to the HPC mixtures with SCC F (SRA) and SCC E (F) performing best. An elastic analysis followed by the procedure described in ASTM C 1581 was used to find the cracking potential for the SCC mixtures. The cracking potential was found to be good in general and was in the range of "low" to "moderately low" signifying better resistance against restrained shrinkage cracking. The chloride permeability, air-void parameters, and freeze-thaw resistance of the selected mixtures are discussed in details in the next chapter. 


\section{CHAPTER SEVEN}

\section{SCUSSI ONS ON AI R-VOI D PARAMETERS, FREEZI NG AND THAWI NG, AND CHLORI DE PERMEABI LI TY}

Concrete structures are particularly susceptible to attacks from external deleterious materials. It is of utmost importance that concrete structures should perform well during its expected service life without any major durability problem. That is, it should maintain its strength and serviceability during its life time. Although concrete is inherently a non-reactive durable material, it is vulnerable to attacks such as frost, deicing chemicals, and sulfate or chloride diffusion. Each of these processes involves movement of water or ions, transporting aggressive agents through the pore structures of concrete. As SCC is a new type of concrete with different pore structure and paste properties, it requires better evaluation of durability properties because of the potential complexity resulted from fillers, supplementary cementing materials or aggregates that may cause unexpected durability problem. In this chapter, the chloride permeability, air-void parameters, and freezing and thawing characteristics of the developed mixtures will be investigated.

\subsection{Chloride Permeability Test}

The problem of chloride attack arises usually when chloride ions ingress from outside. This can be caused by application of de-icing salts in bridge decks during winter season. Ingress of chloride ion takes place by none-steady state diffusion. The protective passive layer on the surface of embedded steel consists of gama- $\mathrm{Fe}_{2} \mathrm{O}_{3}$ that tightly adheres to the steel, which protects the steel to be intact. However, this layer can be destroyed with the presence of chloride ion. This is one the major problem nowadays for the concrete bridge decks and girders in USA.

\subsubsection{Test Method}

The rapid chloride permeability test (RCPT) is a measure of electrical conductivity or resistivity of concrete pore solution. The test was first adopted in AASHTO T 277 and later in ASTM C 1202 (Standard Test Method for Electrical Indication of Concrete's Ability to Resist Chloride Ion Penetration), and is widely used due to its simplicity and rapidity. Many state departments and Federal Highway Administration (FHWA) recommended this test as standard method to evaluate chloride permeability for normal as well as high-performance concrete mixtures. 
The specimens were cast in plastic cylinder molds of diameter $101.6 \mathrm{~mm}$ and height $203.3 \mathrm{~mm}$. All specimens were demolded after 24 hours of casting and cured under lime saturated water at $23 \pm 2$ C. After curing for 56 days, all specimens were removed from water. For RCPT test, disc specimens were cut from the middle of cured cylinder specimens using a diamond cutting saw from each cylinder, two discs of size $102 \mathrm{~mm}$ diameter and $51 \pm 3 \mathrm{~mm}$ height were collected. The middle discs were selected to avoid the heterogeneity of top and bottom portions of the cylinders. Disk specimens were coated on the circumferential surface, dried, put into beaker and vacuumed for 3 hrs. Then distilled water, which was boiled to escape bubbles, was let into the beaker and the disk was soaked with this water for 18 hours. Then, the disk specimens were taken out of water, put into chloride permeability cell and a constant voltage of $60 \mathrm{~V}$ was applied.

The specimens were tested between 60 and 62 days. This extra time was required to condition and prepare the specimens according to ASTM C 1202. For each concrete four discs were prepared. Two discs were tested with standard solutions of $3 \% \mathrm{NaCl}$ and $0.3 \mathrm{~N} \mathrm{NaOH}$, respectively in ach cell as per the standard. The other two discs tested with water used for conditioning of specimens in each cell instead of the standard solutions. The later test is defined as 'blank test'. The purpose of the blank test is to observe the effects of ionic species within concrete pore solutions introduced solely from chemical and mineral admixtures. The temperatures of the tests were monitored by inserting thermocouples inside the test specimens. The current and charge passed were recorded by printing at an interval of 5 minutes for the first hour and then using an interval of 30 minutes until the end of test.
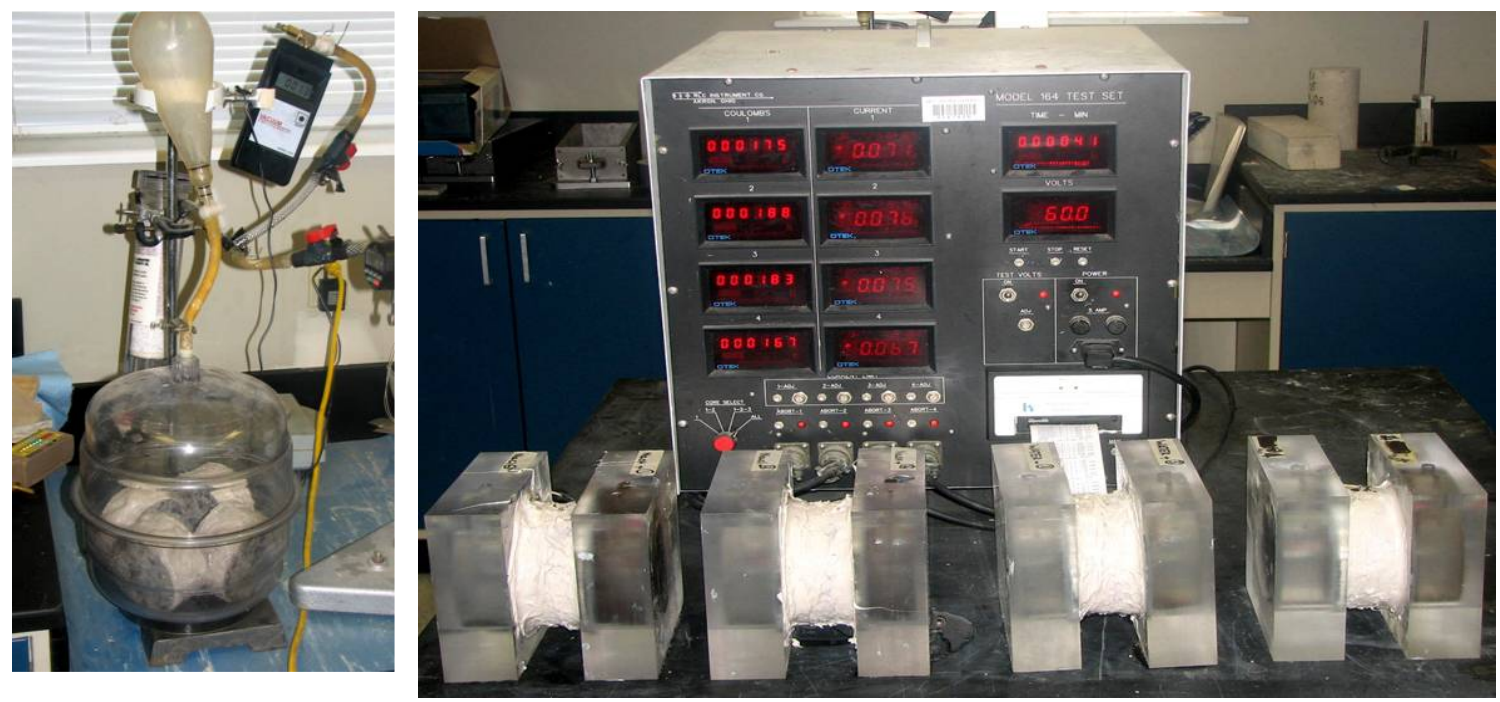

Figure 7.1 RCPT test being conducted in the laboratory 
There are some concerns regarding the RCPT test (Uchoa et. al., 2007). The major concerns are (1) it measures not only the chloride ions movement but other ions movement including hydroxide, which has greater mobility than chloride ions (2) high heat is generated due to high voltage applied across the specimens. This leads to higher values for RCPT tests and (3) the mineral admixtures such as silica fume, fly ash, and slag have significant effects on pore solutions that influences the electrical conductivity subsequently affecting the RCPT results. Lane (2005) proposed modifications to improve the reliability of the RCPT test results by using conductivity values obtained in the first 10 minutes of testing. This is due to the fact that many researchers reported heating problems due to the duration value of 6 hours for the test. That particularly influences the smaller size specimens which yields in greater charge passed. Hence it was suggested that the initial current measurement is more useful to estimate the specimen conductivity. Though Lane proposed the modification using first 10 minutes, most of the other researchers suggested using the 30 minutes charge multiplied by 12 to avoid the heating effect. The use of early values also leads to reduce variability of the test results.

\subsubsection{Test Result and Discussion}

The summary of test results is shown in Table 7.1 below.

Table 7.1 - Summary of charge passed results for all the mixtures

\begin{tabular}{|c|c|c|c|c|c|c|c|}
\hline Mixtures & $\begin{array}{l}360 \\
\text { min. }\end{array}$ & $\begin{array}{c}10 \\
\text { min. } \\
\times 36\end{array}$ & $\min _{12}^{30} x$ & Blank & $\begin{array}{c}360 \\
\text { min. } \\
\text { minus } \\
\text { Blank } \\
\% \\
\end{array}$ & $\begin{array}{c}360 \text { min. } \\
\text { minus } \\
10 \times 36 \\
\min . \%\end{array}$ & $\begin{array}{c}360 \text { min. } \\
\text { minus } \\
30 \times 12 \\
\text { min. } \%\end{array}$ \\
\hline $\begin{array}{l}\text { SCC A (70- } \\
30)\end{array}$ & 1799 & 1872 & 1554 & 1614 & 10.3 & -4.1 & 13.6 \\
\hline $\begin{array}{l}\text { SCC B (50- } \\
50)\end{array}$ & 1820 & 1548 & 1596 & 1588 & 12.7 & 14.9 & 12.3 \\
\hline $\begin{array}{l}\text { SCC C (30- } \\
70)\end{array}$ & 1576 & 1350 & 1380 & 1081 & 31.4 & 14.3 & 12.4 \\
\hline $\begin{array}{l}\text { SCC D (0- } \\
100)\end{array}$ & 1746 & 1476 & 1482 & 1141 & 34.7 & 15.5 & 15.1 \\
\hline SCC E (F) & 2839 & 2304 & 2304 & 1107 & 61.0 & 18.8 & 18.8 \\
\hline SCC F (SRA) & 1341 & 1188 & 1200 & 770 & 42.6 & 11.4 & 10.5 \\
\hline HPC (Typ.) & 1824 & 1408 & 1422 & 1123 & 38.4 & 22.8 & 22.0 \\
\hline
\end{tabular}

Table 7.1 compares the 56-day results from standard 360-min RCPT, 10-min RCPT charge multiplied by 36 to obtain extrapolated charge for 360-min RCPT, 30-min RCPT charge multiplied by 12 to obtain extrapolated charge for 360-min RCPT, and charge passed during blank test. Charge passed values for one typical normal slump 
HPC values are also listed (Uchoa et al., 2008). Charges passed recorded in the blank test were quite high for almost all the cases. This shows that under voltage difference large amount of charge were able to pass through specimens even in absence of chloride ions in the cell solution.

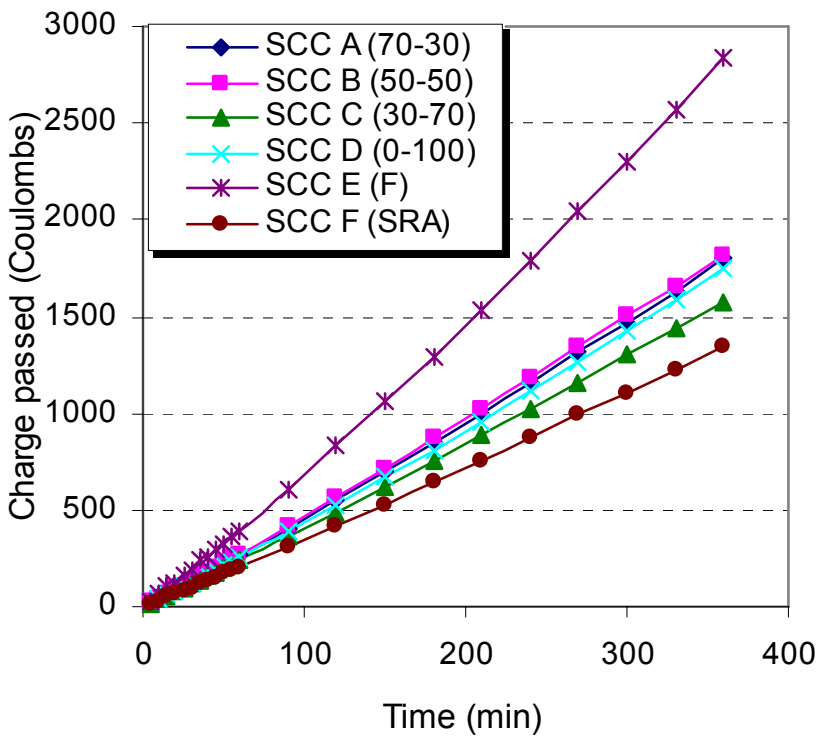

(a)

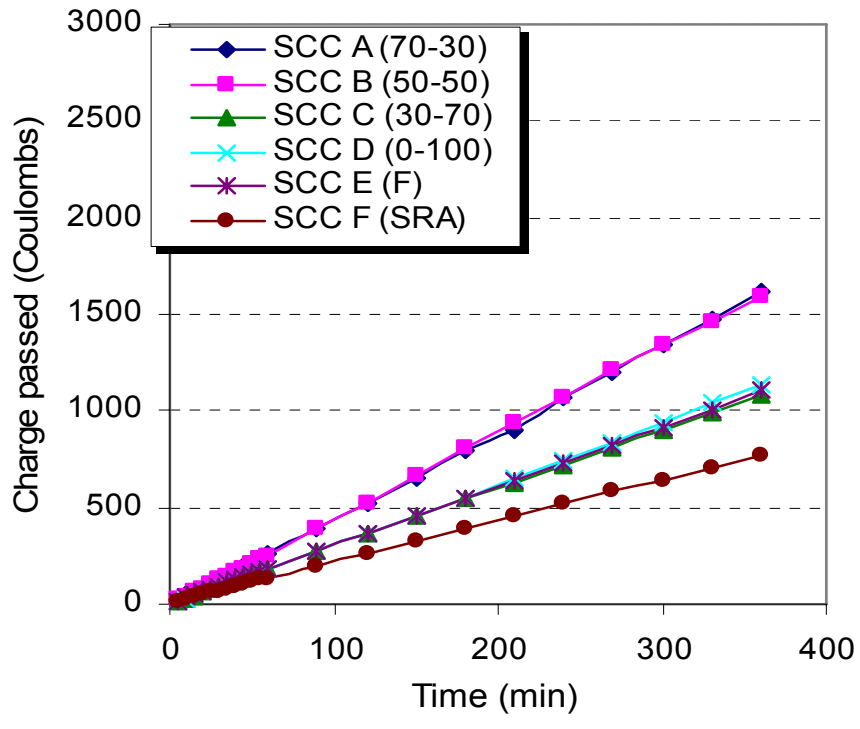

(b)

Figure 7.2 Charge passed versus time for (a) RCPT (b) blank test

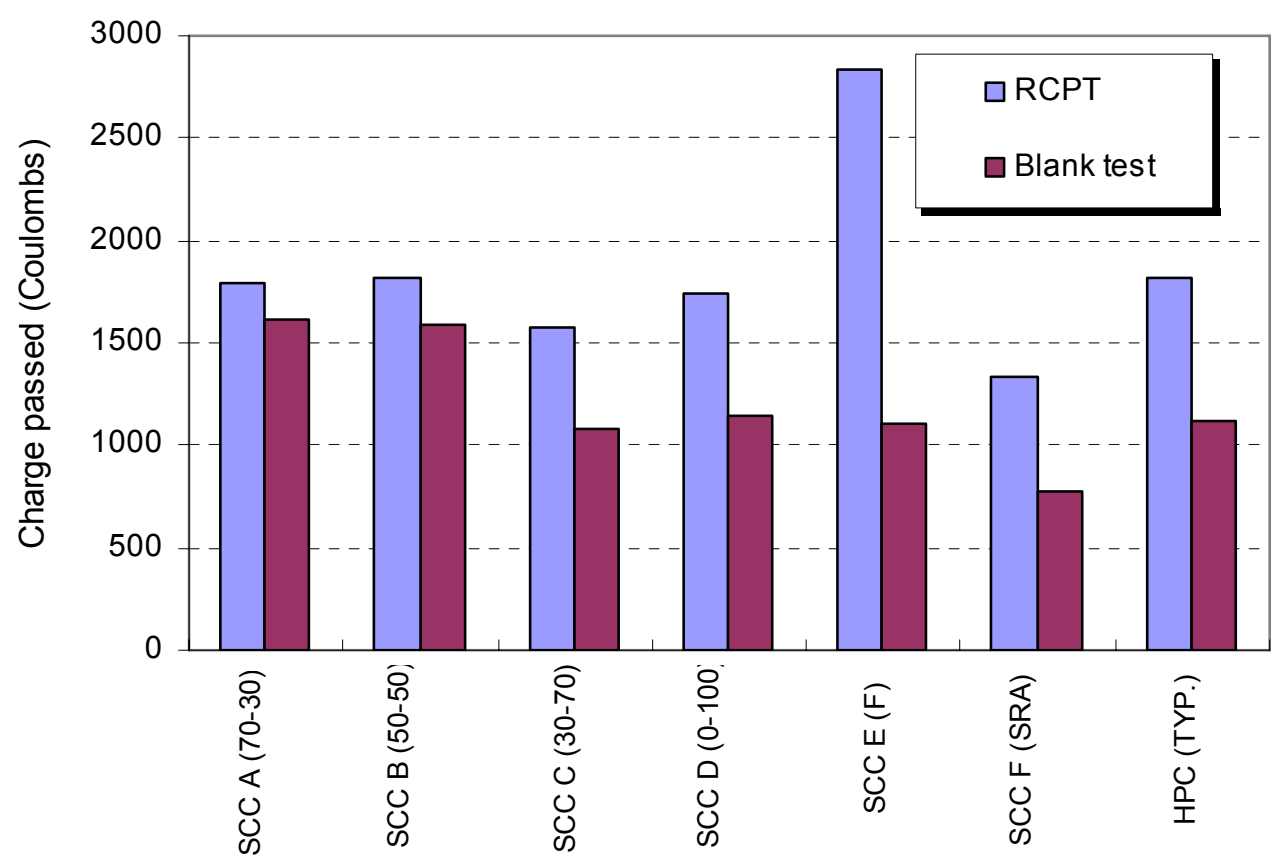

Types of concretes

Figure 7.3 Comparison of charge passed between RCPT and blank test 


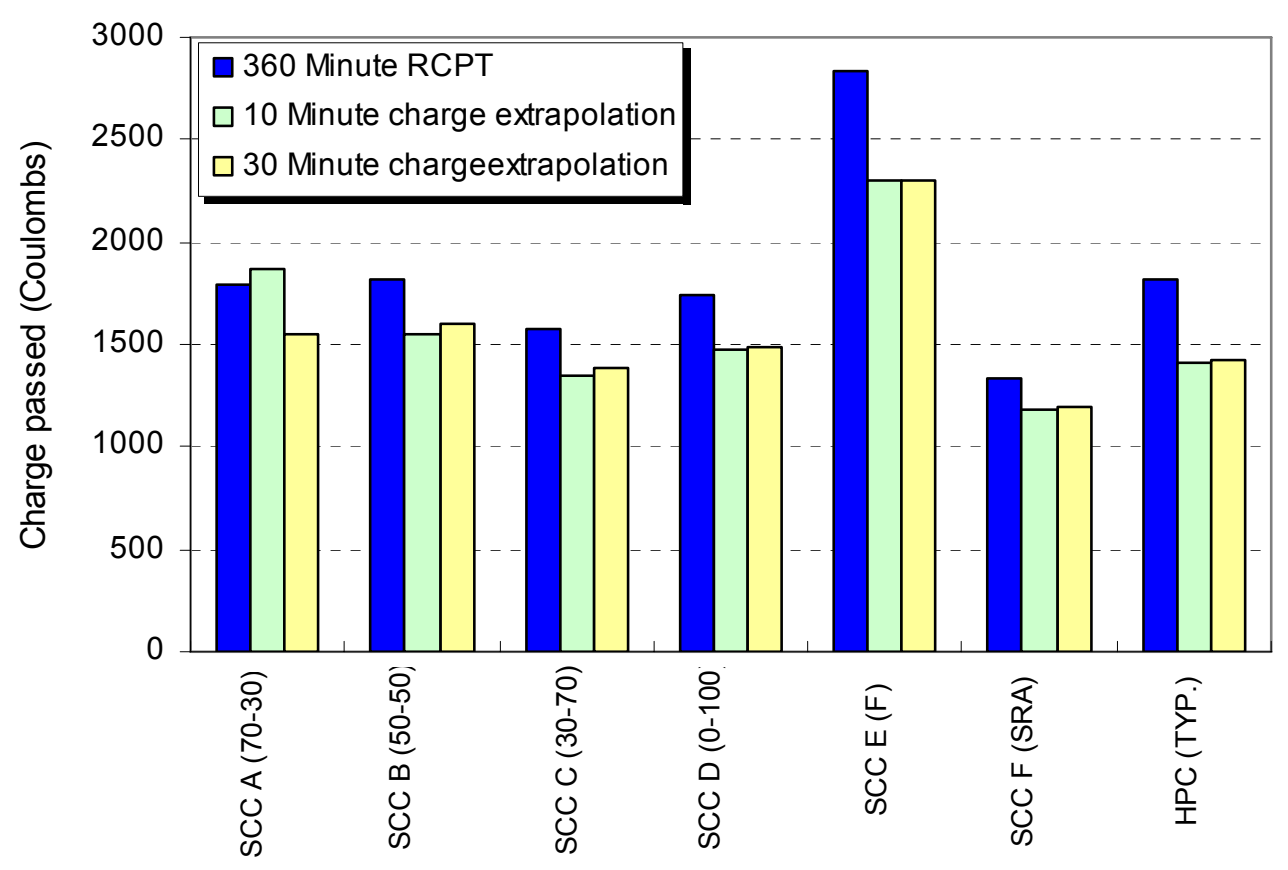

Types of concretes

Figure 7.4 Comparison of normal RCPT and suggested extrapolated charge passed values

Figure 7.2 illustrates charge passed over time for different concrete mixtures for normal 360 min RCPT and the blank test. It is observed that the curves are nonlinear in nature, although the degree of non-linearity is very low. The nature of the curves suggests that the difference between the RCPT and the blank test increased non-linearly with time. It is also observed that the value of charges passed over time was maximum for SCC E (F). Other mixtures had almost similar RCPT values with SCC F (SRA) being the lowest. The abnormal behavior of SCC E (F) was probably due to the fibers. As per ASTM C 1202-05, the presence of reinforcing steel or any other embedded electrically conductive materials may have significant effect on the results as the test results are a function of the electrical resistance. The fibers used in this study may be electrically conductive thus giving erroneous values.

The difference of charge passed between standard RCPT test and the blank test is furnished as percentage in Table 4. The smaller percentage means relatively higher values for the blank test, and therefore a greater influence of pore solutions on RCPT for that particular type of concrete. This difference is graphically illustrated in Figure 7.3. It is observed from Table 4 and Figure 7.3 that for SCC A (70-30) and SCC B (50-50) the difference between standard RCPT test and the blank test was less and in the range of $10 \sim 12 \%$. All other mixtures had a greater difference 
compared to the above mentioned concrete and ranged from $31.4 \%$ for SCC C (3070 ) to $61 \%$ for SCC E (F). In general the difference was in the range of $30 \sim 40 \%$ except SCC A (70-30) and SCC B (50-50). It signifies that pore solutions had greater influence for these two concretes. This may be due the presence of more CA $25 \mathrm{~mm}$ aggregates in the paste. It can be concluded that the influence of pore solutions are relatively higher for mixtures containing higher larger size aggregates.

Figure 7.4 compares the standard $360 \mathrm{~min}$ RCPT values with $10 \mathrm{~min}$ and 30 min extrapolated values. Table 4 also lists the difference between these values in a percentage format. It can be easily seen from the table and figure that the charge passed values over time for standard RCPT test is higher for almost all the mixtures. The only exception was SCC A (70-30). It is also observed that the extrapolated values from 10 min charge passed and 30 minute charge passed were very close. The difference between the standard RCPT test and the $10 \mathrm{~min}$ and $30 \mathrm{~min}$ tests varied in the range of $14 \sim 20 \%$. The temperature of the anode is generally less at the beginning of the test and heat and temperature increases steadily due to the high applied voltage. This promotes escalation of the movement of charges subsequently ending in higher RCPT values. This fact is supported by the differences of charge passed between standard RCPT and the $10 \mathrm{~min}$ and $30 \mathrm{~min}$ extrapolated values.

The difference between the RCPT values for the HPC and the SCC mixtures was very less. Although SCC mixtures had a slightly less values of standard 360 min RCPT charge passed values compared to the typical HPC mixture. The only major difference that was noticed for the HPC was the percentage difference 360 min standard RCPT and the extrapolated values from the charge passed at 10 min and 30 minute were quite higher than that of the SCC mixtures. The average differences for the SCC mixtures were $13 \%$, whereas the average difference for the HPC was $22 \%$. This signifies that the rate of heat generation in case of HPC mixtures were higher than the rate of heat generated for the SCC mixtures.

No general relation was found between charge passed and compressive strength for all the mixtures. This is because the two parameters are controlled by different factors. Charges passed depend on the porosity of the paste, connectivity of the pores, movement of both chloride and hydroxyl ions, and aggregate texture. Whereas, the compressive strength values mainly depend on porosity of paste and strength of C-S-H gel which depend on the $\mathrm{w} / \mathrm{cm}$ ratio, aggregate texture, and bond of aggregate-paste interface. 
According to ASTM C1202, the chloride permeability of concrete may be rated in following five categories

Table 7.2 - Chloride ion permeability based on charge passed

\begin{tabular}{c|c}
\hline $\begin{array}{c}\text { Charge Passed } \\
\text { (Coulombs) }\end{array}$ & $\begin{array}{c}\text { Chloride Ion } \\
\text { Penetrability }\end{array}$ \\
\hline$>4000$ & High \\
$2000-4000$ & Moderate \\
$1000-2000$ & Low \\
$100-1000$ & Very Low \\
$<100$ & Negligible \\
\hline
\end{tabular}

(Adopted from ASTM C 1202-05)

Applying this threshold to the above results, it was found that all the concrete mixtures belonged to low permeability concrete except charge passed value of SCC E (F) which can be categorized as moderately permeable.

Maine Department of Transportation (2003) conducted some studies on experimental use of SCC for precast prestressed box beams. They reported an average RCPT value of 2620 after 138 days and an average value of 1948 after 150 days of casting. Generally RCPT values decreases with age. As the 60-day RCPT values from this experiment is lower than the 138-day and 150-day RCPT values, it may be concluded that SCC A (70-30) through SCC F (SRA) were superior in terms of chloride permeability. Ozyildirim and Lane (2003) evaluated the RCPT properties of 15 SCC mixtures with $\mathrm{w} / \mathrm{cm}$ varied from 0.33 to 0.47 and FA/TA ratio varied between 0.50 and 0.57 . They reported the 28-day RCPT values ranging from 992 to 1726 Coulombs. These values were lesser than the SCC mixtures in this study but first of all their mixture compositions were different and secondly their curing process was also different. Also the 28-day compressive strength for the mixtures was much less than the SCC mixtures used in this study. Suksawang et. al. (2006) conducted evaluation studies on the mechanical properties of SCC. They reported a much higher charge passed for the SCC mixtures compared to two HPC mixtures. Their 56-day charge passed values varied from around 3000 coulombs to around 7000 coulombs. Whereas the RCPT values for the HPC mixtures were around 2500 . They reported that SCC mixtures had significantly higher RCPT values at all testing days. They attributed the results to the increase of paste volume which increases the capillary voids. They also observed that added SCM had a significant effect on the RCPT. They reported around $70 \%$ reduction in the amount of charge passed with the 
addition of SF and FA. These wide variation of test results supports the fact reported in the "Final report of RILEM TC 205-DSC: durability of self-compacting concrete" (2008). It was reported there that the addition of powder content and different admixtures result in different paste volumes, different ionic compositions in the pore solution and perhaps different chloride binding behavior between SCC and OC. Some general findings for RCPT as described in the report are given below

- The type of cement and additional powder used for the concrete have a significant effect on the chloride diffusivity.

- Results suggest that it can not be ensured that the RCPT values for SCC and traditional concrete with same strength grade or same w/c ratio will be same.

- The standard test method of RCPT for normal concrete can be directly adopted for SCC even though the microstructure of SCC is different than NC.

- However, care should be taken to interpret the results particularly when the indirect methods based on principle of electrical resistivity such as ASTM C 1202 or AASHTO T277 was used.

\subsection{Air-Void Parameters}

One of the main disadvantages of concrete is its deterioration under freezing and thawing environment. Only one winter's exposure can badly damage the concrete so much that it effectively precludes the use of concrete in major applications if corrective measures are not taken promptly (Mindess et. al., 2003). All porous materials have the same problem unless the material is specifically designed to resist the freezing and thawing cycles. Air-entraining admixtures are designed to provide the concrete this resistance against freezing and thawing. Properly air-entrained concrete can survive years with exposure to cold weather and serve its purpose as designed. It also helps in making the mixture more uniform and workable.

Air-entraining admixtures increase the amount of air in the concrete which is incorporated during the time of mixing. It is expressed as a percentage of the concrete volume. Generally speaking 2 to $8 \%$ of entrained air provides very good durable mixtures without affecting the strength much. The actual amount depends on the maximum size of the aggregates as more paste is required to provide workable concrete with a lower maximum size of coarse aggregate.

The use of air-entraining admixtures not only improves the freeze-thaw resistance but also increases its workability particularly for mixtures having low cement contents, poor aggregate grading, or harsh aggregate textures. But the 
introduction of air-entraining agents affects the strength in a negative way. As it introduces more voids in the matrix, the capillary porosity is also increased reducing the strength gain. That is particularly a problem for low w/c ratios. Generally $1 \%$ of entrained air reduces the strength by $5 \%$ for a hardened concrete. An optimum amount of air quantity is needed for both strength and freeze-thaw durability. Excessive amount of air can reduce the compressive strength of the mixture drastically. Also, the use of other admixtures used simultaneously used with airentraining admixture affect the air content of the concrete. This is because these admixtures can entrain air by themselves causing an error in the total air entrainment. Thus care should be taken while using many admixtures together with the air-entraining admixture.

The critical parameters for a good air-void system are void frequency, spacing factor, and specific surface area. ASTM C 457-06 (Standard Test Method for Microscopical Determination of Parameters of the Air-Void System in Hardened Concrete) provides test methods to determine these critical parameters. Spacing factor ( $L$ ) as defined by the ASTM C 457 is a parameter related to the maximum distance in the cement paste from the periphery of an air void. It is regarded as the single most important indicator of the durability of the cement paste matrix. The spacing factor usually ranges between $0.1 \mathrm{~mm}$ to $0.2 \mathrm{~mm}$ (0.004 to $0.008 \mathrm{in}$ ) and the maximum value for moderate exposure is usually taken as $0.2 \mathrm{~mm}$ (0.008 in). Although, these values may be somewhat relaxed in case of superplasticized concrete and at low w/c ratios (Mindess et. al., 2003). Void frequency ( $n$ ) can be defined as the voids per unit length of the traverse; the number of air voids intercepted by a traverse line divided by the length of that line. It is a critical parameter in determining the magnitude of the specific surface area and the spacing factor. Specific surface $(\alpha)$ is the surface area of the air voids divided by their volume, expressed in compatible units so that the unit of specific surface is reciprocal length. ASTM C 457 suggested that the usual range of specific surface is between 24 to $43 \mathrm{~mm}^{-1}$ (600 to $1100 \mathrm{in}^{-1}$ ).

There are two methods for measuring the air content of hardened concrete, namely the linear-traverse method and the modified point-count method. In this experiment the modified point-count method was used to determine the air-void parameters of the developed SCC mixtures after 28-days of casting. The results are shown in Table 7.3 below. 
Table 7.3 - Air-void parameters for the SCC mixtures

\begin{tabular}{c|c|c|c|c|c}
\hline Mixture & $\begin{array}{c}\text { Air } \\
\text { Content, } \\
\text { A }\end{array}$ & $\begin{array}{c}\text { Specific } \\
\text { Surface, } \\
\alpha\end{array}$ & $\begin{array}{c}\text { Void } \\
\text { Spacing } \\
\text { Factor, L }\end{array}$ & $\begin{array}{c}\text { Void } \\
\text { Frequency }\end{array}$ & $\begin{array}{c}\text { Paste } \\
\text { Content, } \\
\mathrm{p}\end{array}$ \\
\hline & $(\%)$ & $\mathrm{mm}^{-1}$ & $(\mathrm{~mm})$ & (voids/mm) & $(\%)$ \\
\hline SCC A (70-30) & 15.2 & 17 & 0.10 & 0.64 & 23.9 \\
\hline SCC B (50-50) & 13.6 & 13 & 0.15 & 0.44 & 26.4 \\
\hline SCC C (30-70) & 14.3 & 17 & 0.11 & 0.59 & 27.0 \\
\hline SCC D (0-100) & 12.9 & 13 & 0.17 & 0.42 & 28.3 \\
\hline SCC E (F) & 5.0 & 14 & 0.34 & 0.17 & 27.5 \\
\hline SCC F (SRA) & 4.1 & 17 & 0.34 & 0.16 & 29.9 \\
\hline \multicolumn{7}{|c}{$(1 \mathrm{~mm}=0.039$ in $)$}
\end{tabular}

It is seen from Table 7.3 that the air content of mixtures SCC A (70-30) through SCC $D(0-100)$ were very high and in the range of $13 \sim 15 \%$. The air content of SCC E (F) and SCC F (SRA) were very low in comparison to other mixtures and were in the range of $4 \sim 5 \%$. This increased air content in the four mixtures may have been the effect of the high quantity of WRA and HRWRA used to increase the workability of the mixtures. These admixtures may have entrained additional air apart from the AEA which caused the air content to go up. In case of SCC E (F) and SCC F (SRA), the effect of fiber and SRA counteracted the effect of these admixtures. Fibers are known to increase the water demand causing a mixture of low porosity. The effect of fibers and the admixtures may have cancelled each other. In case of SCC F (SRA) the result can not be interpreted easily, SRA might have reduced the air content of the mixture. These results also explain why the compressive strength values for SCC E (F) and particularly SCC F (SRA) were higher than the other mixtures.

The void spacing factor $(\mathrm{L})$ varied between 0.10 to $0.17(\mathrm{~mm})$ for mixtures SCC A (70-30) through SCC D (0-100). All of the values were between the acceptable values prescribed by ASTM C 457. It may be noted here that though the air content of the mixtures were quite high, the void spacing factors were well within the range. The void spacing factor for SCC E (F) and SCC F (SRA) were quite high and had a value of 0.34 for both the mixtures. Higher void spacing indicates lower air voids which ultimately lead to higher strengths. The values were higher than the prescribed values specified in the ASTM, but as stated earlier, these limits may be relaxed in case of superplasticized concrete and low w/c ratios. Also, the pore structure and microstructure of SCC mixtures are completely different than normal concretes which may have lead to the higher values for the void spacing factor.

A view of the sample prepared and views of air-void system at different depths are shown in the figures below. 


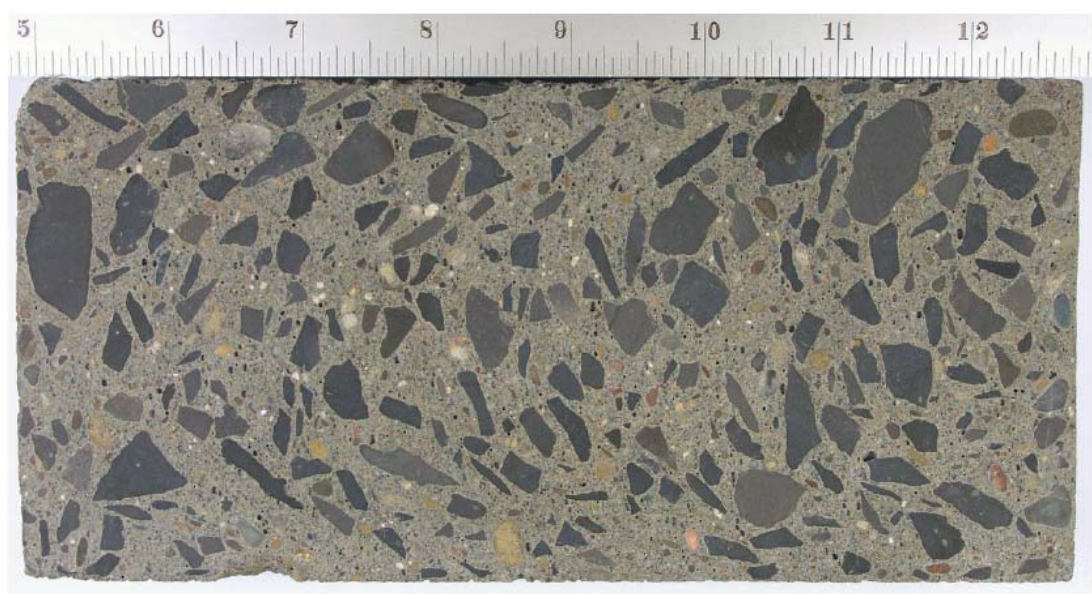

(a)

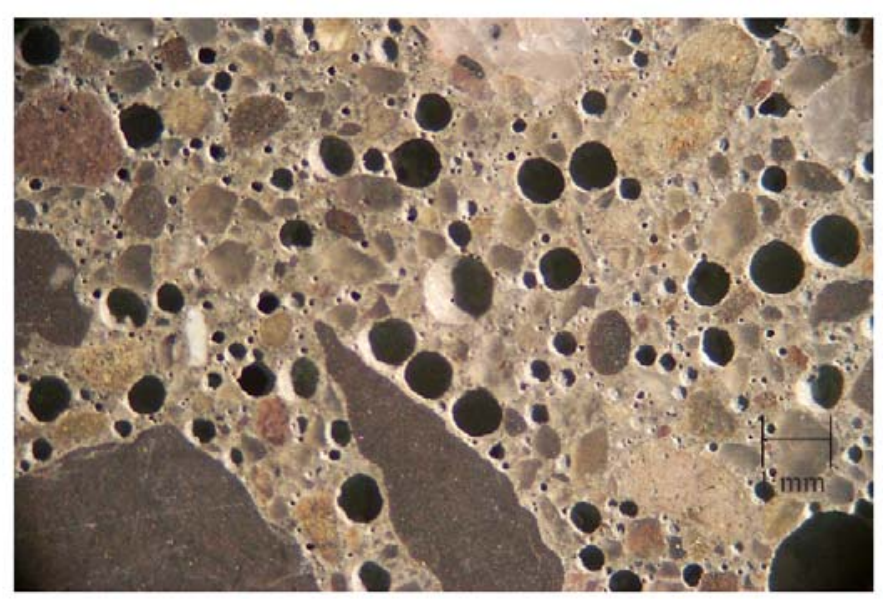

(b)

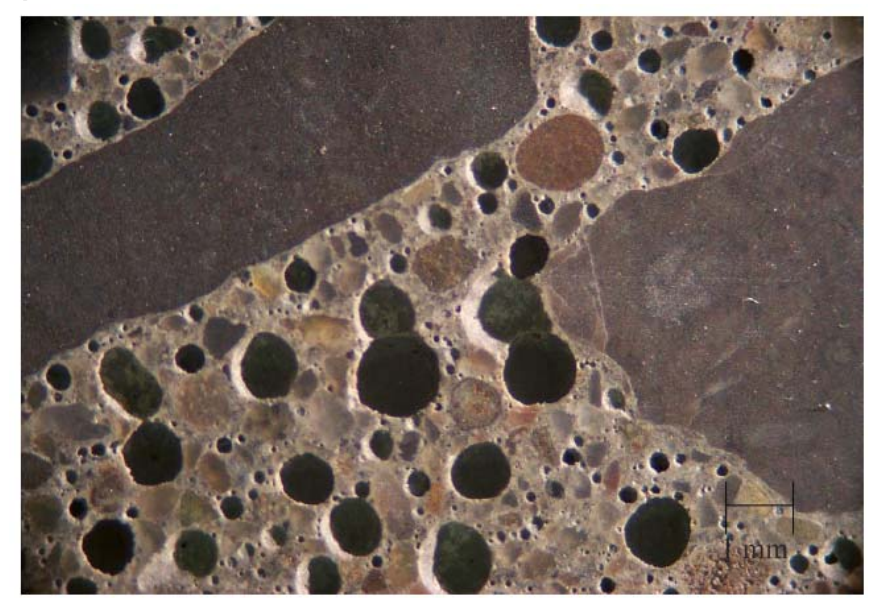

(c)

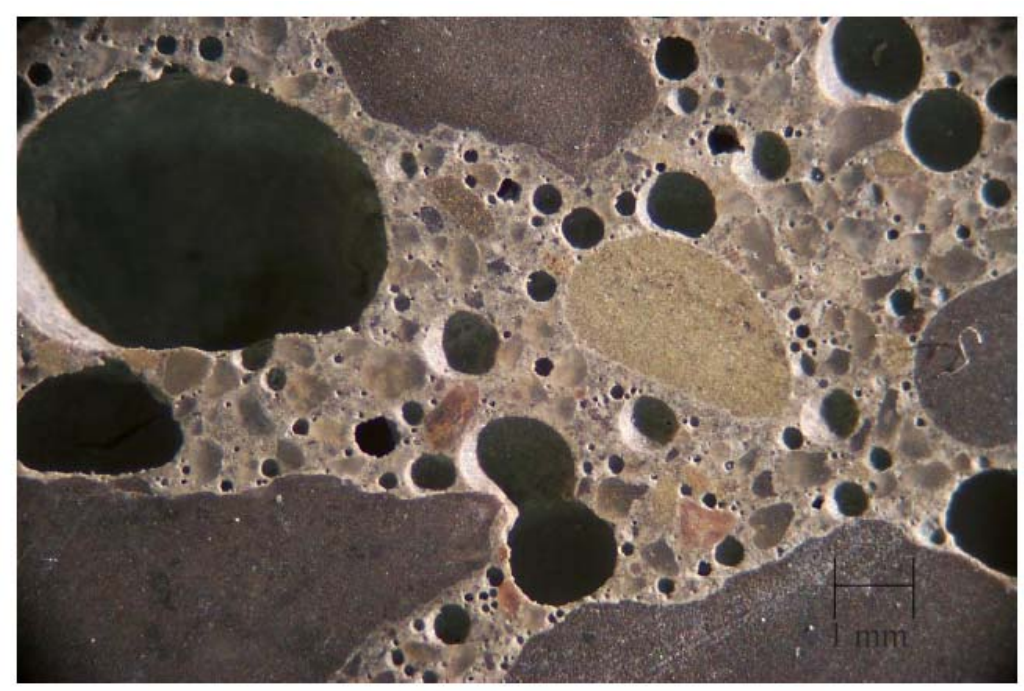

(d)

Figure 7.5 (a) Typical view of the prepared cross section of the cylinder (b) Typical view at a depth of 2 inches in the cylinder (c) Typical view at a depth of 4 inches in the cylinder (d) Typical view at a depth of 6 inches in the cylinder 


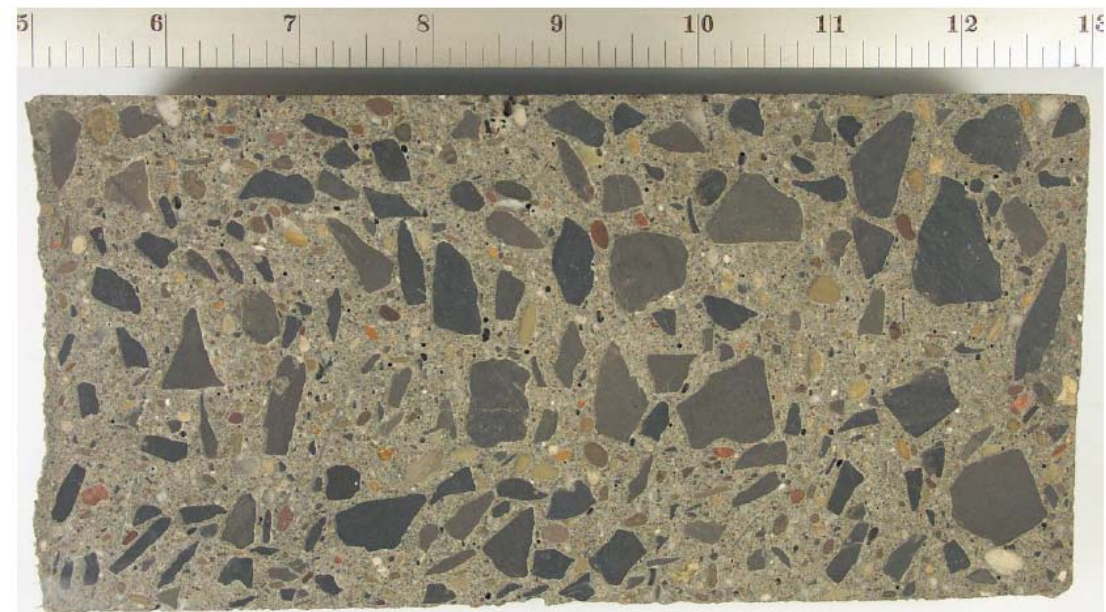

(a)

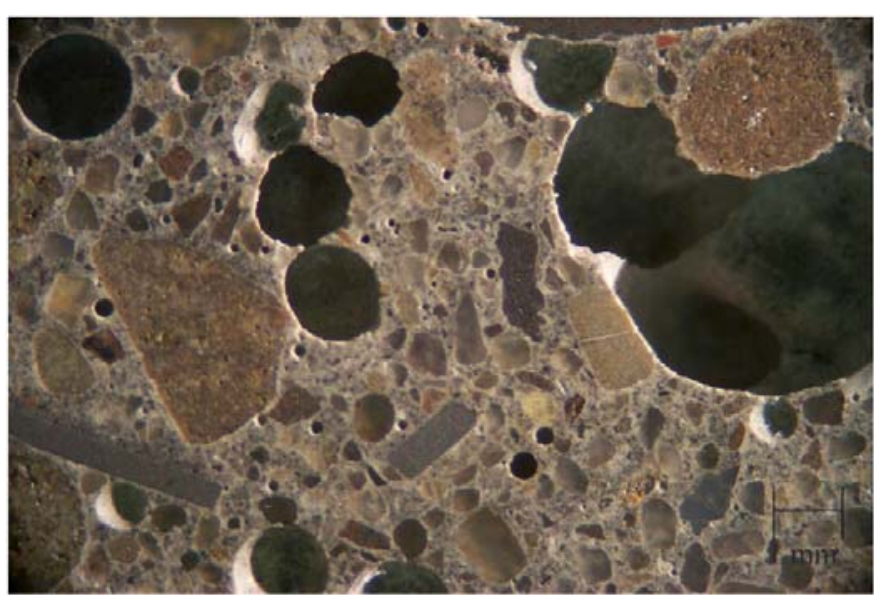

(b)

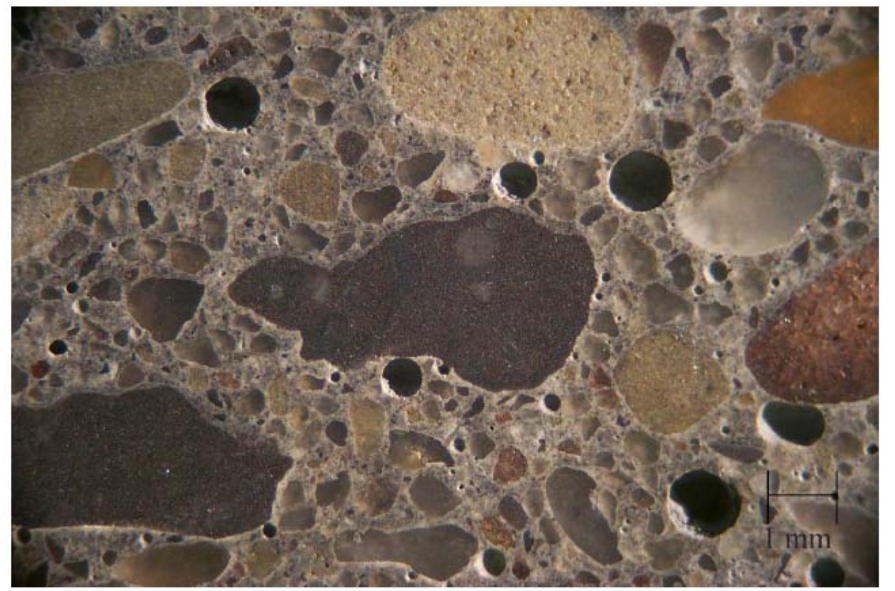

(c)

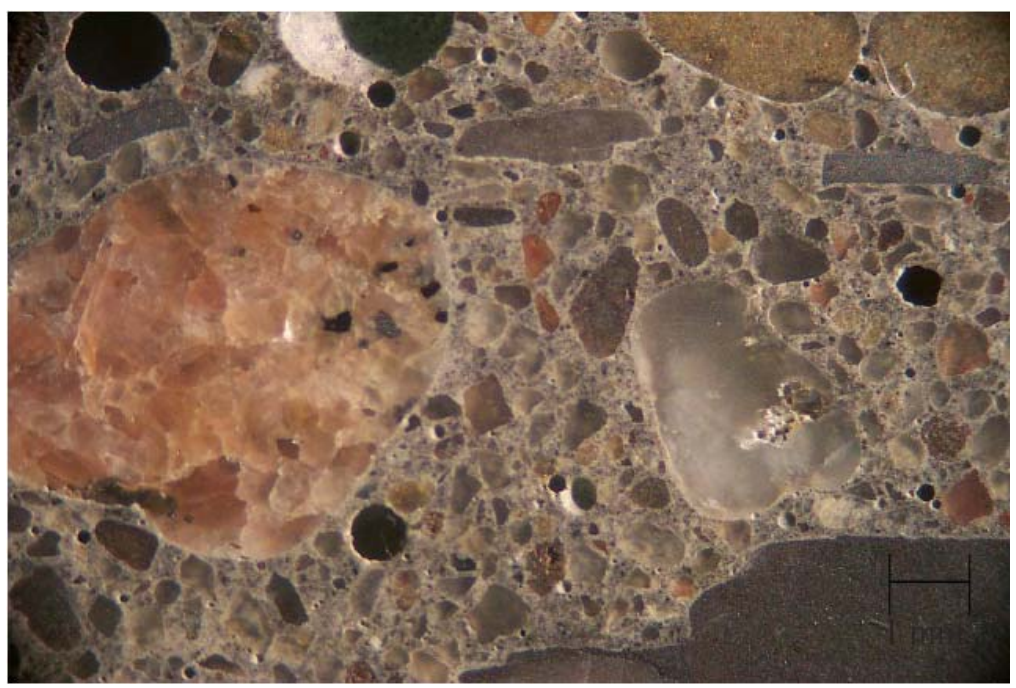

(d)

Figure 7.6 (a) View of the prepared cross section of the cylinder SCC E (F) (b) Typical view at a depth of 2 inches in the cylinder SCC E (F) (c) Typical view at a depth of 4 inches in the cylinder SCC E (F) (d) Typical view at a depth of 6 inches in the cylinder SCC E (F) 


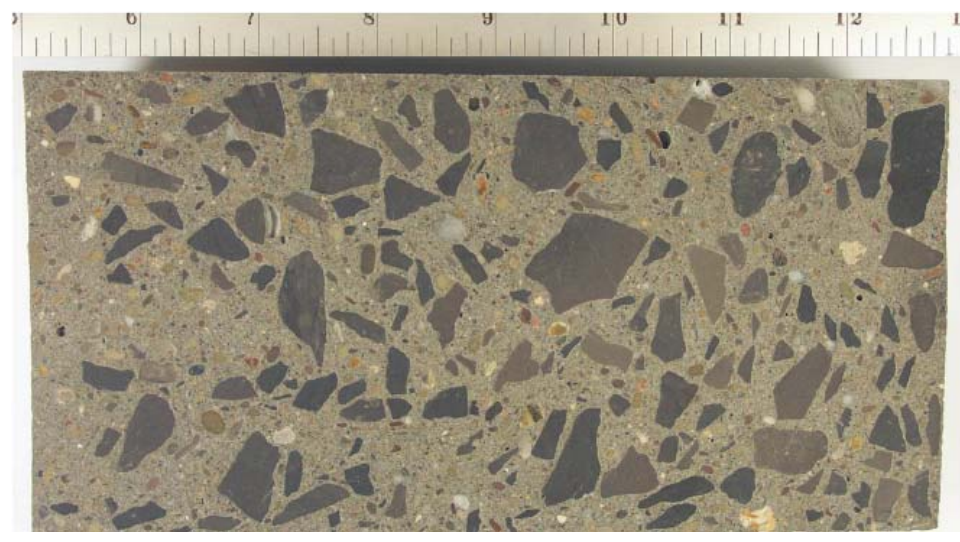

(a)

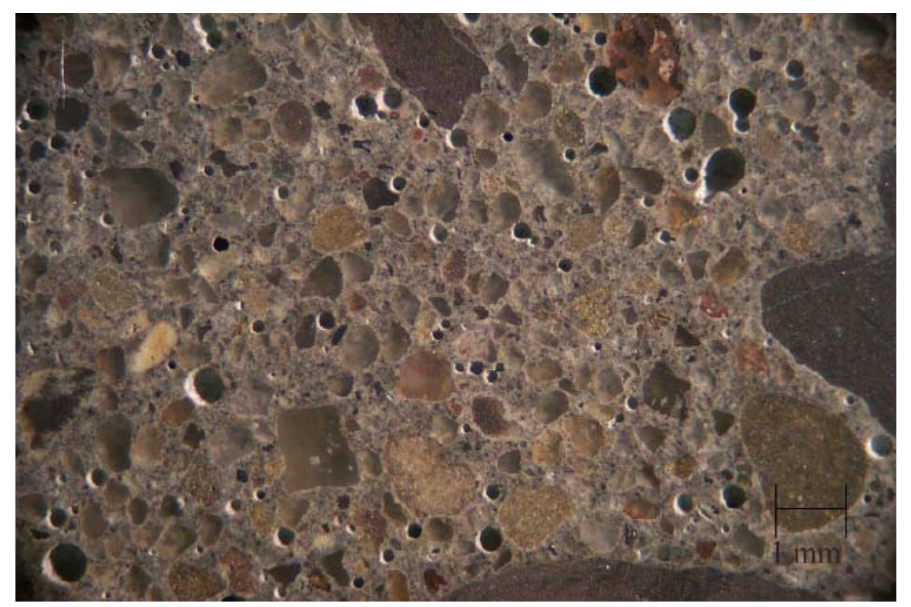

(b)

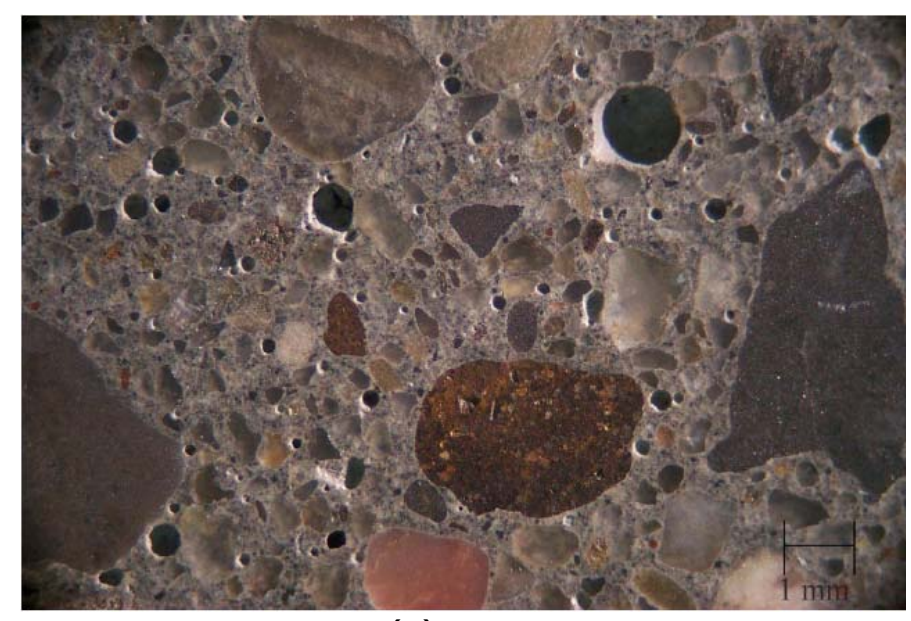

(c)

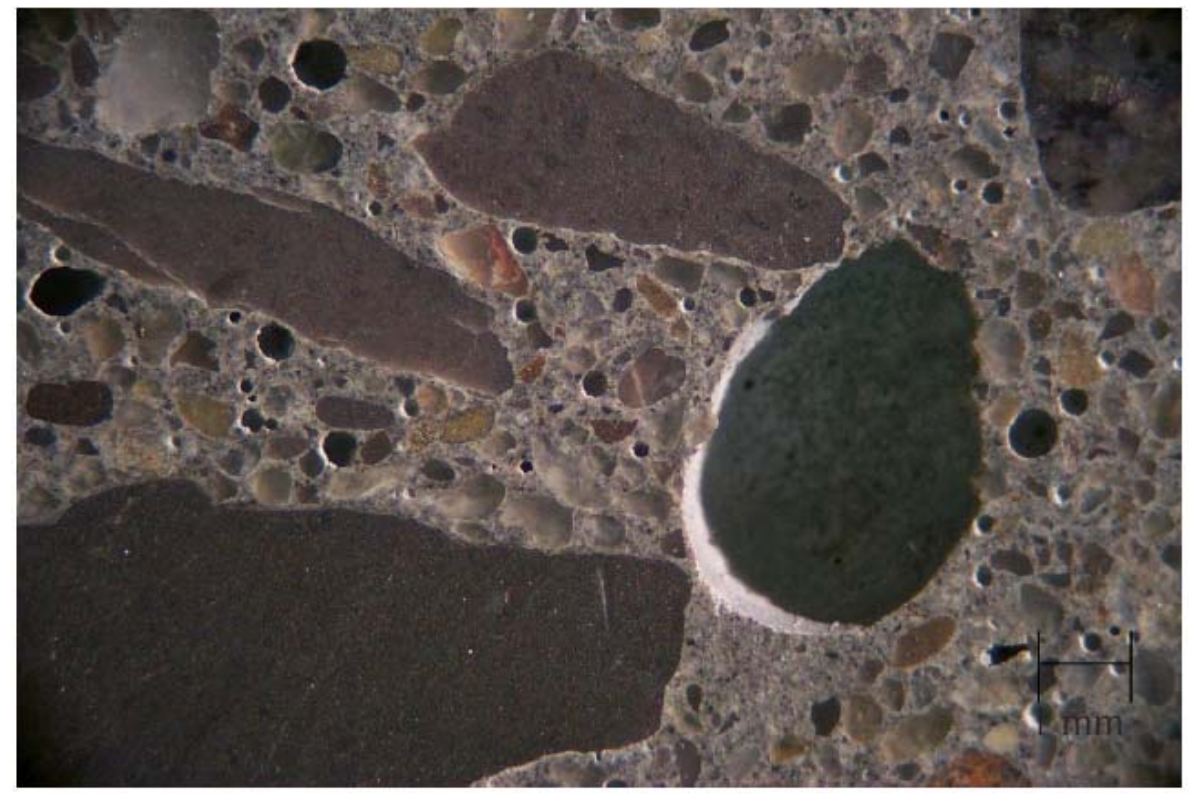

(d)

Figure 7.7 (a) View of the prepared cross section of the cylinder SCC F (SRA) (b) Typical view at a depth of 2 inches in the cylinder SCC F (SRA) (c) Typical view at a depth of 4 inches in the cylinder SCC F (SRA) (d) Typical view at a depth of 6 inches in the cylinder SCC F (SRA) 
Figure 7.5 illustrates typical sample for the air-void test and views at depths 2 in, 4 in, and 6 inch in the cylinders for SCC mixtures SCC A (70-30) through SCC D (0100). Similarly Figure 7.6 and 7.7 illustrates typical sample and views at depths 2 in, 4 in, and 6 in for mixtures SCC E (F) and SCC F (SRA) respectively. From the figures, the difference in distribution of voids between the mixtures is easily demonstrated. For mixtures SCC A (70-30) through SCC D (0-100) smaller and uniformly distributed voids can be located at a depth of $2 \mathrm{in}$. The size of the voids grew at a depth of 4 in; bigger and less voids were found at a depth of 6 in. Voids in the SCC E (F) mixture show different pattern. In this case, voids were bigger and more in number at a depth of 2 in. Size of the voids grew smaller and the number of voids became lesser as the depth increased. Very few voids were noticeable in the figures for SCC E (F). Figure 7.7 illustrates yet another pattern for SCC F (SRA). Very small tiny voids many in numbers can be seen at 2 in depth. As the depth increased from 2 to 6 in, the voids became bigger and achieved maximum size at a depth of 6 in. The frequency of voids in the mixture was more than that of SCC E (F). But the voids in the mixtures SCC A (70-30) through SCC D (0-100) were much prominent, uniform, and more frequent than the other two mixtures. These portray the variance of microstructure caused by fibers and SRA.

As air content has direct impact on compressive strength, the effects of two of the most critical parameters for air content, void spacing factor and void frequency, is investigated below.

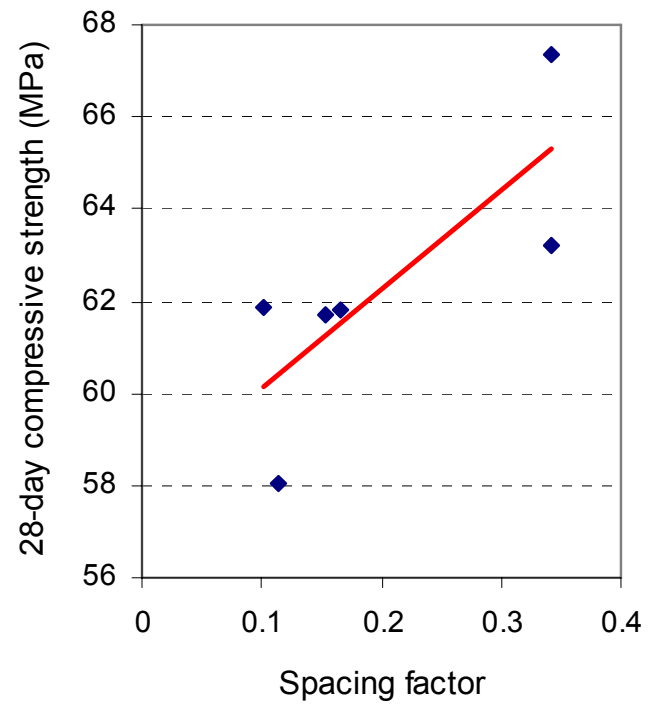

(a)

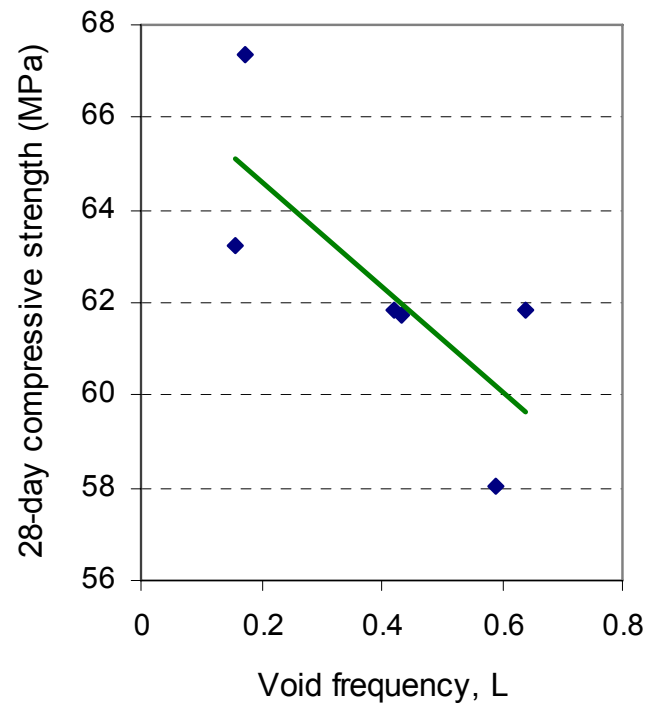

(b)

Figure 7.8 Effect of (a) Spacing factor and (b) Void frequency on 28-day strength 
Figure 7.8 depicts the relation between 28-day compressive strength with spacing factor and void frequency respectively. It can be seen that increased spacing factor resulted in higher compressive strength. As increased spacing factors signifies greater distance from any point in the paste to the edge of nearest void means less number of voids and low capillary porosity. That increases the compressive strength of the mixture. On the contrary, void frequency denotes voids per unit length. Lesser void frequency means lesser number of voids per unit length subsequently leading to higher compressive strength. This scenario can be clearly understood from the trend lines in Figure 7.8 (a) and Figure 7.8 (b).

\subsection{Resistance to Freezing and Thawing}

Freezing and thawing in the cold region of the world can cause severe deteriorations of concrete. The nature of scaling is physical-not chemical. Many researchers now believe that during freezing, stresses resulting from osmotic pressure cause most of the frost damage to cement paste. It was found that during freezing most of the water movement is towards, not away from, site of freezing.

As concrete is a porous material, it is susceptible to damage under repeated cycles of freezing and thawing. As SCC is a new type of concrete with different microstructure compared to normal concrete, the effect of freezing-thawing cycles of SCC needs to be evaluated. As per the "Final report of RILEM TC 205-DSC: durability of self-compacting concrete" (2008), critically saturated SCC is susceptible to damage by exposure to repetitive freeze-thaw cycles. The flowing conclusions were made regarding the frost durability of SCC:

- Internal frost resistance of SCC and normal vibrated do not differ much if the concrete is made with sound aggregate, proper air-void system, resistance to segregation, and adequate strength.

- Greater air-void system can be achieved when the mixture contains more cementitious material or low $\mathrm{w} / \mathrm{cm}$ ratio.

- Care should be taken to fix the dosage of AEA as other admixtures such as WRA, HRWRA, and VMA may affect the air content and air-void parameters of SCC.

- As there are many interfering parameters affecting the freeze-thaw characteristics of SCC, it is advised to evaluate the air-void parameters and freeze-thaw resistance of SCC by standard test methods before using it in 
structures which will be exposed and highly susceptible to salt frost scaling or internal deterioration from repetitive freezing and thawing cycles.

A general rule is that a decrease in the $\mathrm{w} / \mathrm{cm}$ ratio improves the ability of concrete to withstand cycles of freezing and thawing (Mindess et. al., 2003). Studies showed that a concrete mixture with $\mathrm{w} / \mathrm{cm}$ lower than 0.24 does not require any external air entrainment. For higher $\mathrm{w} / \mathrm{cm}$ ratios, entrained air is required to provide resistance against freezing and thawing cycles. As per Mindess, HPC mixtures usually are superior in terms of durability compared to normal concrete mixtures. This is because of the low permeability and greater uniformity and homogeneity combined with lower porosity, which is exhibited by the HPC mixtures.

A number of test methods are available for the evaluation of SCC mixtures subjected to repeated cycles under freezing and thawing. The tests involve subjecting the concrete to different freeze-thaw cycles and measuring the internal damage by monitoring weight loss, decrease in strength, and decrease in dynamic modulus of elasticity. Recently a novel approach of combinations of testing adopted by Ray et al. (2007) to eliminate the limitations of individual testing of freezing and thawing (ASTM C 666) and scaling resistance (ASTM C 672) is a significant step towards assessing the durability. They studied the durability of different HPC mixtures which were simultaneously exposed to freeze-thaw cycles and deicing salt solution. Although the test proved to be efficient and produced meaningful information, the standard test method provided by ASTM C 666 was followed instead in this study as it is a new type of concrete and the durability properties are relatively unknown.

\subsubsection{Test Method}

ASTM C 666/C 666M-03 (Standard Test Method for Resistance of Concrete to Rapid Freezing and Thawing) was used to evaluate the frost resistance of the SCC mixtures in this experiment. There are two procedures for freezing; Procedure $A$ requires the specimen to be completely submerged in water at all times while it is subjected to freezing and thawing and Procedure $B$ requires the specimens to be surrounded by air at the time of freezing but thawed in water. Procedure $A$ was followed during this experiment. As described in the standard, a cooling and heating cycle between $4 \mathrm{C}$ and $-18 \mathrm{C}(40$ to $0 \mathrm{~F}$ ) to be completed in 2 to 5 hours. For procedure $A$, not less than $25 \%$ of the time shall be used for thawing. At the end of cooling period the temperature at the centers of the specimens shall be $-18 \pm 2 \mathrm{C}$ ( 0 $\pm 3 \mathrm{~F}$ ) and at the end of heating period the temperature shall be $4 \pm 2 \mathrm{C}$ (40 \pm 3 
F) with no specimen at any time reaching a temperature lower than $-19 \quad \mathrm{C}\left(\begin{array}{ll}-3 \mathrm{~F} & \mathrm{f}\end{array}\right.$ nor higher than $6 \mathrm{C}\left(\begin{array}{ll}43 & \mathrm{~F}\end{array}\right)$. Figure 7.9 illustrates the freezing and thawing cycles for the SCC mixtures.

Three test specimens each of size $75 \mathrm{~mm} \times 100 \mathrm{~mm} \times 405 \mathrm{~mm}$ ( 3 in $\times 4$ in $x$ 16 in) were cast from the batch for each concrete mixture. The specimens were cured for 14 days prior to testing by immersing in lime saturated water at $23 \pm 2 \mathrm{C}$ $(73.4 \pm 3 \mathrm{~F})$. The testing was started by placing the specimens in the thawing water at the beginning of the thawing cycle. The specimens were removed from the apparatus in thawed condition at 35 cycle interval. As per the standard, the maximum interval can be 36 cycle. After removal, the fundamental transverse frequency and the mass were measured and returned back to the apparatus for following cycles.

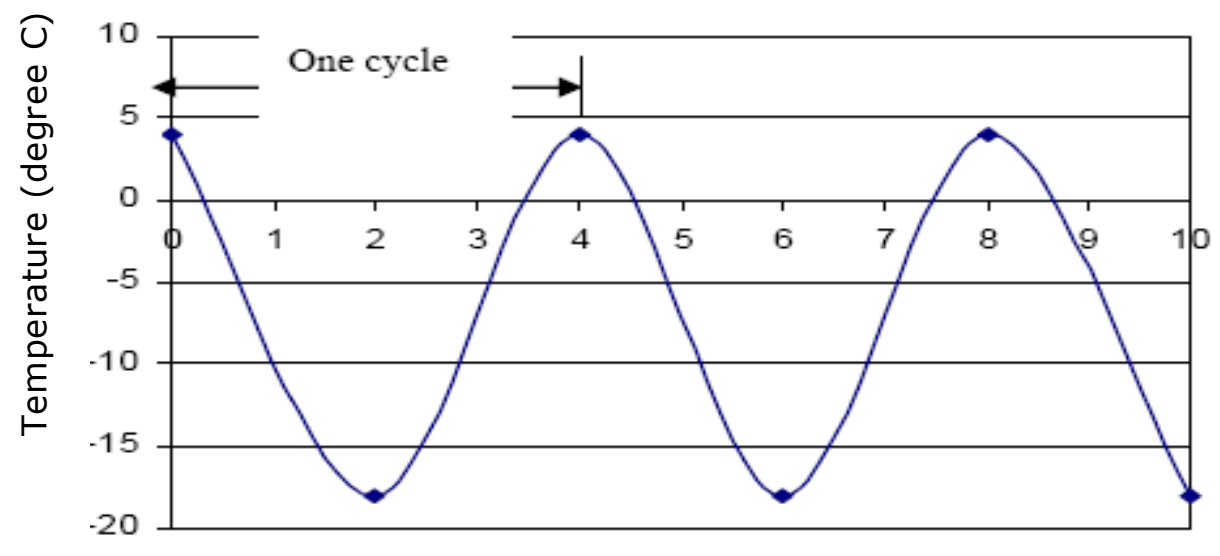

Time (hour)

Figure 7.9 Temperature cycles used for freezing and thawing

The fundamental transverse frequency was measured following ASTM C 215-02 (Standard Test Method for Fundamental Transverse, Longitudinal, and Torsional Resonant Frequencies of Concrete Specimens). This process was repeated until the transverse frequency became $60 \%$ of the original value or 300 cycles whichever happened earlier. The calculations for quantification are as shown below:

$P_{c}=\left(n_{1}^{2} / n^{2}\right) \times 100$

Where:

$\mathrm{P}_{\mathrm{c}}=$ Relative dynamic modulus of elasticity, after c cycles of freezing and thawing expressed as a percentage,

$\mathrm{n}=$ fundamental transverse frequency at 0 cycles of freezing and thawing, and

$\mathrm{n}_{1}=$ fundamental transverse frequency at c cycles of freezing and thawing. 
The durability factor was calculated using the following equation:

$\mathrm{DF}=\mathrm{PN} / \mathrm{M}$

Where:

DF = durability factor of test specimen,

$\mathrm{P}=$ relative dynamic modulus of elasticity at $\mathrm{N}$ cycles, \%,

$\mathrm{N}=$ number of cycles at which $\mathrm{P}$ reaches the specified minimum value for discontinuing the test or the specified number of cycles at which the exposure is to be terminated, whichever is less, and

$M=$ specified number of cycles at which the exposure is to be terminated.

\subsubsection{Test Results and Discussions}

The relative dynamic modulus over different cycles is shown in Figure 7.10.

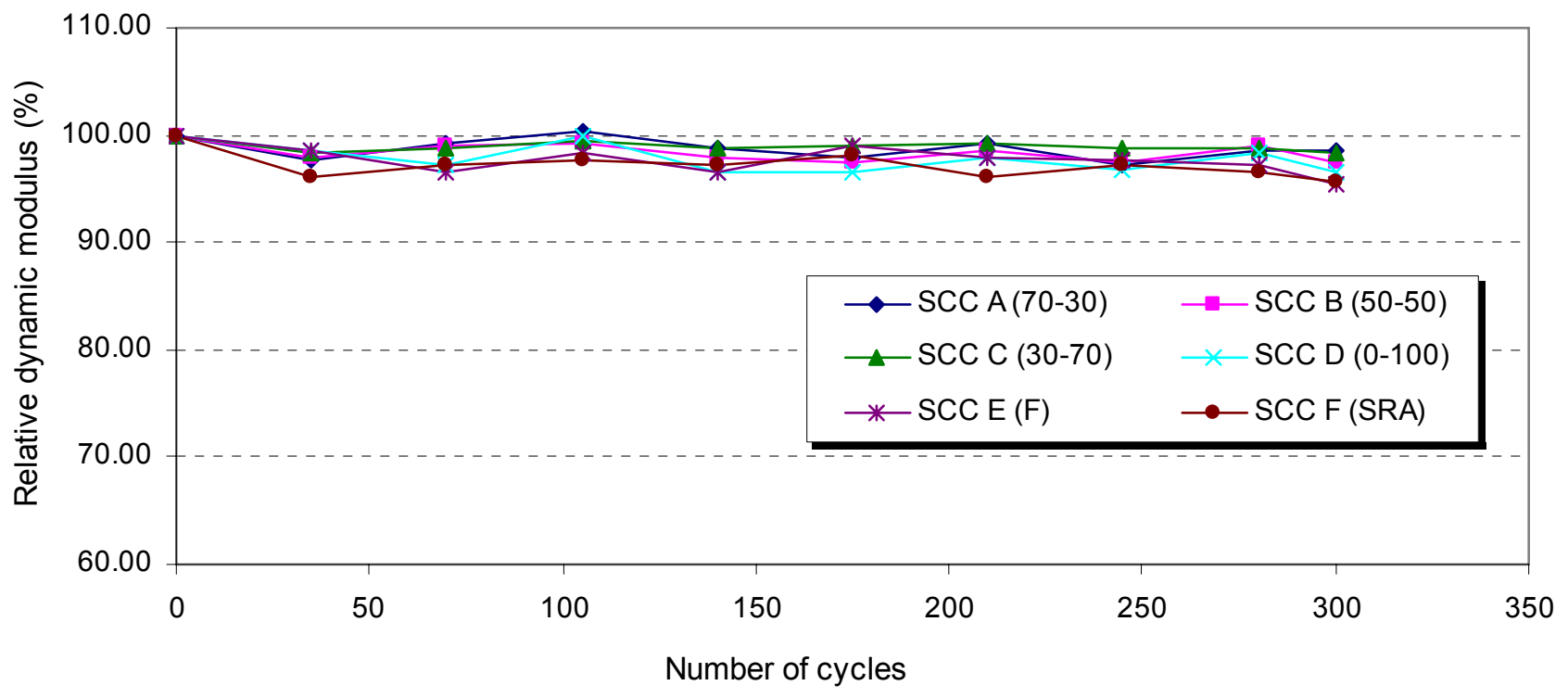

Figure 7.10 Relative dynamic modulus of elasticity versus number of cycles

From the figure it is clearly seen that all the mixtures behaved same under the freezing and thawing cycles. The relative dynamic modulus of elasticity varied between 95 98 \%. As seen, the change in the relative dynamic modulus is very less signifying very good protection against freezing and thawing. Table 7.4 below lists the durability factor (DF) and mass loss of SCC mixtures. It is also observed that none of the mixtures showed a $40 \%$ reduction in their relative dynamic modulus prompting the test to be terminated after 300 cycles. 
Table 7.4 - DF and mass loss for the SCC mixtures

\begin{tabular}{c|c|c}
\hline Mixture & DF & $\begin{array}{c}\text { Mass Loss } \\
(\boldsymbol{\%})\end{array}$ \\
\hline SCC A (70-30) & 98.59 & 0.32 \\
\hline SCC B (50-50) & 97.44 & 1.87 \\
\hline SCC C (30-70) & 98.39 & 2.17 \\
\hline SCC D (0-100) & 96.57 & 2.14 \\
\hline SCC E (F) & 95.51 & 2.30 \\
\hline SCC F (SRA) & 95.76 & 0.60 \\
\hline
\end{tabular}

It is observed from the above table that mass losses were negligible for mixtures SCC A (70-30) and SCC F (SRA) with values $0.32 \%$ and $0.60 \%$ respectively. SCC E (F) had the highest mass loss of $2.30 \%$ followed by mixtures SCC C (30-70) and SCC D (0-100) with a value of $2.17 \%$ and $2.14 \%$ respectively. Hence it can be concluded that SCC mixtures used for this study had a very high freezing-thawing resistance.

Similar observation was made by Christensen and Ong (2005). They examined the relationship between air-void parameters and the resistance of SCC to cycles of freezing and thawing. They had made an extensive database representing a variety of admixture combinations, mixture proportions, materials, and stability. They prepared a plot of durability factor and spacing factor achieved by air-void study. It was concluded that all SCC mixtures with an air-void spacing factor of less than 0.4 $\mathrm{mm}$ had a very high resistance to freezing and thawing cycles. The mixtures with an air content of $2 \%$ in the hardened state had a very high spacing factor and were marginally stable and lost most of the entrained air during placement. For these mixtures the freezing and thawing test failed. But, interestingly, mixtures with high air content and high spacing factors still had durability greater that $60 \%$ after 300 cycles of freezing and thawing. Hence they concluded that durable SCC mixtures can be obtained that has air-void systems with specific surface areas less that $24 \mathrm{~mm}^{-1}$ and spacing factors much larger that $0.20 \mathrm{~mm}$ which are the values specified for achieving durability for conventional concrete. This supports the fact that SCC E (F) and SCC F (SRA) had a very high spacing factor of $0.34 \mathrm{~mm}$, much above the 0.20 $\mathrm{mm}$ limit but still those mixtures showed a very good durability against freezing and thawing. The above statement that SCC mixtures with specific surface areas less than $24 \mathrm{~mm}^{-1}$ can achieve high durability is also supported from the experiment on current SCC mixtures. The specific surface areas achieved in this experiment of six SCC mixtures varied between 0.13 and $0.17 \mathrm{~mm}^{-1}$ which are much below the prescribed limit of $24 \mathrm{~mm}^{-1}$; but still they had a very high resistance against freezing and thawing. 
Figure 7.11 illustrates the relation between spacing factor and durability factor as achieved in this experiment and the data collected by Christensen and Ong (2005). It can be seen that all the data were within a small range. Hence it can be generally stated that the freeze-thaw resistance of SCC mixtures made with $\mathrm{w} / \mathrm{cm}$ ratio 0.40 and below are very high and the DF is above 90\%. Proper care should be taken for mixtures with greater $\mathrm{w} / \mathrm{cm}$ ratio which are exposed to severe freeze-thaw cycles and the mixture shall be evaluated before application in the field.

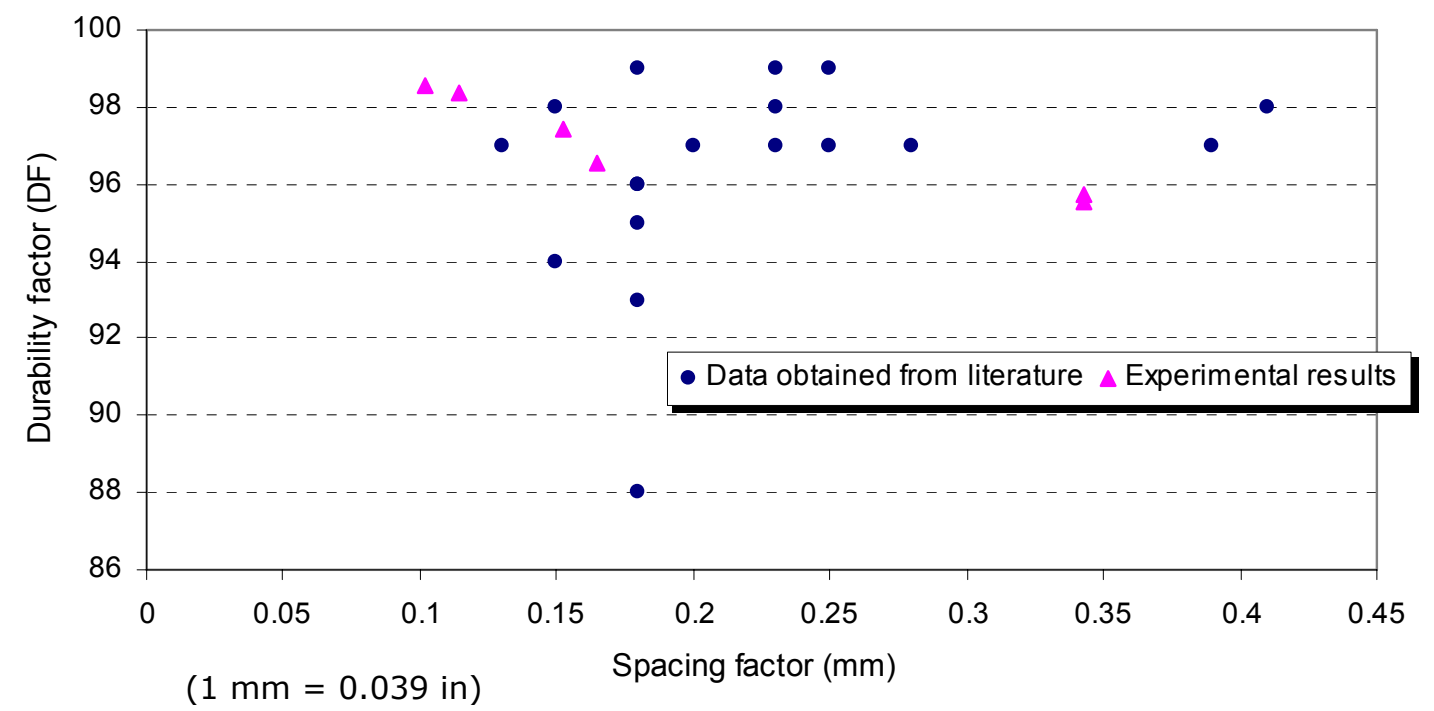

Figure 7.11 Durability factor against spacing factor for different SCC mixtures

A typical range of durability factor and spacing factor was proposed by Mindess et. al. (2003) for traditional vibrated concrete. It was proposed that all the target values should be achieved for a properly air-entrained concrete. These ranges of values and the values achieved by this experiment and from the literature are shown below in Figure 7.12. 


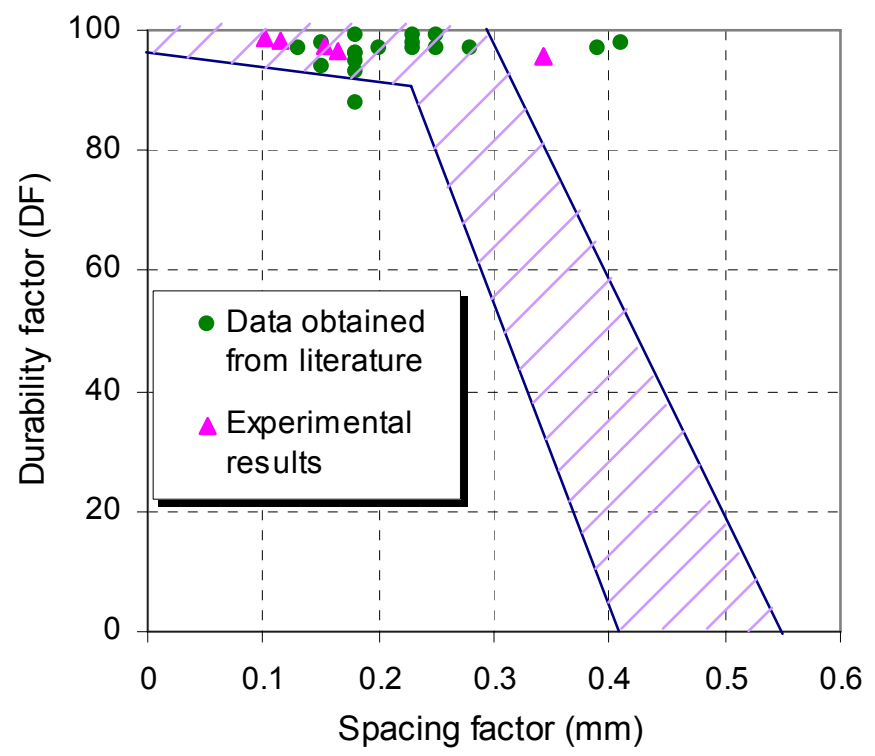

$(1 \mathrm{~mm}=0.039 \mathrm{in})$

Figure 7.12 Relationship between durability factor and spacing factor

The proposed band is shown as the area surrounded by the blue lines. It is observed from the figure that all SCC mixtures were confined in a limited space at the top of the graph signifying very good freeze-thaw resistivity. But the relationships hold well for a spacing factor less than $0.3 \mathrm{~mm}$. It may be stated that SCC mixtures with spacing factors more than $0.3 \mathrm{~mm}$ also showed a very good durability characteristics which are lacking for traditional vibrated concrete as seen from Figure 7.12.

Ozyildirim and Lane (2003) reported similar freeze-thaw resistance for the laboratory SCC mixtures. They reported DF values of $106 \%, 108 \%$, and $96 \%$ and weight loss values of $0.7 \%, 1.0 \%$, and $2.3 \%$ respectively for three SCC mixtures studied. Maine Department of Transportation (2003) conducted some studies on experimental use of SCC for precast prestressed box beams. An average DF of $97.016 \%$ and an average mass loss of $4.3 \%$ was reported. But these average values contained mixtures with no air entrainment also. The DF of the SCC mixtures that contained air, varied from 93 to $100 \%$ and mass loss varied from 3.1 to $5.3 \%$. Similar observations were also noted by Heirman and Vandewalle (2003). They concluded that compared to the reference concrete, SCC mixtures were very good in freezing and thawing resistance. Although they noted somewhat greater amount of scaled material when de-icing salts were added.

Hence, it can be concluded from the above discussions that the SCC mixtures studied in this experiment had superior resistance to freezing and thawing 
cycles compared to normal concrete and at per with the values reported by other researchers on the durability of SCC mixtures. It can also noted here that SCC mixtures with high spacing factor and low specific surface areas can also show high resistance to freezing and thawing in contrast to traditional concrete provided that the $\mathrm{w} / \mathrm{cm}$ ratio is 0.40 or below.

\subsection{Concluding Remarks}

The chloride permeability, air-void parameters and freezing and thawing resistance of the selected SCC mixtures were investigated in this chapter. In general it was observed that SCC mixtures showed very good results against freezing and thawing cycles, although the hardened concrete air content were quite high for some of the mixtures. The freeze-thaw resistance was superior to that of normal vibrated concrete. It may be concluded that SCC mixtures with superior freeze-thaw resistance can be produced with air-content parameters not conforming to the values specified values for normal concrete. RCPT values for the SCC mixtures were also found to be similar as normal concrete and HPC mixtures. In general, the durability performance of the six mixtures was satisfactory if not excellent. 


\section{CHAPTER EIGHT}

\section{CONCLUSI ONS}

\subsection{I ntroduction}

This chapter draws the conclusions on the materials and tests done so far for the self-consolidating concrete mixtures. Based on the study, recommendations on future work are also presented. The following sections discuss the concluding remarks for mixture proportioning, fresh properties, hardened properties, free and restrained shrinkage, chloride permeability, air-void parameters, and freezing and thawing resistance of the SCC mixtures developed; and suggests the scopes for future works.

\subsection{Conclusions}

\subsubsection{Materials and Mixture Proportions}

1. A variety of SCC mixtures were developed using different aggregate sizes and gradation, fillers, mineral admixtures such as slag + silica fume, fly ash + silica fume, fibers, shrinkage reducing admixture.

2. Combined aggregate curves for the SCC mixtures showed that the aggregate gradations spanned across the three ranges namely " $Q$ " for quality filter, " $I$ " for intermediate filter, and " $W$ " for particles smaller than $2.36 \mathrm{~mm}$ (affects the workability), signifying a combination of strength, mobility, and workability of the mixtures.

3. The coarseness factor (CF) and workability factor (WF) for the SCC mixtures were plotted and observed that the resulting trend is above the Shilston'e band optimized for better workability for normal concrete mixtures.

4. While designing SCC mixtures, the aggregate gradation can be chosen such a way that for a given CF, the WF should be above the band proposed by Shilstone. Also, the CF preferably be less than a value of 60 .

5. Mixing procedure for the SCC mixtures was a bit different than normal concrete mixtures. The mixing sequence was altered such a way that finer particles mix well with coarse particles forming a uniform mix. Constant monitoring was required at the time of mixing. 
6. Proper addition of HRWRA seemed to be very important. In this experiment, HRWRA was added in different stages of mixing depending on the desired slump.

7. Mixtures with fibers showed difficulty in achieving a given slump that was easily achieved the same mixture without the fiber.

8. More mixing time was required for the SCC mixtures compared to that of normal vibrated concrete mixtures.

\subsubsection{Fresh Properties of SCC}

1. VSI values for all the SCC mixtures were found to be "1", indicating all the mixtures to be "stable".

2. $T_{50}$ time varied from 1.2 seconds to 2.6 seconds. Increased viscosity was observed for the mixtures containing greater percentage of CA 25.

3. Slump flow values of all the SCC mixtures were found to be satisfactory with almost all of them reaching the target limit of $650 \mathrm{~mm}$.

4. J-ring test on the SCC mixtures indicated that most of the SCC mixtures had a blocking less than $25 \mathrm{~mm}$ (1 in) signifying "no visible blocking".

5. SL+SF mixtures showed least blockage compared to the mixtures made with LP or FA+SF.

6. Column segregation values varied between a wide range of $5 \%$ to $23 \%$ with higher value meaning greater segregation. Amount of VMA may be increased to reduce the higher segregation values, if desired.

7. Due to the higher particle size, mixtures made with greater percentage of $C A$ 25 , showed higher segregation values. It was also observed that higher CF resulted in higher static segregation.

8. Very good L-box passing ability values were shown by all the mixtures. All of them achieved a target limit set as 0.7.

9. Values greater than 0.9 was also achieved by some of the mixtures, indicating very good passing ability and can be of great application where flow through congested reinforcement is needed.

10. No correlation could be achieved between the fresh properties and the CF and the DF. That is due to the fact that the effects of aggregate gradation, fillers, mineral admixtures, fibers, SRA, HRWRA, VMA, AEA, different paste volumes, different $\mathrm{w} / \mathrm{cm}$ and $\mathrm{w} / \mathrm{b}$ ratios were interrelated and it was very difficult to find a correlation between the fresh properties and one of the above parameters. 


\subsubsection{Hardened Properties of SCC and Mixture selection}

1. Compressive strength values for the 17 SCC mixtures were high compared to normal concrete mixtures.

2. Mixtures containing limestone powder developed higher compressive strengths at both 7-day and 28-day compared to those mixtures with slag + silica fume or fly ash + silica fume.

3. The early age compressive strength development was much higher for the mixtures containing LP than the mixtures containing SL+SF or FA+SF.

4. Mixtures with higher CA 25 fraction showed trends of higher compressive strength than other mixtures; mixtures with high CA 25 containing the LP gained the maximum strength compared to the other mixture combinations.

5. The mixtures containing $S L+S F$ and $F A+S F$ gained much more strength from 7-day to 28-day compared to mixtures containing LP. The maximum strength increase in case of a mixture containing LP was $24.31 \%$ and the minimum strength increase was $9.35 \%$. Whereas, the maximum strength increase in case of a mixture containing SL+SF was $79.72 \%$ and the minimum strength increase was $47.24 \%$ and the maximum strength increase in case of a mixture containing FA+SF was $57.16 \%$ and the minimum strength increase was $30.52 \%$. This observation leads to the conclusion that LP contributes to accelerated hydration compared to mineral admixtures like SL+SF or FA+SF. Also, due to its finer particle size, compressive strength values are more for the mixtures containing LP compared to the mixtures containing SL+SF and $\mathrm{FA}+\mathrm{SF}$.

6. There was definite correlation between the $w / p$ ratio and the compressive strength of the mixtures. As LP was a very fine filler material and was included in the powder calculation, the w/p ration for SCC with LP was lowest and the value was 0.29 , whereas $w / p$ ratio for rest of the mixtures was around 0.39 . Higher the $w / p$ ratio, lower the strength.

7. There exist definite correlations between compressive strength and paste volume for all the mixtures. Compressive strength was higher for the concretes made with higher paste volume.

8. There were no definite correlation between CF or WF and compressive strength. This is possible due to the effect of $w / p$ ratio, paste volume, and chemical admixtures on the compressive strength of SCC.

9. The compressive strength values of the selected SCC mixtures were compared with the ACI prediction equation of compressive strength and it 
was observed that $\mathrm{ACI}$ equation underestimates the early age compressive strength of the LP mixtures.

10. Splitting tensile strength values were found to be higher than direct tensile strength and lower than the flexural strength (modulus of rupture) with exceptions of the mixture containing fiber and the mixture containing SRA.

11. It can be also concluded that the ratio for splitting tensile strength to compressive strength for ordinary SCC mixtures containing LP, can be safely assumed as 0.06 .

\subsubsection{Shrinkage and Cracking of Selected SCC Mixtures}

1. Apart from the mixtures containing fiber and SRA, 90-day shrinkage strains of the other mixtures were pretty close and were in the range of 650 micro strains. SCC E (F) had a very low shrinkage value of 500 micro strains and SCC F (SRA) had the lowest shrinkage value of 465 micro strains after 90 days.

2. The shrinkage reducing admixture had a huge impact on the shrinkage strains as it has been reduced by almost $1 / 3^{\text {rd }}$ compared to the other mixtures.

3. Autogenous shrinkage contributed immensely on the total shrinkage of the concrete. As stated earlier, the total shrinkage contains autogenous shrinkage and drying shrinkage both.

4. Though the total shrinkage values of all the SCC mixtures were similar, a comparison relative to their aggregate gradation revealed the fact that the mixtures containing higher CA $25 \mathrm{~mm}$ resulted in less shrinkage compared to the mixtures which contain more CA $12.5 \mathrm{~mm}$.

5. The long term autogenous shrinkage values of the SCC mixtures were really high. This may be due to the lower $w / \mathrm{cm}$ and lower $w / p$ ratio responsible for higher self-desiccation.

6. The ratio of autogenous shrinkage and total shrinkage varied between 0.75 and 0.80 for all the mixtures except SCC E (F) which had a high ratio of 0.88 .

7. 90-day value of shrinkage for NC, HPC and the SCC mixtures were close with shrinkage value of NC being the highest. The shrinkage values of the SCC mixtures were in line with the shrinkage values generated by other researchers.

8. The standard shrinkage prediction models grossly under estimated the free shrinkage values for SCC mixtures at early age except for SCC E (F) and SCC $\mathrm{F}$ (SRA). 
9. For SCC A (70-30) through SCC D (0-100), the 90-day shrinkage value was best predicted by ACI 209R model. Almost all of them have similar shrinkage values at the age of 90 days after casting.

10. The B3 and AASHTO model shrinkage were close at later stage and predicted closest to the values given by ACI $209 \mathrm{R}$ model and the values for SCC mixtures.

11. SCC E (F) and SCC F (SRA) behaved differently than other SCC mixtures due to the fiber and SRA content. The GL and CEB MC90-99 models were closest to the final shrinkage value for SCC E (F) and all the other models over estimated the shrinkage values.

12. The calibrated ACI prediction equation gave fairly good results for all the SCC mixtures considering the residual plot.

13. In terms of the restrained shrinkage cracking test, the mixture containing the SRA cracked last as expected followed by the mixture SCC A (70-30) and the mixture containing fiber. These mixtures cracked between 20 to 30 days after initiation of drying. In the other three remaining mixtures, cracking occurred between 11 and 16 days which are substantially lower than the previous three mixtures.

14. There was definitely a trend between the CF and the age of cracking. Higher the $\mathrm{CF}$, higher was the age when cracks developed.

15. It is observed from that cracking occurred at a period which is very near to the zone when the drying shrinkage values were maximum.

16. The cracking onset values for HPC mixtures varied between 8 and 13 days. Where as the cracking onset day for the SCC mixtures varied from 11 to 30 days. Most importantly the water to binder ratio of the SCC mixtures was around 0.30 . When compared to the HPC mixtures with $w / \mathrm{cm}$ of 0.30 , it was no doubt superior in terms of restrained shrinkage cracking.

17. Post cracking behavior of the fiber reinforced SCC (FRSCC) mixture was found to be superior to the other SCC mixtures.

18. It is observed that all the SCC mixtures had moderately-low to low cracking potential based on average stress rate. SCC F (SRA), SCC E (F), and SCC A (70-30) had the lowest average stress rate, hence it had the lowest potential for cracking as expected. All the other mixtures had a moderately-low potential for cracking based on the average stress rate. 
19. Potential for cracking based on net time-to-cracking indicates a low to moderately-high cracking potential for the SCC mixtures. SCC F (SRA) had a low potential for cracking followed by SCC A (70-30) and SCC F (SRA) which had moderately-low potential for cracking. SCC B (50-50) and SCC D (0-100) had a moderately-high possibility of cracking when compared to the net timeto-cracking.

20. In general, it may be concluded that all the SCC mixtures were good against cracking with SCC F (SRA) having the lowest potential for cracking and SCC B (50-50) and SCC D (0-100) having moderately-high potential for cracking. All the other mixtures had moderately-low potential for cracking. Hence it is recommended that SCC B (50-50) and SCC D (0-100) may not be used where cracking can be a crucial factor like tanks, bridge decks and other important structures.

\subsubsection{Discussions on Air-void Parameters, Freezing and Thawing, and Chloride Permeability}

1. The difference between the RCPT values for the HPC and the SCC mixtures was observed as very less. Although SCC mixtures had a slightly less values of standard 360 min RCPT charge passed values compared to the typical HPC mixture.

2. The only major difference that was noticed for the HPC mixtures was the percentage difference $360 \mathrm{~min}$ standard RCPT and the extrapolated values from the charge passed at 10 min and 30 minute were quite higher than that of the SCC mixtures.

3. No general relation was found between charge passed and compressive strength for all the mixtures. This is because the two parameters are controlled by different factors.

4. It was found that all the concrete mixtures belonged to low permeability concrete category prescribed by ASTM except charge passed value of SCC E (F) which can be categorized as moderately permeable.

5. The difference between the standard RCPT test and the $10 \mathrm{~min}$ and $30 \mathrm{~min}$ tests varied in the range of $14 \sim 20 \%$. The temperature of the anode is generally less at the beginning of the test and heat and temperature increases steadily due to the high applied voltage. This promotes escalation of the movement of charges subsequently ending in higher RCPT values. This 
fact was supported by the differences of charge passed between standard RCPT and the 10 min and 30 min extrapolated values.

6. Charges passed recorded in the blank test were quite high for almost all the cases. This shows that under voltage difference, large amount of charge were able to pass through specimens even in absence of chloride ions in the cell solution.

7. Air content of mixtures SCC A (70-30) through SCC D (0-100) were observed very high and were in the range of $13 \sim 15 \%$. The air content of SCC E (F) and SCC F (SRA) were very low in comparison to other mixtures and were in the range of $4 \sim 5 \%$. That may be due to the entirely different pore structure of the mixture containing fiber and SRA.

8. Though the air content of the mixtures were quite high, the void spacing factors were well within the range except SCC E (F) and SCC F (SRA) which had a high void spacing factor.

9. Increased spacing factor and lower void frequency resulted in higher compressive strength.

10. The relative dynamic modulus of elasticity varied between $95 \sim 98 \%$ after 300 cycles of freezing and thawing. As seen, the change in the relative dynamic modulus is very less signifying very good protection against freezing and thawing.

11. SCC mixtures with spacing factors more than $0.30 \mathrm{~mm}$ also showed a very good durability characteristics which is completely out of range for traditional vibrated concrete.

12. SCC mixtures studied in this experiment had superior resistance to freezing and thawing cycles compared to normal concrete and at per with the values reported by other researchers on the durability of SCC mixtures.

\subsection{Suggestions for Future Work}

1. There exists very few fracture studies on SCC. The six established SCC mixtures can be further studied for their fracture properties. As it is a new type of mixture composition, fracture properties may be significantly different than NC and HPC leading to an entirely different fracture energy and crack propagation behavior.

2. All the selected six SCC mixtures LP in common. Similar tests can be done for the other 11 mixtures containing SL+SF and FA+SF. 
3. The modulus of elasticity of SCC mixtures is generally lower than that of normal concrete. A study of modulus of elasticity and creep can be conducted to better understand the behavior of SCC.

4. Although many researches have been done regarding the form-work pressure of SCC, it may be better to conduct tests to establish the form-work pressure of the selected SCC mixtures and provide guidelines for the design of the form-work.

5. Many tests on SCC have been done so far in laboratory scale. Behavior of prototype structure made with these SCC mixtures at plant scale may be studied to simulate the actual field conditions. 


\section{REFERENCES}

AASHTO PP 34-99, "Standard Practice for Estimating the Cracking Tendency of Concrete," 2006.

ACI Committee 209, "Prediction of Creep, Shrinkage, and Temperature Effects in Structures (ACI 209R-82)," American Concrete Institute, Farmington Hills, Michigan, 1982.

ACI Committee 209, "Report on Factors Affecting Shrinkage and Creep of Hardened Concrete (ACI 209.1R-05)," American Concrete Institute, Farmington Hills, Michigan, July 2005.

ACI Committee 237, "Self-Consolidating Concrete (ACI 237R-07)," American Concrete Institute, Farmington Hills, Michigan, April 2007.

Ambrosia, M. D. D., and Lange, D. A., "Self-Consolidating Concrete," Structure Magazine, January 2007, pp. 48-50.

Ambrosia, M. D. D.; Lange, D. A.; and Brinks, A. J., "Mechanical performance of selfconsolidating concrete at early age," Young researcher's forum; proceedings of the international conference, 2005, pp. 83-94.

Assaad, J., "Formwork Pressure of Self-Consolidating Concrete - Influence of Thixotropy," Doctoral Thesis, Université de Sherbrooke, 2004.

Assaad, J. J., and Khayat, K. H., "Effect of Casting Rate and Concrete Temperature on Formwork Pressure of Self-Consolidating Concrete," Materials and Structures, V. 39, 2006, pp. 333-341.

Assie, S.; Escadeillas, G.; and Marschese, G., "Durability of Self-Compacting Concrete," Third International Symposium on Self-Compacting Concrete, Reykjavik, Iceland, 17-20 August 2003.

ASTM C 215, "Standard Test Method for Fundamental Transverse, Longitudinal, and Torsional Resonant Frequencies of Concrete Specimens," ASTM International, West Conshohocken, PA., 2002, pp. 143-149.

ASTM C 457, "Standard Test Method for Microscopical Determination of Parameters of the Air-Void System in Hardened Concrete," ASTM International, West Conshohocken, PA., 2006, pp. 251-263.

ASTM C 469, "Standard Test Method for Static Modulus of Elasticity and Poisson's Ratio of Concrete in Compression," ASTM International, West Conshohocken, PA., 2002, pp. 265-268.

ASTM C 496, "Standard Test Method for Splitting Tensile Strength of Cylindrical Concrete Specimens," ASTM International, West Conshohocken, PA., 2004, pp. 293297.

ASTM C 666, "Standard Test Method for Resistance of Concrete to freezing and Thawing," ASTM International, West Conshohocken, PA., 2003, pp. 347-352. 
ASTM C 1202, "Standard Test Method for Electrical Indication of Concrete's Ability to Resist Chloride Ion Penetration," ASTM International, West Conshohocken, PA., 2005, pp. 647-652.

ASTM C 1581, "Standard Test Method for Determining Age at Cracking and Induced Tensile Stress Characteristics of Mortar and Concrete under Restrained Shrinkage," ASTM International, West Conshohocken, PA., 2004, pp. 791-796.

ASTM C 1610, "Standard Test Method for Static Segregation of Self-Consolidating Concrete Using Column Technique," ASTM International, West Conshohocken, PA., 2006, pp. 1-4.

ASTM C 1611, "Standard Test Method for Slump Flow of Self-Consolidating Concrete," ASTM International, West Conshohocken, PA., 2005, pp. 1-6.

ASTM C 1621, "Standard Test Method for Passing Ability of Self-Consolidating Concrete by J-Ring," ASTM International, West Conshohocken, PA., 2006, pp. 1-4.

Bazant, Z. P., and Baweja, S., "Creep and Shrinkage Prediction Model for Analysis and Design of Concrete Structures: Model B3," Materials and Structures, V. 28, 1995, pp. 357-365.

Bhattacharya, A.; Ray I., and Davalos J. F., "Effects of aggregate grading and Admixture/Filler on Self-Consolidating Concrete," The Open Construction and Building Technology Journal, V. 2, 2008, pp. 89-95.

Bhattacharya, A.; Ray I., and Davalos J. F., "Evaluations of Self-Consolidating Concrete Using West Virginia Aggregates," The Third North American Conference on the Design and Use of Self-Consolidating Concrete, ACBM, Nov. 10-12, 2008, Chicago, USA.

Billberg, P., "Self-compacting concrete for civil engineering structures-the Swedish experience," Swedish Cement and Concrete Research Institute, Stockholm, CBI Report 2:99, 1999, pp. 80.

Bosiljkov, V. B., "SCC mixes with poorly graded aggregate and high volume of limestone filler," Cement and Concrete Research, V. 33, 2003, pp. 1279-1286.

Brooks, J. J., " Influence of mix proportions, plasticizers and superplasticizers on creep and drying shrinkage of concrete," Magazine of Concrete Research, Vol. 41, No. 148,1989 , pp. $145-154$

Brooks, J. J., and Neville, A. M., "Creep and shrinkage of concrete as affected by admixtures and cement replacement materials", Creep and Shrinkage of Concrete: Effect of Materials and Environment, ACI SP-135, 1992, pp. 19-36.

Brown, D. A.; Schindler, A. K.; Bailey, J. D.; Goldberg, A. D.; Camp III, W. M.; and Holley, D. W., "Evaluation of Self-Consolidating Concrete for Drilled Shaft Applications at Lumber River Bridge Project, South Carolina," Transportation Research Record: Journal of the Transportation Research Board, No. 2020, 2007, pp. 67-75. 
Bui, V. K.; Akkaya, Y.; and Shah, S. P., "Rheological Model for Self-Consolidating Concrete," ACl Materials Journal, V. 99, No. 6, Nov.-Dec. 2002, pp. 549-559.

Bui, V. K.; Shah, S. P.; and Akkaya Y., "A new approach in mix design of selfconsolidating concrete," First North American conference on the Design and Use of Self-Consolidating Concrete, Nov., 2002, pp. 71-76.

Carlson, R. W., "Cracking of Concrete," Boston Society of Civil Engineers, BSCE, Jan. 1942.

Carlson, R. W., and Reading, T. J., "Model Study of Shrinkage Cracking in Concrete Building Wall," ACl Structural Journal, V. 85, No. 4, 1998, pp. 395-404.

Chatterjee, A., "Shrinkage and Strength Characterizations of Concrete Containing Supplementary Cementing Materials," Thesis (M.S.), West Virginia University, 2004.

Christensen, B. J., and Ong, F. S., "The Resistance of Self-Consolidating Concrete (SCC) to Freezing and Thawing Cycles," Proceedings of The Second North American Conference on the Design and Use of Self-Consolidating Concrete (SCC) and the Fourth International RILEM symposium on Self-Compacting Concrete, IL, 2005, pp. 347-354.

Chopin, D.; Larrard de, L.; and Cazacliu, B., "Why do HPC and SCC require a longer mixing time?" Cement and Concrete Research, V. 34, No. 12, 2004, pp. 22372243.

European Federation of Producers and Contractors of Specialist Products for Structures (EFNARC), Specification and Guidelines for SCC, EFNARC, Surrey, 2002. Also available on the internet at: www.efnarc.org.

Fan, D., "Durability Studies of High Performance Concrete Used for Bridge Decks," Thesis (M.S.), West Virginia University, 2005.

Felekoglu, B.; Turkel, S.; and Baradan, B., "Effect of water/cement ratio on the fresh and hardened properties of self-compacting concrete," Building and Environment J ournal, V. 42, 2007, pp. 1795-1802.

Fernandez-Gomez, J., and Landsberger, G. A., "Evaluation of Shrinkage Prediction Models for Self-Consolidating Concrete," ACI Materials Journal, V. 104, No. 5, Sept.Oct. 2007, pp. 464-473.

Ghezal, A., and Khayat, K. H., "Optimizing self-consolidating concrete with limestone filler by using statistical factorial design methods," ACl Materials Journal, V. 99, No. 3, 2002, pp. 264-272.

Gong, Z., "Cracking Studies of High-Performance Concrete for Bridge Decks," Doctoral Dissertation, West Virginia University, 2006.

Goodier, C. I., "Development of self-compacting concrete," Proceedings of the Institution of Civil Engineers: Structures and buildings, 2003, pp. 405-414. 
Gregori, A.; Ferron, R. P.; Sun, Z.; and Shah, S. P., "Experimental Simulation of Self-Consolidating Concrete Formwork Pressure," ACl Materials Journal, V. 105, No. 1, Jan.-Feb. 2008, pp. 97-104.

Hammer, T. A., "Cracking Susceptibility Due to Volume Changes of Self-Compacting Concrete (SCC)," International RILEM Symposium on Self-Compacting Concrete, ed. Wallevik, O., and Nielsson, I., 2003.

Hammer, T. A.; Johansen, K.; and Bjontegaard, O., "Volume Changes as Driving Forces to Self-Induced Cracking of Norwegian SCC," Proceedings of the Second International Symposium on Self-Compacting Concrete, Tokyo, Japan, 2001, pp. 423-432.

Heirman, G., and Vandewalle, L., "The influence of fillers on the properties of SelfCompacting concrete in fresh and hardened state," Third International Symposium on Self-compacting Concrete. Reykjavik, Iceland, August, 2003.

Hwang, S. D., and Khayat, K. H., "Effect of Composition on Restrained Shrinkage Cracking of Self-Consolidating Concrete Used in Repair," $\mathrm{ACl}$ Materials Journal, V. 105, No. 5, Sept.-Oct. 2008, pp. 499-509.

Hwang, S. D.; Khayat, K. H.; and Bonneau, O., "Performance-based specifications of self-consolidating concrete used in structural applications," ACI Materials Journal, V.103, No. 2, 2006; pp. 121-129.

Interim Guidelines for the Use of Self-Consolidating Concrete in Precast/Prestressed Concrete Institute Member Plants, PCI, TR-6-03, 2003.

Khayat, K. H., and Assaad, J., "Measurement systems for determining formwork pressure of highly-flowable concrete," Materials and Structures J ournal, V.41, 2008, pp. 37-46.

Khayat, K. H., and Roussel, Y., "Testing and performance of fiber-reinforced, selfconsolidating concrete," Materials and Structures Journal, V.33, 2000, pp. 391-397.

Khayat, K., and Ghezal, A., "Effect of Viscosity-Modifying Admixture- High-Range Water-Reducing Admixture Combination on Flow Properties of SCC Equivalent Mortar," Proceedings of the Third International RILEM Symposium on SelfCompacting Concrete, Reykjavik, Iceland, 2003, pp. 369-385.

Klug, Y., and Holschemacher, K., "Comparison of the Hardened Properties of Self Compacting and Normal Vibrated Concrete," RILEM Proceedings PRO 33 of the 3rd International RILEM Symposium on Self-Compacting Concrete, Reykjavik, Iceland, 2003, pp. 597-605.

Mindess, S.; Young J. F., and Darwin D., "Concrete," Second Edition, Prentice Hall, 2003.

Nehdi, M., and Ladanchuk, J. D., "Fiber synergy in fiber-reinforced self-consolidating concrete," ACl Materials Journal, V. 101, No. 6, 2004, pp. 508-517. 
Neville, A. M., "Properties of Concrete", Fourth Edition, Addison Wesley Longman Limited, Harlow, England, 1996.

Okamura, H., and Ouchi M., "Self-Compacting Concrete Development, Present Use and Future," Proceedings of the First International RI LEM Symposium on SCC, 1999, pp. 3-14.

Ouchi, M., "History of Development and applications of Self-Compacting concrete in Japan." Proceedings of the International Workshop on Self-Compacting Concrete, Japan, 1998.

Ouchi, M.; Nakamura, S.; Osterberg, T.; Hallberg, S. E.; and Lwin, M., "Applications of Self-Compacting concrete in Japan, Europe and The United States." Federal Highway Administration, 2003.

Ozawa, K.; Maekawa, K.; Kunishima, M.; and Okamura, H., "Development of high performance concrete based on the durability design of concrete structures" Proceedings of the second East-Asia Pacific Conference on Structural Engineering and Construction (EASEC-2), v. 1, 1989, pp. 445-450, ChiangMai.

Ozylidrium, C., and Lane, D. S., "Evaluation of Self-Consolidating Concrete," Virginia Transportation Research Council VTRC 03-R13, Charlottesville, Virginia, June 2003.

Paczkowski, P.; Kaszynska, M.; Nowak, A. S.; and Lutomirski, T., "Self-Consolidating Concrete for On-Site Bridge Applications," Bridge Design, Construction and Maintenance, 2007, pp. 312-320.

Poppe, A. M., and Schutter, G. D., "Creep and Shrinkage of Self-Compacting Concrete," First International Symposium on Design, Performance and Use of SelfConsolidating Concrete SCC'2005, China, May 2005, pp. 329-336.

Ramsburg, P., "The Effects of Form Materials and Release Agent Types On the Appearance of Self-Consolidating Concrete," 2004 Concrete Bridge Conference: Building a New Generation of Bridges, 2004.

Ray, I.; Davalos, J. F., and Fan, D., "Combined Freeze-Thaw and Deicing Salt Tests for High-Performance Concrete," The First International Conference on Recent Advances in Concrete Technology, Washington D.C., Sept. 19-21, 2007, pp. 241252.

Ray, I.; Davalos, J. F., and Morris, J., "Shrinkage and Cracking Evaluations of HighPerformance Concrete for Bridge Decks in West Virginia," Proceedings of the International Conference on Civil Engineering in the New Millennium, Opportunities and Challenges, India, Vol. II, Jan 2007, pp. 1091-1098.

RILEM Technical Committee., "Final report of RILEM TC 205-DSC: Durability of SelfCompacting Concrete," Materials and Structures, V. 41, 2008, pp. 225-233.

Roziere, E.; Granger, S.; Turcy, P. h.; and Loukili, A., "Influence of paste volume on shrinkage cracking and fracture properties of self-compacting concrete," Cement \& Concrete Composites, V. 29, 2007, pp.626-636. 
Sakamoto, J.; Matsuako, Y.; Shindoh, T.; and Tangtermsirikul, S., "An application of super workable concrete to construction of actual structures," Transactions of the Japan Concrete Institute, V. 13, 1991, pp. 41-48.

"Self-Compacting Concrete," Proceedings of the First International RILEM Symposium on Self-Compacting Concrete, Stockholm, Sweden, 1999.

"Self-Compacting Concrete," Proceedings of the Third International RILEM Symposium on Self-Compacting Concrete, Reykjavik, Iceland, 2003.

Shilstone, J. M., "Concrete mixture optimization," Concrete International, V. 12, No. 6, 1990, pp. 33-39.

Sugamata, T.; Ohno, A.; and Ouchi, M., "Trends in research into polycarboxylatebased Superplasticizer in Japan" Second North American conference on the Design and Use of Self-Consolidating Concrete, Nov., 2005, pp. 97-104.

Suksawang, N.; Nassif, H.; and Najm, H. S., "Evaluation of mechanical properties for self-consolidating, normal, and high-performance concrete," Transportation Research Record, No. 1979, 2006, pp. 36-45.

Turcry, P., and Loukili, A., "A Study of Plastic Shrinkage of Self-Compacting Concrete," Third International Symposium on Self-Compacting Concrete, Reykjavik, Iceland, 17-20, August 2003,

Turcry, P., and Loukili, A., "Evaluation of Plastic Shrinkage of Self-Consolidating Concrete," ACl Materials Journal, V. 103, No. 4, July-August 2006, pp. 272-278.

Turcry, Ph.; Loukili, A.; and Haidar, K., "Mechanical properties, Plastic Shrinkage and Free Deformations of Self-Consolidating Concrete," Proceedings of the First North American Conference on the Design and Use of Self-Consolidating Concrete, 2003, pp. 152-158.

Turcry, Ph.; Loukili, A.; Haidar, K.; Pijaudier-Cabot, G.; and Belarbi, A., "Cracking Tendency of Self-Compacting Concrete Subjected to Restrained Shrinkage: Experimental Study and Modeling," Journal of Materials in Civil Engineering, V. 18, No. 1, 2006, pp. 46-54.

Uchoa, S. B.; Ray I.; Davalos J. F., and Tonholo J., "Comparative Studies of Chloride Permeability, Conductivity, and Salt-Ponding Tests of Concrete Containing Different Admixtures", International J ournal of Modelling, Identification and Control (IJMIC), Special Issue: Modelling, Monitoring and Control of Durability of Concrete Structures (accepted).

Vachon, M., and Daczko, J., "U.S. Regulatory Work on SCC," Proceedings of the first North American Conference on the Design and Use of SCC, ACBM, Chicago, Ill., Nov. 12-13, 2002, pp. 423-428.

Vanhove, Y., and Djelal, C., "Formwork Pressures with Self-Compacting Concrete," Concrete, June 2002, pp. 22-23.

www.efnarc.org 
www.graceconstruction.com

www.selfconsolidatingconcrete.org

Xie, Y.; Li, Y.; and Long, G., "Influence of aggregate on properties of selfconsolidating concrete," First International Symposium on Design, Performance and Use of Self-Consolidating Concrete SCC 2005, China, 2005, pp. 161-171.

Zhu, W., and Gibbs, J. C., "Use of different limestone and chalk powders in selfcompacting concrete," Cement and Concrete Research, V. 35, 2005, pp. 1457-1462. 


\section{APPENDIX A}

\section{Typical Calculation for SCC Mixture Proportion}

\section{$\operatorname{SCC} 1$}

For 1cum. of SCC:

\section{Cl. 4.4.1.1 Coarse Aggregate Content:}

Course Aggregate Content CA $25=A_{57}:=563 \cdot \mathrm{kg}$

Course Aggregate Content CA $12.5=\quad \mathrm{A}_{12.5}:=241 \cdot \mathrm{kg}$

Total Course Aggregate $\mathrm{A}_{\mathrm{T}}:=\mathrm{A}_{57}+\mathrm{A}_{12.5} \quad \mathrm{~A}_{\mathrm{T}}=804 \mathrm{~kg}$

Bulk dry-rodded unit weight of course aggregate $\quad \mathrm{d}_{\mathrm{A}}:=1600 \mathrm{~kg}$ per cum.

Hence,

Dry course aggregate should be as per 237R-17, $A:=0.5 \cdot d_{A} \quad A=800 \mathrm{~kg} \quad$ ok Absolute Volume of course aggregate $=\quad \mathrm{V}_{\mathrm{abs}}:=0.299 \frac{\mathrm{m}^{3}}{\mathrm{~m}^{3}}$ of concrete

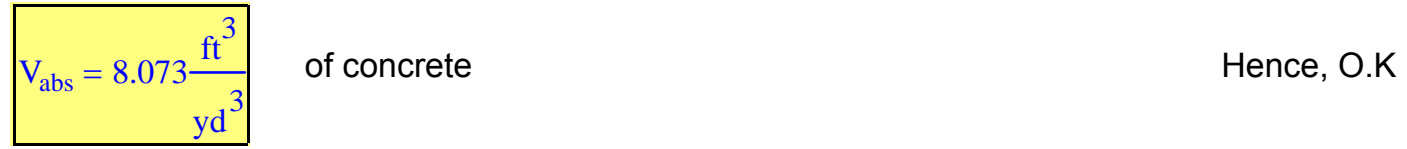

As per ACI 237R-17, approximately the absolute volume should be 7.5 to $9 \mathrm{cft}$. for 1 cubic yard of concrete. Hence O.K.

Cl. 4.4.2

Cement $=$

$$
\underset{\mathrm{C}}{\mathrm{C}}:=386 \cdot \frac{\mathrm{kg}}{\mathrm{m}^{3}}
$$

Slag $=$

Silica Fume $=$

$$
\mathrm{SL}:=0 \cdot \frac{\mathrm{kg}}{\mathrm{m}^{3}}
$$

Limestone Filler $=\quad \mathrm{L}:=112 \cdot \frac{\mathrm{kg}}{\mathrm{m}^{3}}$ 
Powder Content, $\quad \mathrm{P}:=\mathrm{C}+\mathrm{SL}+\mathrm{SF}+\mathrm{L} \quad \mathrm{P}=839.406 \frac{\mathrm{lb}}{\mathrm{yd}^{3}}$

Hence, O.K.

As per ACi 237R-17, appropriate powder content for initial testing should be 650 to $800 \mathrm{lb} / \mathrm{yd} 3$. Also, while performing trial batches, it may be more prudent to start with higher powder contents, and then optimize the mixture for improved economy.

\section{Cl. 4.4 .3}

Paste Volume $=\quad \mathrm{V}_{\mathrm{p}}:=324.99 \mathrm{~m}^{3}$

Morar $V$ olume=

Mortar Volume= and air) (includes cementitious \& other powder, water, admixtures

Total Volume $=$

$$
\mathrm{V}_{\mathrm{T}}:=944.51 \cdot \mathrm{m}^{3}
$$

Hence,

Paste Volume as a percentage $=\frac{V_{\mathrm{p}}}{\mathrm{V}_{\mathrm{T}}} \cdot 100=34.408 \%$ Hence O.K. Mortar Volume as a percentage $=$

$$
\frac{\mathrm{V}_{\mathrm{m}}}{\mathrm{V}_{\mathrm{T}}} \cdot 100=68.321 \%
$$
Hence O.K.

As per ACI 237R-17, Paste fraction should be between 34 to $40 \%$ and Mortar fraction should be between 68 to $72 \%$ (calculated on volume). The common target ratios are: Paste volume ratio 0.34 to 0.40 and Mortar volume ratio 0.60 to 0.70 .

Powder Content $=\underset{\mathrm{m}}{\mathrm{P}}:=498 \cdot \frac{\mathrm{kg}}{\mathrm{m}^{3}} \quad$ (including limestone powder) Slightly Higher Typical Cement (powder content) as per ACl $237 \mathrm{R}-17$ is 386 to $475 \mathrm{~kg} / \mathrm{m} 3$ as per Table 4.2 . 


\section{APPENDIX B}

\section{Aggregate Mix Proportioning}

\begin{tabular}{|c|c|c|c|c|c|}
\hline & & \multicolumn{4}{|c|}{ Course Aggregate \# 57} \\
\hline & & Wt. retained & $\begin{array}{l}\text { Amount } \\
\text { Retained }\end{array}$ & $\begin{array}{l}\text { Cumulative } \\
\text { amount } \\
\text { retained }\end{array}$ & $\begin{array}{l}\text { Cumulative } \\
\text { amount } \\
\text { Passing }\end{array}$ \\
\hline \multicolumn{2}{|c|}{ Sieve Size } & (gm.) & (wt. \%) & $(\%)$ & $(\%)$ \\
\hline $25 \mathrm{~mm}$ & $1 "$ & 36.30 & 0.88 & 0.88 & 99.12 \\
\hline $19 \mathrm{~mm}$ & $3 / 4 "$ & 626.50 & 15.20 & 16.09 & 83.91 \\
\hline $12.5 \mathrm{~mm}$ & $1 / 2 "$ & 1778.40 & 43.16 & 59.25 & 40.75 \\
\hline $9.5 \mathrm{~mm}$ & $3 / 8 "$ & 1052.90 & 25.55 & 84.80 & 15.20 \\
\hline $4.75 \mathrm{~mm}$ & No. 4 & 587.20 & 14.25 & 99.05 & 0.95 \\
\hline $2.36 \mathrm{~mm}$ & No. 8 & 13.20 & 0.32 & 99.37 & 0.63 \\
\hline $1.18 \mathrm{~mm}$ & No. 16 & 1.70 & 0.04 & 99.41 & 0.59 \\
\hline \multicolumn{2}{|c|}{ Sample Weight } & 4120.40 & & & \\
\hline
\end{tabular}

\begin{tabular}{|c|c|c|c|c|c|}
\hline & & \multicolumn{4}{|c|}{ Course Aggregate \# 8} \\
\hline & & Wt. retained & $\begin{array}{l}\text { Amount } \\
\text { Retained }\end{array}$ & $\begin{array}{l}\text { Cumulative } \\
\text { amount } \\
\text { retained }\end{array}$ & $\begin{array}{l}\text { Cumulative } \\
\text { amount } \\
\text { Passing }\end{array}$ \\
\hline \multicolumn{2}{|c|}{ Sieve Size } & (gm.) & (wt. \%) & $(\%)$ & $(\%)$ \\
\hline $19 \mathrm{~mm}$ & $3 / 4 "$ & 0.00 & 0.00 & 0.00 & 100.00 \\
\hline $12.5 \mathrm{~mm}$ & $1 / 2 "$ & 4.50 & 0.41 & 0.41 & 99.59 \\
\hline $9.5 \mathrm{~mm}$ & $3 / 8 "$ & 127.20 & 11.45 & 11.86 & 88.14 \\
\hline $4.75 \mathrm{~mm}$ & No. 4 & 827.20 & 74.47 & 86.33 & 13.67 \\
\hline $2.36 \mathrm{~mm}$ & No. 8 & 137.50 & 12.38 & 98.70 & 1.30 \\
\hline $1.18 \mathrm{~mm}$ & No. 16 & 3.10 & 0.28 & 98.98 & 1.02 \\
\hline
\end{tabular}




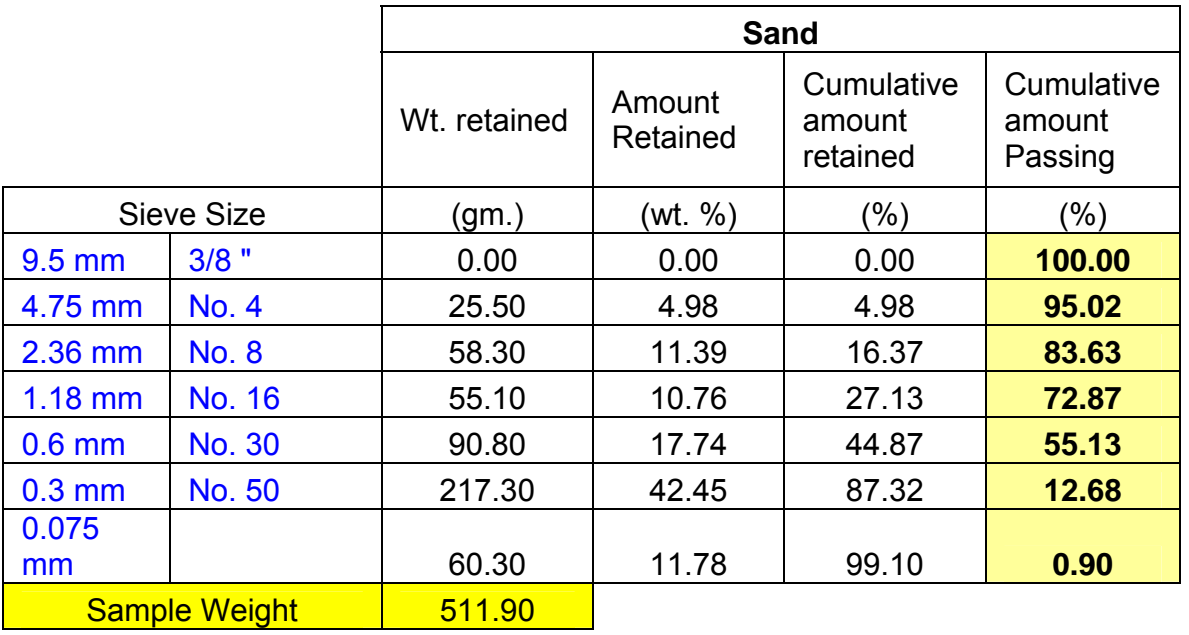

\section{Combined Aggregate Grading (35/15/50)}

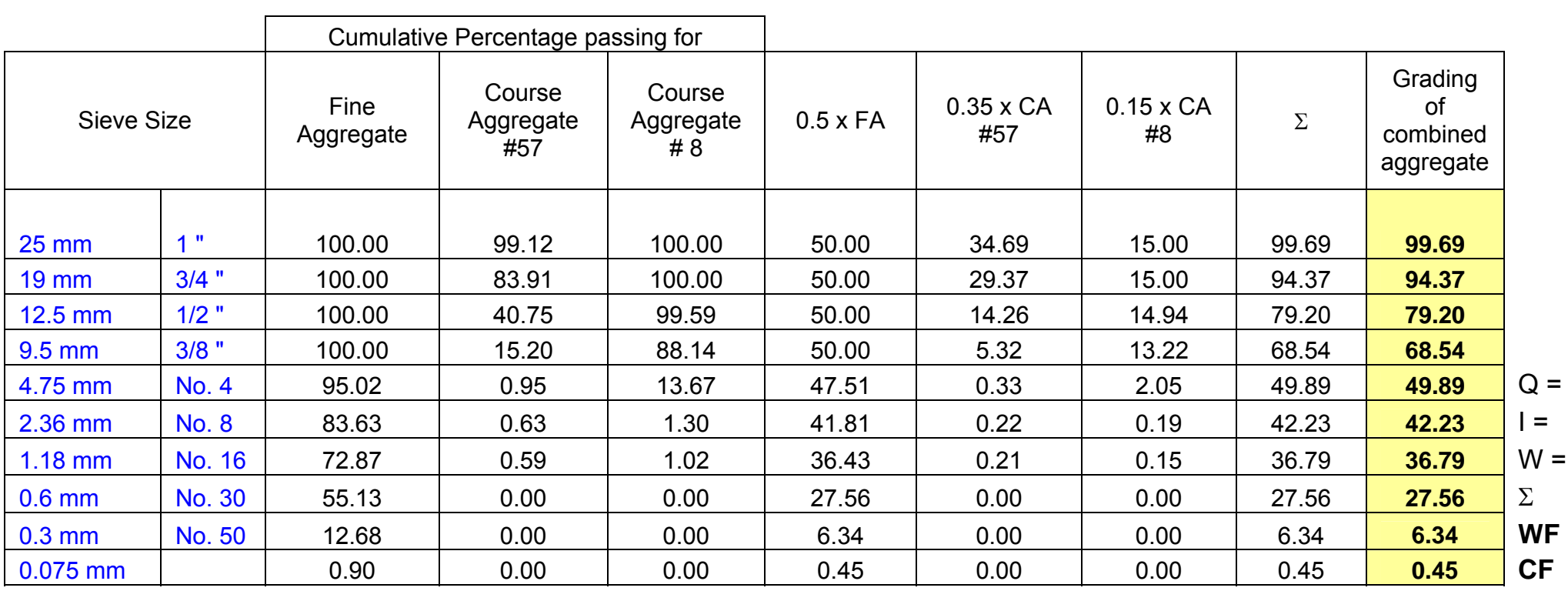


Combined Aggregate Grading (25/25/50)

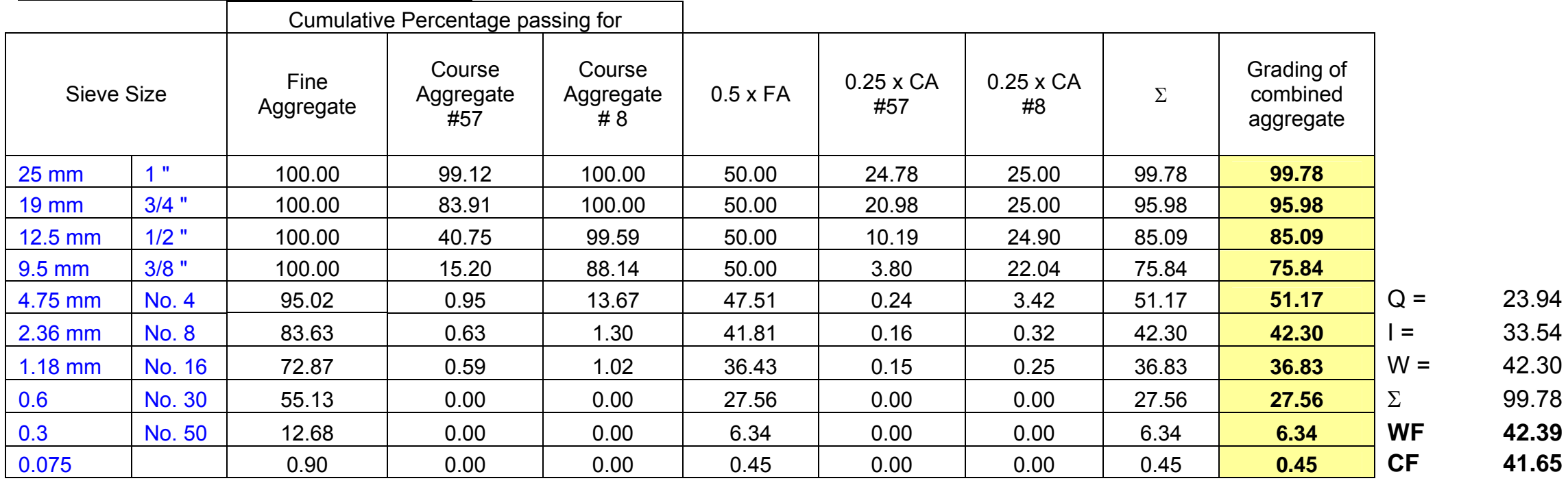

Combined Aggregate Grading (0/50/50)

Cumulative Percentage passing for

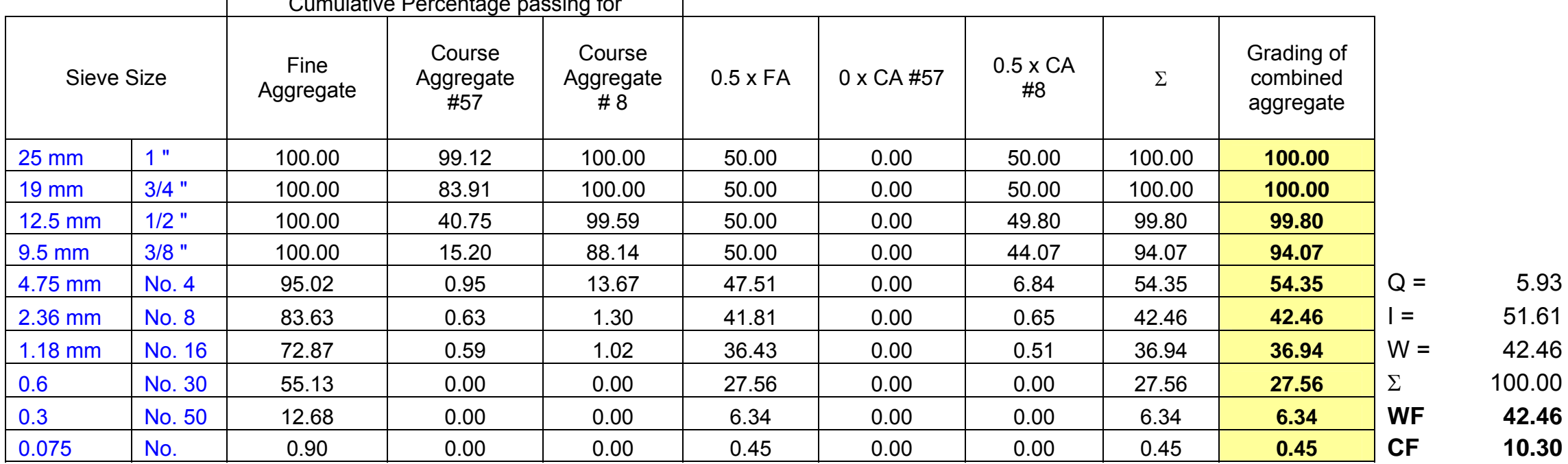


Combined Aggregate Grading (15/35/50)

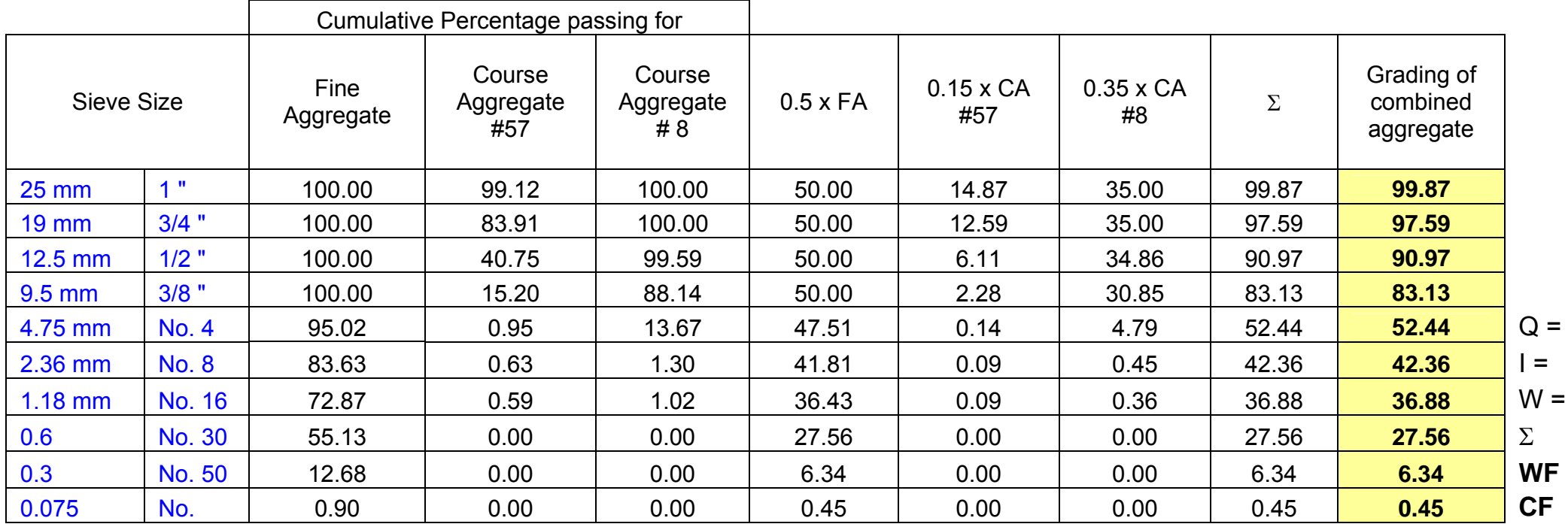

$Q=$

16.74

Combined Aggregate Grading (27/27/46

\begin{tabular}{|c|c|c|c|c|c|c|c|c|c|}
\hline \multicolumn{2}{|c|}{ oniming } & \multicolumn{3}{|c|}{ Cumulative Percentage passing for } & \multirow[b]{2}{*}{$0.46 \times \mathrm{FA}$} & \multirow[b]{2}{*}{$\begin{array}{c}0.27 \times \mathrm{CA} \\
\# 57\end{array}$} & \multirow[b]{2}{*}{$\begin{array}{c}0.27 \times \mathrm{CA} \\
\# 8\end{array}$} & \multirow[b]{2}{*}{$\Sigma$} & \multirow[b]{2}{*}{$\begin{array}{l}\text { Grading of } \\
\text { combined } \\
\text { aggregate }\end{array}$} \\
\hline \multicolumn{2}{|c|}{ Sieve Size } & $\begin{array}{c}\text { Fine } \\
\text { Aggregate }\end{array}$ & $\begin{array}{c}\text { Course } \\
\text { Aggregate } \\
\# 57\end{array}$ & $\begin{array}{c}\text { Course } \\
\text { Aggregate } \\
\# 8\end{array}$ & & & & & \\
\hline 25 & $1 "$ & 100.00 & 99.12 & 100.00 & 46.00 & 26.76 & 27.00 & 99.76 & 99.76 \\
\hline 19 & $3 / 4 "$ & 100.00 & 83.91 & 100.00 & 46.00 & 22.66 & 27.00 & 95.66 & 95.66 \\
\hline 12.5 & $1 / 2 "$ & 100.00 & 40.75 & 99.59 & 46.00 & 11.00 & 26.89 & 83.89 & 83.89 \\
\hline 9.5 & $3 / 8 "$ & 100.00 & 15.20 & 88.14 & 46.00 & 4.10 & 23.80 & 73.90 & 73.90 \\
\hline 4.75 & No. 4 & 95.02 & 0.95 & 13.67 & 43.71 & 0.26 & 3.69 & 47.66 & 47.66 \\
\hline 2.36 & No. 8 & 83.63 & 0.63 & 1.30 & 38.47 & 0.17 & 0.35 & 38.99 & 38.99 \\
\hline 1.18 & No. 16 & 72.87 & 0.59 & 1.02 & 33.52 & 0.16 & 0.27 & 33.95 & 33.95 \\
\hline 0.6 & No. 30 & 55.13 & 0.00 & 0.00 & 25.36 & 0.00 & 0.00 & 25.36 & 25.36 \\
\hline 0.3 & No. 50 & 12.68 & 0.00 & 0.00 & 5.83 & 0.00 & 0.00 & 5.83 & 5.83 \\
\hline 0.075 & No. & 0.90 & 0.00 & 0.00 & 0.41 & 0.00 & 0.00 & 0.41 & 0.41 \\
\hline
\end{tabular}




\section{Combined Aggregate Grading (29/29/42)}

\begin{tabular}{|c|c|c|c|c|c|c|c|c|c|}
\hline & & Cumulativ & Percentage pas & $\mathrm{ng}$ for & & & & & \\
\hline Sie & e Size & Fine Aggregate & $\begin{array}{c}\text { Course } \\
\text { Agareqate \#57 }\end{array}$ & $\begin{array}{l}\text { Course } \\
\text { Aggregate }\end{array}$ & $0.42 \times \mathrm{FA}$ & $\begin{array}{c}0.29 \times C A \\
\# 57\end{array}$ & $\begin{array}{c}0.29 \times \mathrm{CA} \\
\# 8\end{array}$ & $\Sigma$ & $\begin{array}{l}\text { Grading } \\
\text { of } \\
\text { combined }\end{array}$ \\
\hline 25 & $1 "$ & 100.00 & 99.12 & 100.00 & 42.00 & 28.74 & 29.00 & 99.74 & 99.74 \\
\hline 19 & $3 / 4 "$ & 100.00 & 83.91 & 100.00 & 42.00 & 24.34 & 29.00 & 95.34 & 95.34 \\
\hline 12.5 & $1 / 2 "$ & 100.00 & 40.75 & 99.59 & 42.00 & 11.82 & 28.88 & 82.70 & 82.70 \\
\hline 9.5 & $3 / 8 "$ & 100.00 & 15.20 & 88.14 & 42.00 & 4.41 & 25.56 & 71.97 & 71.97 \\
\hline 4.75 & No. 4 & 95.02 & 0.95 & 13.67 & 39.91 & 0.28 & 3.97 & 44.15 & 44.15 \\
\hline 2.36 & No. 8 & 83.63 & 0.63 & 1.30 & 35.12 & 0.18 & 0.38 & 35.68 & 35.68 \\
\hline 1.18 & No. 16 & 72.87 & 0.59 & 1.02 & 30.60 & 0.17 & 0.30 & 31.07 & 31.07 \\
\hline 0.6 & No. 30 & 55.13 & 0.00 & 0.00 & 23.15 & 0.00 & 0.00 & 23.15 & 23.15 \\
\hline 0.3 & No. 50 & 12.68 & 0.00 & 0.00 & 5.32 & 0.00 & 0.00 & 5.32 & 5.32 \\
\hline 0.075 & No. & 0.90 & 0.00 & 0.00 & 0.38 & 0.00 & 0.00 & 0.38 & 0.38 \\
\hline
\end{tabular}

